Universidade de São Paulo

Instituto de Física

\title{
Composição do aerossol atmosférico na Amazônia com influência antropogênica: Estudo de caso no experimento GoAmazon
}

\author{
André Araújo Bürger
}

Orientador: Prof. Dr. Paulo Eduardo Artaxo Netto

Dissertação de mestrado apresentada ao Instituto de Física como requisito parcial para a obtenção do título de Mestre em Ciências.

Banca Examinadora:

Prof. Dr. Paulo Eduardo Artaxo Netto (IF/USP)

Profa. Dra. Luciana Varanda Rizzo (ICAQF/UNIFESP)

Profa. Dra. Maria de Fátima Andrade (IAG/USP) 
FICHA CATALOGRÁFICA

Preparada pelo Serviço de Biblioteca e Informação do Instituto de Física da Universidade de São Paulo

Burger, André Araújo

Composição do aerossol atmosférico na Amazônia com influência antropogênica: estudo de caso no experimento GoAmazon 2014/15.

São Paulo, 2017.

Dissertação (Mestrado) - Universidade de São Paulo. Instituto de Física. Depto. de Física Aplicada.

Orientador: Prof. Dr. Paulo Eduardo Artaxo Netto

Área de Concentração: Física Atmosférica

Unitermos: 1. Aerossol; 2. Poluição atmosférica; 3. Amazônia;

4. Manaus.

USP/IF/SBI-120/2017 


\title{
University of São Paulo \\ Physics Institute
}

\section{Anthropogenic Influence on Atmospheric Aerosol Composition at Amazon Basin: Case Study of GoAmazon Campaign}

\author{
André Araújo Bürger
}

Supervisor: Prof. Dr. Paulo Eduardo Artaxo Netto

Dissertation submitted to the Physics Institute of the University of São Paulo in partial fulfillment of the requirements for the degree of Master of Science.

Examining Committee:

Prof. Dr. Paulo Eduardo Artaxo Netto (IF/USP)

Profa. Dra. Luciana Varanda Rizzo (ICAQF/UNIFESP)

Profa. Dra. Maria de Fátima Andrade (IAG/USP) 

Se você quiser eu danço com você Meu nome é nuvem, pó, poeira, movimento

O meu nome é nuvem Ventania, flor de vento $\mathrm{Eu}$ danço com você o que você dançar

Nuvem Cigana Lô Borges e Ronaldo Bastos 



\section{Agradecimentos}

Agradeço aos meus pais, Eliana e Pearcy, por sempre acreditado em minha capacidade e sempre trazerem novas perspectivas sobre diversos assuntos, amor, carinho, paciência, muita paciência, e outras diversas virtudes.

À minha namorada Vanessa pelo amor, companheirismo, conversas, carinho, tentativas de trilhas e ser extremamente responsável na cozinha.

Ao professor Dr. Paulo Artaxo por me aceitar como aluno e pela orientação ao longo do trabalho.

Aos colegas de sala, sempre dispostos a tirar dúvidas, discutir resultados e ajudar em qualquer tipo de problema.

Aos diversos amigos que tornam o período no IFUSP mais tranquilo.

Aos técnicos de laboratório Ana, Alcides, Fernando, Guilherme e Fábio Jorge que trabalham duramente para manter os equipamentos e a pesquisa em dia e estão sempre dispostos a ajudar.

Ao Joel Brito por estar sempre disposto a tirar dúvidas, ser paciente e uma ótima pessoa.

Aos meus grandes amigos de vida que me acompanharam e me ajudaram durante todo meu trajeto através da pratica musical, papos sobre tecnologia, cervejas, motores, dentre outros.

À cachorra Molly Tossa por sempre me receber com pulos e abraços e animar os finais de semana com suas lambidas e incessantes tentativas de dizer algo. 



\section{Resumo}

Foi avaliado quantitativamente o impacto que as atividades antropogênicas da cidade de Manaus causam na composição elementar dos aerossóis na Amazônia central. Para isso, foram amostrados aerossóis em três sítios experimentais entre 2014 e 2015: 1) ZF2, sítio com floresta preservada, 2) Hotel TIWA com impacto direto de emissões de Manaus e 3) Manacapuru sítio vento abaixo da cidade de Manaus. Dos filtros coletados obteve-se a concentração de diferentes componentes do material particulado (MP): Black Carbon Equivalente ( $\mathrm{BCe})$, elementos traço ( $\mathrm{Na}$ até $\mathrm{Pb}$ ), concentração de MP e carbono elementar e orgânico (EC e OC) separados em MP Fino (MPF, diâmetro menor que 2,5 $\mu \mathrm{m}$ ) e MP grosso (MPG, diâmetro entre 2,5 $\mu \mathrm{m}$ e $10 \mu \mathrm{m}$ ). A concentração média de MPF apresentou forte sazonalidade em todos os sítios com concentrações variando de $2,3 \pm 2,7 \mu \mathrm{g} / \mathrm{m}^{3}$ para $5,5 \pm 2,7 \mu \mathrm{g} / \mathrm{m}^{3}$ na $Z F 2$ e $3,7 \pm 2,0 \mu \mathrm{g} / \mathrm{m}^{3}$ para $11,0 \pm 7,6 \mu \mathrm{g} / \mathrm{m}^{3}$ no TIWA na estação chuvosa e seca, respectivamente. Elementos traços associados a processos industriais e/ou veiculares apresentaram concentração média de aproximadamente 2 a 6 vezes maior no sítio TIWA que na ZF2. O balanço de massa indicou que entre $50 \%$ e $80 \%$ do MPF foi de matéria orgânica (MO), 15\% a 20\% foi de sulfato e de 8 a $20 \%$ de BCe. Comparações entre as concentrações de MO, indicaram aerossol mais envelhecido em Manacapuru. A aplicação da Análise de Componentes Principais Absoluta (ACPA) no MPF extraiu fatores regionais em todos os sítios: queima de biomassa, poeira mineral e aerossol marinho, além de fatores como poluição industrial e veicular nos sítios afetados pela pluma de Manaus. Além desses fatores encontrados pela ACPA, o método Positive Matrix Factorization (PMF) extraiu um fator biogênico no MPF e mais de um fator marinho para o MPG relacionados com o processamento do aerossol marinho. A concentração de MP extraído no TIWA para fatores diretamente relacionados com atividade antropogênica é em média de $905 \mathrm{ng} / \mathrm{m}^{3}$ (MPF) e $1285 \mathrm{ng} / \mathrm{m}^{3}$ (MPG).

Palavras-Chave: aerossol; Amazônia; poluição atmosférica; Manaus. 



\begin{abstract}
This work quantitatively investigated the impact of anthropogenic emissions from Manaus City on the elemental composition of aerosol at Central Amazonia collecting particulate matter (PM) from 2014 to 2015 at ZF2, upwind of Manaus and TIWA and Manacapuru, downwind of Manaus. From the filters collected, different components of the PM were measured: equivalent Black Carbon $(\mathrm{eBC})$, trace elements ( $\mathrm{Na}$ to $\mathrm{Pb}$ ), $\mathrm{PM}$ concentration and Elemental and Organic Carbon (EC and $\mathrm{OC}$ ) with fine (FPM, diameter < 2.5um) and coarse (CPM, 2.5um < diameter < 10um) mode separated. At the dry season, FPM concentration was $5,5 \mathrm{ug} / \mathrm{m}^{3}$ at $Z F 2$ and $11,0 \mathrm{ug} / \mathrm{m}^{3}$ at TIWA and for the CPM it was of $5,5 \mathrm{ug} / \mathrm{m}^{3}, 7,1 \mathrm{ug} / \mathrm{m}^{3}$, respectively. During the wet season, reduction on the concentration of all sites at both modes was observed. Mass Balance Analysis showed that Organic Matter (OM) varied approximately from $50 \%$ to $80 \%$, sulfate from $15 \%$ to $20 \%$ and eBC from $8 \%$ to $20 \%$ for the FPM. Comparisons between OM, obtained through spectrometry, and OC showed a more aged aerosol at Manacapuru than at TIWA. Absolute Principal Components Analysis (APCA) extracted three main factors at all sites for the FPM: biomass burning, marine aerosol and soil dust whilst PMF could also extract a biogenic factor. For the sites downwind of Manaus, factors related with anthropogenic emission were extracted. For the CPM three factors were identified at all sites: biogenic emission, soil dust and marine aerosol. PMF also found a second factor related with $\mathrm{Cl}$ depletion on marine aerosol. At the site TIWA both methods extracted a factor identified as pollution and PMF also found a factor related with vehicular emissions whilst at Manacapuru on APCA extracted a pollution factor. Direct anthropogenic emissions- vehicular and pollution factors - at TIWA varies from $880 \mathrm{ng} / \mathrm{m}^{3}$ (ACPA) to $930 \mathrm{ng} / \mathrm{m}^{3}$ (PMF) in fine mode. In the coarse mode $790 \mathrm{ng} / \mathrm{m}^{3}$ (APCA) to $1780 \mathrm{ng} / \mathrm{m}^{3}$ (PMF).
\end{abstract}

Keywords: Amazon; aerosol; atmospheric pollution; Manaus; 



\section{LISTA DE FIGURAS}

Figura 1: diagrama esquemático de emissão, deposição, processamento e influências associadas ao aerossol. A interferência do aerossol na forçante radiativa é indicada por sua influência direta na radiação e em nuvens pelas siglas ERFari e ERFaci (do inglês, effective radiative forcing aerosolradiation interactions e aerosol-cloud interactions).

Figura 2: exemplo de distribuição de tamanho de aerossóis e os principais processos, fontes e sumidouros envolvidos em cada moda.

Figura 3: impacto dos aerossóis sobre o balanço de radiação global, levando em conta os efeitos diretos e indiretos dos aerossóis no clima, incluindo mecanismos de retroalimentação no sistema climático.

Figura 4: forçantes radiativas calculadas com base o ano de 1750. Nota-se que enquanto gases de efeito estufa apresentam forçante positiva, provocando o aquecimento do planeta, os aerossóis atuam contrabalanceando, com forçante radiativa negativa.

Figura 5: mapa da Amazônia Legal do Brasil com o desmatamento acumulado até 2011 destacado em rosa.

Figura 6: taxa de desmatamento da Amazônia de 1988 até 2016. Em 2004 é implementado o Plano de Ação para Prevenção e Controle do Desmatamento na Amazônia Legal (PPCDAm) que contribuiu de maneira fundamental para a redução de desmatamento na Amazônia.

Figura 7: microscopia eletrônica de varredura de PBAP coletados por filtros durante a estação chuvosa. As faixas brancas nas fotos correspondem a $2 \mu \mathrm{m}$.

Figura 8: representação esquemática da complexa relação entre atmosfera e biosfera na Amazônia, enfatizando o papel de aerossóis.

Figura 9: representação esquemática da classificação da grandeza medida de acordo com a técnica empregada.

Figura 10: Sítios amostrais utilizados neste trabalho: ZF2 (TOz), TIWA (T2) e Manacapuru (T3). Observamos nesta figura sua localização em relação à Manaus e a seta indicando a direção predominante do vento.

Figura 11: chuva acumulada mensal em Manaus para o ano de 2014 e 2015........................................30

Figura 12: rosa dos ventos para o sítio da ZF2 durante o ano de 2014. A direção de vento predominante é de leste.

Figura 14: torre TT34 e contêiner utilizados durante o experimento Go Amazon2014/15 .......................32

Figura 15: torre e contêiner instalado vento abaixo de Manaus, nas margens do Rio Negro....................33

Figura 16: fotos do sítio Manacapuru durante o GoAmazon2014/15.....................................................34

Figura 17: NILU filter holder system desmontado possibilitando ver seus estágios................................34

Figura 18: balança ultramicroanalítica eletrônica XP6U Mettler. .........................................................36

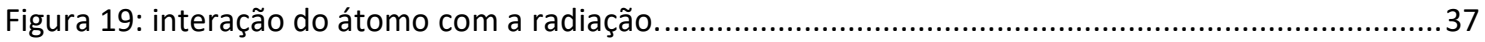

Figura 20: representação esquemática da interação entre raios-x e amostra. Cada cor de raio-x retroespalhado visa ilustrar a energia característica de cada elemento......................................38

Figura 21: aparelho Epsilon 5 fabricado pela companhia PANalytical. ...............................................38

Figura 22: esquema da geometria tridimensional do Epsilon5 da PANalytical. O feixe que sai do tubo de raios $x$ em amarelo, chega no alvo secundário, que o reflete em um ângulo de $90 \circ$, gerando o feixe azul, que por sua vez irradia a amostra que gera o feixe roxo que chega ao detector (Fonte: www.panalytical.com).

Figura 23: esquema representando o analisador termo-óptico diferencial da Sunset Instruments..........40

Figura 24: termograma obtido através do método termo-óptico. O sinal medido durante a primeira etapa com atmosfera inerte é interpretado como carbono orgânico (OC). Ao entrar oxigênio na atmosfera considera-se que é carbono elementar (EC) ao qual pode estar misturado a carbono orgânico pirolizado (PC).

Figura 25: regressão multilinear entre a concentração de S versus MPF e BCe para o sítio da ZF2. O resíduo do ponto 7 (assinalado) é maior do que 3. O R2 do ajuste foi igual a $0,76 \ldots \ldots \ldots \ldots \ldots \ldots \ldots \ldots . . .48$

Figura 26: regressão multilinear final entre a concentração de S versus MPF e BCe para o sítio da ZF2. O R2 do ajuste foi igual a 0,97.

Figura 27: comparação entre o coeficiente de absorção obtido pelo aetalômetro AE33 em 880nm e o BCe obtido por refletância dos filtros de policarbonato na fração fina no sítio TIWA. A reta em vermelho representa o ajuste realizado entre os resultados de ambas as técnicas. 
Figura 28: comparação entre o coeficiente de absorção obtido pelo aetalômetro AE31 em 880nm e o BCe obtido por refletância dos filtros de policarbonato da fração fina no sítio Manacapuru. A reta em vermelho representa o ajuste realizado entre os resultados de ambas as técnicas. ..................55

Figura 29: comparação entre o coeficiente de absorção obtido pelo aetalômetro AE33 em 880nm e o EC obtido através da análise termo-óptica dos filtros de quartzo na fração fina no sítio TIWA. A reta em vermelho representa o ajuste realizado entre os resultados de ambas as técnicas durante a estação seca, enquanto a azul é para a estação chuvosa................................................................56

Figura 30: comparação entre o coeficiente de absorção obtido pelo aetalômetro AE31 em 880nm e o EC obtido através da análise termo-óptica dos filtros de quartzo na fração fina no sítio Manacapuru. A reta em vermelho representa o ajuste realizado entre os resultados de ambas as técnicas durante a estação seca, enquanto a azul é para a estação chuvosa...........................................................56

Figura 31: comparação entre a concentração de BCe (obtido por refletância dos filtros de policarbonato) versus a concentração de EC (obtido através da análise termo-óptica) para a estação seca do sítio ZF2. . .58

Figura 32: comparação entre a concentração de BCe (obtido por refletância dos filtros de policarbonato) versus a concentração de EC (obtido através da análise termo-óptica) para a estação chuvosa. ....59

Figura 33: comparação entre a concentração de BCe (obtido por refletância dos filtros de policarbonato) versus a concentração de EC (obtido através da análise termo-óptica) para a estação seca no sítio TIWA. . .59

Figura 34: comparação entre concentração de massa calculada a partir dos resultados do SMPS e o carbono total na fração fina obtido pelo método termo-óptico no sítio Manacapuru.....................60

Figura 35: distribuição de tamanho médio do material particulado e TC com desvio-padrão da média

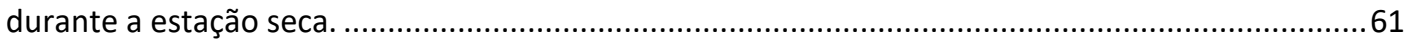

Figura 36: comparação entre a concentração de matéria orgânica medida pelo ACSM versus carbono orgânico medido pelo método termo-óptico no sítio TIWA............................................................62

Figura 37: comparação entre a concentração de matéria orgânica medida pelo AMS versus carbono orgânico medido pelo método termo-óptico no sítio Manacapuru..................................................63

Figura 38: série temporal do material particulado fino e grosso para a estação ZF2. A região em azul indica a estação chuvosa. Em vermelho está exposta a razão entre a concentração de MP2,5 e

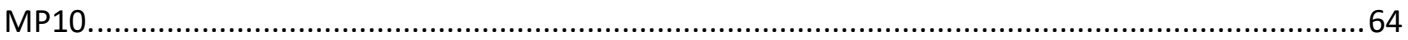

Figura 39: série temporal do material particulado fino e grosso para a estação TIWA. A região em azul indica a estação chuvosa. Em vermelho está exposta a razão entre a concentração de MP2,5 e MP10.

Figura 40: série temporal do material particulado fino e grosso para a estação Manacapuru. A região em azul indica a estação chuvosa. Em vermelho está exposta a razão entre a concentração de MP2,5 e MP10.

Figura 41: série temporal do black carbon equivalente determinados nos filtros de policarbonato para a estação ZF2. A região em azul indica a estação chuvosa...........................................................66

Figura 42: série temporal do black carbon equivalente para a estação TIWA. A região em azul indica a estação chuvosa.

Figura 42: série temporal do black carbon equivalente para a estação Manacapuru. A região em azul indica a estação chuvosa.

Figura 43: cálculo do HySplit para retrotrajetória das massas de ar que chegaram a ZF2 no dia 30 de setembro de 2014 em três alturas sobre o solo: 500m em vermelho, $1000 \mathrm{~m}$ em azul e $2000 \mathrm{~m}$ em verde e pontos em vermelho representando focos de queimada. É possível verificar a passagem dessas massas de ar por diversos focos de queimada até a chegada na ZF2.

Figura 44: focos de queimada acumulados por mês com o sítio ZF2 em destaque.................................69

Figura 45: concentração média dos elementos majoritários da fração fina nos três sítios durante o período do projeto GoAmazon2014/15. A concentração dos elementos marcados com asterisco foram multiplicadas por um fator 10 para melhor visualização.

Figura 46: concentração média dos elementos minoritários da fração fina nos três sítios durante o período do projeto GoAmazon2014/15.

Figura 47: concentração média dos elementos majoritários da fração grossa nos três sítios durante o período do projeto GoAmazon2014/15.

Figura 49: concentração média dos elementos minoritários da fração grossa nos três sítios durante o período do projeto GoAmazon2014/15.............................................................................73

Figura 50: série temporal de OC e EC no MPF da ZF2 e a relação OC/EC em vermelho. ..........................74 
Figura 51: série temporal de OC e EC no MPF do sítio TIWA e a relação OC/EC em vermelho.

Figura 52: série temporal de OC e EC no MPF de Manacapuru e a relação OC/EC em vermelho. .............75

Figura 53: concentração média e percentual em relação a concentração média de MPF separados por fatores semelhantes e sítios obtidos por meio da ACPA e PMF.

Figura 53: concentração média e percentual em relação a concentração média de MPF para as concentrações encontradas para o fator queimada através da ACPA e PMF. Escala Logarítmica.. 105

Figura 55: concentração média e percentual em relação a concentração média de MPF para as concentrações encontradas para o fator biogênico através do método PMF. A ACPA não extraiu este fator para o MPF.

106

Figura 54: concentração de massa de aerossóis para diferentes impactos da pluma de Manaus (menor impacto à esquerda e maior impacto à direita). Observamos um acréscimo de $3 \mu \mathrm{g} / \mathrm{m}^{3}$ de orgânicos e também acréscimos significativos no sulfato. Medidas realizadas através de um espectrômetro de massa AMS..... 106

Figura 56: concentração média e percentual em relação a concentração média de MPF para as concentrações encontradas para o fator marinho através da ACPA e PMF.

Figura 57: concentração média e percentual em relação a concentração média de MPG para as concentrações encontradas por fator através da ACPA e PMF. 108

Figura 58: concentração média e percentual em relação a concentração média de MPG para as concentrações encontradas para o fator marinho 1 através da ACPA e PMF. 109

Figura 59: concentração média e percentual em relação a concentração média de MPG para as concentrações encontradas para o fator marinho 2 através da ACPA e PMF. 110

Figura 60: concentração média e percentual em relação a concentração média de MPG para as concentrações encontradas para o fator marinho 3 através da ACPA e PMF. 



\section{LISTA DE TABELAS}

TABELA 1: RESUMO GERAL DOS FILTROS DE POLICARBONATO COLETADOS DURANTE O PROJETO GOAMAZON2014/15. CADA AMOSTRAGEM CORRESPONDE AO PAR DE FILTROS DE COLETA DE MPF E MPG.

TABELA 2: RESUMO GERAL DOS FILTROS DE QUARTZO COLETADO DURANTE O PROJETO GOAMAZON2014/15

.35

TABELA 3: PROTOCOLO DE TEMPERATURAS EUSAAR_2 COM A ATMOSFERA E O TEMPO DE CADA ESTÁGIO.

TABELA 4: CÁLCULO DOS VALORES E INCERTEZAS PARA A CONSTRUÇÃO DO BANCO DE DADOS PARA O PMF

TABELA 5: SÍNTESE SOBRE AS CONCENTRAÇÕES DE MATERIAL PARTICULADO FINO E GROSSO E A RAZÃO ENTRE MPF/MP10 OBTIDOS DURANTE O EXPERIMENTO GOAMAZON2014/15 ..........................65

TABELA 6: SÍNTESE DAS CONCENTRAÇÕES DE BCE NA MODA FINA E GROSSA E A RAZÃO ENTRE BCE/MP10 OBTIDOS DURANTE O EXPERIMENTO GOAMAZON2014/15.

TABELA 7: CONCENTRAÇÕES MÉDIAS DE OC, EC, RAZÃO OC/EC E O NÚMERO DE AMOSTRAS (N) PARA OS SÍTIOS ZF2, MANACAPURU E TIWA PARA A ESTAÇÃO SECA DE 2014 .......................................75

TABELA 8: CONCENTRAÇÕES DE CARBONO OBTIDOS DURANTE AS ETAPAS COM ATMOSFERA INERTE DO MÉTODO TERMO-ÓPTICO E CARBONO PIROLÍTICO.

TABELA 9: RECONSTRUÇÃO DE MASSA DO MPF DA ZF2 EXPOSTAS EM PERCENTUAL DA CONCENTRAÇÃO GRAVIMÉTRICA MÉDIA. O VALOR MÉDIO DE MPF FOI DE 5,5MG/M³ E 2,2MG/M DURANTE A ESTAÇÃO SECA E CHUVOSA, RESPECTIVAMENTE. SOMA NÃO INCLUI O PERCENTUAL DE MATÉRIA ORGÂNICA, JÁ QUE ESTE NÃO FOI NECESSARIAMENTE MEDIDO EM PARALELO COM OS OUTROS TIPOS DE AEROSSÓIS.

TABELA 10: RECONSTRUÇÃO DE MASSA DO MPF DO TIWA EXPOSTA EM PERCENTUAL DA CONCENTRAÇÃO GRAVIMÉTRICA MÉDIA. O VALOR MÉDIO DE MPF FOI DE 11,0MG/M³ E 3,7MG/M ${ }^{3}$ DURANTE A ESTAÇÃO SECA E CHUVOSA, RESPECTIVAMENTE. SOMA NÃO INCLUI O PERCENTUAL DE MATÉRIA ORGÂNICA, JÁ QUE ESTE NÃO FOI NECESSARIAMENTE MEDIDO EM PARALELO COM OS OUTROS TIPOS DE AEROSSÓIS..

TABELA 11: RESULTADOS DA ACPA APLICADA AO MPF DA ZF2 COLETADO DURANTE O GOAMAZON2014/15 APÓS ROTAÇÃO VARIMAX. A TABELA MOSTRA A CONCENTRAÇÃO MÉDIA DE CADA ELEMENTO POR FATOR E O PERCENTUAL QUE REPRESENTA EM RELAÇÃO À CONCENTRAÇÃO MÉDIA DO MESMO. AS DUAS ÚLTIMAS LINHAS MOSTRAM O AUTOVALOR E A VARIÂNCIA ASSOCIADA A CADA FATOR.

TABELA 12: RESULTADOS DA ACPA APLICADA AO MPG DA ZF2 COLETADO DURANTE O GOAMAZON2014/15 APÓS ROTAÇÃO VARIMAX. A TABELA MOSTRA A CONCENTRAÇÃO MÉDIA DE CADA ELEMENTO POR FATOR E O PERCENTUAL QUE REPRESENTA EM RELAÇÃO À CONCENTRAÇÃO MÉDIA DO MESMO. AS DUAS ÚLTIMAS LINHAS MOSTRAM O AUTOVALOR E A VARIÂNCIA ASSOCIADA A CADA FATOR.

TABELA 13: RESULTADOS DA ACPA APLICADA AO MPF DO TIWA COLETADO DURANTE O GOAMAZON2014/15 APÓS ROTAÇÃO VARIMAX. A TABELA MOSTRA A CONCENTRAÇÃO MÉDIA DE CADA ELEMENTO POR FATOR E O PERCENTUAL QUE REPRESENTA EM RELAÇÃO À CONCENTRAÇÃO MÉDIA DO MESMO. AS DUAS ÚLTIMAS LINHAS MOSTRAM O AUTOVALOR E A VARIÂNCIA ASSOCIADA A CADA FATOR.

TABELA 14: CONCENTRAÇÃO MÉDIA POR FATOR DOS ELEMENTOS QUE NÃO FORAM INCLUÍDOS NA ACPA.

TABELA 15: RESULTADOS DA ACPA APLICADA AO MPG DO TIWA COLETADO DURANTE O GOAMAZON2014/15 APÓS ROTAÇÃO VARIMAX. A TABELA MOSTRA A CONCENTRAÇÃO MÉDIA DE CADA ELEMENTO POR FATOR E O PERCENTUAL QUE REPRESENTA EM RELAÇÃO À CONCENTRAÇÃO MÉDIA DO MESMO. AS DUAS ÚLTIMAS LINHAS MOSTRAM O AUTOVALOR E A VARIÂNCIA ASSOCIADA A CADA FATOR.

TABELA 16: CONCENTRAÇÃO MÉDIA POR FATOR DOS ELEMENTOS QUE NÃO FORAM INCLUÍDOS NA ACPA.

TABELA 17: RESULTADOS DA ACPA APLICADA AO MPF DE MANACAPURU COLETADO DURANTE O GOAMAZON2014/15 APÓS ROTAÇÃO VARIMAX. A TABELA MOSTRA A CONCENTRAÇÃO MÉDIA DE 
CADA ELEMENTO POR FATOR E O PERCENTUAL QUE REPRESENTA EM RELAÇÃO À CONCENTRAÇÃO MÉDIA DO MESMO. AS DUAS ÚLTIMAS LINHAS MOSTRAM O AUTOVALOR E A VARIÂNCIA ASSOCIADA A CADA FATOR.

TABELA 18: CONCENTRAÇÃO MÉDIA POR FATOR DOS ELEMENTOS QUE NÃO FORAM INCLUÍDOS NA ACPA.

TABELA 19: RESULTADOS DA ACPA APLICADA AO MPF DE MANACAPURU COLETADO DURANTE O GOAMAZON2014/15 APÓS ROTAÇÃO VARIMAX. A TABELA MOSTRA A CONCENTRAÇÃO MÉDIA DE CADA ELEMENTO POR FATOR E O PERCENTUAL QUE REPRESENTA EM RELAÇÃO À CONCENTRAÇÃO MÉDIA DO MESMO. AS DUAS ÚLTIMAS LINHAS MOSTRAM O AUTOVALOR E A VARIÂNCIA ASSOCIADA A CADA FATOR.

TABELA 20: CONCENTRAÇÃO MÉDIA POR FATOR DOS ELEMENTOS QUE NÃO FORAM INCLUÍDOS NA ACPA.

TABELA 21: INCERTEZAS RELATIVAS OBTIDAS ATRAVÉS DA EQUAÇÃO 15 COM K=2 PARA CADA SÍTIO DURANTE O PROJETO GOAMAZON2014/15 E OS OBTIDOS POR YATKIN ET AL. (2016). ESSES RESULTADOS FORAM APLICADOS ÀS CONCENTRAÇÕES ELEMENTARES A FIM DE CONTRSTUIR A MATRIZ DE INCERTEZA NECESSÁRIA PARA RODAR O PMF.

TABELA 22: RESULTADOS DO PMF APLICADO AO MPF DA ZF2 COLETADO DURANTE O GOAMAZON2014/15. A TABELA MOSTRA A CONCENTRAÇÃO MÉDIA DE CADA ELEMENTO POR FATOR E O PERCENTUAL QUE REPRESENTA EM RELAÇÃO À CONCENTRAÇÃO MÉDIA DO MESMO.93

TABELA 23: CONCENTRAÇÃO MÉDIA DE MPF ASSOCIADO A CADA FATOR POR ESTAÇÃO. O PERCENTUAL MOSTRADO É RELATIVO À CONCENTRAÇÃO DE MPF DA ESTAÇÃO.

TABELA 24: RESULTADOS DO PMF APLICADO AO MPG DA ZF2 COLETADO DURANTE O GOAMAZON2014/15. A TABELA MOSTRA A CONCENTRAÇÃO MÉDIA DE CADA ELEMENTO POR FATOR E O PERCENTUAL QUE REPRESENTA EM RELAÇÃO À CONCENTRAÇÃO MÉDIA DO MESMO.95

TABELA 25: CONCENTRAÇÃO MÉDIA DE MPG ASSOCIADO A CADA FATOR POR ESTAÇÃO. O PERCENTUAL MOSTRADO É RELATIVO À CONCENTRAÇÃO DE MPG DA ESTAÇÃO.

.96

TABELA 26: RESULTADOS DO PMF APLICADO AO MPF DO TIWA COLETADO DURANTE O GOAMAZON2014/15. A TABELA MOSTRA A CONCENTRAÇÃO MÉDIA DE CADA ELEMENTO POR FATOR E O PERCENTUAL QUE REPRESENTA EM RELAÇÃO À CONCENTRAÇÃO MÉDIA DO MESMO.98

TABELA 27: CONCENTRAÇÃO MÉDIA DE MPF ASSOCIADO A CADA FATOR POR ESTAÇÃO. O PERCENTUAL MOSTRADO É RELATIVO À PARTICIPAÇÃO DO FATOR NO MPF DA ESTAÇÃO SECA OU CHUVOSA.. 98

TABELA 28: RESULTADOS DO PMF APLICADO AO MPG DO TIWA COLETADO DURANTE O GOAMAZON2014/15. A TABELA MOSTRA A CONCENTRAÇÃO MÉDIA DE CADA ELEMENTO POR FATOR E O PERCENTUAL QUE REPRESENTA EM RELAÇÃO À CONCENTRAÇÃO MÉDIA DO MESMO.99

TABELA 29: CONCENTRAÇÃO MÉDIA DE MPG ASSOCIADO A CADA FATOR POR ESTAÇÃO. O PERCENTUAL EXPOSTO É RELATIVO À CONCENTRAÇÃO DE MPG DA ESTAÇÃO.

TABELA 30: RESULTADOS DO PMF APLICADO AO MPF DE MANACAPURU COLETADO DURANTE O GOAMAZON2014/15. A TABELA MOSTRA A CONCENTRAÇÃO MÉDIA DE CADA ELEMENTO POR FATOR E O PERCENTUAL QUE REPRESENTA EM RELAÇÃO À CONCENTRAÇÃO MÉDIA DO MESMO.

101

TABELA 31: CONCENTRAÇÃO MÉDIA DE MPF ASSOCIADO A CADA FATOR POR ESTAÇÃO. O PERCENTUAL EXPOSTO É RELATIVO À CONCENTRAÇÃO DE MPF DA ESTAÇÃO. 101

TABELA 32: RESULTADOS DO PMF APLICADO AO MPG DE MANACAPURU COLETADO DURANTE O GOAMAZON2014/15. A TABELA MOSTRA A CONCENTRAÇÃO MÉDIA DE CADA ELEMENTO POR FATOR E O PERCENTUAL QUE REPRESENTA EM RELAÇÃO À CONCENTRAÇÃO MÉDIA DO MESMO.

TABELA 33: CONCENTRAÇÃO MÉDIA DE MPG ASSOCIADO A CADA FATOR POR ESTAÇÃO. O PERCENTUAL EXPOSTO É RELATIVO À CONCENTRAÇÃO DE MPG DA ESTAÇÃO. 103 


\section{SUMÁRIO}

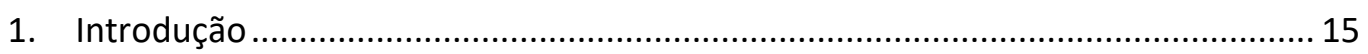

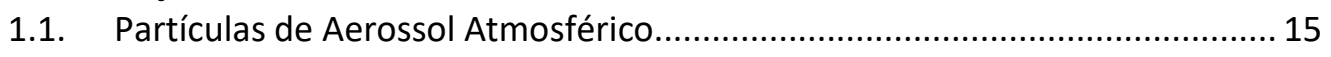

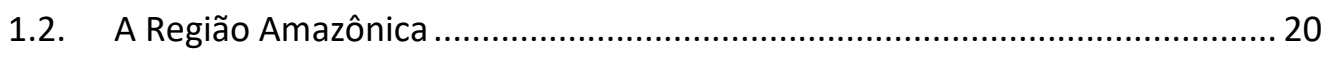

1.2.1. Composição dos aerossóis da região Amazônica........................................ 21

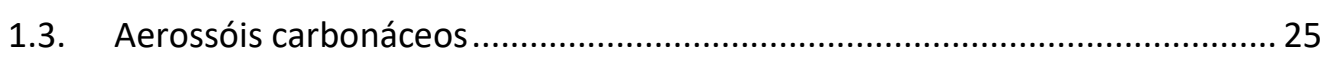

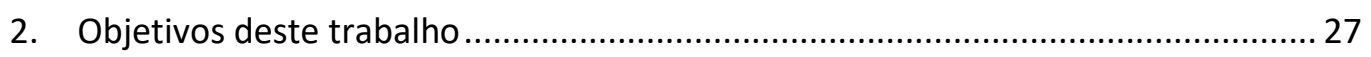

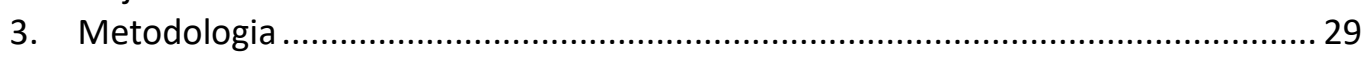

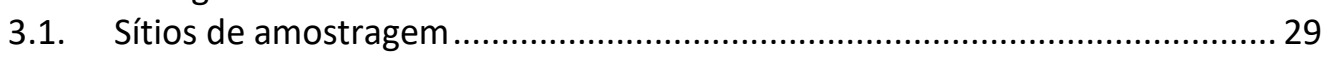

3.1.1. O Sítio experimental da Reserva Biológica de Cuieiras - Manas ZF2 (TOz)31

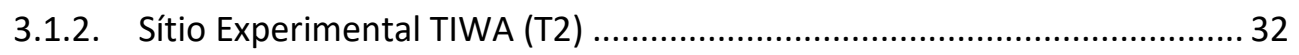

3.1.3. A estação amostradora de Manacapuru (T3).......................................... 33

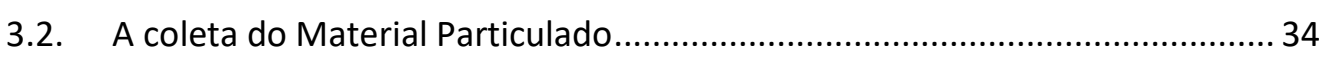

3.3. Análises aplicadas aos filtros amostradores de aerossol ............................... 36

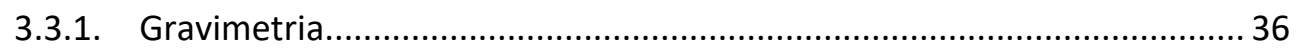

3.3.2. Análise de elementos traços por espectrometria de fluorescência de raios $\times \quad 36$

3.3.3. Análise do Black Carbon Equivalente através da Refletância 39

3.3.4. Análise de carbono orgânico e elementar por análise Termo-Óptica diferencial 39

3.4. Análise de Fatores - Modelos Receptores

3.4.1. Análise de componentes principais e análise de componentes principais absoluta 43

3.4.2. PMF - Positive Matrix Factorization 45

3.4.2.1. Multilinear Engine ............................................................................ 47

3.4.3. Diferenças entre os métodos ACP e PMF............................................... 47

3.4.4. Tratamento das bases de dados para aplicação dos modelos receptores 48

3.5. Comparação entre técnicas de medidas ......................................................... 50

3.5.1. Comparação com o coeficiente de absorção medido por aetalômetro ... 50

3.5.2. Comparação com a concentração de matéria orgânica obtida por espectrômetro de massa............................................................................................... 51

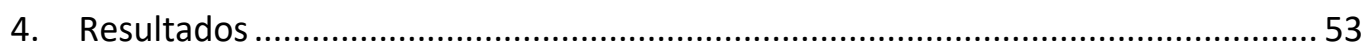

4.1. Comparação entre técnicas de medidas ....................................................... 53

4.1.1. Comparação do Black Carbon Equivalente medido por refletância versus Coeficiente de Absorção medido por Aetalômetro

4.1.2. Comparação de elemental carbon obtido através da técnica termo-óptica versus black carbon equivalente obtido através da refletância . 57

4.1.3. Comparação entre total carbon e concentração de massa através do scanning mobility particle sizer (SMPS) 60 
4.1.4. Matéria Orgânica versus Carbono Orgânico obtido através do método termo-óptico 61

4.2. Material Particulado na Amazônia Central .....................................................63 63

4.3. Black carbon equivalente na Amazônia Central...............................................66 66

4.4. Composição elementar do aerossol na Amazônia Central .............................. 70

4.5. Análise do aerossol carbonáceo na Amazônia Central .................................... 73

4.5.1. Série temporal dos aerossóis carbonáceos .................................................. 73

4.5.2. Análise da fração orgânica dos termogramas ............................................. 76

4.6. Reconstituição da massa gravimétrica .......................................................... 77

4.7. Identificação das fontes de material particulado utilizando a ACPA .............. 79

4.7.1. ACPA aplicada ao material particulado fino da ZF2 ................................. 80

4.7.2. ACPA aplicada ao material particulado grosso da ZF2 …......................... 81

4.7.3. ACPA aplicada ao material particulado fino do TIWA ................................. 83

4.7.4. ACPA aplicada ao material particulado grosso do TIWA............................ 85

4.7.5. ACPA aplicada ao material particulado fino de Manacapuru ....................87 87

4.7.6. ACPA aplicada ao material particulado grosso de Manacapuru ............... 89

4.8. Identificação das fontes de material particulado utilizando o PMF ............... 91

4.8.1. Construção da matriz de incertezas para o PMF.......................................... 91

4.8.2. PMF aplicado ao material particulado fino da ZF2 .................................. 92

4.8.3. PMF aplicado ao material particulado grosso da ZF2 .............................. 95

4.8.4. PMF aplicado ao material particulado fino do TIWA ................................ 97

4.8.5. PMF aplicado ao material particulado grosso do TIWA ............................. 99

4.8.6. PMF aplicado ao material particulado fino de Manacapuru..................... 100

4.8.7. PMF aplicado ao material particulado grosso de Manacapuru ............... 102

4.8.8. Comparação entre os fatores encontrados pelos dois métodos multivariados (ACPA e PMF) para a fração fina do MP ................................................... 103

4.8.9. Comparação entre os fatores encontrados pelos dois métodos multivariados (ACPA e PMF) para a fração grossa do MP................................................ 107

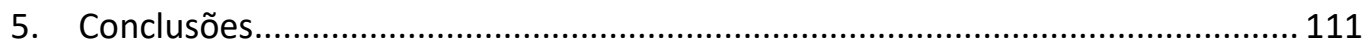

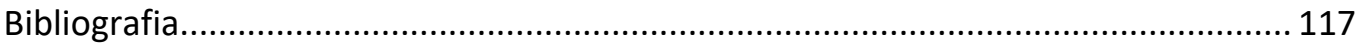

APÊNDICE A - Concentrações Elementares na Moda Fina e Grossa separadas por

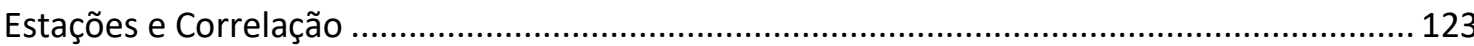

APÊNDICE B - Material complementar da análise de componentes principais (ACP). 132

B1. Factor Scores da ACP aplicada ao MPF da ZF2 ............................................ 132

B2. Factor Scores da ACP aplicada ao MPG da ZF2 .............................................. 133

B3. Factor Scores da ACP aplicada ao MPF do TIWA ............................................. 134

B4. Factor Scores da ACP aplicada ao MPG do TIWA ........................................... 135

B5. Factor Scores da ACP aplicada ao MPF de Manacapuru................................ 136

B6. Factor Scores da ACP aplicada ao MPG de Manacapuru ............................... 137

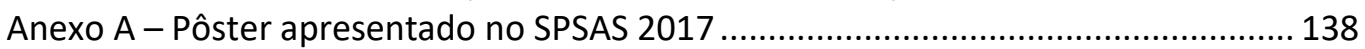

Anexo B - Pôster apresentado no 5th iLEAPS (2017)................................................. 139 


\section{Introdução}

O planeta Terra é caracterizado por uma atmosfera que o envolve contendo gases e partículas de aerossóis. Dentre as diferentes regiões da atmosfera, nós vivemos na troposfera, camada que contém aproximadamente $75 \%$ da massa da atmosfera. Esta camada é composta majoritariamente de nitrogênio (78\%), oxigênio (21\%) e argônio (1\%), além de outros gases traços. Em menor quantidade, temos vapor de água, cuja concentração é controlada pela termodinâmica, precipitação e evaporação, e, por conseguinte, possui uma concentração muito variável. Além destes gases, nossa atmosfera possui partículas sólidas ou líquidas em suspensão, chamadas de aerossóis atmosféricos. Os aerossóis são fundamentais no equilíbrio do fluxo de radiação terrestre, fazem parte do controle do clima e do sistema hidrológico, e exercem importantes funções nos ecossistemas terrestres (ARTAXO et al., 2013).

\subsection{Partículas de Aerossol Atmosférico}

Aerossol atmosférico pode ser definido como uma porção de partículas suspensas em um volume de gás, de modo que podem ser sólidas, líquidas, ou uma mistura de ambas as fases (KOLB; WORSNOP, 2012). Uma maneira de classificar os aerossóis do ponto de vista de mecanismo de produção é entre primários e secundários. Componentes primários são aqueles emitidos diretamente como partículas da fonte para a atmosfera. Aerossóis secundários formam-se na atmosfera (FUZZI, S. et al., 2005) a partir de processos de conversão gás-partícula. Devido ao processamento atmosférico e diversidade de fontes emissoras, na atmosfera encontram-se essas partículas na forma de complexas misturas internas e externas(MARTIN; ANDREAE; ARTAXO; et al., 2010). A Figura 1 mostra um panorama geral da emissão e do processamento do aerossol na atmosfera, mostrando quais os principais tipos de compostos e partículas emitidas, como elas interagem entre si, como envelhecem e a implicação desses processos na forçante radiativa. 
Figura 1: diagrama esquemático de emissão, deposição, processamento e influências associadas ao aerossol. A interferência do aerossol na forçante radiativa é indicada por sua influência direta na radiação e em nuvens pelas siglas ERFari e ERFaci (do inglês, effective radiative forcing aerosol-radiation interactions e aerosol-cloud interactions).

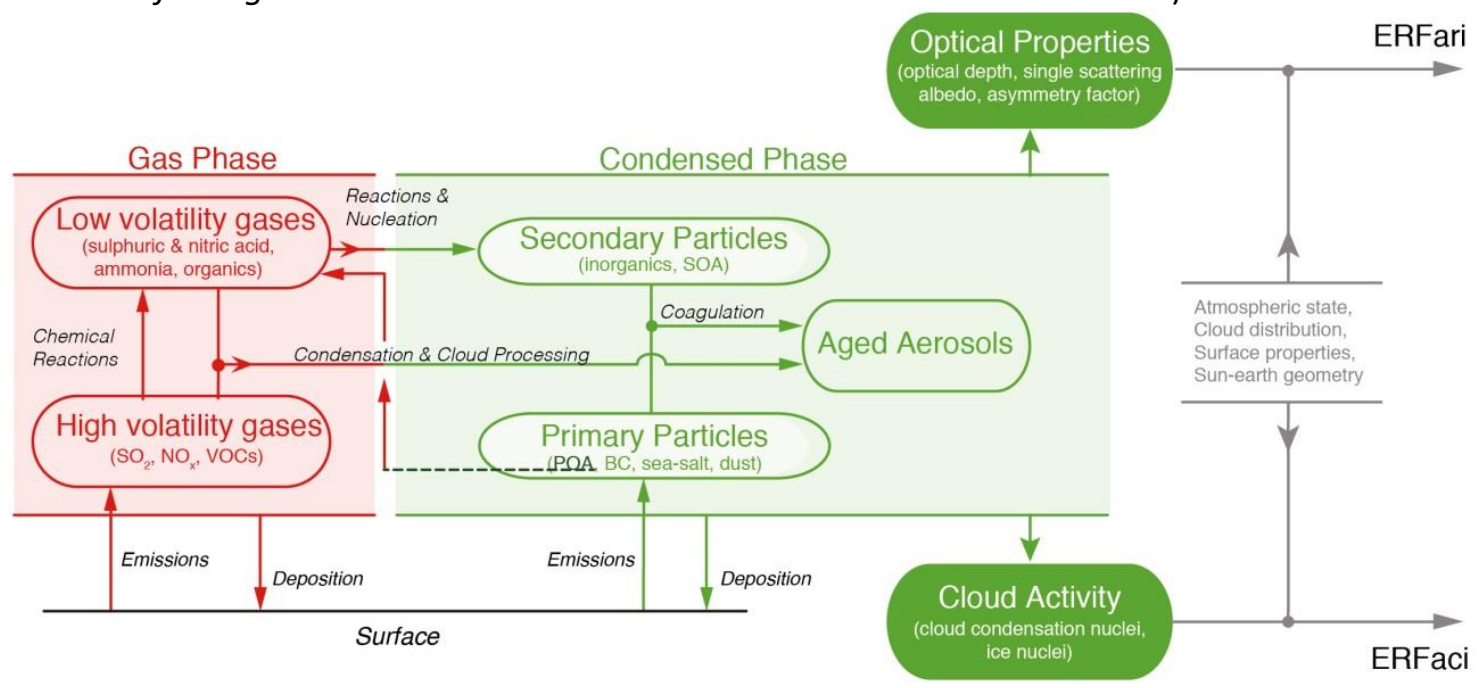

Fonte: BOUCHER et al. (2013).

Na figura acima, a parte em vermelho refere-se às principais emissões na fase gasosa, com destaque para os compostos orgânicos voláteis (VOC, do inglês volatile organic compounds), dióxido de enxofre $\left(\mathrm{SO}_{2}\right)$ e óxidos de nitrogênio $\left(\mathrm{NO}_{2}, \mathrm{NOy}\right)$, enquanto que a verde corresponde ao material particulado: Primary Organic Aerosol (POA), Black Carbon (BC, referente ao componente do aerossol com propriedades ópticas e composição similar à fuligem), sal marinho, poeira mineral e partículas secundárias. Posterior à introdução desses elementos na atmosfera, complexos processamentos ocorrem de modo a gerar Low Volatity Gases (ácido sulfúrico e nítrico, amônia, VOCs) e partículas secundárias (aerossóis inorgânicos e Secondary Organic Aerosol, SOA). Nos dias atuais, os principais emissores de BC, sulfato, nitrato e amônia são fontes antropogênicas, enquanto que sal marinho, poeira mineral e PBAP são majoritariamente de origem natural. O aerossol orgânico, seja ele primário ou secundário, é influenciado tanto por fontes naturais quanto antropogênicas (BOUCHER et al., 2013).

O aerossol na atmosfera pode espalhar e absorver luz afetando o balanço radiativo e a estrutura térmica da atmosfera. Os aerossóis também podem servir de superfície para condensação de vapor de água, levando a formação de núcleos de condensação de nuvens e de gelo. O sistema atmosférico é muito dinâmico e ocorrem interações heterogêneas que modificam sua composição química (KOLB; WORSNOP, 2012). 
Outra forma útil de se classificar o aerossol é a partir de seu diâmetro aerodinâmico, isto é o diâmetro de uma esfera de densidade $1 \mathrm{~g} / \mathrm{cm}^{3}$ que tem a mesma velocidade terminal de queda no ar que a partícula em questão (FINLAYSON-PITTS; PITTS, 1999). O uso do diâmetro aerodinâmico para classificar o aerossol vai de encontro com a necessidade de se compreender processos de produção, remoção e transporte atmosférico, conforme se pode ver na Figura 2 (SEINFELD; PANDIS, 2006).

Figura 2: exemplo de distribuição de tamanho de aerossóis e os principais processos, fontes e sumidouros envolvidos em cada moda.
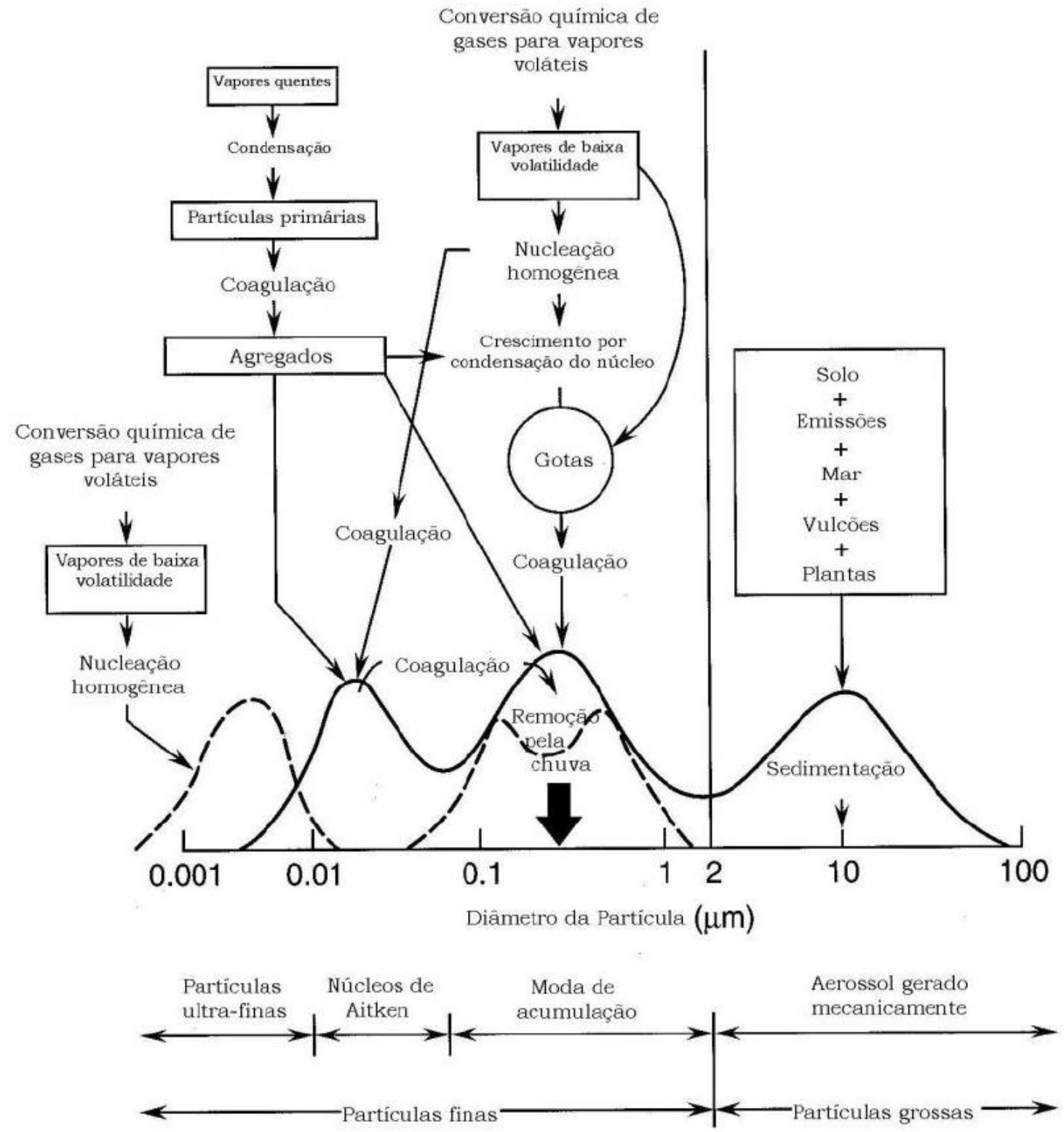

Fonte: SEINFELD and PANDIS (2006), tradução de (JUNIOR, 2015).

$\mathrm{Na}$ figura verificam-se quatro diferentes grupos de partículas que possuem diferentes propriedades. $\mathrm{O}$ grupo com aerossóis de menor diâmetro é chamado de moda de nucleação 
e é o que geralmente possui a maior quantidade de partículas na atmosfera devido à condensação de vapores em processos de combustão e por nucleação de outras espécies atmosféricas. Suas dimensões são de alguns nanômetros e são importantes na formação e crescimento de partículas maiores. Logo após, contemplando partículas com dimensões com cerca de $0,01 \mu \mathrm{m}$ e $0,1 \mu \mathrm{m}$ de diâmetro, tem-se a moda de Aitken formada através da condensação das partículas da moda de nucleação. A moda de acumulação que compreende partículas com diâmetro de $0,1 \mu \mathrm{m}$ até $2,5 \mu \mathrm{m}$ ocorre principalmente devido ao processo de coagulação de partículas menores e da condensação de vapores em partículas, fazendo-as crescerem. Esta moda costuma dominar as distribuições de área superficial e massa de aerossol. O nome de "moda de acumulação" deve-se ao fato dos processos de remoção serem pouco eficientes, e as partículas se "acumulam" nesta faixa de tamanho. Por fim, partículas com diâmetros maiores que $2,5 \mu \mathrm{m}$, chamadas de moda grossa, são majoritariamente formadas a partir de processos mecânicos.

O aerossol lançado na atmosfera participa de diversos processos, um deles, importante para o entendimento das mudanças climáticas, relaciona-se com sua interação com a radiação eletromagnética direta e indiretamente. Esta interação entre as partículas de aerossol e radiação leva a uma alteração no balanço energético da Terra. A Figura 3 ilustra os principais processos de como aerossóis e nuvens contribuem para alteração no balanço radiativo, temperatura superficial e às mudanças climáticas.

Figura 3: impacto dos aerossóis sobre o balanço de radiação global, levando em conta os efeitos diretos e indiretos dos aerossóis no clima, incluindo mecanismos de retroalimentação no sistema climático.

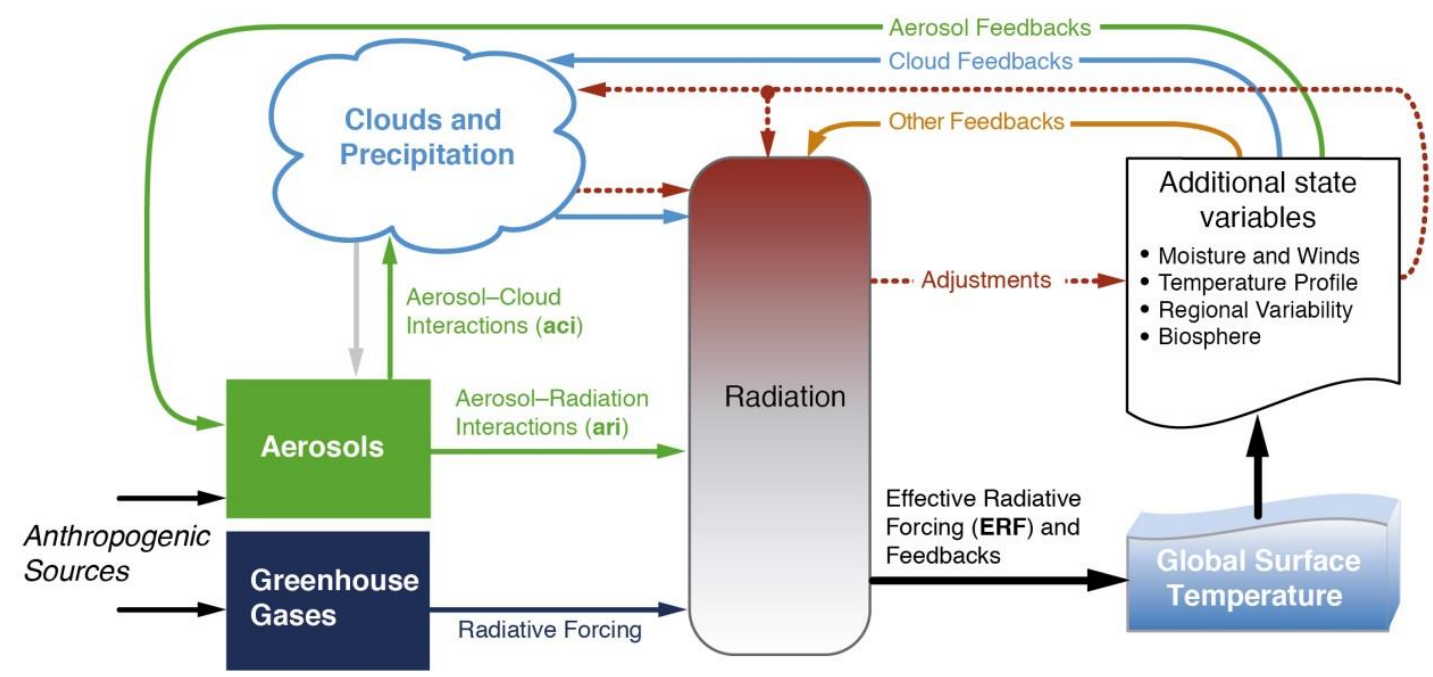

Fonte: BOUCHER et al. (2013). 
O melhor entendimento desses processos possibilita avaliar o impacto dos aerossóis e gases de efeito estufa de origem antrópica no balanço radiativo terrestre. À medida deste impacto dá-se o nome de forçante radiativa, que é um cálculo da alteração líquida no balanço radiativo terrestre em resposta a perturbações externas sendo que valores positivos significam aquecimento e, valores negativos, resfriamento. A Figura 4 mostra quantitativamente a forçante radiativa dos principais componentes atmosféricos que levam a mudanças no clima em relação a condições anteriores à revolução industrial. Verifica-se que a forçante radiativa associada a aerossóis, de forma direta e indireta, tem o efeito médio de esfriar a superfície, entretanto apresentam a maior incerteza em relação aos demais componentes, tornando necessários mais estudos nesta área. O efeito do Black Carbon é de aquecimento da atmosfera.

Figura 4: forçantes radiativas calculadas com base o ano de 1750. Nota-se que enquanto gases de efeito estufa apresentam forçante positiva, provocando o aquecimento do planeta, os aerossóis atuam contrabalanceando, com forçante radiativa negativa.

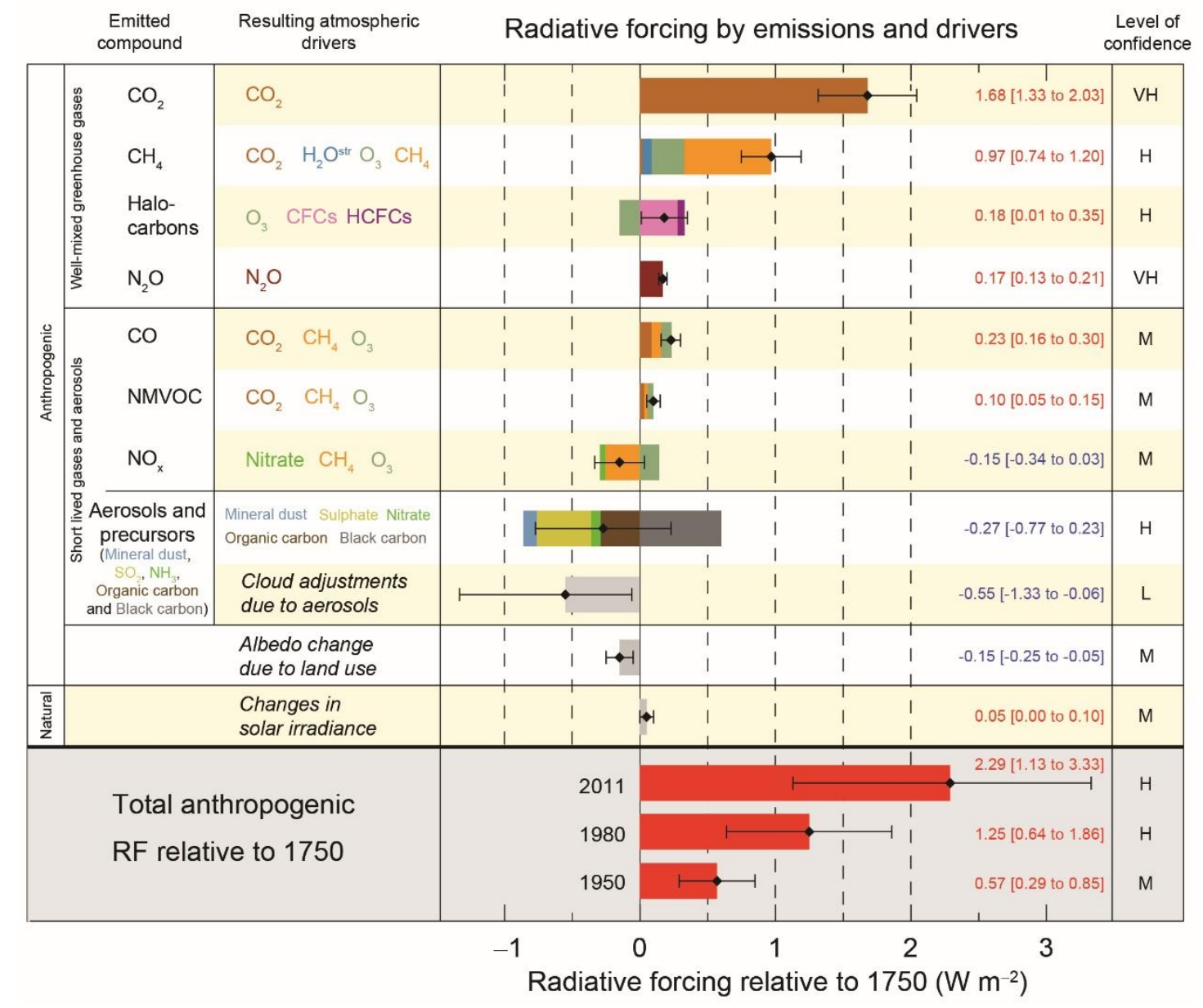

Fonte: BOUCHER et al. (2013). 


\subsection{A Região Amazônica}

A Bacia Amazônica compreende uma área de 6,9 milhões de $\mathrm{km}^{2}$, dos quais $80 \%$ são de floresta tropical primária. A Amazônia tem influência no ecossistema global de diferentes formas: estima-se que a floresta armazene $90-120 \mathrm{PgC}$ de biomassa viva mais $160 \mathrm{PgC}$ em seu solo, de $10-20 \%$ da biodiversidade global e que o Rio Amazonas seja responsável pelo fluxo de aproximadamente $20 \%$ de água doce mundial (ANDREAE, M. O. et al., 2015). No Brasil, a Amazônia Legal abrange os estados do Acre, Amazônia, Roraima, Pará, Amapá, Rondônia, Mato Grosso, Tocantins e parte do Maranhão e Goiás que corresponde a cerca de $59 \%$ do território brasileiro (Figura 5) com 69\% dos aproximadamente 20,3 milhões de habitantes vivendo em zonas urbanas (IBGE, 2017).

Figura 5: mapa da Amazônia Legal do Brasil com o desmatamento acumulado até 2011 destacado em rosa.

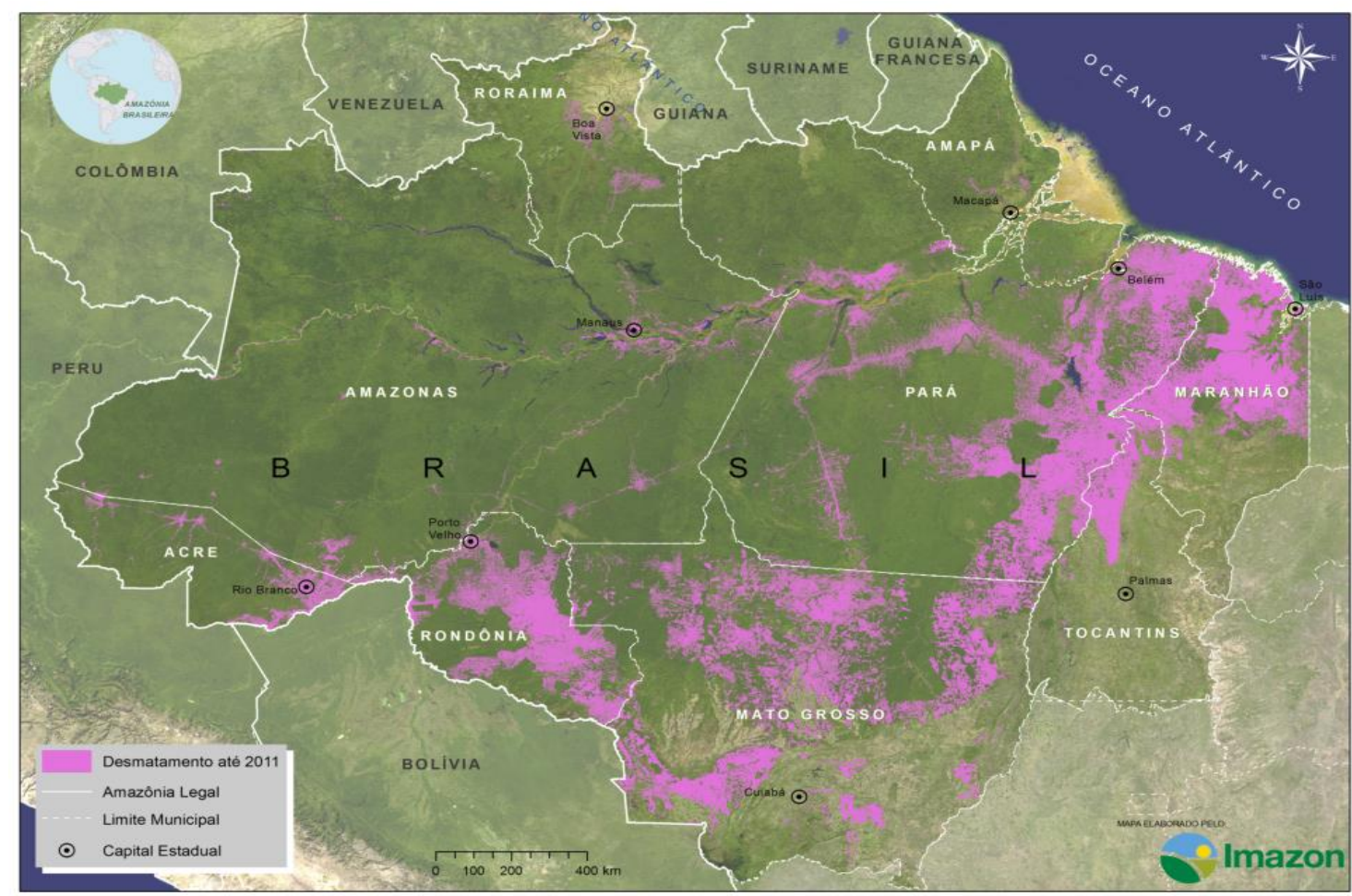

Fonte: IMAZON (2017).

Através do intensivo processo de ocupação humana, a região vem sofrendo significativas mudanças no uso do solo que tem como principais agentes do desmatamento a expansão da pecuária e da agricultura. Por outro lado, nota-se na Figura 6 um decréscimo na área desmatada por ano desde 2004 até o presente quando comparado à série histórica: uma redução de $71 \%$ na área desmatada. A redução do desmatamento neste período deve- 
se a uma série de fatores associados a políticas governamentais e ações ligadas à expansão de áreas agropecuárias (MMA, 2017b; NEPSTAD et al., 2014).

Figura 6: taxa de desmatamento da Amazônia de 1988 até 2016. Em 2004 é implementado o Plano de Ação para Prevenção e Controle do Desmatamento na Amazônia Legal (PPCDAm) que contribuiu de maneira fundamental para a redução de desmatamento na Amazônia.

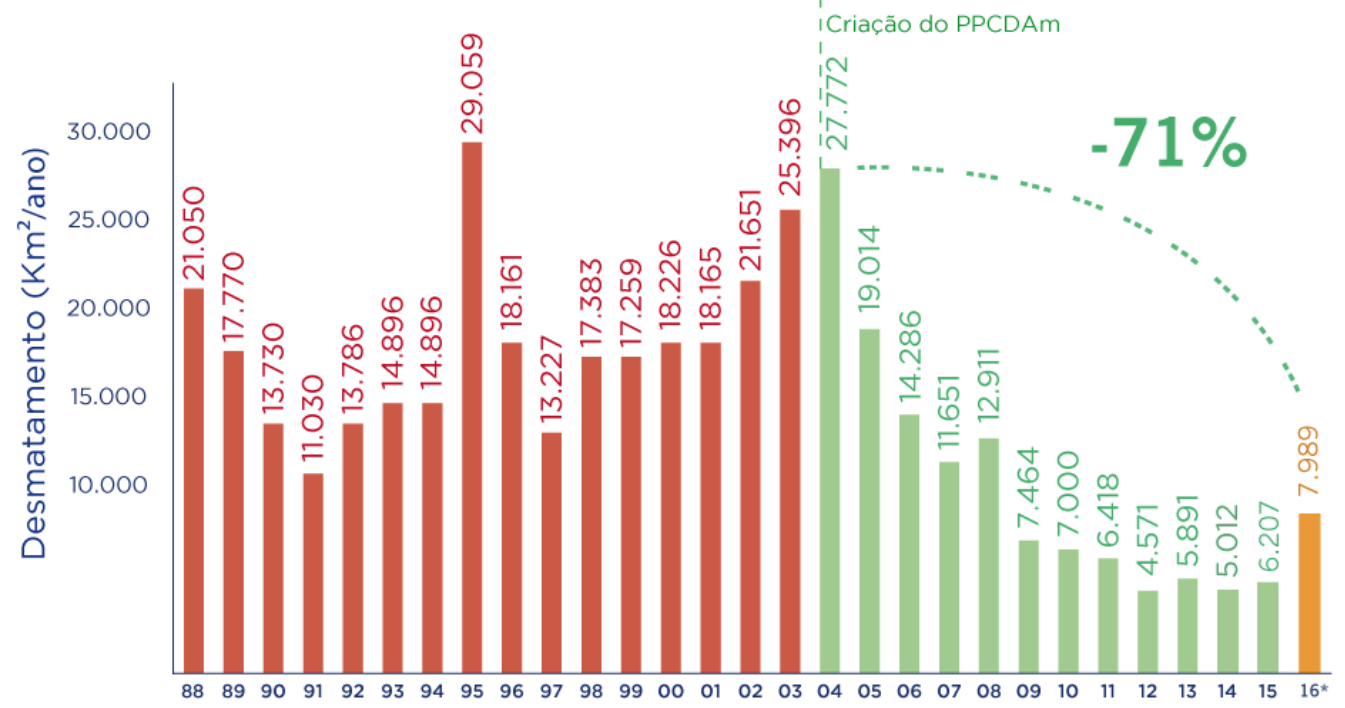

Fonte: MMA (2017a).

A atmosfera Amazônica representa uma das regiões continentais mais próximas da composição atmosférica anteriores à revolução industrial (ANDREAE, MEINRAT O., 2007; MARTIN; ANDREAE; ARTAXO; et al., 2010). A cidade de Manaus, circundada por floresta primária tropical constitui um ambiente único para o estudo do efeito das atividades humanas na qualidade do ar (MARTIN et al., 2017).

\subsubsection{Composição dos aerossóis da região Amazônica}

Na Amazônia, de modo geral, a principal fonte responsável pela emissão de aerossóis é a biosfera sendo que na estação seca esta fonte combina-se com a influência antropogênica das emissões de queimadas (MARTIN; ANDREAE; ARTAXO; et al., 2010). Como principais grupos de aerossóis que afetam a composição da atmosfera amazônica temos a emissão e produção de partículas primárias da vegetação como pólen, esporos, detritos da vegetação e micróbios que recebem o nome de Aerossol Primário Biológico (PBAP, do inglês Primary Biological Aerosol Particles) (MARTIN; ANDREAE; ALTHAUSEN; et al., 2010; MARTIN; ANDREAE; ARTAXO; et al., 2010; POSCHL et al., 2010). Este tipo de aerossol é responsável por aproximadamente $85 \%$ da massa de aerossol maior que $1 \mu$ m durante a estação chuvosa e estima-se que sua emissão é relativamente constante durante o ano (GILARDONI et al., 
2011; HUFFMAN et al., 2012). A Figura 7 mostra algumas micrografias eletrônicas dessas partículas coletadas em filtros na estação chuvosa em região de floresta não perturbada.

Figura 7: microscopia eletrônica de varredura de PBAP coletados por filtros durante a estação chuvosa. As faixas brancas nas fotos correspondem a $2 \mu \mathrm{m}$.
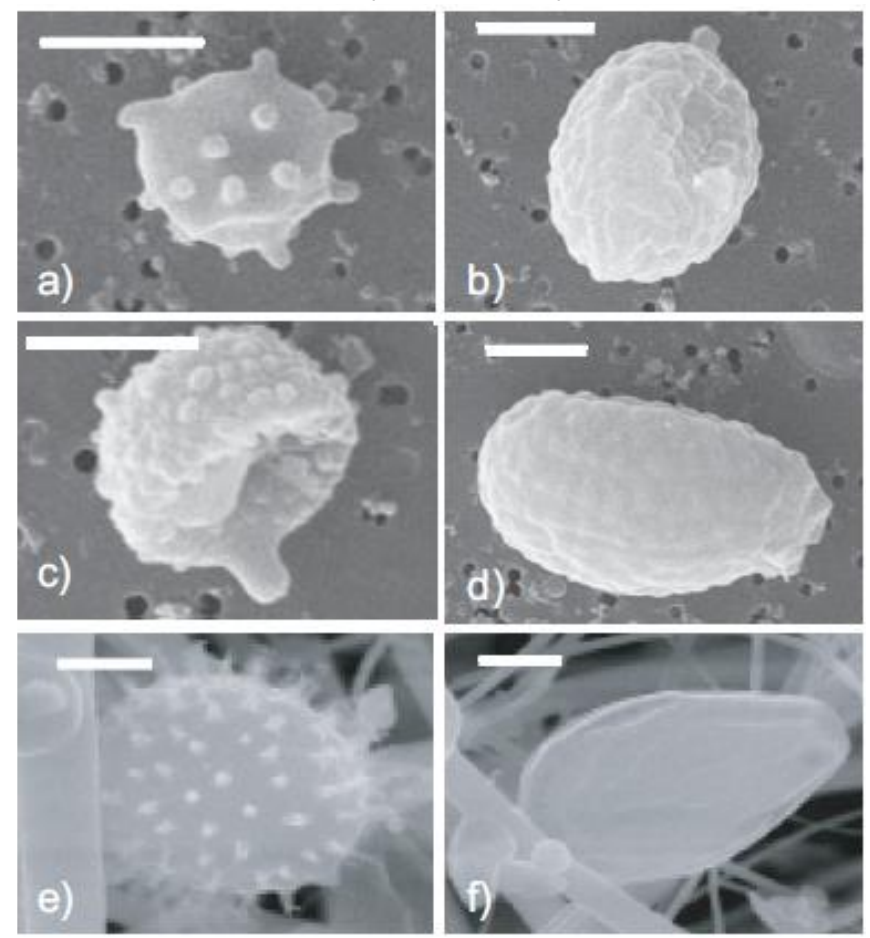

Fonte: GILARDONI et al. (2011).

Além de PBAPs, a vegetação também emite compostos orgânicos voláteis. $O$ tipo de VOC emitido está diretamente ligado à espécie da planta emissora, tornando a estimativa de VOCs emitidos pela floresta uma tarefa complexa pelo fato da Amazônia conter da ordem de $10^{5}$ espécies de plantas (MARTIN; ANDREAE; ARTAXO; et al., 2010). Sabe-se que os principais tipos de VOCs emitidos pela floresta são isopreno, monoterpenos, VOCs oxigenados entre outros (ARTAXO et al., 2005; POSCHL et al., 2010). Após a emissão, uma porção dos VOCs sofrem processamento dando origem a partículas de aerossol secundário, chamadas de Secondary Organic Aerosol (SOA) (POHLKER et al., 2012). O processamento dos VOCs na atmosfera ocorre com a reação com $\mathrm{O}_{3}, \mathrm{OH}$ ou $\mathrm{NO}_{3}$. Assim, $\mathrm{OH}$ é chamado de "detergente da atmosfera" devido à alta incidência de radiação nos trópicos combinada com a alta concentração de $\mathrm{H}_{2} \mathrm{O}$ (ARTAXO et al., 2005; CHEN et al., 2009). Medidas na Amazônia Central durante o experimento GoAmazon mostram que a fração em massa de SOA para partículas menores que 1 mícron é de 70 a 85\%. 
Outra importante componente do aerossol Amazônico é a poeira mineral. Este tipo de aerossol está associado às emissões locais de poeira do solo, além do transporte transatlântico de poeira do deserto do Saara que ocorre principalmente quando a Zona de Interconvergência Tropical (ZCIT) está deslocada para o sul de Manaus, o que ocorre durante a estação chuvosa, mais precisamente entre os meses de fevereiro e abril (BEN-AMI et al., 2010; WANG et al., 2016). Quando analisadas as séries temporais de material particulado na Amazônia, nota-se diversos picos de concentrações especialmente na moda grossa, compatível com a duração desses eventos, entretanto, também é possível observar acréscimo de partículas de solo no MP fino, devido ao desgaste que ocorre no longo transporte a que são submetidas tais partículas (MARTIN; ANDREAE; ARTAXO; et al., 2010; PAULIQUEVIS et al., 2012). Os elementos Ti, Fe, Al, Si e Ca são usualmente empregados como traçadores desta fonte (ARANA, A.; ARTAXO, 2014; BEN-AMI et al., 2010; PAULIQUEVIS et al., 2012).

Aerossol marinho gerado no Oceano Atlântico é transportado para a região Amazônica com a presença marcante de elementos como o Sódio e Cloro, principalmente na fração grossa. Além disso, o dimetilsulfureto emitido pela superfície oceânica contribui para a formação de partículas secundárias através de processos de oxidação (MARTIN; ANDREAE; ARTAXO; et al., 2010; POSCHL et al., 2010).

A Figura 8 mostra de forma geral como os aerossóis são parte integrante do complexo relacionamento entre a biosfera e a atmosfera na Amazônia. Aerossóis influenciam fortemente o balanço de energia, o ciclo hidrológico, o balanço de carbono e outros fatores. 
Figura 8: representação esquemática da complexa relação entre atmosfera e biosfera na Amazônia, enfatizando o papel de aerossóis.

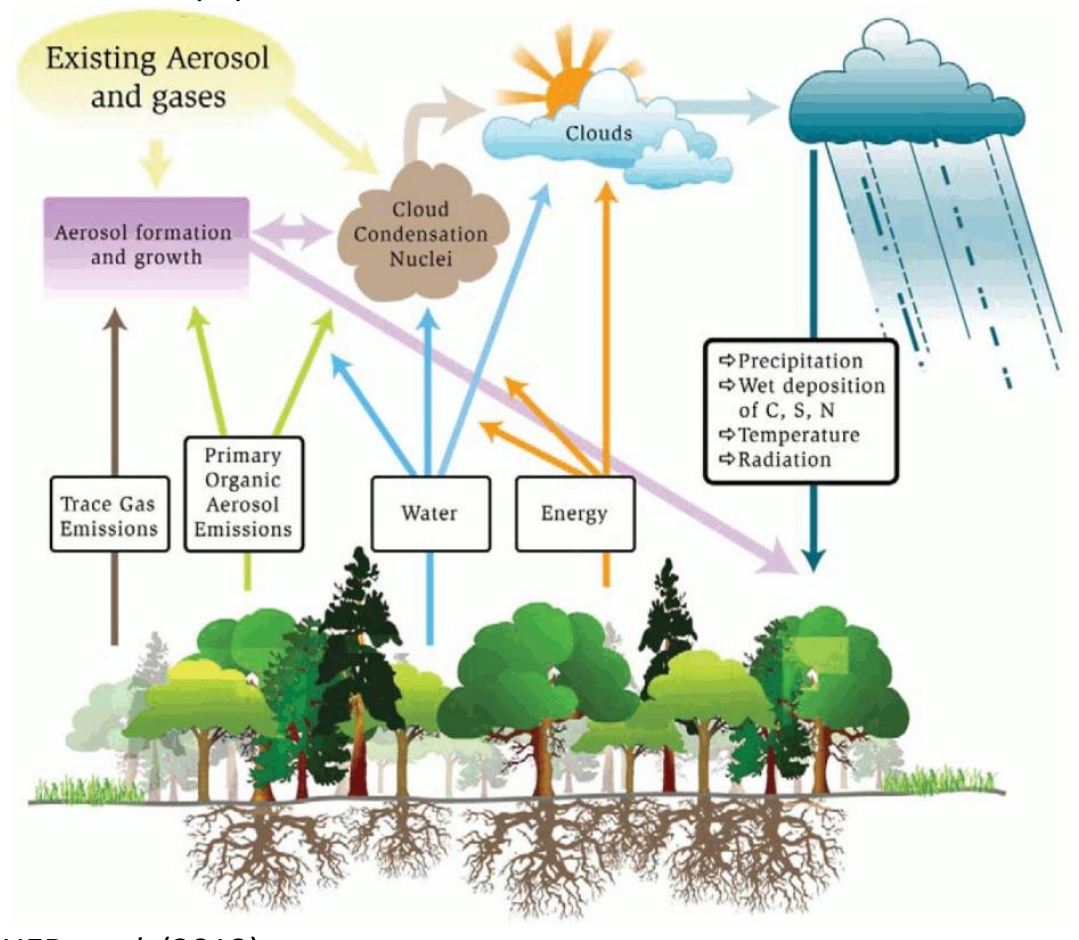

Fonte: BOUCHER et al. (2013).

Conforme já mencionado, grandes áreas de florestas são desmatadas anualmente (Figura 6) com a finalidade de mudar o uso da térrea para a prática de pecuária e agricultura (ARTAXO et al., 2013; NEPSTAD et al., 2014). Para isto utiliza-se da queima de biomassa após o desmatamento, intensificando as emissões de queimadas de Agosto a Dezembro. Neste período verifica-se um aumento de duas ordens de grandeza no número de partículas por volume de ar em áreas mais impactadas pelas plumas de queimada, alterando o balanço radiativo e composição dos aerossóis (ARTAXO et al., 2013). Medidas realizadas durante a estação seca indicam a prevalência de partículas de aerossol orgânico, além de compostos inorgânicos como $\mathrm{KCl}, \mathrm{K}_{2} \mathrm{SO}_{4}$, entre outros e gases traço (ARTAXO et al., 2002, 2013; MARTIN; ANDREAE; ARTAXO; et al., 2010). Tais influências causadas pelas emissões da queima de biomassa atuam desde em escala local até milhares de quilômetros de distância (ARTAXO et al., 2005). Além da queima de biomassa de dentro da região amazônica também ocorre o transporte intercontinental de emissões de queimadas da África.

A atividade antrópica da cidade de Manaus também influencia na composição da atmosfera com a emissão de gases traços e partículas secundárias que modificam as propriedades físicas e ópticas dos aerossóis. Estudo realizado por KUHN et al. (2010) quantificou maiores concentrações de ozônio, monóxido de carbono e material particulado, 
esta última atinge $9000 \mathrm{~cm}^{-3}$, um alto impacto quando comparamos com situações de background de $300 \mathrm{~cm}^{-3}$ (MARTIN; ANDREAE; ARTAXO; et al., 2010).

\subsection{Aerossóis carbonáceos}

Aerossóis carbonáceos são, em geral, o principal constituinte na massa do material particulado atmosférico. Eles influenciam significativamente o clima, seja diretamente através do espalhamento e absorção de radiação, seja de maneira indireta afetando propriedades de nuvens e seu tempo de vida. Na Amazônia, GILARDONI et al. (2011) encontrou concentrações médias de matéria orgânica da ordem de $70 \%$ da massa total para partículas finas e grossas, sendo que a concentração na moda fina aumenta durante a estação seca devido a queimadas. Para se referir às diferentes medidas envolvendo carbono, este trabalho baseou-se em diferentes trabalhos anteriores (ANDREAE, M. O.; GELENCSÉR, 2006; KARANASIOU et al., 2015) que levam em conta processos de emissão, características morfológicas, composição química, propriedades ópticas e técnicas de medição:

- Carbono Total (TC, do inglês Total Carbon): refere-se à quantidade total de carbono particulado, englobando a fração orgânica e elementar;

- Carbono Orgânico (OC, do inglês Organic Carbon): refere-se à fração de carbono particulado presente em compostos majoritariamente orgânicos. Na atmosfera é encontrado em partículas diretamente emitidas, entretanto é comumente encontrado em partículas secundárias formadas através da condensação de VOCs. Durante a aplicação da técnica de termo-óptica, esses compostos são os primeiros a pirolizar ou serem liberados durante a fase de atmosfera inerte, portanto, fração menos refratária. Tem fortes propriedades de espalhamento de radiação, e fraca capacidade de absorção.

- Carbono Elementar (EC, do inglês Elemental Carbon): refere-se à fração de carbono elementar com composição próxima à fuligem (ou soot). Operacionalmente é utilizado como a fração de carbono menos volátil que oxida em altas temperaturas e com a presença de uma atmosfera oxidativa. Tem altas propriedades de absorção de radiação.

- Light-absorbing Carbon: termo genérico para substâncias carbonáceas absorvedoras de luz que inclui fração orgânica (Brown Carbon) e a fração elementar. 
- Black Carbon (BC): carbono altamente absorvedor de luz com propriedades ópticas semelhantes às da fuligem. Os resultados das análises de refletância serão expostos como Black Carbon Equivalente (BCe).

- Brown Carbon ( $\mathrm{BrC})$ : fração de matéria orgânica absorvedora de luz que não é BC.

Deve-se ter em mente que os termos descritos acima não se referem a um tipo de partícula em específico e que, cada um dos diferentes e complexos compostos contendo carbono reagem de diferentes maneiras às diferentes técnicas analíticas empregadas (ANDREAE, M. O.; GELENCSÉR, 2006). Continua a ser um desafio a caracterização da fração orgânica em seus efeitos de absorção e espalhamento.

A Figura 9 apresenta de forma esquemática as diferentes nomenclaturas utilizadas de acordo com a técnica utilizada e o carbono analisado.

Figura 9: representação esquemática da classificação da grandeza medida de acordo com a técnica empregada.

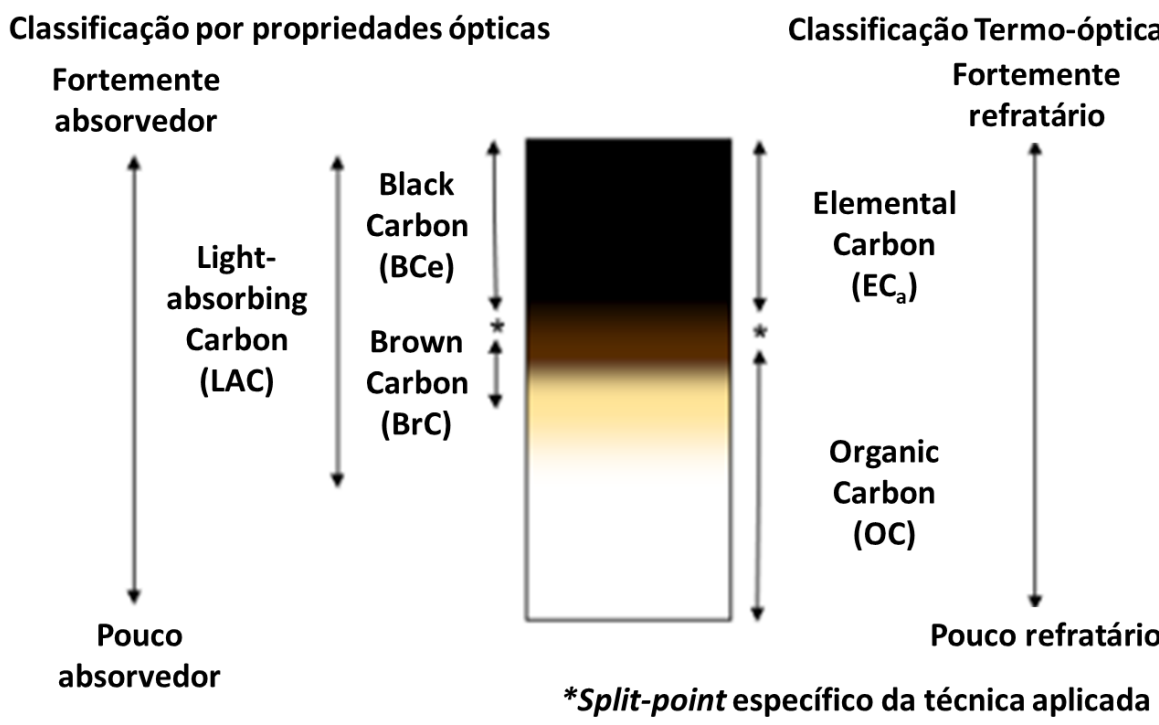

Fonte: traduzido de US EPA (2012). 


\section{Objetivos deste trabalho}

Esta pesquisa está inserida dentro do projeto GoAmazon 2014/15 (The Observations and Modeling of the Green Ocean Amazon). O GoAmazon tem foco em entender e quantificar as complexas interações entre as emissões naturais da vegetação, a química atmosférica, e a produção de aerossol quando emissões naturais interagem com emissões urbanas de Manaus.

Sendo parte do GoAmazon (MARTIN et al., 2016), este projeto tem por objetivo específico investigar fontes e processos que regulam as concentrações atmosféricas das componentes orgânica e inorgânica dos aerossóis atmosféricos na parte Central da Amazônia, levando em conta a influência antropogênica da cidade de Manaus.

Os objetivos específicos podem ser descritos como:

1) investigar a interação entre a pluma de Manaus e as emissões biogênicas influenciam no teor de elementos traços no aerossol vento abaixo da pluma urbana;

2) investigar a influencia desta interação na componente carbonácea do aerossol;

3) investigar a influencia desta interação nas propriedades óticas do aerossol;

4) quantificar através de modelos estatísticos multivariados as diferentes componentes de aerossóis. 


\section{Metodologia}

Para atingirmos os objetivos deste trabalho coletou-se material particulado (MP) em três sítios da Amazônia Central: ZF2 (T0), TIWA (T2) e Manacapuru (T3). Com a aplicação das técnicas descritas nesta seção obteve-se a concentração de MP, Black Carbon equivalente (BCe), elementos traço, carbono orgânico (OC) e carbono elementar (EC).

\subsection{Sítios de amostragem}

Um dos focos do trabalho é analisar o impacto da poluição de Manaus nas propriedades de partículas de aerossóis biogênicos naturais. Para isso operamos por 2 anos uma estação amostradora em área remota, a ZF2, que representa a atmosfera "limpa", sem impactos da poluição urbana de Manaus. Esta estação recebeu o código TOz no experimento GoAmazon 2014/15. Uma segunda estação amostradora foi operada próxima do centro de Manaus, no chamado "Hotel TIWA", para que possamos analisar a composição do aerossol urbano bem misturado e o código T2 foi associado a este sítio. Esta estação está localizada na margem oposta do Rio Negro a Manaus. Uma terceira estação amostradora foi operada em Manacapuru, cerca de $60 \mathrm{~km}$ vento abaixo de Manaus, referenciada também como T3. A disposição espacial dos sítios de amostragem deste trabalho está exposta na Figura 10.

Figura 10: Sítios amostrais utilizados neste trabalho: ZF2 (TOz), TIWA (T2) e Manacapuru (T3). Observamos nesta figura sua localização em relação à Manaus e a seta indicando a direção predominante do vento.

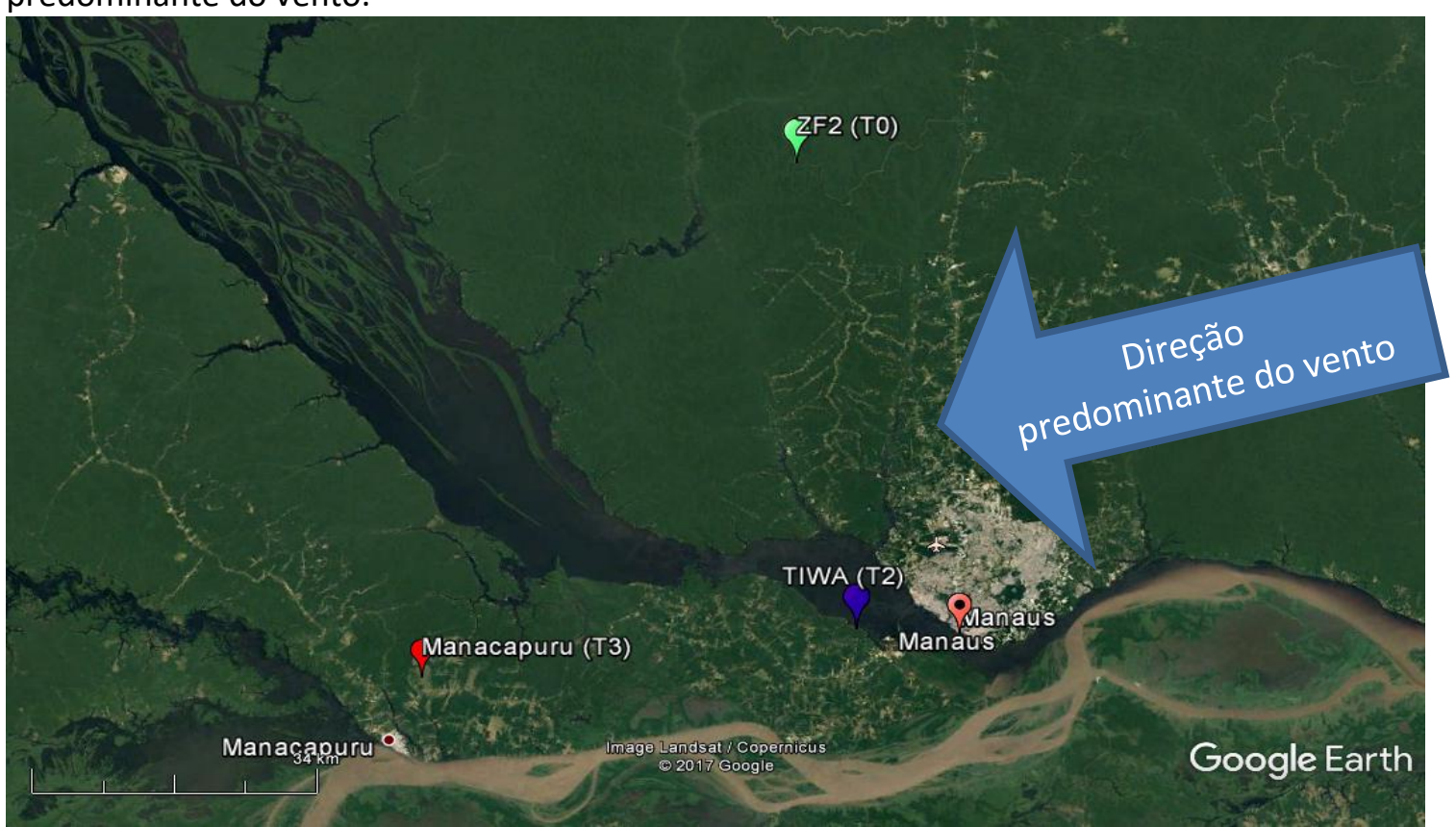

Fonte: Google Earth. 
Verifica-se que o sítio ZF2 está 50km a noroeste de Manaus, TIWA a $8 \mathrm{~km}$ da borda da cidade de Manaus e Manacapuru 60km vento abaixo da cidade. A direção preferencial do vento é de Nordeste. A estratégia para a escolha desses sítios foi realizada de modo a haver um sítio sem influência de pluma antropogênica de Manaus, o ZF2, e outros dois sítios sob a influência desta pluma de Manaus: TIWA e Manacapuru. As medidas no sítio TIWA referemse a aerossóis recém-emitidos, ou seja, quando a pluma urbana está pouco envelhecida. 0 sítio Manacapuru está vento abaixo do sítio TIWA, sendo que a pluma de Manaus leva de cinco a seis horas para chegar em Manacapuru.

A Figura 11 apresenta a precipitação média para o ano de 2014 e 2015 em Manaus. Nota-se maiores valores deste índice nos meses de janeiro a maio e menores valores de junho a dezembro. Assim caracterizou-se o primeiro período como chuvoso e o segundo como seco.

Figura 11: chuva acumulada mensal em Manaus para o ano de 2014 e 2015.

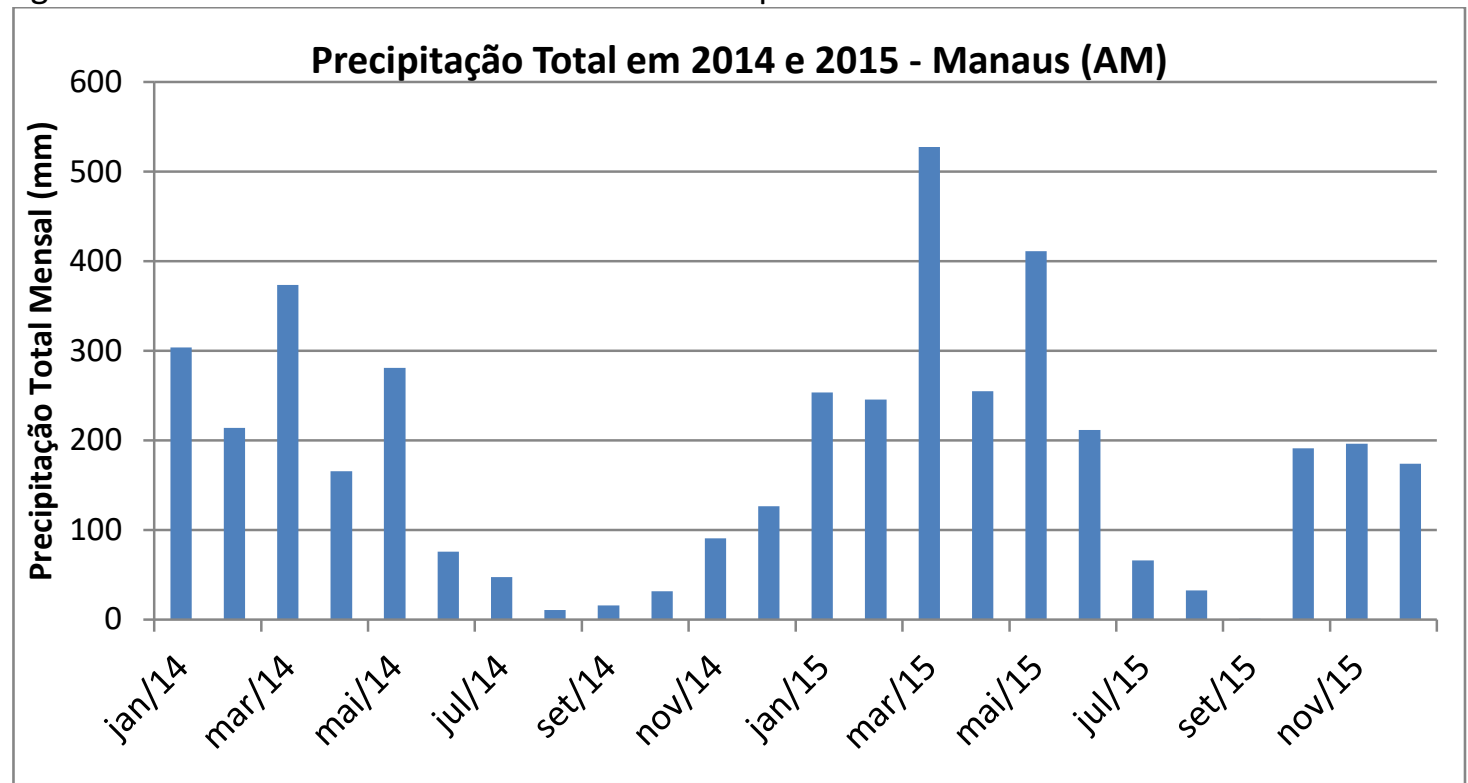

Fonte: Dados da rede do INMET. Disponível em: http://www.inmet.gov.br/sim/gera_graficos.php. Acessado em novembro de 2016. 


\subsubsection{O Sítio experimental da Reserva Biológica de Cuieiras - Manas ZF2 (T0z)}

O sítio experimental ZF2 está inserido em uma área de reserva biológica com floresta primária, a Rebio Cuieras, a aproximadamente $50 \mathrm{~km}$ ao noroeste (vento acima) de Manaus. Ela é administrada pelo Instituto Nacional de Pesquisas Amazônicas (INPA) e abrange uma área de 22.735ha de floresta tropical úmida. A vegetação típica é de floresta tropical primária não perturbada, com grande diversidade de espécies vegetais e dossel que varia entre 30 a 40m (MARTIN; ANDREAE; ALTHAUSEN; et al., 2010). Durante a maior parte do tempo, as massas de ar que chegam na reserva passam por $1600 \mathrm{~km}$ de floresta intocada, vindas do Atlântico tropical, até serem amostradas na torre. Na Figura 12 pode-se verificar a rosa dos ventos para o sítio ZF2 durante o ano de 2014. A direção predominante dos ventos é de leste.

Figura 12: rosa dos ventos para o sítio da ZF2 durante o ano de 2014. A direção de vento predominante é de leste.

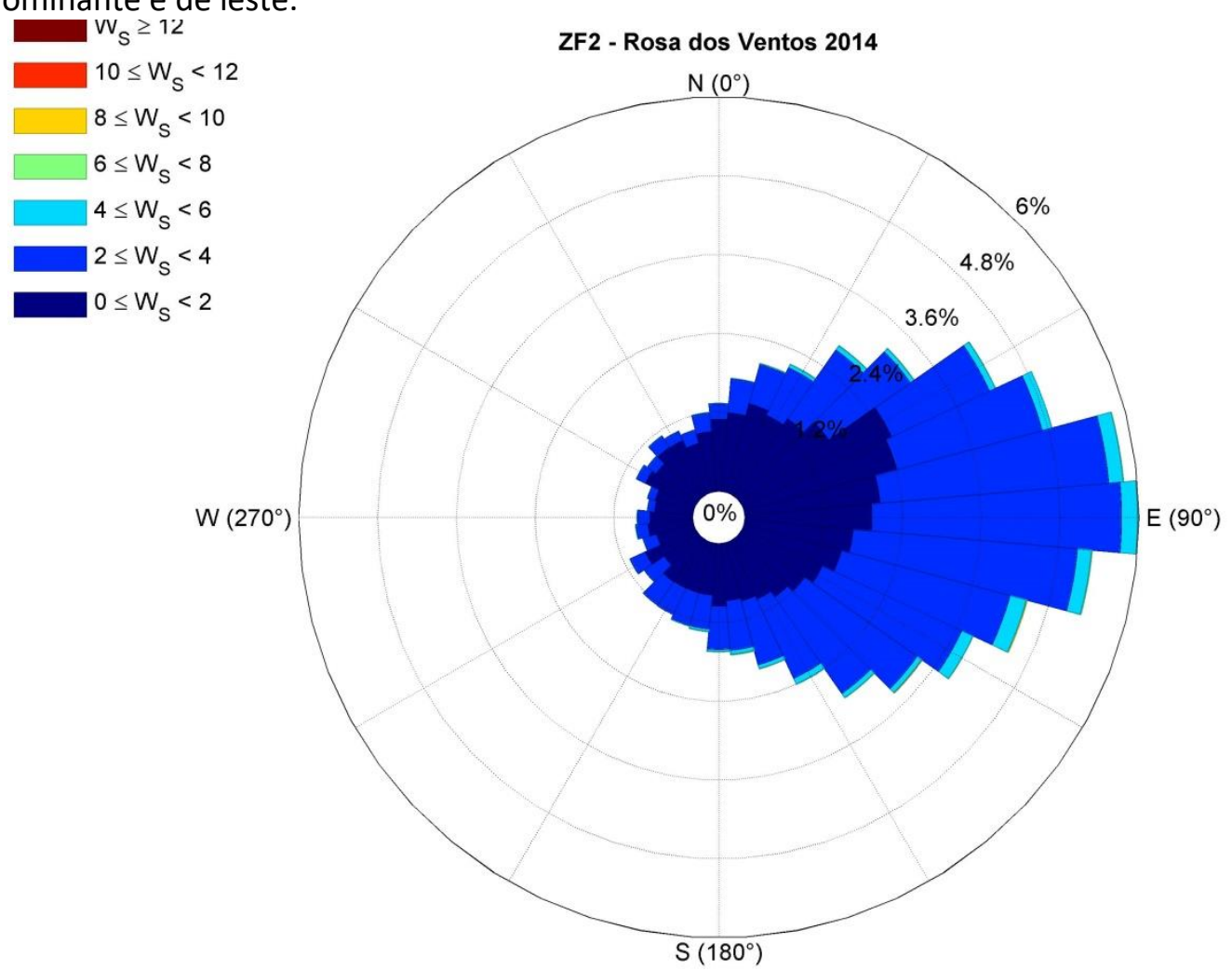

Fonte: INPA (2015).

A Figura 13 mostra a torre TT34, operacional desde janeiro de 2008 (INPA, 2015), e o contêiner utilizado na coleta de aerossol do projeto do GoAmazon. O inlet utilizado pelos equipamentos do contêiner está localizado a 38,75 metros de altura, 10m acima do dossel da vegetação, o que faz com que seu diâmetro de corte nominal de $10 \mu \mathrm{m}$, seja na verdade, de $7 \mu \mathrm{m}$ devido a perdas ao longo do inlet (MARTIN; ANDREAE; ALTHAUSEN; et al., 2010). 
Figura 13: torre TT34 e contêiner utilizados durante o experimento Go Amazon2014/15.

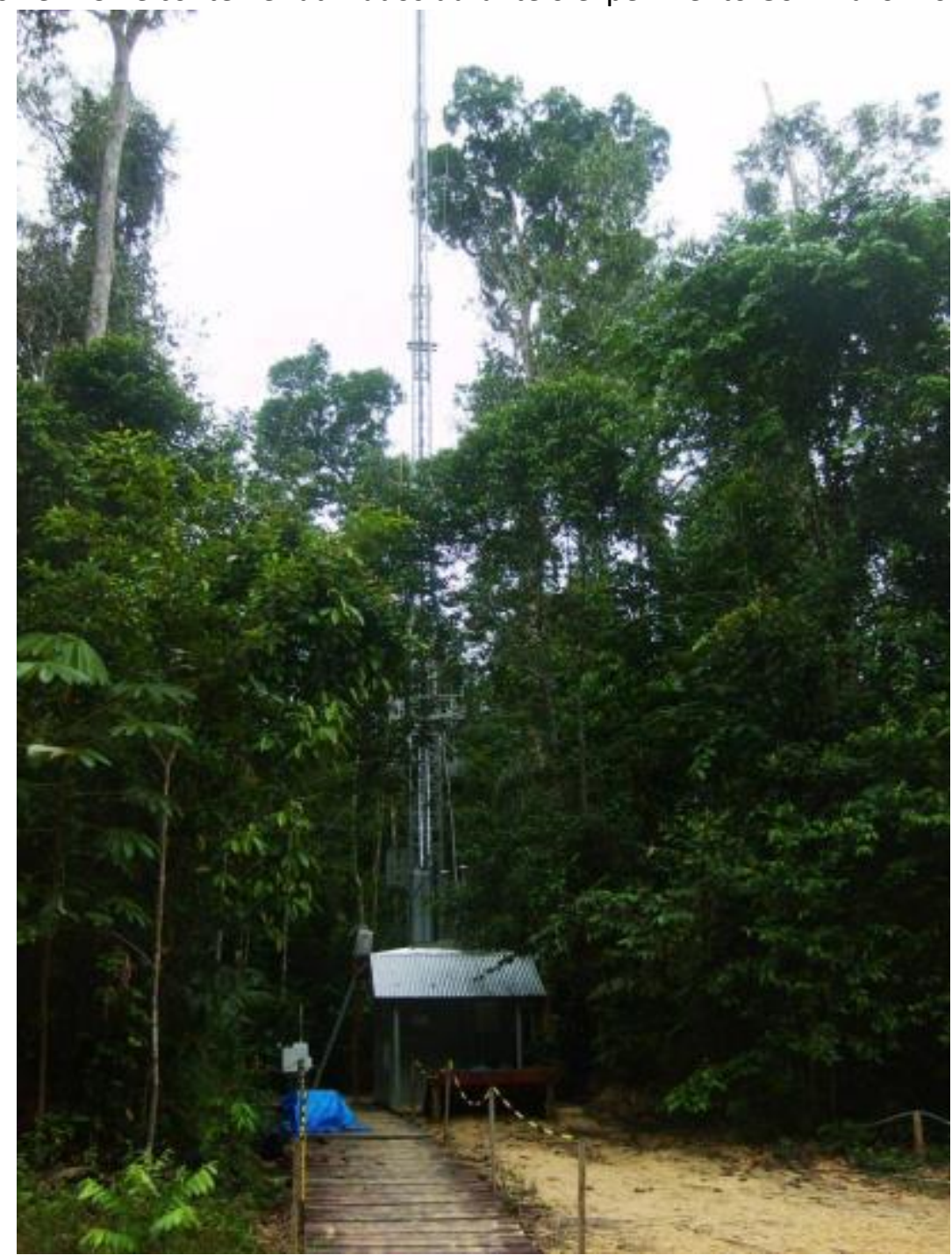

\subsubsection{Sítio Experimental TIWA (T2)}

O sítio experimental Hotel TIWA foi instalado em janeiro de 2014 com recursos do projeto temático FAPESP 2013/05014-0. Ele está a 8km do centro de Manaus e geralmente vento abaixo da cidade, na margem do Rio Negro. O objetivo deste sítio é medir as propriedades atmosféricas logo após a emissão, antes do envelhecimento da pluma urbana durante o transporte entre a cidade e Manacapuru. A Figura 14 é uma foto às margens do Rio Negro e mostra o contêiner utilizado para a coleta de aerossol localizada imediatamente vento abaixo de Manaus. 
Figura 14: torre e contêiner instalado vento abaixo de Manaus, nas margens do Rio Negro.

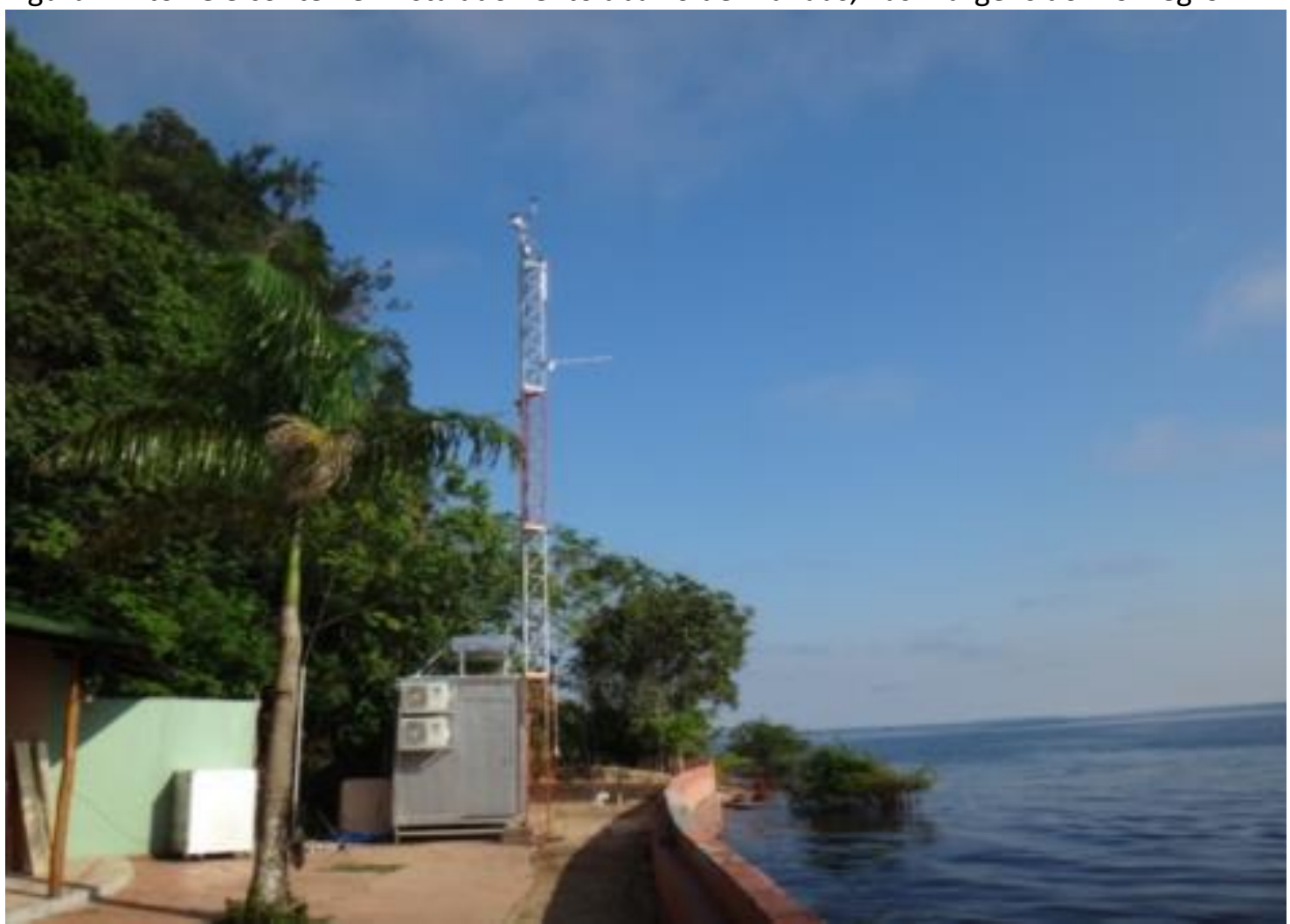

\subsubsection{A estação amostradora de Manacapuru (T3)}

Na estação amostradora de Manacapuru foram instalados 19 containers com amplo conjunto de equipamentos para medição de propriedades de aerossol, nuvens e gases traços (Figura 15). Ela foi implementada com a colaboração de grupos americanos e brasileiros a fim de possibilitar o estudo de como os ciclos de vida do aerossol e das nuvens são influenciadas pela poluição urbana de Manaus já que este sítio está distante $60 \mathrm{~km}$ vento abaixo de Manaus, de modo que as massas de ar que passam pela cidade chegam neste sítio após duas a seis horas (ANDREAE, MEINRAT O et al., 2013; ARM, 2017). 
Figura 15: fotos do sítio Manacapuru durante o GoAmazon2014/15.
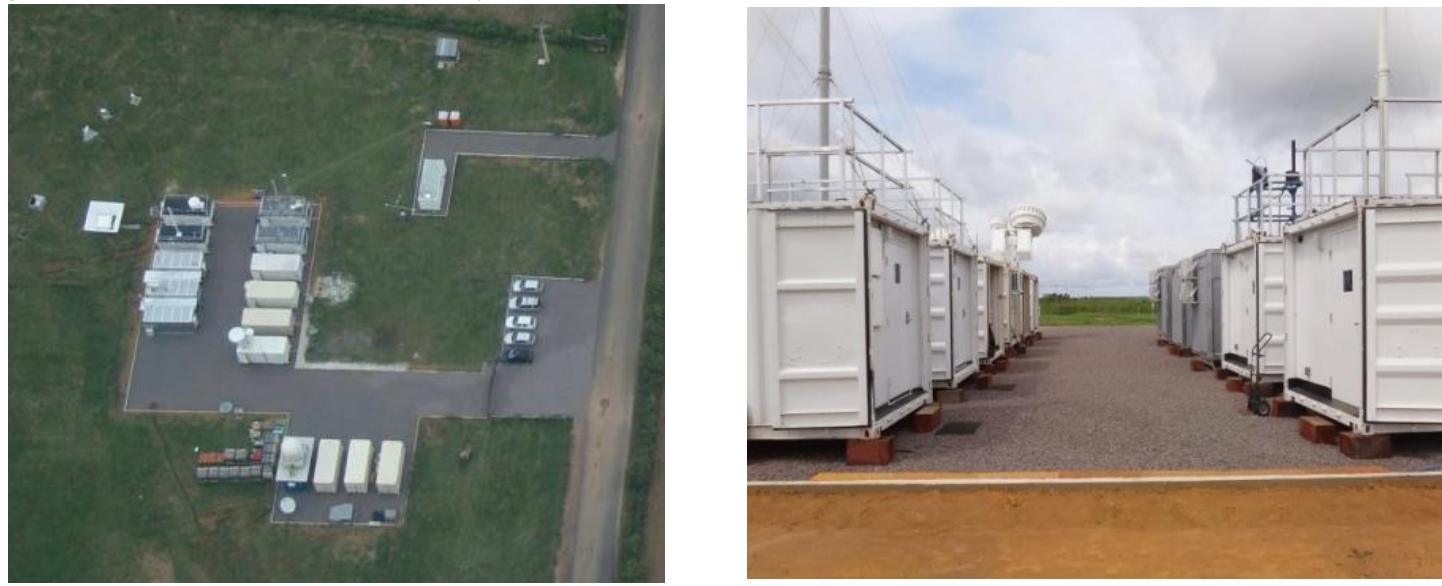

\subsection{A coleta do Material Particulado}

Em cada sítio deste trabalho utilizou-se amostradores de material particulado fino e grosso (AFG) para coletar o material particulado dos sítios deste experimento. A figura abaixo é uma foto do amostrador desmontado.

Figura 16: NILU filter holder system desmontado possibilitando ver seus estágios.

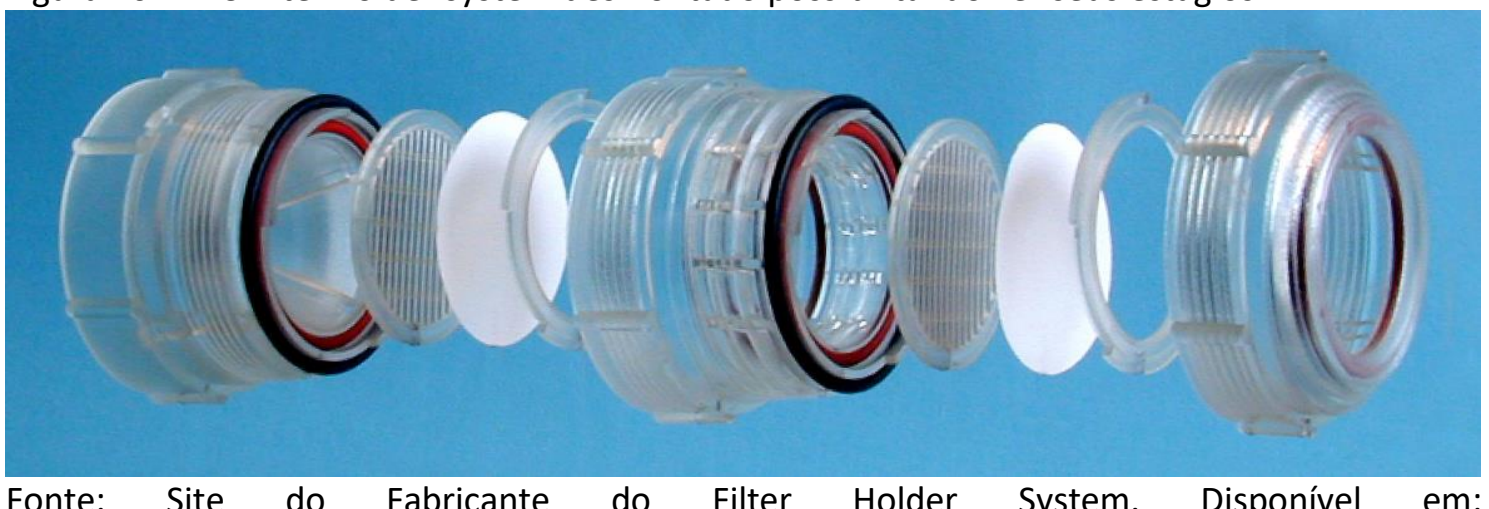

Fonte: Site do Fabricante do Filter Holder System. Disponível em: http://products.nilu.no/ProductsDivision/FilterHolders.aspx. Acessado em julho de 2017.

Este amostrador foi construído pela Norwergian Institute for Air Research (NILU) e comporta até dois filtros ao mesmo tempo, possibilitando a separação do material particulado em moda fina e grossa. Dois tipos de filtros foram utilizados neste equipamento: de policarbonato e de quartzo. Utilizou-se filtros de policarbonato para a coleta de MP a fim de realizar a gravimetria, refletância e espectrometria de raios-x e filtros de quartzo para análise termo-óptica. A coleta com filtros de policarbonato foi realizada através de dois filtros da marca Nuclepore que separou o a fração fina do aerossol (diâmetro aerodinâmico menor que $2,5 \mu \mathrm{m}$ ) da fração grossa (entre $2,5 \mu \mathrm{m}$ e $10 \mu \mathrm{m}$ ) com um inlet que possibilitasse a passagem apenas de partículas com diâmetro aerodinâmica acima de $10 \mu \mathrm{m}$. O fluxo de ar 
utilizado foi $16 \mathrm{l} / \mathrm{min}$. Uma completa caracterização do amostrador pode ser encontrada em HOPKE et al. (1997).

A Tabela 1 mostra o início, fim e tempo médio de exposição, e o número de pares de filtros de policarbonato coletados que foram utilizados neste trabalho para os três diferentes sítios de coleta.

Tabela 1: resumo geral dos filtros de policarbonato coletados durante o projeto GoAmazon2014/15. Cada amostragem corresponde ao par de filtros de coleta de MPF e MPG.

\begin{tabular}{ccccccc}
\hline \multicolumn{5}{c}{ Filtros de Policarbonato coletados durante o GoAmazon2014/15 } \\
\hline $\begin{array}{c}\text { Sítio } \\
\text { experimental }\end{array}$ & $\begin{array}{c}\text { Início da } \\
\text { amostragem }\end{array}$ & $\begin{array}{c}\text { Fim da } \\
\text { amostragem }\end{array}$ & $\begin{array}{c}\text { Tempo médio de } \\
\text { exposição (dias) }\end{array}$ & $\begin{array}{c}\text { Número de } \\
\text { amostras } \\
\text { coletadas }\end{array}$ \\
\hline ZF2 & setembro-14 & setembro-15 & 3,9 & \pm & 1,7 & 72 \\
TIWA & março-14 & fevereiro-15 & 2,5 & \pm & 1,3 & 74 \\
Manacapuru & março-14 & maio-15 & 2,8 & \pm & 1,0 & 87 \\
\hline
\end{tabular}

Das 72 amostras coletadas no sítio experimental da ZF2, 36 filtros foram coletados durante a estação chuvosa, dos 74 filtros coletados no TIWA, 28 foram coletados durante a estação chuvosa e dos 87 filtros de Manacapuru, 53 foram coletados na estação chuvosa.

Além dos filtros de policarbonato, coletou-se filtros de quartzo utilizados nas análises de carbono orgânico e elementar. A Tabela 2 mostra o início, fim, tempo médio de exposição, e o número de filtros de quartzo coletados que foram utilizados neste trabalho.

Tabela 2: resumo geral dos filtros de quartzo coletado durante o projeto GoAmazon2014/15.

\begin{tabular}{ccccccc}
\hline \multicolumn{6}{c}{ Filtros de Quartzo para o GoAmazon2014/15 } \\
\hline $\begin{array}{c}\text { Sítio } \\
\text { experimental }\end{array}$ & $\begin{array}{c}\text { Início da } \\
\text { amostragem }\end{array}$ & $\begin{array}{c}\text { Fim da } \\
\text { amostragem }\end{array}$ & $\begin{array}{c}\text { Tempo médio de } \\
\text { exposição (dias) }\end{array}$ & $\begin{array}{c}\text { Número de } \\
\text { amostras } \\
\text { coletadas }\end{array}$ \\
\hline ZF2 & setembro-14 & junho-15 & 3,8 & \pm & 1,5 & 44 \\
TIWA & fevereiro-14 & fevereiro-15 & 2,2 & \pm & 0,9 & 59 \\
Manacapuru & fevereiro-14 & fevereiro-15 & 2,4 & \pm & 1,3 & 62 \\
\hline
\end{tabular}

Uma parte da coleta de filtros de quartzo foi realizada através do método "Quartz behind Quartz" (QBQ) a fim de estimar a quantidade de artefato positivo devido à adsorção de material orgânico gasoso no filtro (SUBRAMANIAN et al., 2004, 2010), entretanto, conforme será discutido na seção 4.5, grande parte dos resultados dos filtros de backup 
ficaram abaixo do limite de detecção do equipamento. Isso indica que não temos artefato positivo significativo na Amazônia Central.

\subsection{Análises aplicadas aos filtros amostradores de aerossol}

\subsubsection{Gravimetria}

A análise gravimétrica é utilizada para medir quanto de material particulado foi coletado pelo filtro. Para isso, a massa do filtro foi medida antes e após sua exposição em campo, de modo que a diferença em massa é devida ao material depositado. Conhecendo-se o volume de ar que passou pelo sistema, obtemos a concentração atmosférica de material particulado. Para essa análise, foi utilizada a balança ultramicroanalítica eletrônica, modelo XP6U, da marca Mettler com precisão nominal de 0,1ug, como a da Figura 17.

Figura 17: balança ultramicroanalítica eletrônica XP6U Mettler.

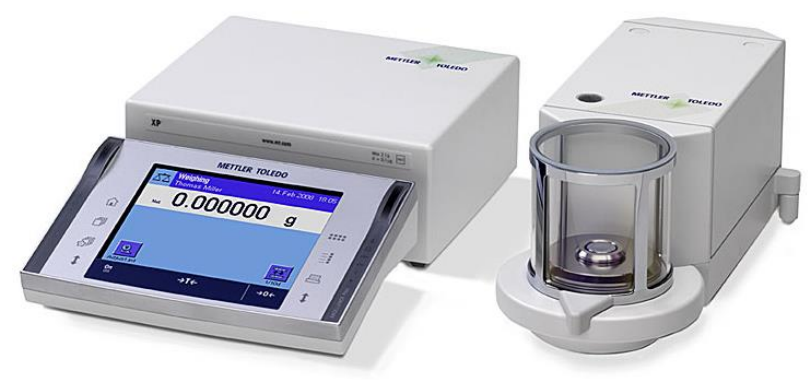

Para a realização da pesagem, a temperatura e umidade relativa do laboratório eram controladas em $20^{\circ} \mathrm{C}$ e $50 \%$, respectivamente. Um importante cuidado na etapa prépesagem, é estabilizar os filtros em temperatura, umidade relativa do ar e bombardeá-los com partículas alfa de ${ }^{210} \mathrm{Po}$, a fim de evitar que cargas eletrostáticas alterem os resultados de pesagem. Esse procedimento deve ser feito tanto antes, quanto depois da coleta do material particulado. Outro ponto a ser destacado é a utilização do chamado 'filtro branco'. Este filtro passa por todo o processo descrito acima, porém, não é amostrado em campo, servindo de controle. A utilização deste filtro é importante, pois muitas vezes o aumento de massa do filtro não é exclusivamente devido ao material particulado depositado e sim, devido ao acúmulo de água na superfície do filtro ou desenvolvimento de micro-organismos em seu material, dentre outros contaminantes eventuais.

\subsubsection{Análise de elementos traços por espectrometria de fluorescência de raios $\mathbf{X}$}

Ao estimularmos um átomo com raios $X$, uma série de processos ocorrem nas camadas eletrônicas. Dentre os principais, espalhamento Compton e Rayleigh e 
fluorescência (Figura 18). Para identificar elementos que compõem um material, o fenômeno da fluorescência é muito utilizado, pois as propriedades que emanam deste processo estão intimamente relacionadas com a composição do material que a emitiu.

Figura 18: interação do átomo com a radiação.

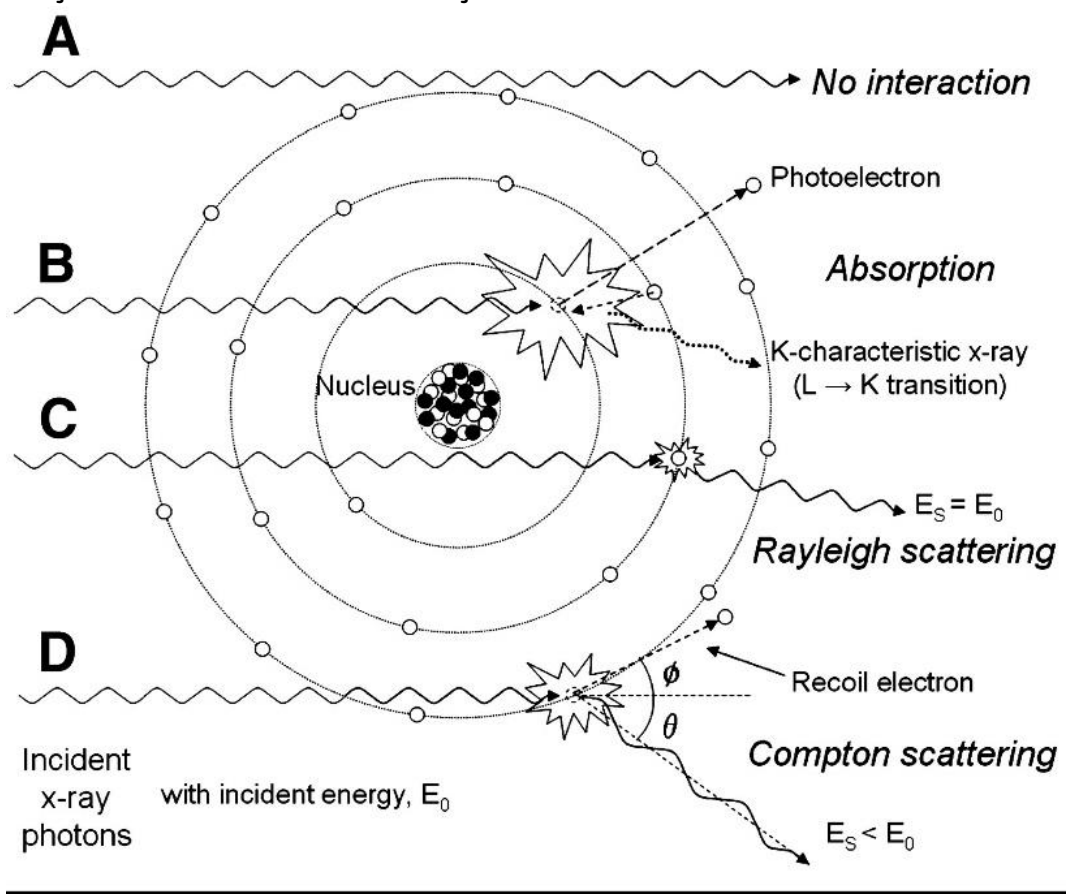

Fonte: SEIBERT and BOONE, (2005)

Na figura acima, a fluorescência corresponde ao fenômeno $B$, onde temos um fóton que excita o átomo ao expulsar um elétron de uma camada interna. Para que o átomo se estabilize energeticamente, um elétron de uma camada mais externa e energética ocupa essa vacância. Essa energia a mais que o elétron da camada mais externa possui será emitida como um raio-x característico. No caso do exemplo, ocorre uma transição da camada L para K. Como esse raio-x depende da estrutura atômica, diferentes elementos irão emitir radiação com diferentes energias.

Com este princípio, ao irradiarmos uma amostra multielementar , ocorrerá o que está ilustrado na Figura 19. Cada elemento irá emitir fótons característicos que serão detectados por um detector de estado sólido. 
Figura 19: representação esquemática da interação entre raios-x e amostra. Cada cor de raio-x retroespalhado visa ilustrar a energia característica de cada elemento.

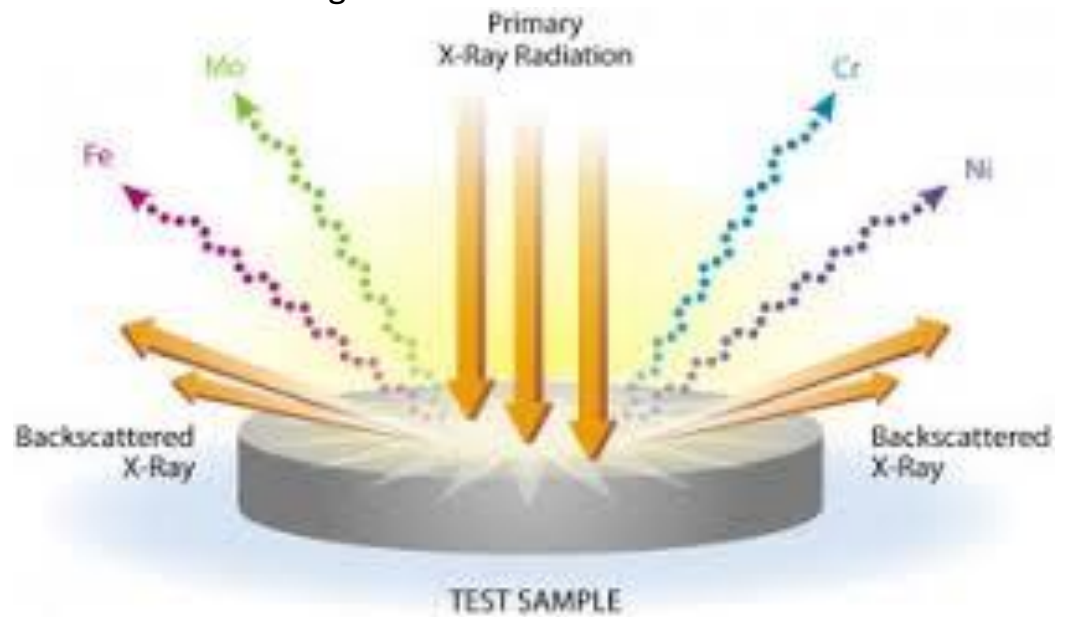

Para aplicar a técnica de fluorescência de raios-x, foi utilizado o espectrômetro Epsilon 5 da empresa PANalytical (Figura 20) que utiliza a técnica de fluorescência de raios $x$ por dispersão em energia, ou, em inglês, Energy Dispersive X-Ray Fluorescence (EDXRF).

Figura 20: aparelho Epsilon 5 fabricado pela companhia PANalytical.

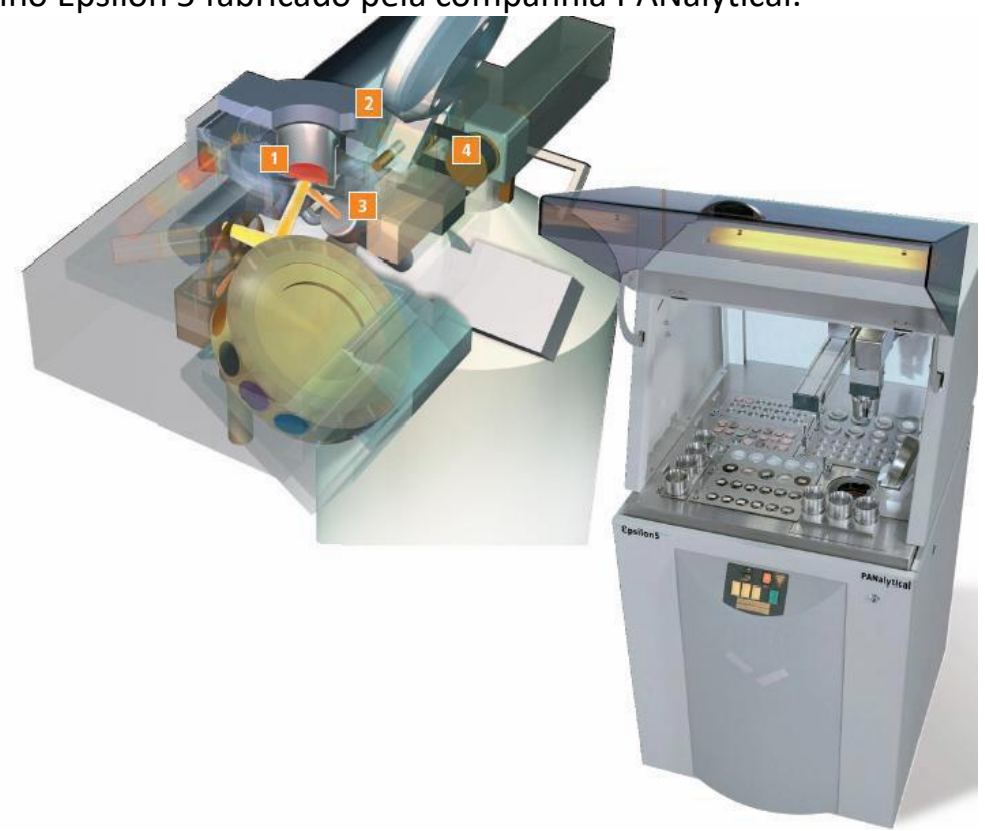

O Epsilon 5 é equipado com um tubo de raio-x de 600W com um ânodo de gadolínio (Gd) que opera entre $25 \mathrm{kV}$ e $100 \mathrm{kV}$ e um detector de estado sólido de alta resolução de germânio (Ge) resfriado por nitrogênio (VAN GRIEKEN; MARKOWICZ, 2002). Este equipamento conta com uma geometria tridimensional, o que o diferencia quanto aos outros no mercado que possuem geometria bidimensional. Maiores informações sobre este equipamento e seu processo de calibração podem ser encontradas em ARANA (2014). 


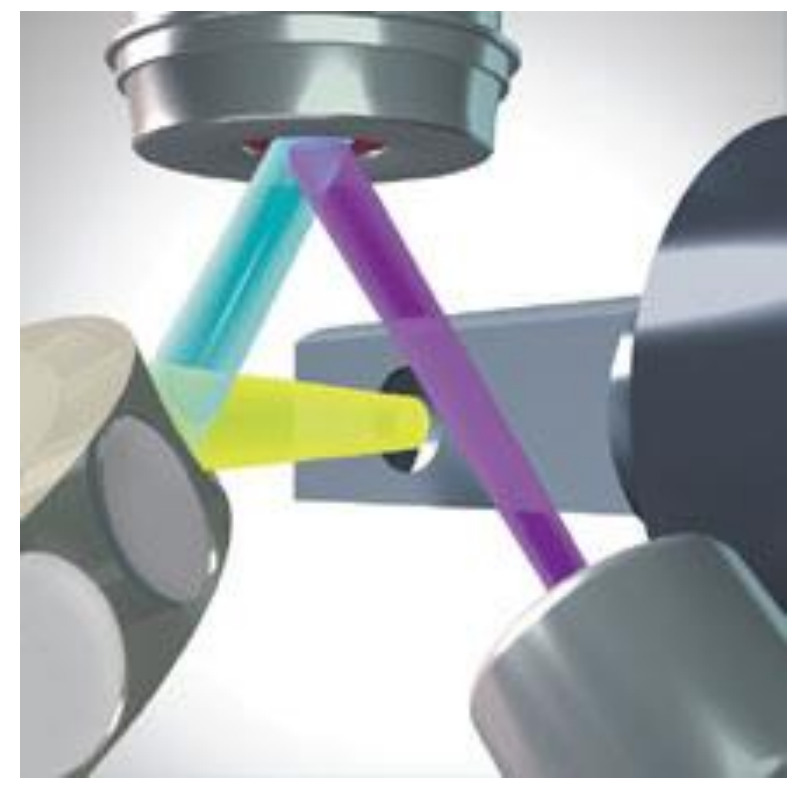

Figura 21: esquema da geometria tridimensional do Epsilon5 da PANalytical. 0 feixe que sai do tubo de raios $x$ em amarelo, chega no alvo secundário, que o reflete em um ângulo de 90으, gerando o feixe azul, que por sua vez irradia a amostra que gera o feixe roxo que chega ao detector (Fonte: www.panalytical.com).

\subsubsection{Análise do Black Carbon Equivalente através da Refletância}

Para medir o Black Carbon Equivalente nos filtros de policarbonato, utilizou-se um refletômetro de luz branca difusa da empresa Diffusion Systems com pico de radiância próximo a 550nm. Através deste equipamento, mede-se o quanto da intensidade total da luz incidente no filtro é atenuada de forma a obter-se o valor de refletância relativa. Com este valor, a área do filtro e o volume de ar que passou pelo filtro, encontrou-se a concentração de BCe coletada através da curva de calibração obtida empiricamente por LOUREIRO et al. (1994) e exposta na equação abaixo.

$$
\mathrm{BC}_{e}=\frac{\left(88,317-(77,5471 * \log (R))+16,6943 *(\log (R))^{2}\right) * A}{\text { Volume }}
$$

\subsubsection{Análise de carbono orgânico e elementar por análise Termo-Óptica} diferencial

Utilizou-se um analisador termo-óptico diferencial da Sunset Laboratory para mensurar a quantidade de OC e EC presentes nos filtros de quartzo. O esquema do instrumento pode ser visto na Figura 22. 
Figura 22: esquema representando o analisador termo-óptico diferencial da Sunset Instruments.

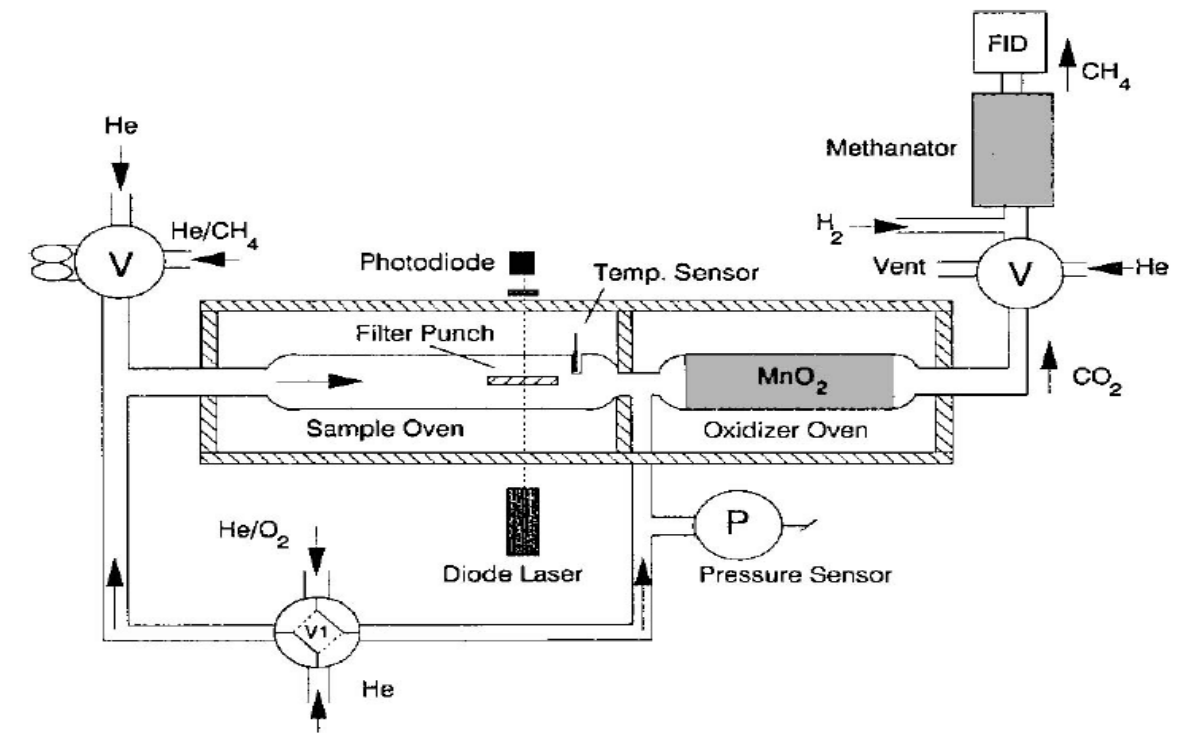

Fonte: (BIRCH; CARY, 1996)

Esse tipo de analisador aplica na amostra um processo de duas etapas de aquecimento: primeiramente em uma atmosfera neutra $(\mathrm{He})$ e, posteriormente, em uma atmosfera contendo $2 \%$ de $\mathrm{O} 2(\mathrm{He}-\mathrm{Ox})$. Durante todo o processo de aquecimento e combustão, a absorção de radiação pela amostra é monitorada através de um feixe de laser He-Ne. Durante esse processo, o carbono presente no filtro é vaporizado e reduzido a $\mathrm{CH}_{4}$ em um metanador. Esse $\mathrm{CH}_{4}$ é finalmente medido no detector FID. O resultado gráfico dessa análise chama-se termograma e um exemplo pode ser observado na Figura 23. A análise inicia com a elevação da temperatura em etapas durante a atmosfera inerte de He até chegar em $650^{\circ} \mathrm{C}-820^{\circ} \mathrm{C}$, dependendo do protocolo. Idealmente, nestas condições, ocorre a dessorção de todo o OC, e nos estágios finais, ocorre a decomposição dos carbonatos. Ao fim deste processo verifica-se que a transmitância do filtro diminuiu em relação à inicial devido à ocorrência de pirólise de compostos orgânicos termicamente instáveis, ou seja, parte do OC pirolisou durante a primeira etapa de amostra passando a ter característica de EC, aumentando a absorção de luz. A segunda etapa desta análise começa com a temperatura por volta dos $500^{\circ} \mathrm{C}$ e, com a presença de oxigênio na atmosfera do equipamento, a oxidação do carbono elementar é favorecida, de forma que a transmitância do filtro aumenta. O carbono volatilizado até o ponto em que o laser volta a ter a transmitância inicial (Split point) é considerado carbono pirolítico. Após o "split point", 
considera-se que o carbono liberado é o EC. O limite de detecção desta técnica é de $0,2 \mu \mathrm{g} / \mathrm{m}^{2}$ e sua precisão é de $5 \%$ (VECCHI et al., 2009).

Figura 23: termograma obtido através do método termo-óptico. O sinal medido durante a primeira etapa com atmosfera inerte é interpretado como carbono orgânico (OC). Ao entrar oxigênio na atmosfera considera-se que é carbono elementar (EC) ao qual pode estar misturado a carbono orgânico pirolizado (PC).

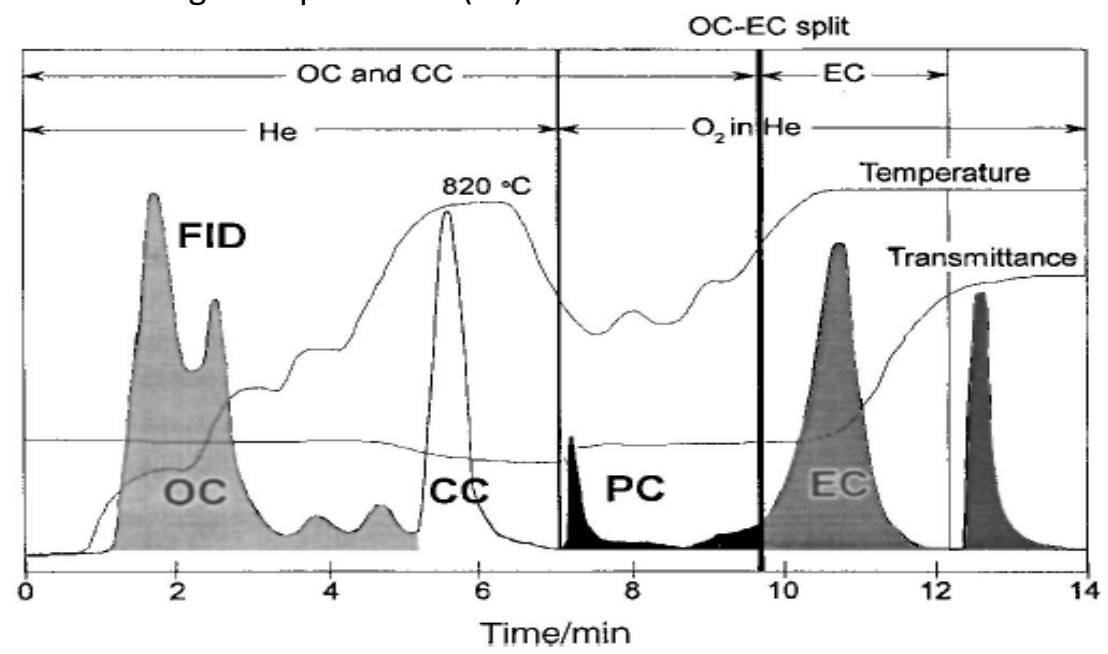

Fonte: (BIRCH; CARY, 1996)

A escolha do protocolo utilizado neste trabalho baseou-se no trabalho de ARANA (2014), onde os resultados dos três principais métodos utilizados atualmente são comparados a partir de amostras de aerossol coletados na Amazônia: NIOSH 870 (U.S. Environmental Protection Agency) (NIOSH, 1996), IMPROVE A (Interagency Monitoring of Protected Visual Environments) (CHOW et al., 1993) e EUSAAR_2 (CAVALLI et al., 2010).

ARANA (2014) aponta a pequena diferença dentre os resultados dos métodos IMPROVE A e EUSAAR_2, optando pelo último por conta do menor tempo de análise necessário. Os estágios utilizados pelo protocolo EUSAAR_2 estão expostos na Tabela 3. 
Tabela 3: protocolo de temperaturas EUSAAR_2 com a atmosfera e o tempo de cada estágio.

\begin{tabular}{|c|c|}
\hline & EUSAAR_2 \\
\hline & $\begin{array}{c}\text { Temperatura, } \\
\text { tempo }\end{array}$ \\
\hline & ${ }^{\circ} \mathbf{C}, \mathbf{s}$ \\
\hline & 1,10 \\
\hline & 200,120 \\
\hline Atmosfera & 300,150 \\
\hline inerte com & 450,180 \\
\hline & 650,180 \\
\hline & 1,30 \\
\hline Atmosfera & 500,120 \\
\hline oxidativa & 550,120 \\
\hline com & 700,70 \\
\hline $\mathrm{He}+\mathrm{O}_{2}$ & 850,80 \\
\hline $\begin{array}{c}\text { Calibração } \\
\text { Ox }\end{array}$ & 1,110 \\
\hline
\end{tabular}

Offline $\quad 0,1$

Obtém-se, então a quantidade de carbono relativa às espécies orgânica e carbono elementar através das equações:

$$
O C=O C 1+O C 2+O C 3+O C 4+P C
$$

$E$

$$
E C=E C 1+E C 2+E C 3+E C 4-P C
$$

Em que cada um dos índices relativos ao OC e EC referem-se à temperatura na qual ocorre a dessorção daquela quantia de carbono do filtro, assim, é um indicativo da volatilidade dos compostos.

\subsection{Análise de Fatores - Modelos Receptores}

A série temporal das concentrações obtidas pelas técnicas anteriormente descritas, ou seja, de concentração de elementos químicos, black carbon equivalente e material particulado são resultantes de processos de emissões de diferentes tipos de aerossol por diferentes fontes e o processamento atmosférico, e portanto, pode-se escrever a Equação 4 descrevendo o balanço de massa entre o receptor e a fonte:

$$
x_{i j}=\sum_{k=1}^{p} g_{i k} f_{k j}
$$


Desta forma, $x_{i j}$ refere-se à concentração da espécie química $j$ obtida no i-ésimo filtro em $\mathrm{ng} / \mathrm{m}^{3}, g_{i k}$ refere-se à intensidade da contribuição da fonte $k$ no i-ésimo filtro, $f_{k j}$ que representa o perfil da k-ésima fonte em relação ao j-ésimo elemento - o produto $g_{i k} f_{k j}$ resulta na concentração do elemento j para o i-ésimo filtro ajustado pelo modelo. Com as medidas de concentrações dos elementos e o perfil dos processos das fontes que atuaram naquele aerossol, determina-se a intensidade de cada fonte em determinada amostra através do método dos mínimos quadrados e do algoritmo de Chemical Mass Balance $(C M B)$. Entretanto, no caso dos aerossóis atmosféricos, os perfis de fontes não são conhecidos e, portanto, da Equação 4, determina-se apenas os valores $x_{i j}$. A fim de mensurar a contribuição e o perfil das fontes utiliza-se do método de análise de fatores (CESARI et al., 2016; HOPKE, 1991). Neste trabalho utilizou-se os métodos de Análise de componentes principais (ACP) junto com a Análise de componentes principais absoluta (ACPA) através do software SPSS IBM e Positive Matrix Factorization (PMF) através do algoritmo ME-2 pelo software PMF5.0 da US EPA (United States Environmental Protection Agency) que estão descritos em maiores detalhes nas seções seguintes.

\subsubsection{Análise de componentes principais e análise de componentes principais absoluta}

A análise de componentes principais (ACP) é uma técnica estatística que tem por base a premissa de que as variáveis medidas, no nosso caso concentrações de elementos traços, intercorrelacionam-se (THURSTON; SPENGLER, 1985). Dessa forma, há uma quantidade de informação na base de dados que é possível ser condensada em um menor número de variáveis ou fatores de forma a facilitar a interpretação daquela base de dados.

A aplicação matemática deste princípio se dá a partir da Equação 4. Com o propósito de tornar comparáveis as concentrações dos diferentes elementos, que diferem por ordens de magnitude, elas são normalizadas para média zero e desvio-padrão unitário:

$$
Z_{i j}=\frac{x_{i j}-<x_{j}>}{S_{j}}
$$

De forma que $\left\langle x_{j}>\right.$ é o valor médio do elemento $j$ e $S_{j}$ é o desvio padrão do elemento $j$. Deste ponto em diante, o problema consiste em encontrar os autovetores e autovalores da matriz de covariância $\mathrm{D}$ dos dados contidos na matriz Z: 
Junto com

$$
D_{j x j}=<(Z)(Z)^{T}>
$$

$$
\operatorname{det}(D-\lambda I)=0
$$

na qual $\lambda$ representa o autovalor e $I$ representa a matriz identidade. Ao realizar o cálculo da Equação 7, $j$ autovalores que representam a variância de um fator principal são calculados, de forma que:

$$
\sum_{a=1}^{j} \lambda_{a}=\lambda_{1}+\cdots+\lambda_{j}=j
$$

Levando em consideração todos os autovalores encontrados, calcula-se o a-ésimo autovetor $l$ :

$$
D l_{a}=\lambda_{a} I l_{a}
$$

O autovetor $l$ corresponde ao factor loading, contendo associações entre a variável antiga $D$ e os fatores principais $Y$ :

$$
\begin{gathered}
\mathrm{Y}_{1}=l_{1}^{\mathrm{T}} \mathrm{D}=l_{11} \mathrm{~d}_{1}+l_{21} \mathrm{~d}_{2}+\ldots+l_{\mathrm{p} 1} \mathrm{~d}_{\mathrm{p}} \\
\mathrm{Y}_{2}=l_{2}^{\mathrm{T}} \mathrm{D}=l_{12} \mathrm{~d}_{1}+l_{22} \mathrm{~d}_{2}+\ldots+l_{\mathrm{p} 2} \mathrm{~d}_{\mathrm{p}} \\
\cdot \\
\mathrm{Y}_{\mathrm{p}}=l_{\mathrm{p}} \mathrm{T}^{\mathrm{T}} \mathrm{D}=l_{1 \mathrm{p}} \mathrm{d}_{1}+l_{2 \mathrm{p}} \mathrm{d}_{2}+\ldots+l_{\mathrm{pp}} \mathrm{d}_{\mathrm{p}}
\end{gathered}
$$

Da forma como apresentada na Equação 10, onde temos $p$ fatores principais, é uma solução exata e explica a totalidade da variância do conjunto de dados. Com o intuito de aproveitar-se do resultado obtido pela $A C P$, é de bom grado que o número de fatores principais retidos seja bem menor que o número inicial de variáveis, ou seja, convém truncar a série no t-ésimo fator, com $t<p$ de modo que a variância explicada seja a maior possível. Uma ferramenta útil para saber em quantos fatores as variáveis são explicadas sem perda de informação é verificar quão próximo de $j$ a soma dos autovalores dos fatores levados em conta na solução chega. O algoritmo ordena os fatores pelo valor do autovalor, e assim, o primeiro fator explica a maior variabilidade. Como o autovalor $\lambda_{a}$ nos indica a variância que o fator $a$ explica da variância da variável original, $\lambda_{a}<1$ explicam menos que a variância 
correspondente a uma variável original. Entretanto, deve-se realizar esta operação com cautela, a fim de não excluir uma fonte de pouca intensidade.

Até este momento realizou-se uma redução dimensional da base de dados originais, que deu origem a uma base ortogonal. A fim de maximizar a projeção da base de dados original na nova base são realizadas rotações a fim de facilitar a interpretação dos dados. A rotação aplicada neste trabalho foi a Varimax (ANDRADE, 1993; GERAB, 1996).

Com estas operações realizadas temos, então, os factor loadings $I$, que associam a variável antiga $d$ às componentes principais $Y$, tratando-se no nosso caso do perfil de emissão da fonte. Tem-se também os factor scores, que indicam a influência de cada componente principal para cada amostra, ou seja, a contribuição da fonte para cada amostra. A partir desses resultados, a técnica para calcular o valor de cada elemento para determinado fator é a aplicação da ACPA - Análise de Componentes Principais Absoluto. Neste trabalho utilizou-se do método de conversão do Caso Zero (GERAB, 1996). Este método consiste em criar uma amostra em que todos os elementos sejam nulos (caso zero), realizar a ACP e, através do peso (loading) obtido para o caso zero, realizam-se manipulações algébricas que insere os absolute principal factor scores (APFS). Por fim, faz-se necessário uma regressão multi-linear entre os valores das amostras e os APFS (este como variável independente). Assim, é possível obter a concentração média de cada elemento através da conversão do coeficiente encontrado na regressão multi-linear e o APFS médio daquela base de dados (GERAB, 1996; JUNIOR, 2015).

\subsubsection{PMF - Positive Matrix Factorization}

O Positive Matrix Factorization (PMF) é uma ferramenta de análise de fator multivariada que decompõe uma matriz de entrada, X em duas matrizes G e F (NORRIS et al., 2009), conforme mostra a Equação 11:

$$
x_{i j}=\sum_{k=1}^{p} g_{i k} f_{k j}+e_{i j}
$$

Aplicado à nossa base de dados da série temporal de diversos elementos obtidos dos filtros:

- $\quad i$ : refere-se ao filtro;

- $\quad j$ : refere-se à espécie química; 
- $\quad k$ : refere-se à k-ésima fonte das $p$ contabilizadas no estudo.

Desta forma, $x_{i j}$ refere-se à concentração do elemento $j$ obtido no i-ésimo filtro em $\mathrm{ng} / \mathrm{m}^{3}, g_{i k}$ refere-se à contribuição da fonte $k$ para o i-ésimo filtro, $f_{k j}$ que representa o perfil da k-ésima fonte em relação ao j-ésimo elemento, desta forma, o produto $g_{i k} f_{k j}$ resulta na concentração do elemento j para o i-ésimo filtro ajustado pelo PMF, e $e_{i j}$ é o resíduo entre o mensurado $x_{i j}$ e o calculado pelo produto entre a contribuição $g_{i k}$ com o perfil da fonte $f_{k j}$ levando em consideração as $p$ fontes.

Este termo de resíduo é ponderado pela incerteza $u_{i j}$ associada ao elemento $\mathrm{j}$ da amostra i através da função Q:

$$
Q=\sum_{i=1}^{n} \sum_{j=1}^{m}\left[\frac{x_{i j}-\sum_{k=1}^{p} g_{i k} f_{k j}}{u_{i j}}\right]^{2}=\sum_{i=1}^{n} \sum_{j=1}^{m}\left[\frac{e_{i j}}{u_{i j}}\right]^{2}
$$

Em cada ajuste com o PMF, dois valores de $Q$ são calculados:

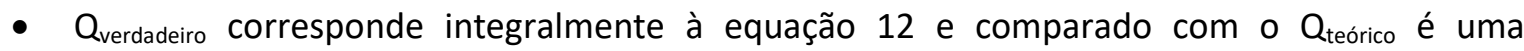
grandeza que representa a qualidade do ajuste;

- $Q_{\text {robusto: }}$ corresponde à Equação 12 com a condição de que se a razão entre resíduo e incerteza, $\frac{e_{i j}}{u_{i j}}$, for maior que quatro este ponto não entrará na somatória.

Desta forma, a razão entre $Q_{r}$ e $Q_{v}$ indicará a influência de pontos outliers no ajuste, e, por conseguinte, deve-se identificar tais pontos a fim de verificar o motivo.

A técnica do PMF, conforme verifica-se na Equação 12, necessita de uma matriz de incertezas, a qual irá ponderar o ajuste para cada elemento de cada amostra. Assim, a matriz de incertezas neste trabalho foi montada baseada na proposta por POLISSAR et al. (1998):

Tabela 4: cálculo dos valores e incertezas para a construção do banco de dados para o PMF.

\begin{tabular}{ccc}
\hline & Valor Utilizado & Incerteza \\
\hline Valores determinados & $x_{i j}^{k}=v_{i j}^{k}$ & $\sigma_{i j}^{k}=u_{i j}^{k}+d_{i j}^{k} / 3$ \\
\hline Valores abaixo do limite de detecção & $x_{i j}^{k}=d_{i j}^{k} / 2$ & $\sigma_{i j}^{k}=\bar{d}_{i j}^{k} / 2+d_{i j}^{k} / 3$ \\
\hline Missing values & $x_{i j}^{k}=\tilde{v}_{i j}^{k}$ & $\sigma_{i j}^{k}=4 \tilde{v}_{i j}^{k}$ \\
\hline Onde $v_{i j}^{k}$ é a concentração medida, $u_{i j}^{k}$ é a incerteza associada à medida, $d_{i j}^{k}$ é o
\end{tabular}

limite de detecção da i-ésima amostra e j-ésimo elemento em cada sítio $k, \tilde{v}_{i j}^{k}$ é a média geométrica das concentrações medidas. 
Após obter a solução da rodada base, esta evidentemente não é única. Pode-se considerar infinitas soluções através de rotações ortogonais ou não. Assim, para um par de matrizes $\mathrm{G}$ e $\mathrm{F}$ pode ser transformado em matrizes $\mathrm{G}^{*}$ e $\mathrm{F}^{*}$ como o mesmo valor de $\mathrm{Q}$ por meio de rotação (NORRIS et al., 2009). Assim a rotação fica como:

$$
G^{*}=G T \quad F^{*}=T^{-1} F
$$

Esta transformação força linhas e colunas das matrizes $F$ e $G$ a se somarem ou se subtraírem, de acordo com a intensidade do FPEAK (REFF; EBERLY; BHAVE, 2007). Ao realizar essa rotação é gerado um novo valor de $Q$ e, de acordo com NORRIS et al. (2009) é aceitável valores deste até $5 \%$ daquele encontrado na rodada sem FPEAK, a rodada base.

\subsubsection{Multilinear Engine}

Neste trabalho utilizou-se do PMF 5.0 da US EPA. Para resolver o problema proposto pelo PMF este software utiliza-se de um algoritmo externo chamado Multilinear Engine 2 (ME-2), capaz de resolver problemas multilineares. O PMF5.0 recebe os dados do usuário, concentrações e incertezas das amostras, envia para o processamento através do ME-2. Este busca a convergência até que o valor de $Q$ seja mínimo através do método do gradiente mínimo (BROWN et al., 2015; NORRIS et al., 2009).

\subsubsection{Diferenças entre os métodos ACP e PMF}

Pode-se citar as seguintes diferenças entre os métodos:

- Possibilidade de ponderação de um dado específico, por exemplo a concentração de um elemento em determinada amostra, no PMF;

- O algoritmo do PMF trabalha diretamente com as concentrações dos elementos, não sendo necessária regressão multilinear para obtê-las;

- O PMF implementa uma condição física importante de restringir as soluções a valores maiores ou iguais a zero, enquanto que a ACPA pode resultar em valores negativos de concentração de determinado elemento em determinada componente;

- Necessidade de definir o número de fatores a serem extraídos no PMF, enquanto que através da ACP pode-se ter como referência o truncamento no fator com autovalor menor que a unidade. 


\subsubsection{Tratamento das bases de dados para aplicação dos modelos receptores}

As concentrações atmosféricas de material particulado na Amazônia estão dentre os menores encontrados em áreas continentais de nosso planeta, com exceção da Antártica. (ANDREAE, 2007). Na análise de fluorescência alguns elementos químicos com baixa concentração não foram possíveis de serem determinados acima do limite de detecção, se tornando um dos chamados valores faltantes. Assim foi necessária uma análise estatística cuidadosa de elemento por elemento em cada sítio de modo a possibilitar sua inserção nos modelos receptores através de regressão multilinear. A estimativa dos valores faltantes foi feita com regressão linear múltipla, e para elementos que não possuíam mais que $10 \%$ de valores faltantes. Realizou-se a regressão multilinear da concentração de um elemento com os demais elementos a fim de verificar a existência de outliers. Identificados, estes poucos valores eram substituídos pelo valor predito pela regressão baseada em todos os demais elementos. A Figura 24 mostra a regressão realizada entre o elemento S e elementos que se correlacionam com ele: MPF e BCe.

Figura 24: regressão multilinear entre a concentração de $S$ versus MPF e BCe para o sítio da ZF2. O resíduo do ponto 7 (assinalado) é maior do que 3 . O R2 do ajuste foi igual a 0,76 .

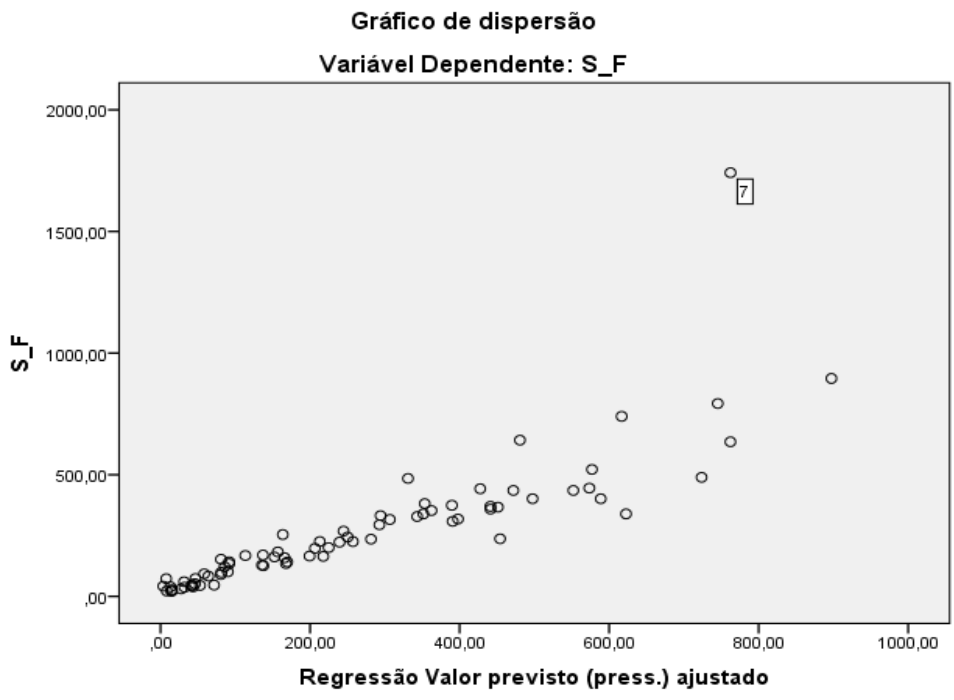

Durante as interações, verificou-se a presença de alguns outros pontos que possuíam resíduo da regressão linear múltipla maior que 3, sendo necessária a correção de um total de quatro valores de concentração do elemento $S$ (neste caso, uma alteração de $6 \%$ da base de dados relativa as concentrações deste elemento) da fração fina da ZF2. A regressão final é apresentada na Figura 25. 
Figura 25: regressão multilinear final entre a concentração de $S$ versus MPF e BCe para o sítio da ZF2. O R2 do ajuste foi igual a 0,97.

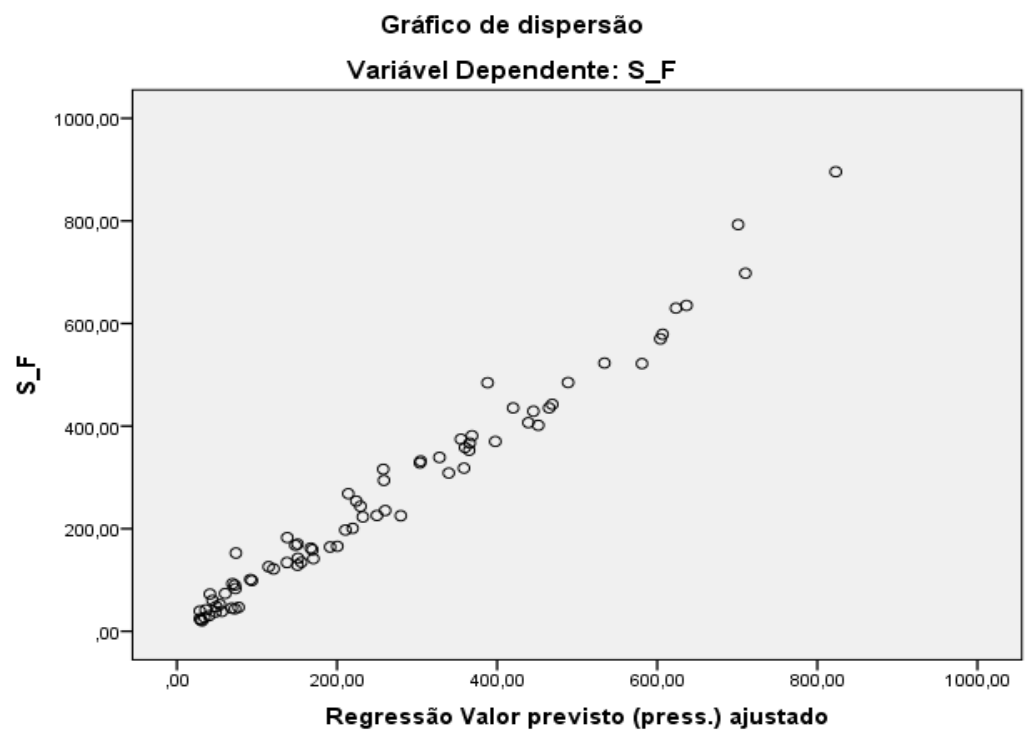

Posterior a esta validação de elementos com base de dados completos (sem valores faltantes), outros elementos com pequenas quantidades de valores faltantes passaram pelo mesmo processo.

Neste ponto é possível gerar as matrizes de concentração utilizadas para a técnica PMF utilizando-se da Tabela 4. Deve-se ressaltar que não se considerou qualquer medida como valor abaixo do limite de detecção, portanto, utilizou-se das operações mostradas nas linhas referentes a valores determinados e valores faltantes da Tabela 4.

Por outro lado, para trabalhar na ACP é desejável não se ter valores faltantes na concentração de elementos, já que esta técnica estatística exige uma base completa (GERAB, 1996). Para isso, a fim de poder incluir na análise elementos mais difíceis de medir e, portanto, com sua série temporal de concentrações incompleta, realizou-se regressões multilineares entre esses elementos e outros que apresentavam correlação com ele a fim de estimar os valores faltantes. Desta forma, as matrizes de concentração [X] utilizadas em cada técnica diferem apenas na determinação dos valores faltantes.

Tanto no PMF quanto na ACP incluiu-se apenas os elementos cujo $75 \%$ de sua série temporal manteve-se original a fim de não influenciar na tendência média dos dados (CASTANHO, 1999; HEIDAM, 1982). 


\subsection{Comparação entre técnicas de medidas}

É fundamental garantir ao máximo a qualidade das medidas dos filtros, pois sua coleta na Amazônia é complicada pela logística difícil. A coleta de filtros ocorreu em paralelo com a operação de outros equipamentos que medem várias propriedades de aerossóis, possibilitando a comparação entre técnicas de medida de instrumentos em tempo real e de filtros que integram estas propriedades por alguns dias tornando possível a validação das medidas obtidas pelos filtros. Essas comparações foram realizadas de acordo com os equipamentos disponíveis em cada sítio.

\subsubsection{Comparação com o coeficiente de absorção medidlo por aetalômetro}

O aetalômetro mede a atenuação da radiação em sete comprimentos de onda (370, $430,470,520,565,700$ e $800 \mathrm{~nm}$ ) transmitido através de um filtro interno que coleta continuamente partículas de aerossol e calcula o coeficiente de absorção $b_{a b s}$ através da seguinte equação:

$$
b_{a b s}=\frac{A}{Q} \frac{\Delta A T N}{\Delta t}
$$

onde $\mathrm{A}$ é a área do filtro, $\mathrm{Q}$ é a taxa de fluxo volumétrico, $\triangle A T N$ é a variação de atenuação medida e $\Delta t$ é o tempo de coleta de MP. Detalhes sobre o aetalômetro podem ser encontrados em diversos artigos (RIZZO et al., 2013; SATURNO et al., 2017; SCHMID et al., 2006).

Comparou-se o valor médio de $b_{a b s}\left(\mathrm{PM}_{1}\right)$ integrado para o mesmo período de amostra dos filtros com a concentração de $\mathrm{BCe}\left(\mathrm{MP}_{2,5}\right)$ obtida através da refletância nos filtros de policarbonato e EC $\left(\mathrm{MP}_{2,5}\right)$ obtida através do método termal-óptico aplicado aos filtros de quartzo. A comparação foi realizada para o babs em $880 \mathrm{~nm}$ pois neste comprimento de onda $\mathrm{O} B C$ absorve consideravelmente mais radiação que outros componentes do material particulado (PETZOLD et al., 2013).

A comparação entre $b_{\text {abs }}$ e concentração de EC possibilita o cálculo do Coeficiente de Absorção Mássico (MAC, do inglês Mass Absorption Coefficient) que é definido como a razão entre estas duas grandezas e indica a secção de choque de absorção óptica e que é utilizado para calcular a concentração de BCe através de medidas de absorção: 


$$
M A C=\frac{b_{a b s}}{[E C]}
$$

3.5.2. Comparação com a concentração de matéria orgânica obtida por espectrômetro de massa

O espectrômetro de massa monitora em tempo real a concentração de massa e a composição do material particulado não-refratário na fração submicrométrica. Maiores detalhes sobre este equipamento pode ser encontrado em NG et al. (2011). Dentre as concentrações de diferentes componentes medidos está a de matéria orgânica (OM, do inglês Organic Matter) no $\mathrm{PM}_{1}$ possibilitando portanto a comparação desta medida com a concentração de carbono orgânico no $\mathrm{PM}_{2,5}$ obtida através da técnica termo-óptica. Da comparação entre [OM] e [OC] obtém-se a densidade de $\rho_{\mathrm{OM}}$. Esta grandeza está relacionada com o processamento do aerossol já que valores próximos de 1,4 relaciona-se com aerossol recém-emitido, enquanto que valores maiores, próximos de 2,0 relacionam-se com aerossóis envelhecidos pois os componentes de aerossóis secundários são mais oxigenados do que a maioria dos aerossóis primários (TURPIN; LIM, 2001).

Em Manacapuru também foi realizada a comparação entre a concentração de material particulado obtida por um scanning mobility particle sizer (SMPS) e o Total Carbon (a soma de OC e EC) obtida pela técnica termo-óptica. Isso foi feito integrando-se a distribuição de tamanho de $10 \mathrm{~nm}$ a $500 \mathrm{~nm}$. Para o cálculo da massa através da distribuição de tamanho do aerossol assumiu-se partículas esféricas, com densidade de $1,5 \mathrm{~g} / \mathrm{cm}^{3}$ (POSCHL et al., 2010). 


\section{Resultados}

Nesta seção são apresentados os resultados referentes à identificação de fontes de aerossóis, utilizando modelos multivariados e as extensas bases de dados coletadas. A seção 4.1 apresenta comparações de validação de resultados obtidos através de medidas dos filtros com as de outros equipamentos. Os resultados de concentração de material particulado fino (MPF) e grosso (MPG) estão na seção 4.2 seguido dos resultados de Black Carbon Equivalente (BCe) (seção 4.3) e elementos traços (seção 4.4) divididos por sítios. Posteriormente, na seção 4.5, encontram-se os resultados obtidos pela análise termo-óptica com as concentrações de carbono orgânico (OC), elementar (EC) e análises dos termogramas. A partir desses resultados, é realizada na seção 4.6 a análise do balanço de massa. Finalmente, as seções 4.7 e 4.8 apresentam os resultados das análises de fatores, ACPA e PMF, respectivamente.

\subsection{Comparação entre técnicas de medidas}

É fundamental garantir ao máximo a qualidade das medidas dos filtros, pois sua coleta na Amazônia é complicada pela logística difícil. Desenvolvemos várias abordagens para garantir ao máximo a qualidade dos dados em análise e as conclusões deste trabalho. A coleta de filtros ocorreu em paralelo com a operação de outros equipamentos que medem várias propriedades de aerossóis, possibilitando a comparação entre técnicas de medida de instrumentos em tempo real e de filtros que integram estas propriedades por alguns dias. Neste capítulo é apresentada a comparação de medidas realizadas por aetalômetro, SMPS e ACSM com os resultados obtidos através de gravimetria, refletância e análise termo-óptica de acordo com a disponibilidade de dados de cada sítio. A fim de tornar esta comparação viável, foi necessária a adequação do período de exposição entre os equipamentos: os resultados aqui expostos para estes equipamentos são os valores médios integrados obtidos durante o período de amostragem do filtro amostrado em paralelo no tempo.

\subsubsection{Comparação do Black Carbon Equivalente medido por refletância versus} Coeficiente de Absorção medido por Aetalômetro

Nos sítios TIWA e Manacapuru foi possível comparar a concentração de BCe obtido por refletância nos filtros com a absorção de radiação em 880nm obtida por aetalômetro (Aethalometer ${ }^{\circledR}$ Model AE33 no TIWA e Aethalometer ${ }^{\circledR}$ Models AE31 em Manacapuru) 
conforme pode ser observado nas Figuras 26 e 27 (TIWA) e (Manacapuru). Observa-se no ajuste de regressão linear realizado na Figura 26 , referente a comparação no sítio TIWA, coeficiente de determinação $R^{2}$ de 0,72 e uma boa consistência entre os resultados obtidos por diferentes métodos. Salienta-se que nesta figura, valores da estação chuvosa e seca estão incluídos, codificado pelas cores. Na estação chuvosa, observa-se uma maior inclinação da reta de regressão linear. Na Figura 27, referente ao sítio de Manacapuru, verifica-se coeficiente de determinação menor, $\operatorname{com} \mathrm{R}^{2}$ de 0,32 e pode ser observada uma maior dispersão de dados principalmente durante a estação seca (pontos esverdeados e amarelados). Isso pode ser causado pelas diferentes propriedades das emissões de BC da cidade de Manaus, que tem características diferentes da relação com aerossóis da estação chuvosa e seca.

Figura 26: comparação entre o coeficiente de absorção obtido pelo aetalômetro AE33 em $880 \mathrm{~nm}$ e o BCe obtido por refletância dos filtros de policarbonato na fração fina no sítio TIWA. A reta em vermelho representa o ajuste realizado entre os resultados de ambas as técnicas.

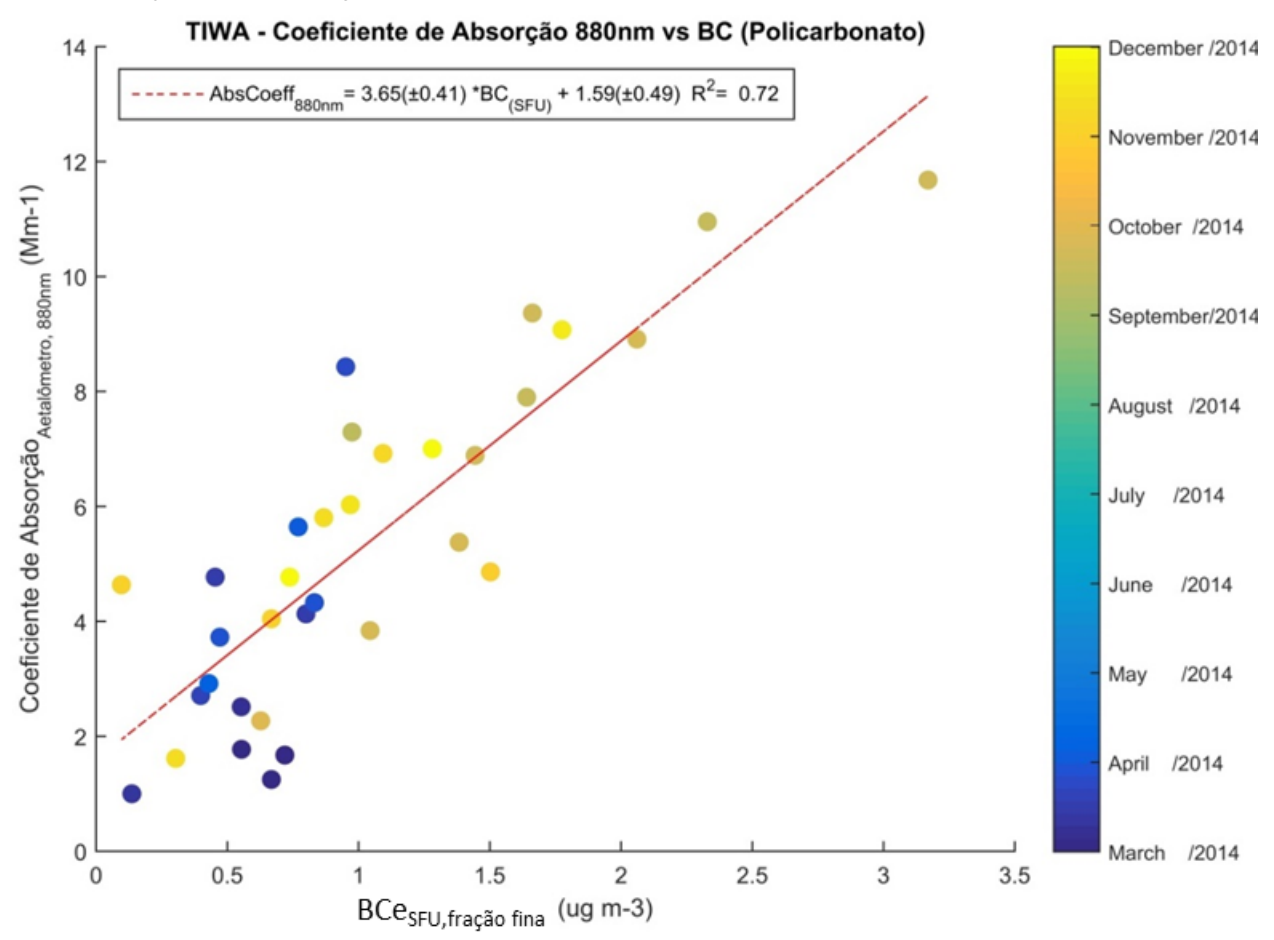


Figura 27: comparação entre o coeficiente de absorção obtido pelo aetalômetro AE31 em $880 \mathrm{~nm}$ e o BCe obtido por refletância dos filtros de policarbonato da fração fina no sítio Manacapuru. A reta em vermelho representa o ajuste realizado entre os resultados de ambas as técnicas.

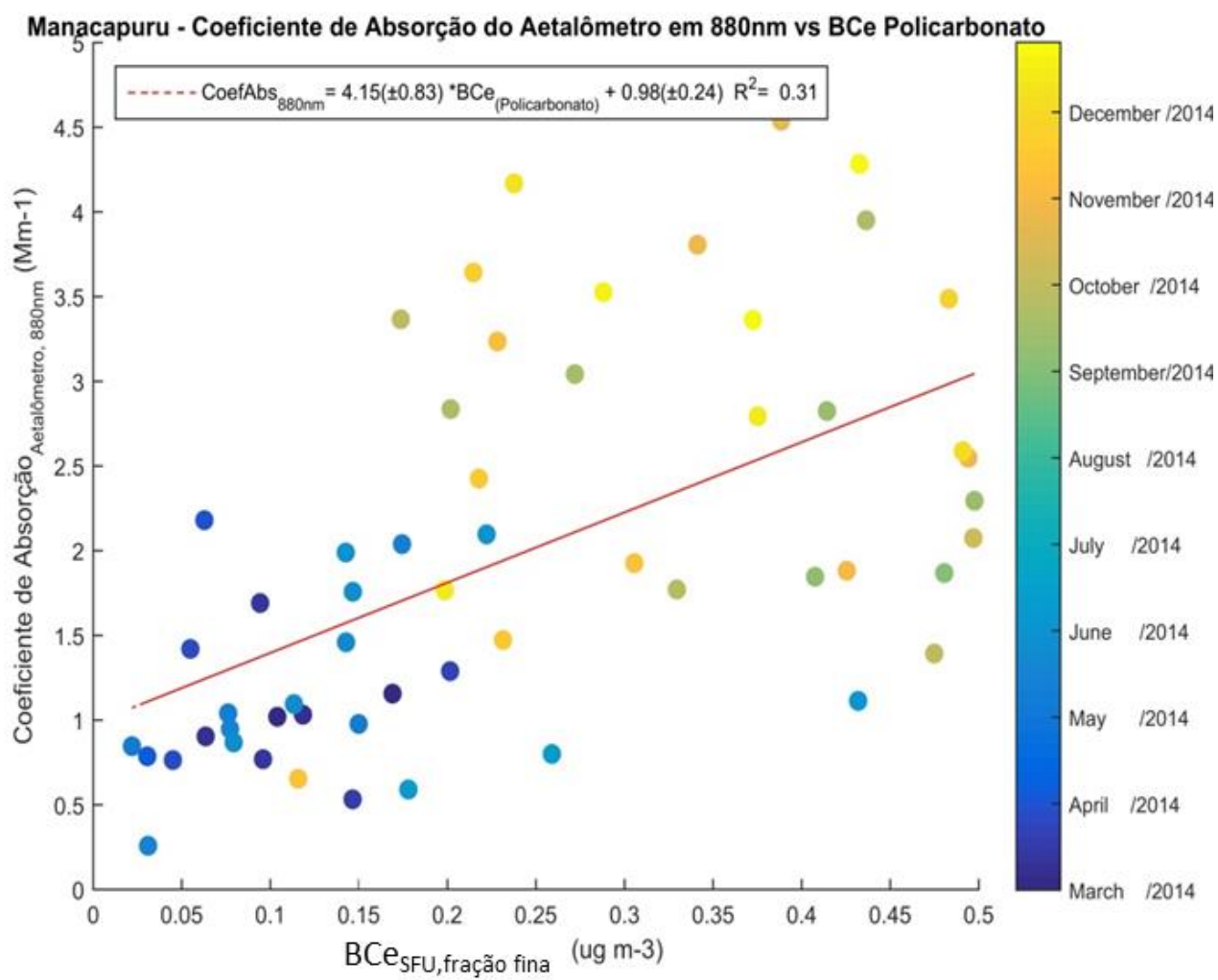

A comparação dessa mesma medida de coeficiente de absorção no aetalômetro com o EC obtido através da análise termo-óptica está nas Figura 28 e Figura 29. Verifica-se em ambos os sítios coeficientes de determinação maiores que 0,60 (significativos dentro de $p=0,05)$, indicando uma boa consistência entre ambas as técnicas de medição. 
Figura 28: comparação entre o coeficiente de absorção obtido pelo aetalômetro AE33 em $880 \mathrm{~nm}$ e o EC obtido através da análise termo-óptica dos filtros de quartzo na fração fina no sítio TIWA. A reta em vermelho representa o ajuste realizado entre os resultados de ambas as técnicas durante a estação seca, enquanto a azul é para a estação chuvosa.

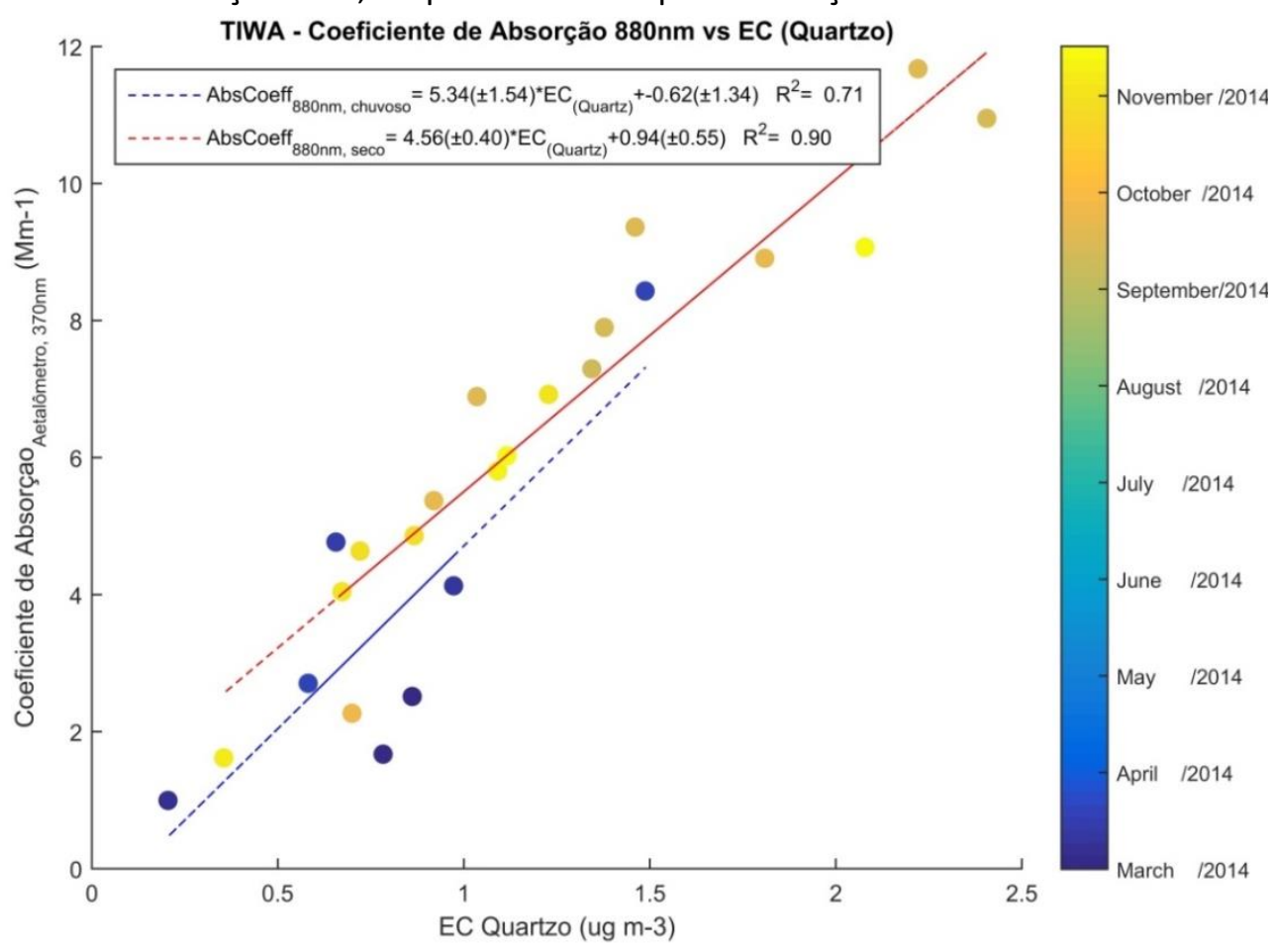

Figura 29: comparação entre o coeficiente de absorção obtido pelo aetalômetro AE31 em $880 \mathrm{~nm}$ e o EC obtido através da análise termo-óptica dos filtros de quartzo na fração fina no sítio Manacapuru. A reta em vermelho representa o ajuste realizado entre os resultados de ambas as técnicas durante a estação seca, enquanto a azul é para a estação chuvosa.

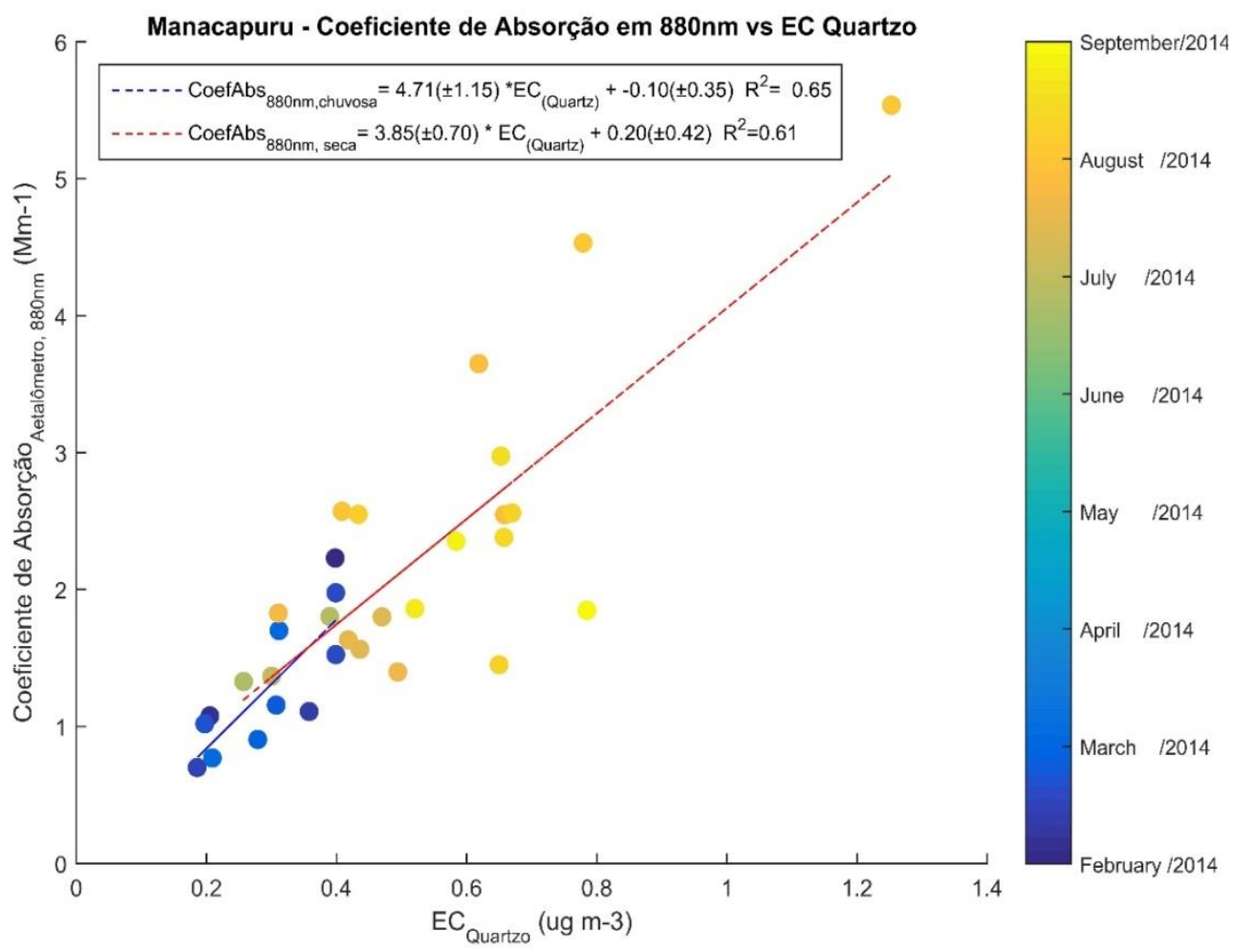


O coeficiente angular ajustado às medidas de coeficiente de absorção e concentração de EC indica o MAC. Nos ajustes observados nas Figuras 28 e 29, observa-se baixos valores médios de MAC, entre 3,85 e 5,34 $\mathrm{m}^{2} / \mathrm{g}$, quando comparados com o sugerido pelo fabricante de 18,3 m²/g. CHENG et al., (2016) obtém baixos valores de MACs relacionados à BCe de queima de biomassa e sugere que isto ocorre devido à superestimação de valores de EC na técnica termal-óptica em amostras com razão OC/EC>3.

Através das comparações acima expostas, verifica-se que ocorre uma grande dispersão na comparação realizada entre BCe e coeficiente de absorção em Manacapuru, que não ocorre quando comparamos este último com o EC, indicando a ocorrência de problemas na amostragem dos filtros de policarbonato em Manacapuru. Entretanto, os filtros de Manacapuru apresentaram consistência interna em análises multilineares realizadas com seus elementos, estando aptos, portanto, à realização das análises de fatores a fim de quantificar as fontes de material particulado neste sítio.

\subsubsection{Comparação de elemental carbon obtido através da técnica termo-óptica versus black carbon equivalente obtido através da refletância}

Para os sítios ZF2 e TIWA foi possível realizar a comparação entre a concentração de EC obtido pela aplicação da técnica termo-óptica nos filtros de quartzo e a concentração de BCe obtido através da técnica de refletância realizada nos filtros de quartzo. A comparação durante a estação seca para a ZF2 está na Figura 30 e o ajuste realizado entre as técnicas apresenta coeficiente de correlação $R^{2}$ de 0,92 (significativo dentro de $p=0,05$ ) com uma

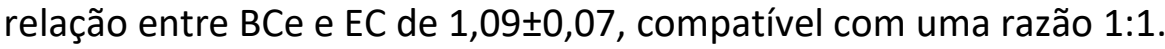


Figura 30: comparação entre a concentração de BCe (obtido por refletância dos filtros de policarbonato) versus a concentração de EC (obtido através da análise termo-óptica) para a estação seca do sítio ZF2.

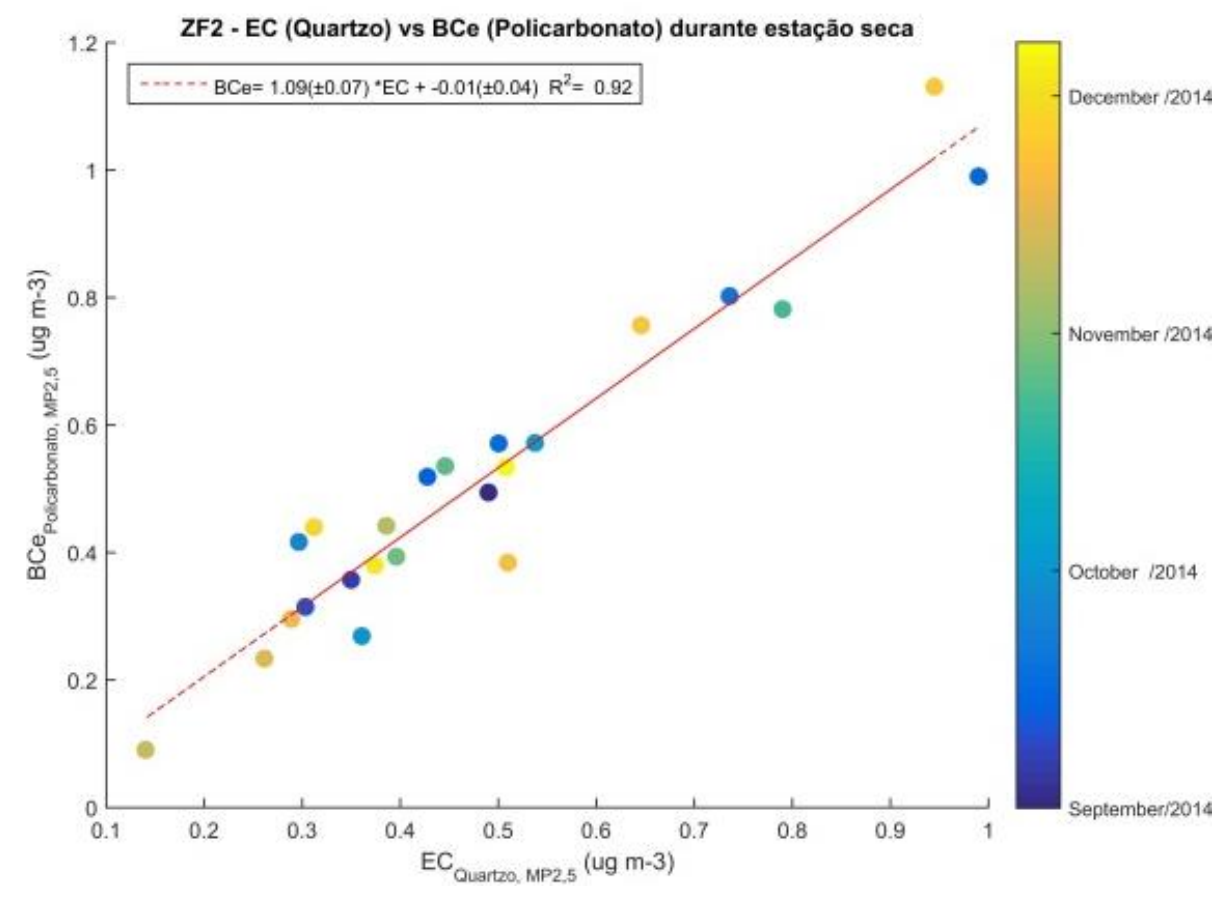

Nas Figuras 31 e 32 observa-se as comparações realizadas no sítio TIWA. Durante a estação chuvosa o R2 do ajuste é de 0,84, maior que o obtido durante a estação seca de 0,63 e ambos os coeficientes lineares são compatíveis com zero dentro de três desvios-padrões.

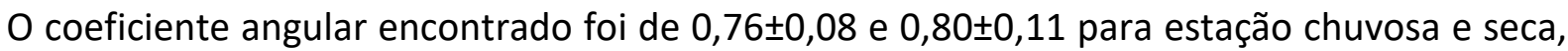
respectivamente, dois valores estatisticamente compatíveis. Esse coeficiente angular é semelhante ao encontrado por JUNIOR (2015) no sítio IFUSP, que foi de 0,79 $\pm 0,04$. Esta relação $\mathrm{BCe} / \mathrm{EC}$ menor que a unidade pode ter ocorrido devido a um possível OC pirolítico mais absorvedor de luz que o EC, resultando em uma superestimação da massa de EC por métodos termo-ópticos, conforme já reportado para locais urbanos em CHENG et al. (2016). 
Figura 31: comparação entre a concentração de BCe (obtido por refletância dos filtros de policarbonato) versus a concentração de EC (obtido através da análise termo-óptica) para a estação chuvosa.

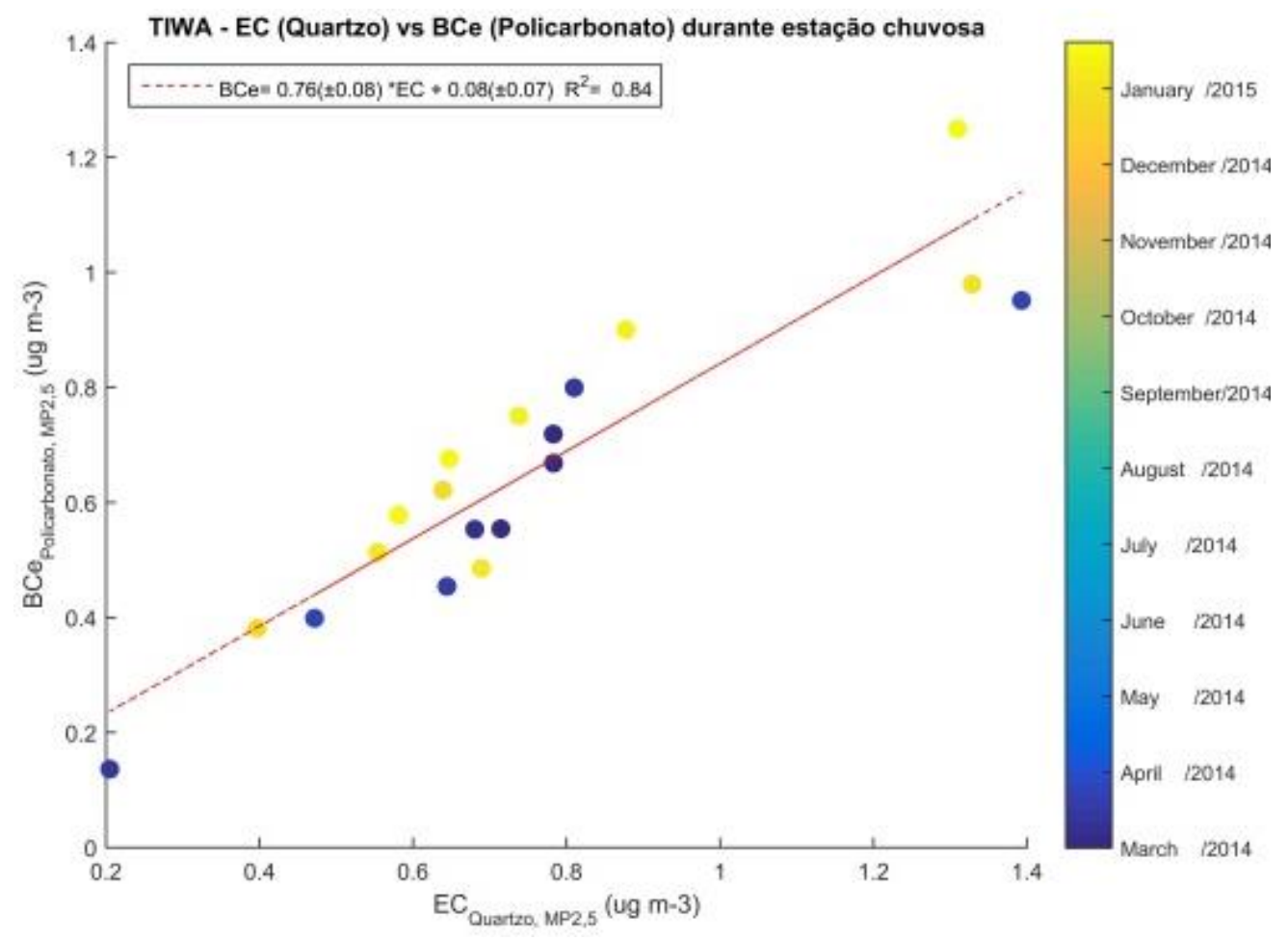

Figura 32: comparação entre a concentração de BCe (obtido por refletância dos filtros de policarbonato) versus a concentração de EC (obtido através da análise termo-óptica) para a estação seca no sítio TIWA.

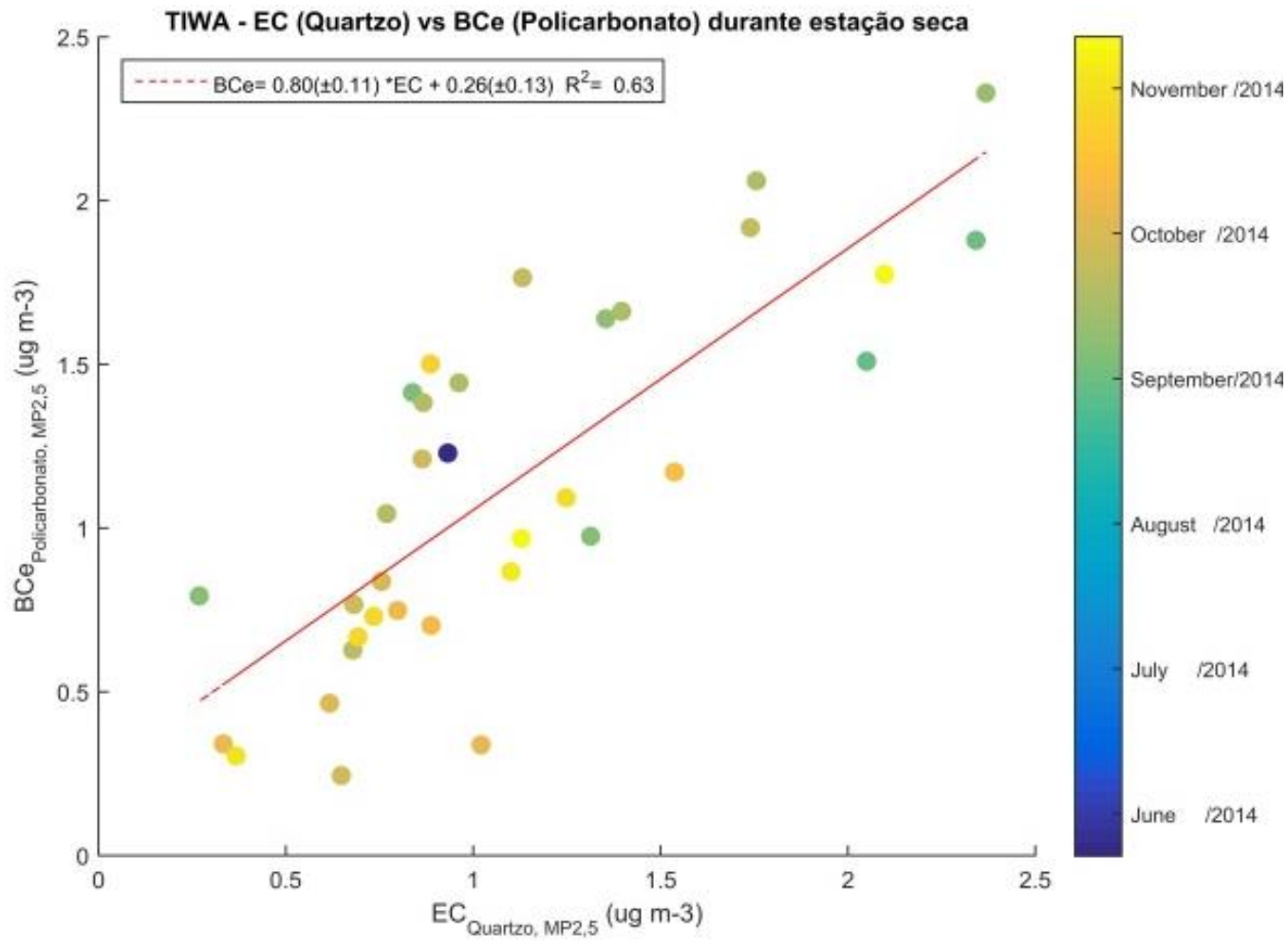


4.1.3. Comparação entre total carbon e concentração de massa através do scanning mobility particle sizer (SMPS)

Neste procedimento de verificação de qualidade dos dados, também foi possível a utilização do scanning mobility particle sizer (SMPS) para a obtenção da concentração de massa no sítio de Manacapuru, conforme Figura 33.

Figura 33: comparação entre concentração de massa calculada a partir dos resultados do SMPS e o carbono total na fração fina obtido pelo método termo-óptico no sítio Manacapuru.

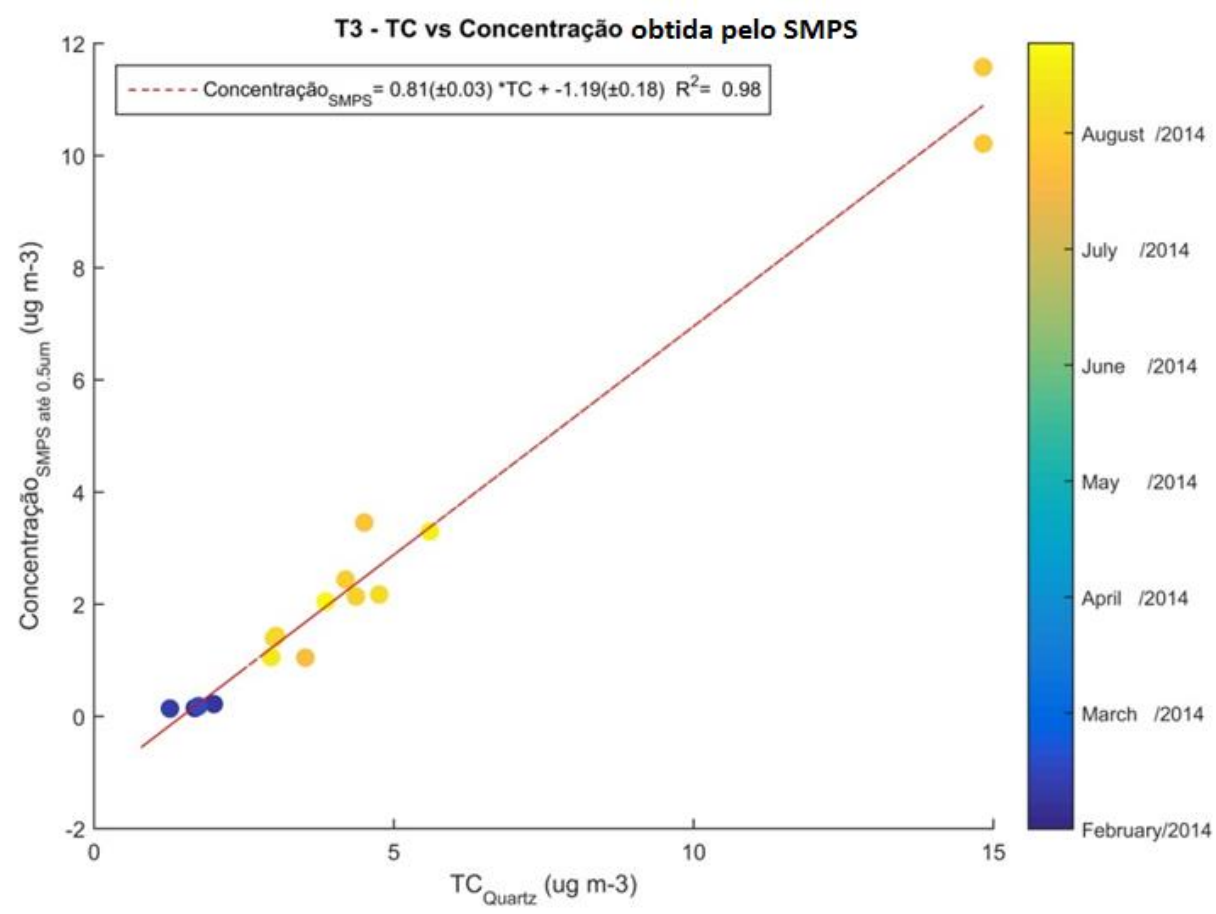

A comparação apresenta valor de $R^{2}$ de 0,98 (significativo dentro de $p=0,05$ ). Na equação, entretanto verifica-se um fator linear de $-1,19 \pm 0,18 \mu \mathrm{g} / \mathrm{m}^{3}$, que pode ser explicado através do resultado de distribuição de massa dos compostos carbonáceos por diâmetro da partícula obtido por SOTO-GARCÍA et al., (2011), mostrado na Figura 34. Nela, verifica-se

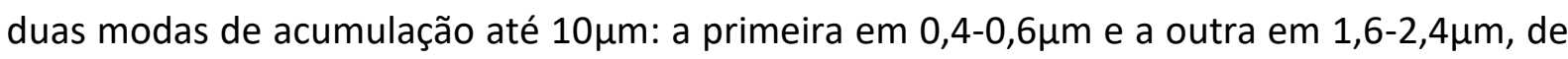
forma que o SMPS coletou partículas até $0,5 \mu \mathrm{m}$, ou seja, até a metade da primeira moda. Além disso, a concentração calculada através do SMPS leva em conta outros elementos além do carbono. 
Figura 34: distribuição de tamanho médio do material particulado e TC com desvio-padrão da média durante a estação seca.

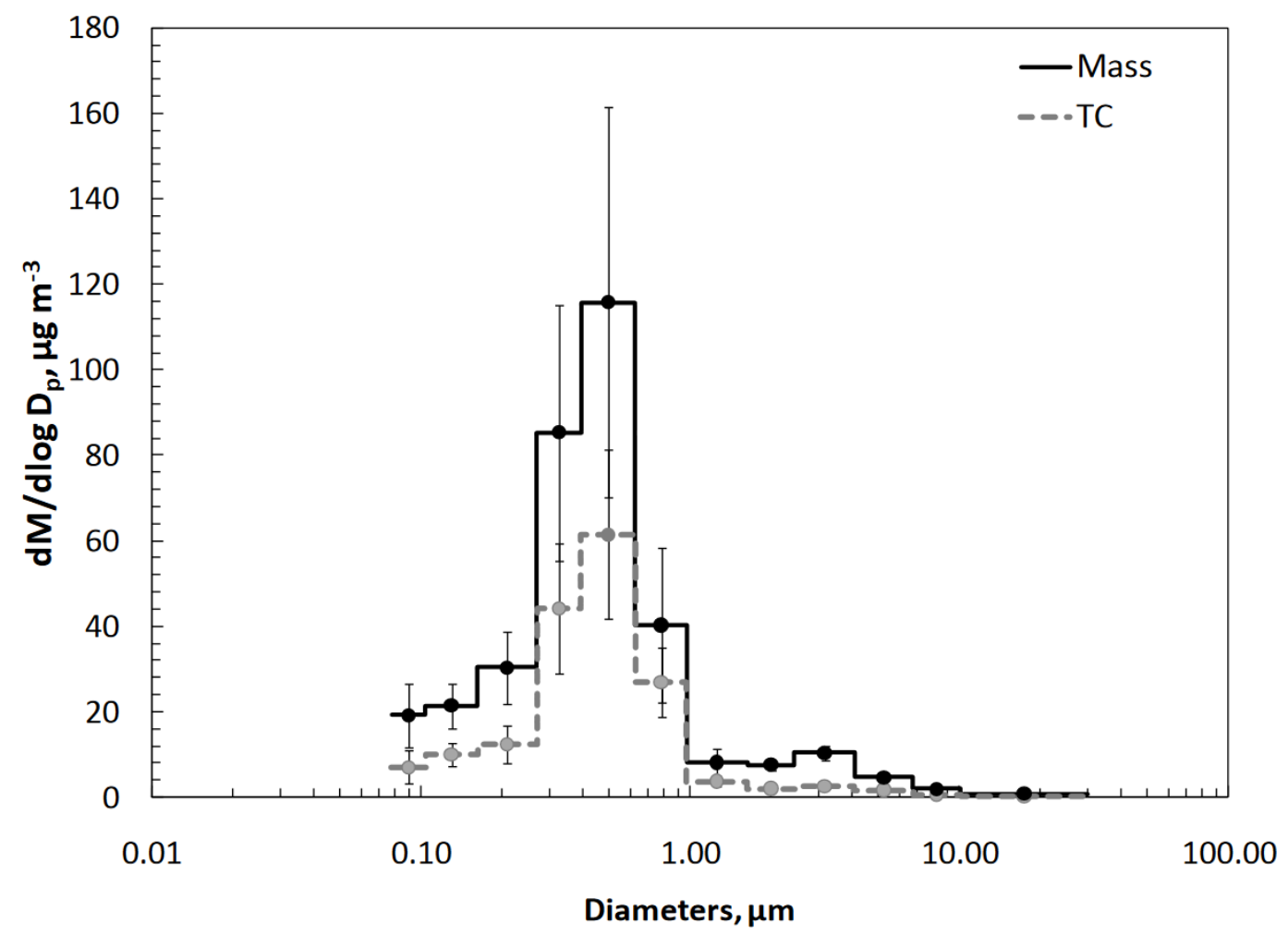

Fonte: SOTO-GARCÍA et al., 2011.

4.1.4. Matéria Orgânica versus Carbono Orgânico obtido através do método termo-óptico

O carbono orgânico é uma das componentes mais importantes do aerossol amazônico, mas sua determinação é difícil e com vários artefatos de acordo com a técnica de medida. Realizou-se comparações entre a concentração de carbono orgânico medida pela técnica termo-óptica e equipamentos que medem a concentração de matéria orgânica como - Aerodyne Aerosol Mass Spectrometer (AMS) em Manacapuru e o Aerosol Chemical Speciation Monitor (ACSM) no TIWA.

A Figura 35 ilustra a comparação entre matéria orgânica e carbono orgânico no sítio experimental TIWA. Verifica-se um ajuste estatístico com $\mathrm{R}^{2}$ de 0,75 (significativo dentro de $p=0,05$ ) e coeficiente linear de $3,20 \pm 2,18$. O coeficiente angular deste sítio representa a

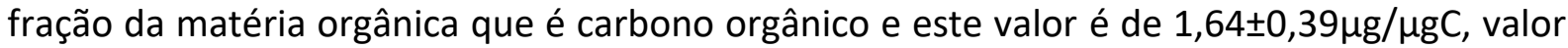
próximo do estimado por TURPIN (2001), de 1,6 para locais urbanos. 
Figura 35: comparação entre a concentração de matéria orgânica medida pelo ACSM versus carbono orgânico medido pelo método termo-óptico no sítio TIWA.

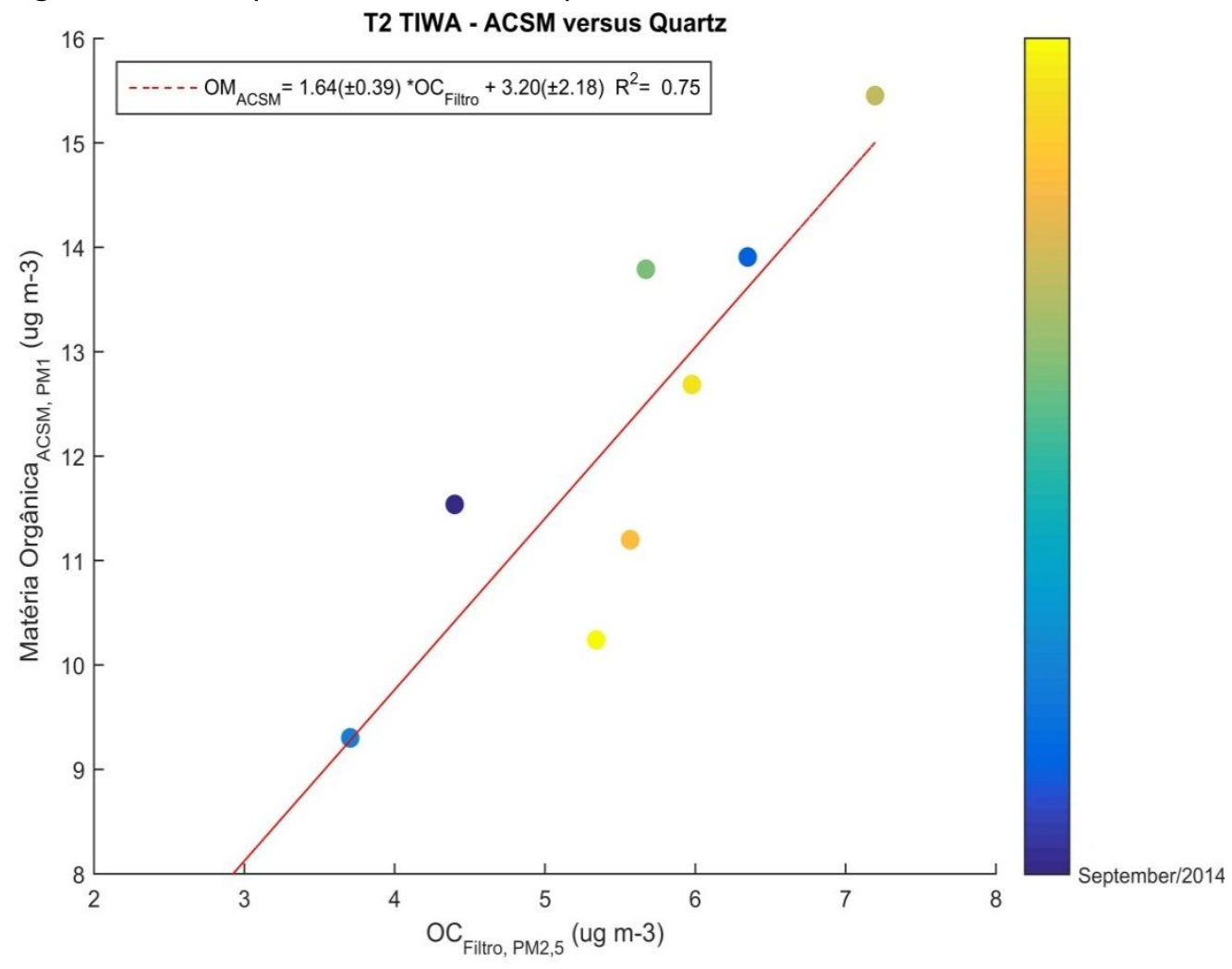

A Figura 36 compara a matéria orgânica medida pelo Aerosol Mass Spectrometer (AMS) da Universidade de Harvard e cedidos por Suzanne de Sá e o resultado de OC coletado pelos filtros de quartzo. $O$ ajuste possui um coeficiente de determinação de 0,95. 0 coeficiente linear calculado apresenta média de $2,33 \pm 1,06 \mu \mathrm{gOM} / \mathrm{m}^{3}$ e o coeficiente angular

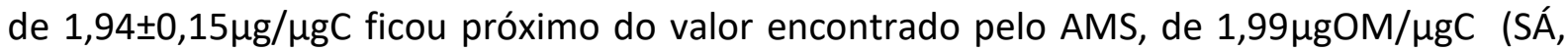
2016), e é compatível com 2,1 $\pm 0,1 \mu \mathrm{g} / \mu \mathrm{gC}$ obtido por TURPIN (2001) para aerossóis envelhecidos não urbanos.

Os resultados obtidos nesta seção serão utilizados para a conversão de OC para matéria orgânica para a reconstrução do balanço de massa na seção 4.7. 
Figura 36: comparação entre a concentração de matéria orgânica medida pelo AMS versus carbono orgânico medido pelo método termo-óptico no sítio Manacapuru.

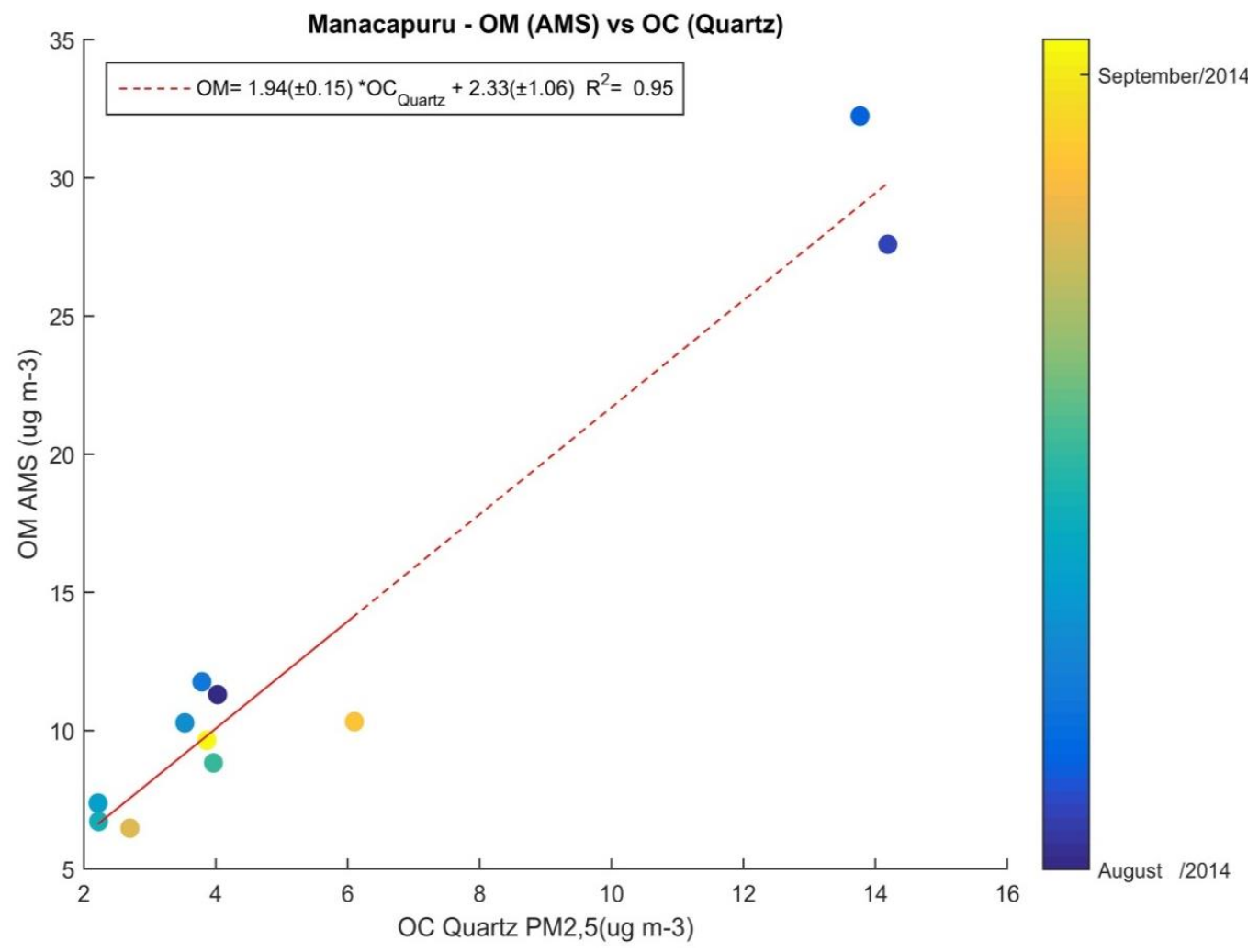

Com as análises acima se conclui que os dados coletados pelos filtros apresentaram consistência com os obtidos a partir de outros equipamentos independentes, com exceção dos filtros de policarbonato de Manacapuru, que apresentaram baixo coeficiente de determinação no ajuste com os resultados de black carbon medidos pelo aetalômetro. Os coeficientes encontrados nos ajustes mostraram-se compatíveis com os observados na literatura e/ou com os obtidos por outras técnicas.

\subsection{Material Particulado na Amazônia Central}

Nesta seção são apresentados os resultados acerca da concentração de material particulado (MP) obtida através da análise gravimétrica. Para abreviar uma extensa apresentação de resultados, o leitor pode verificar as concentrações, desvios-padrões, quantidade de amostras separados por moda e estação no Apêndice A.

As Figura 37 a 40 apresentam a série temporal da concentração de material particulado junto com a razão entre a fração fina e o material particulado total após um ano de coleta de filtros nos sítios ZF2, TIWA e Manacapuru. Em seguida, a Tabela 5, mostra a concentração média de MPF e MPG e a razão MPF/MP10 no período do experimento. 
Figura 37: série temporal do material particulado fino e grosso para a estação ZF2. A região em azul indica a estação chuvosa. Em vermelho está exposta a razão entre a concentração de MP2,5 e MP10.

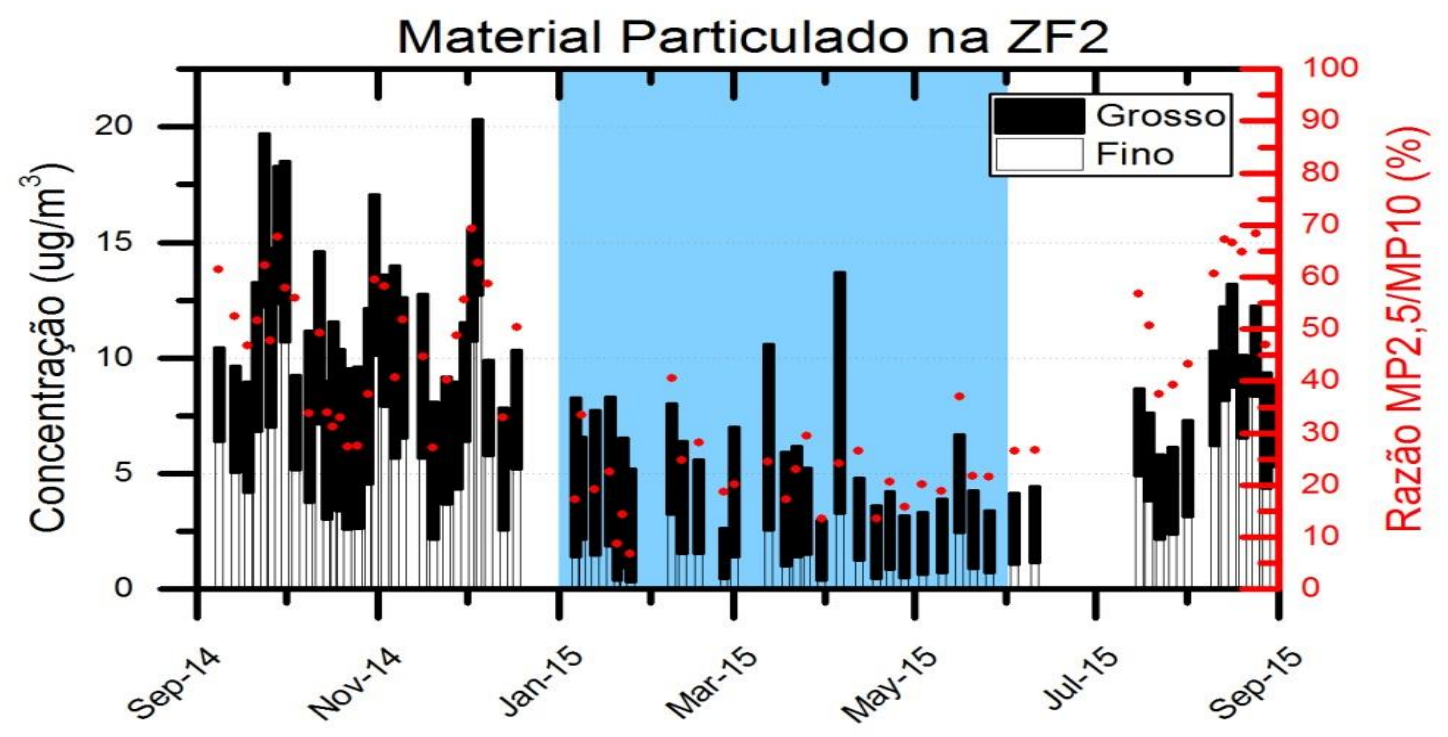

Figura 38: série temporal do material particulado fino e grosso para a estação TIWA. A região em azul indica a estação chuvosa. Em vermelho está exposta a razão entre a concentração de MP2,5 e MP10.

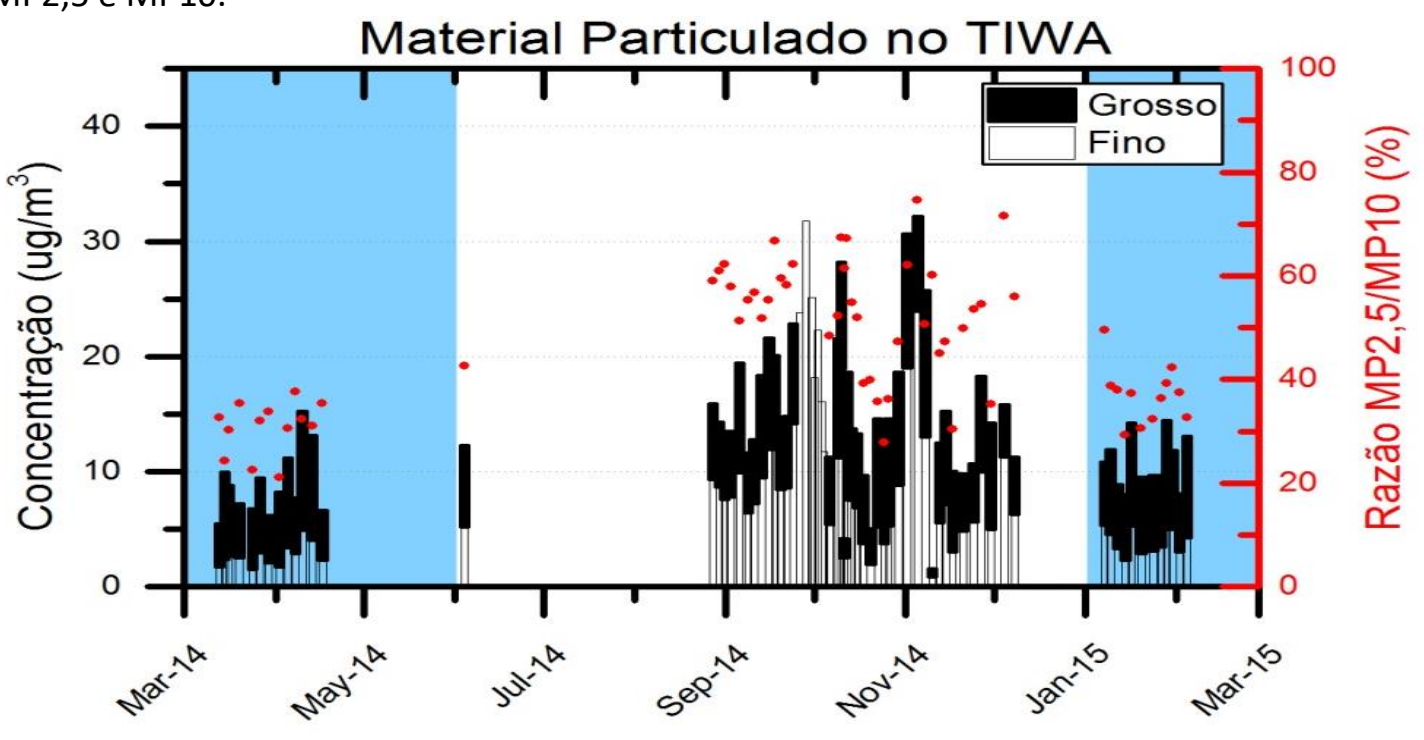


Figura 39: série temporal do material particulado fino e grosso para a estação Manacapuru. A região em azul indica a estação chuvosa. Em vermelho está exposta a razão entre a concentração de MP2,5 e MP10.

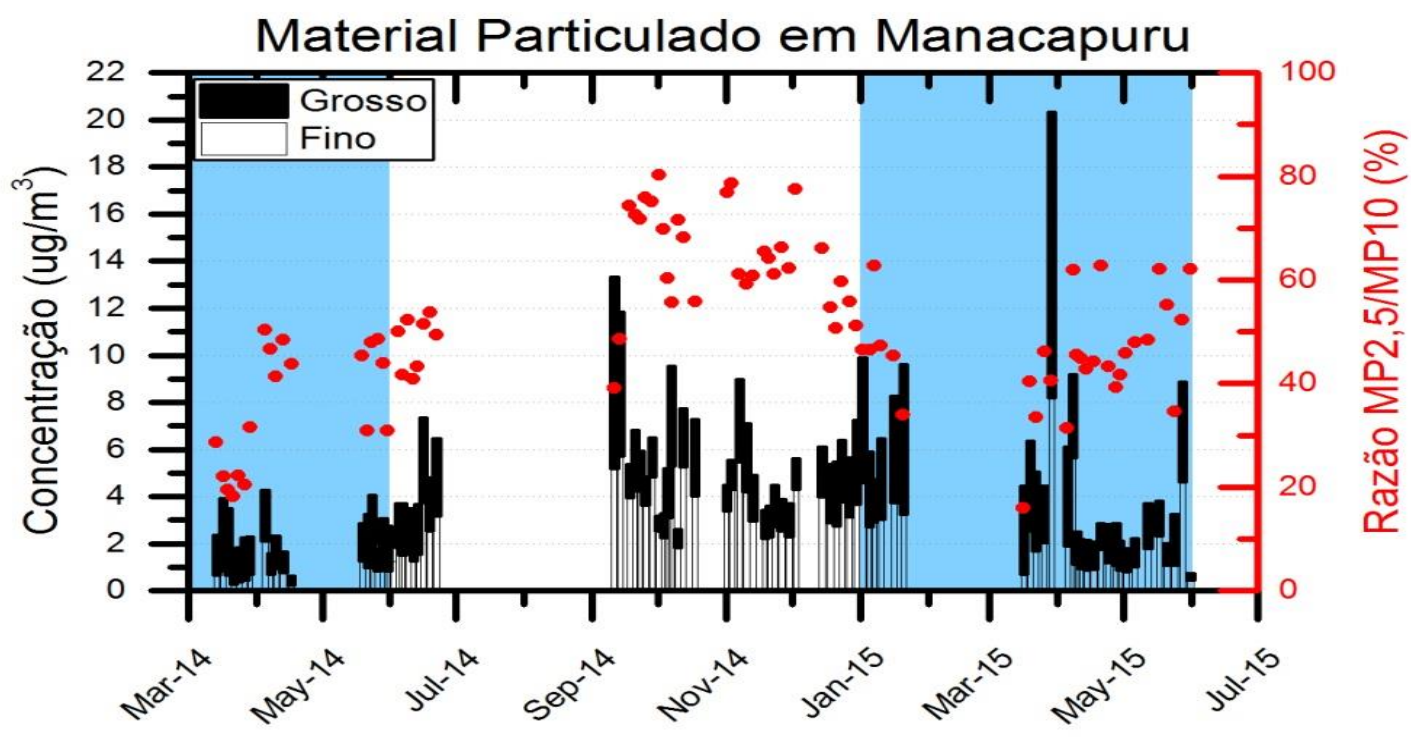

Tabela 5: síntese sobre as concentrações de material particulado fino e grosso e a razão entre MPF/MP10 obtidos durante o experimento GoAmazon2014/15.

\begin{tabular}{ccrcccccccc}
\hline \multicolumn{10}{c}{ Tabela síntese das concentrações de material particulado nos sítios do GoAmazon $2014 / 2015$} \\
\hline \multirow{2}{*}{ Sítio } & \multirow{2}{c}{ Estação } & \multicolumn{10}{c}{ Valor médio } \\
& MPF $\left(\mu \mathrm{g} / \mathrm{m}^{3}\right)$ & MPG $\left(\mu \mathrm{g} / \mathrm{m}^{3}\right)$ & Razão MPF/MP10 (\%) \\
\hline \multirow{2}{*}{ ZF2 } & Seca & 5,5 & \pm & 2,7 & 5,4 & \pm & 1,5 & 48 & \pm & 14 \\
& Chuvosa & 2,3 & \pm & 2,7 & 4,7 & \pm & 1,7 & 31 & \pm & 16 \\
\multirow{3}{*}{ TIWA } & Seca & 11,0 & \pm & 7,6 & 7,1 & \pm & 2,5 & 55 & \pm & 12 \\
& Chuvosa & 3,7 & \pm & 2,0 & 6,3 & \pm & 1,7 & 40 & \pm & 13 \\
& Seca & 3,2 & \pm & 1,3 & 2,2 & \pm & 1,5 & 61 & \pm & 12 \\
& Chuvosa & 1,9 & \pm & 1,5 & 2,3 & \pm & 1,8 & 44 & \pm & 13 \\
\hline
\end{tabular}

Os valores médios do presente estudo no sítio ZF2 são compatíveis com outros estudos realizados na região (ARANA, A.; ARTAXO, 2014; ARTAXO et al., 1998; WANG et al., 2016) demonstrando pouca alteração ao longo do tempo nos processos de formação de aerossol neste sítio, rodeado por floresta intocada. A variabilidade do MPF é maior dentre as estações seca e chuvosas quando comparadas ao do MPG. Isto ocorre por conta da maior emissão de MPF durante a estação de seca por conta da queima de biomassa em relação ao período chuvoso e à constante emissão de PBAPs pela vegetação no MPG. Esta maior variabilidade do MPF já foi observado em trabalhos anteriores (ARTAXO et al., 2013; FUZZI, SANDRO et al., 2007). Observa-se ainda valores médios de concentração maiores no sítio 
TIWA do que na ZF2 em ambas as modas e estações. Os menores valores que ocorrem em Manacapuru são devido ao problema de coleta de material particulado.

\subsection{Black carbon equivalente na Amazônia Central}

Nesta seção são apresentados os resultados acerca da concentração de black carbon equivalente (BCe) obtida através da análise de refletância realizada nos filtros de policarbonato. As Figura 40 a 43 apresentam a série temporal de BCe na fração fina e grossa para os três sítios do experimento GoAmazon2014/15 durante o período de aproximadamente um ano.

Figura 40: série temporal do black carbon equivalente determinados nos filtros de policarbonato para a estação ZF2. A região em azul indica a estação chuvosa.

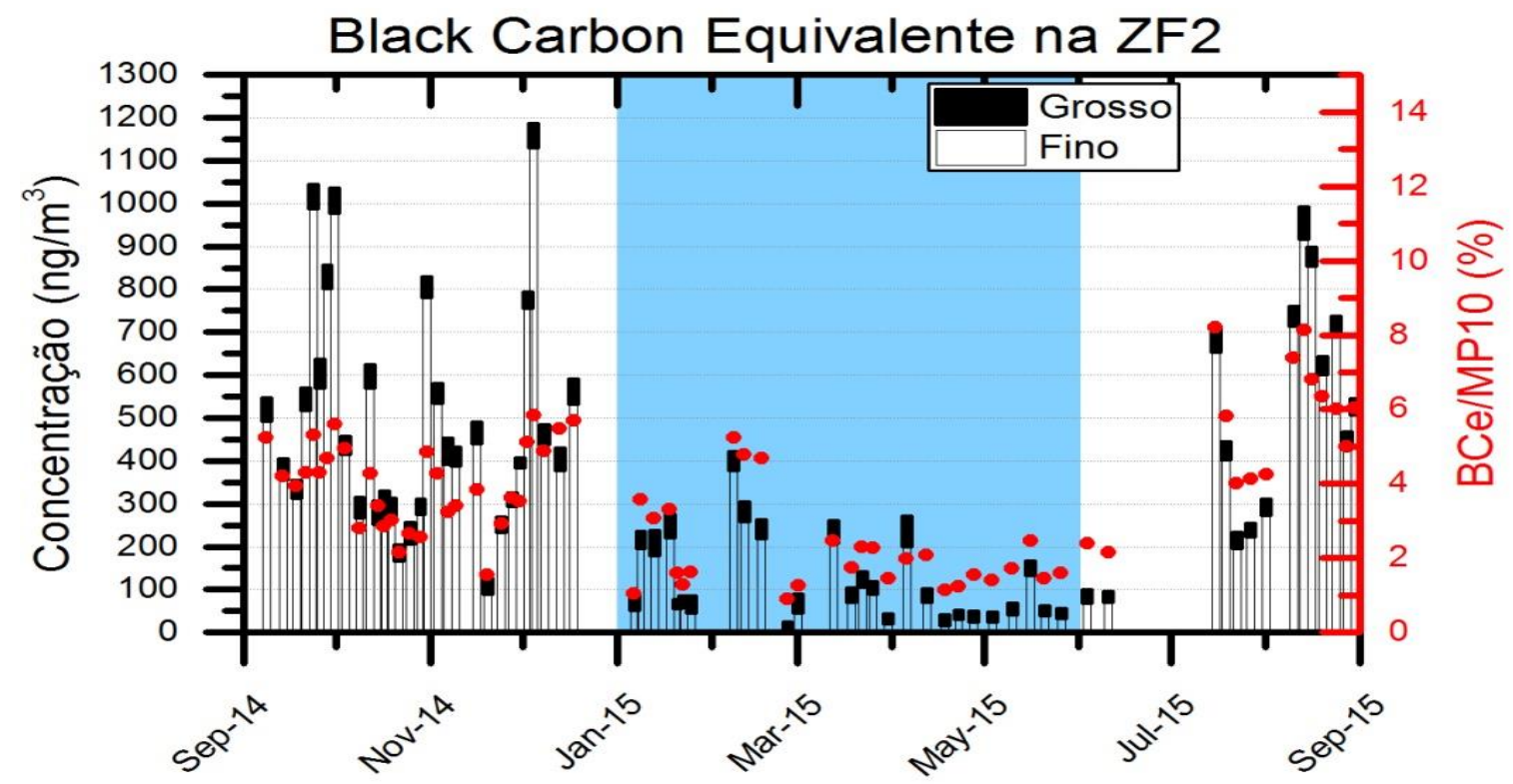


Figura 41: série temporal do black carbon equivalente para a estação TIWA. A região em azul indica a estação chuvosa.

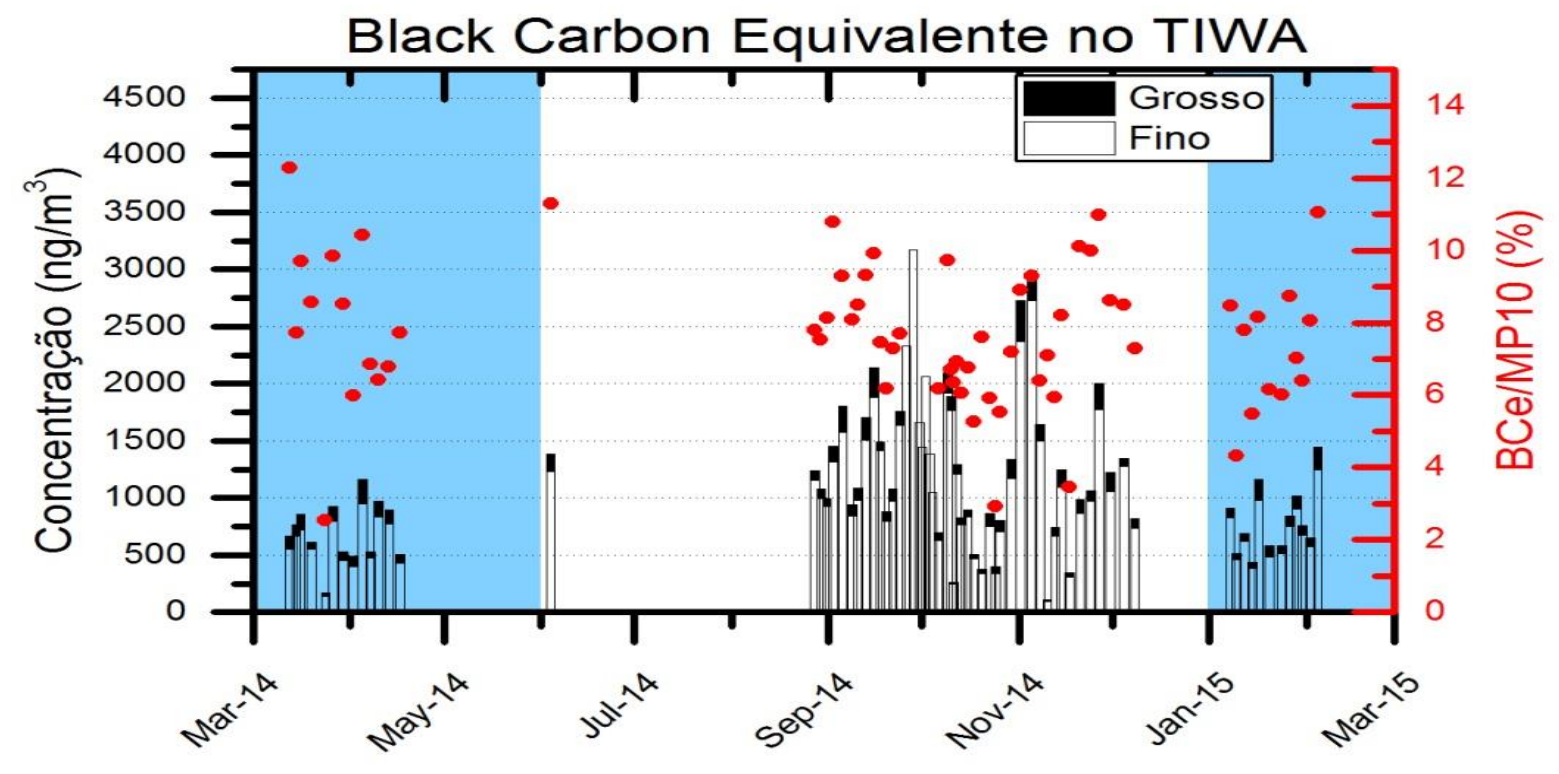

Figura 42: série temporal do black carbon equivalente para a estação Manacapuru. A região em azul indica a estação chuvosa.

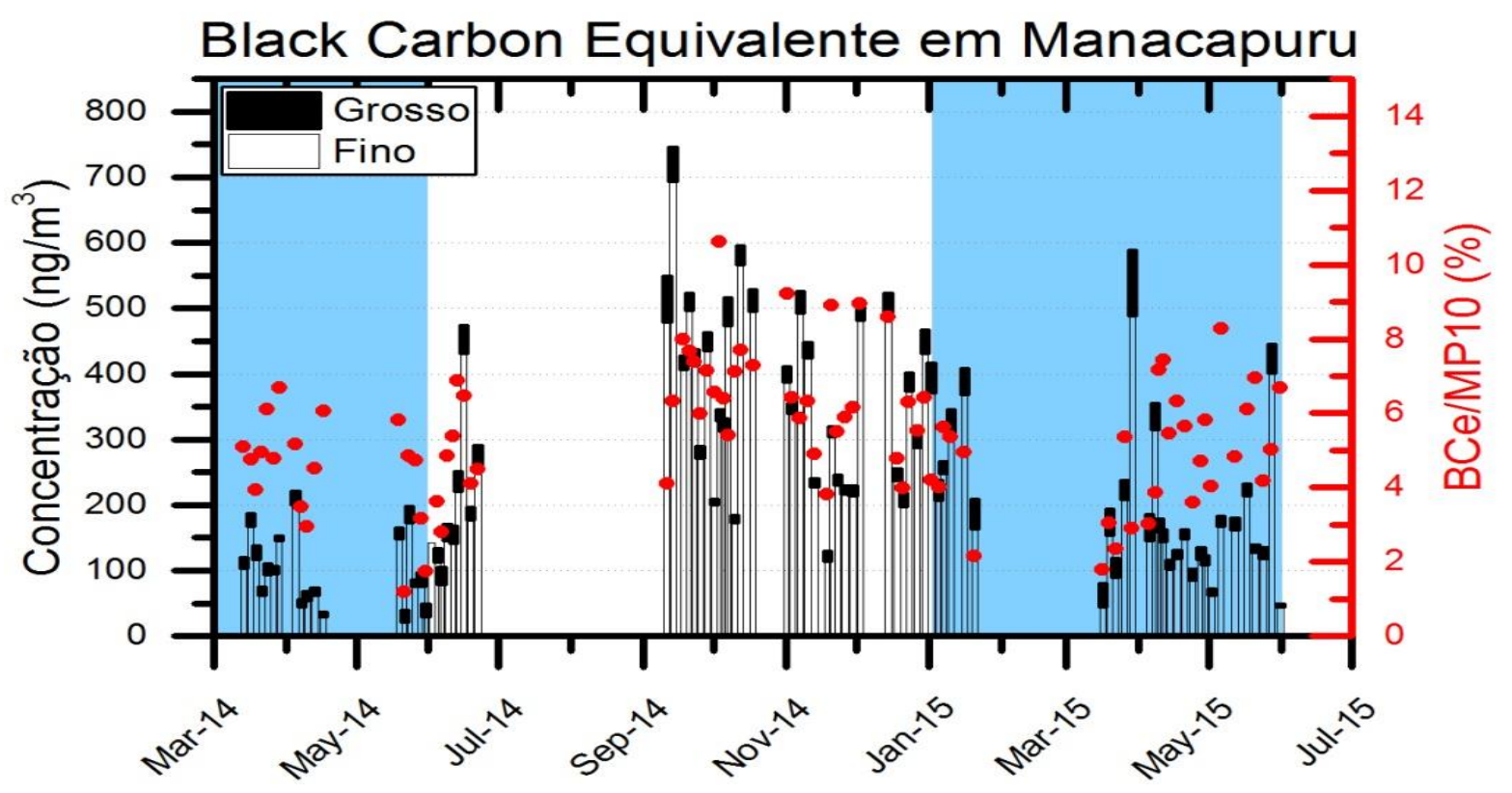

Visualiza-se no fim de setembro de 2014 a máxima concentração de BCe nos sítios ZF2 e TIWA. Na figura abaixo, podemos verificar as retrotrajetórias das massas de ar calculadas pelo Hysplit (STEIN et al., 2015) em três alturas sobre o solo (500m em vermelho, $1000 \mathrm{~m}$ em azul e $2000 \mathrm{~m}$ em verde) que chegam à ZF2 no período de amostragem deste filtro. Os pontos em vermelho representam os focos de queimada monitorados por satélites 
que foram obtidos através o site do INPE (2017). Verifica-se que essas massas de ar passam por diversos focos de incêndio desde sua entrada no continente, explicando a alta concentração de BCe nestas amostras.

Figura 43: cálculo do HySplit para retrotrajetória das massas de ar que chegaram a ZF2 no dia 30 de setembro de 2014 em três alturas sobre o solo: $500 \mathrm{~m}$ em vermelho, $1000 \mathrm{~m}$ em azul e $2000 \mathrm{~m}$ em verde e pontos em vermelho representando focos de queimada. É possível verificar a passagem dessas massas de ar por diversos focos de queimada até a chegada na ZF2.

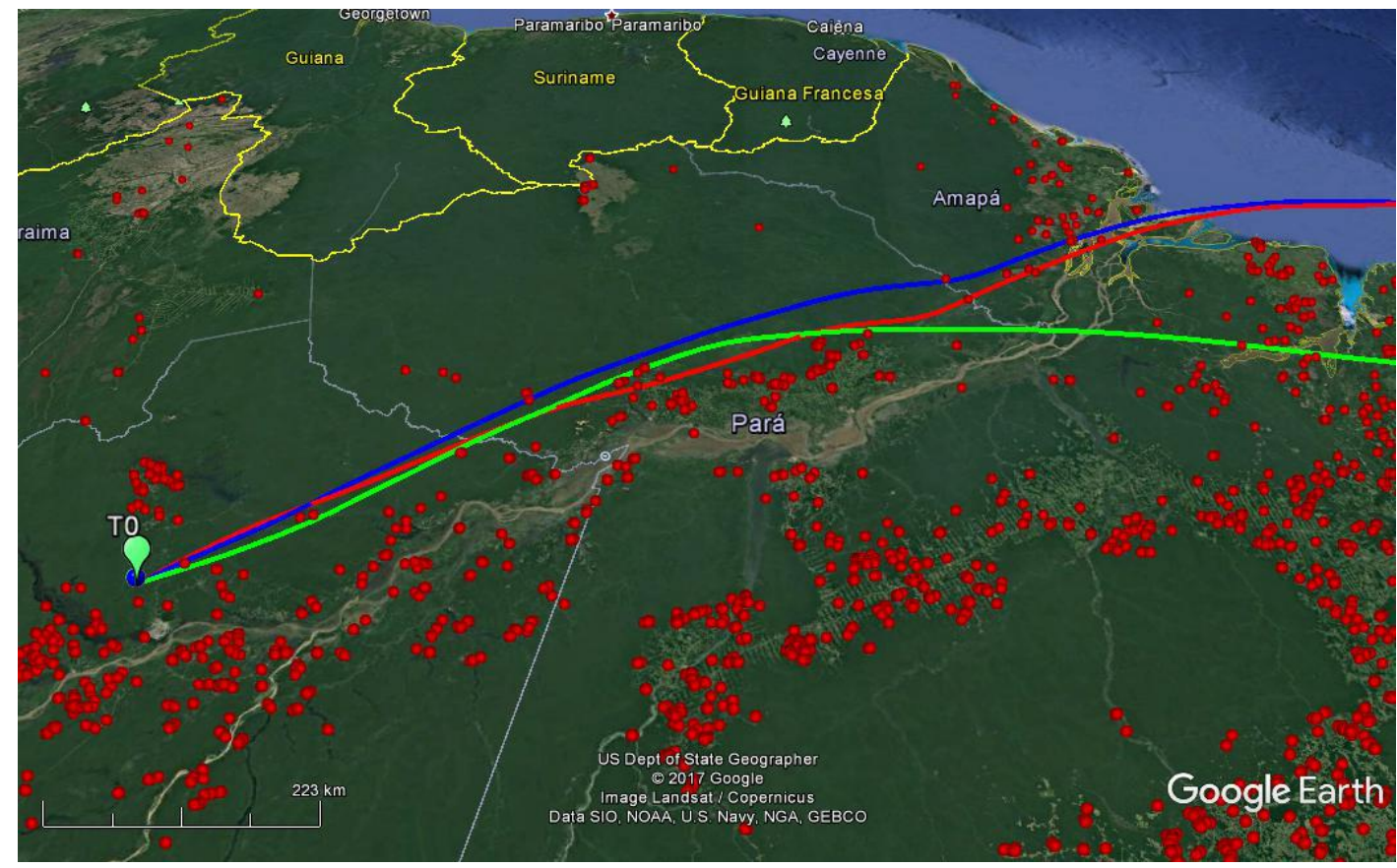

Para comparação, pode-se verificar os focos de queimada acumulados por mês para os meses de setembro e dezembro de 2014 e março e maio de 2015, que apontam a influência das queimadas no aumento da concentração de BCe, conforme já verificado em trabalho anterior (PAULIQUEVIS et al., 2012). 
Figura 44: focos de queimada acumulados por mês com o sítio ZF2 em destaque.
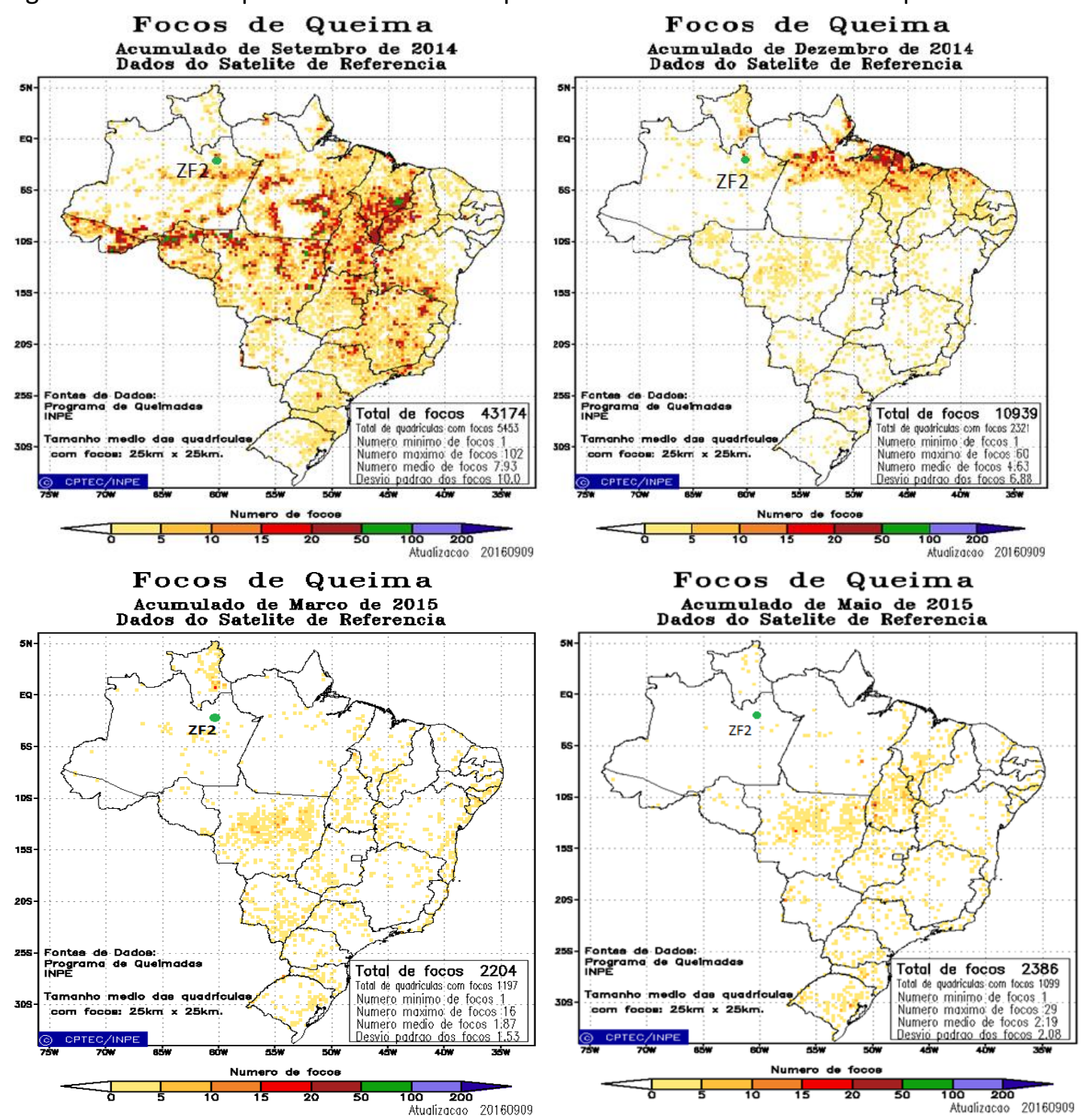

Fonte: Portal Programa Queimadas (INPE). Disponível em: https://queimadas.dgi.inpe.br/queimadas/outros-produtos/mapas-mensais-filmes. Acessado em maio de 2017.

As concentrações médias de $\mathrm{BCe}$ na moda fina e grossa e a razão $\mathrm{BCe}_{\text {total }} / \mathrm{MP10}$ estão sintetizadas na Tabela 6 para os três sítios. Verifica-se que o TIWA apresenta a maior concentração de BCe na moda fina durante a estação seca, com $1920 \mathrm{ng} / \mathrm{m}^{3}$ deste componente. Na moda grossa as concentrações encontradas no TIWA também são as maiores. A influência de queimadas durante a estação seca explica a maior concentração de BCe em todos os sítios na estação seca. RIZZO et al. (2013) estimou através de medidas com aetalômetro que a concentração de BCe no MP10 varie entre 5 e $10 \%$ do MP total no sítio ZF2 em medidas entre 2008 e 2011, compatível com a razão BCe/MP10 encontrada durante a estação seca no mesmo sítio, $4,3 \pm 1,6 \%$. 
Tabela 6: síntese das concentrações de BCe na moda fina e grossa e a razão entre BCe/MP10 obtidos durante o experimento GoAmazon2014/15.

\begin{tabular}{|c|c|c|c|c|c|c|c|c|c|c|}
\hline \multicolumn{11}{|c|}{ Tabela síntese das concentrações de BCe nos sítios do GoAmazon2014/2015 } \\
\hline \multirow{2}{*}{ Sítio } & \multirow{2}{*}{ Estação } & \multicolumn{9}{|c|}{ Valor médio } \\
\hline & & \multicolumn{3}{|c|}{ Fração Fina $\left(\mathrm{ng} / \mathrm{m}^{3}\right)$} & \multicolumn{3}{|c|}{ Fração Grossa (ng/m³) } & \multicolumn{3}{|c|}{ Razão BCe/MP10 (\%) } \\
\hline \multirow{2}{*}{ ZF2 } & Seca & 448 & \pm & 245 & 42 & \pm & 11 & 4,3 & \pm & 1,6 \\
\hline & Chuvosa & 190 & \pm & 240 & 35 & \pm & 13 & 2,7 & \pm & 1,6 \\
\hline \multirow{2}{*}{ TIWA } & Seca & 1920 & \pm & 653 & 120 & \pm & 73 & 7,7 & \pm & 1,9 \\
\hline & Chuvosa & 673 & \pm & 254 & 98 & \pm & 43 & 7,6 & \pm & 2,0 \\
\hline \multirow{2}{*}{ Manacapuru } & Seca & 316 & \pm & 150 & 23 & \pm & 12 & 4,9 & \pm & 1,7 \\
\hline & Chuvosa & 178 & \pm & 124 & 21 & \pm & 14 & 44 & \pm & 13 \\
\hline
\end{tabular}

\subsection{Composição elementar do aerossol na Amazônia Central}

Através da análise de fluorescência de Raios $X$ aplicada aos filtros de policarbonato, obteve-se a composição elementar do material particulado nos três sítios para as frações fina e grossa. Nesta seção os resultados são apresentados separados pela fração fina e grossa e elementos majoritários e minoritários com a concentração média de cada elemento durante todo o período de coleta do GoAmazon2014/15. Detalhes como a concentração, desvio padrão e número de amostras medidas separadas por estação chuvosa e seca podem ser encontrados no Apêndice A.

A Figura 45 mostra a concentração média dos elementos majoritários na fração fina nos três sítios. Os elementos majoritários com maiores concentrações na fração fina são Al, $\mathrm{Si}, \mathrm{Ca}, \mathrm{Fe}$ e $\mathrm{Na}$, S e K, elementos associados principalmente à poeira do solo e queima de biomassa, respectivamente. 
Figura 45: concentração média dos elementos majoritários da fração fina nos três sítios durante o período do projeto GoAmazon2014/15. A concentração dos elementos marcados com asterisco foram multiplicadas por um fator 10 para melhor visualização.

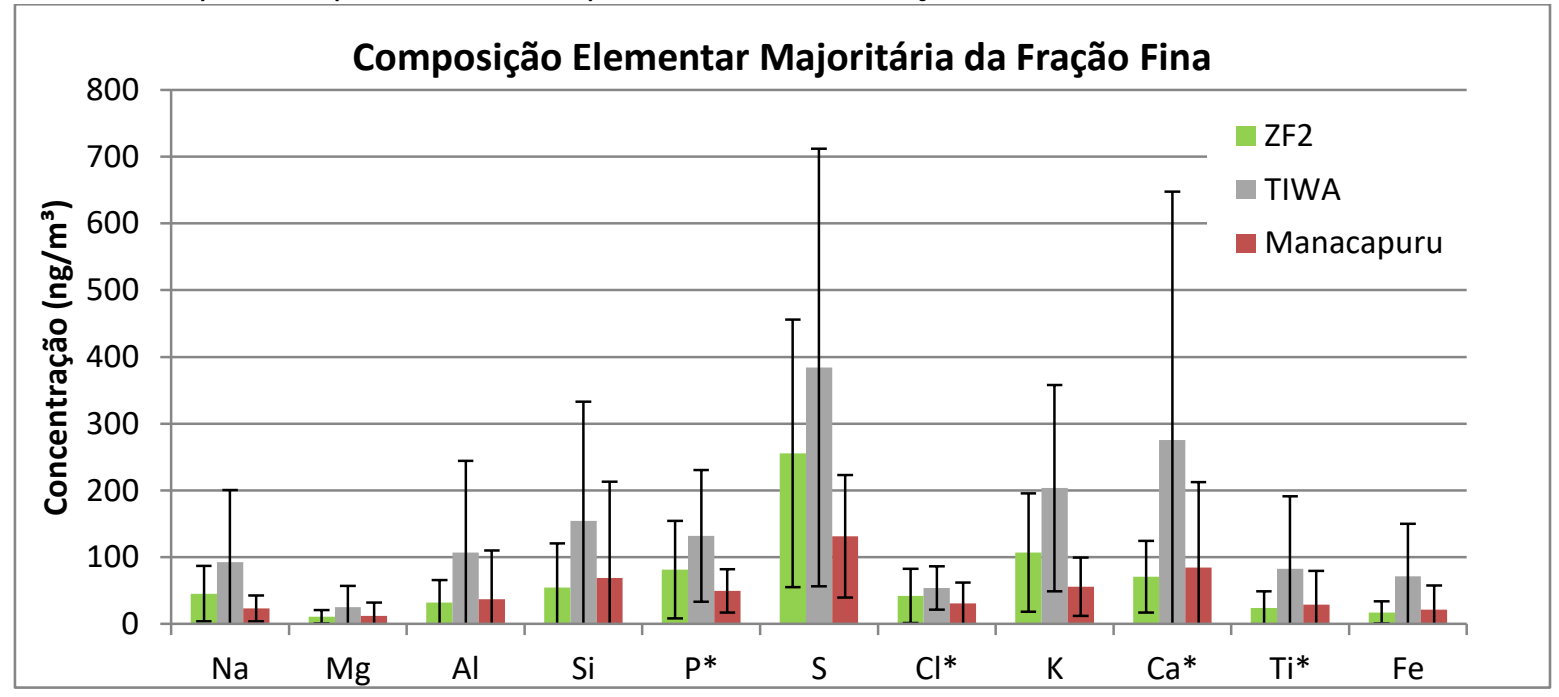

Os elementos com menores concentrações médias estão expostos na Figura 46. Este gráfico apresenta alguns elementos relacionados à emissão biogênica e de queimada como $\mathrm{Zn}$, Se e $\mathrm{Br}$, elementos de solo como $\mathrm{Ti}, \mathrm{Mn}$ e processos industriais/veicular como o $\mathrm{Ti}, \mathrm{Cr}$, $\mathrm{Mn}, \mathrm{Ni}, \mathrm{Cu}, \mathrm{Zn}, \mathrm{Cd}, \mathrm{Sb}$ e $\mathrm{Pb}$.

Figura 46: concentração média dos elementos minoritários da fração fina nos três sítios durante o período do projeto GoAmazon2014/15.

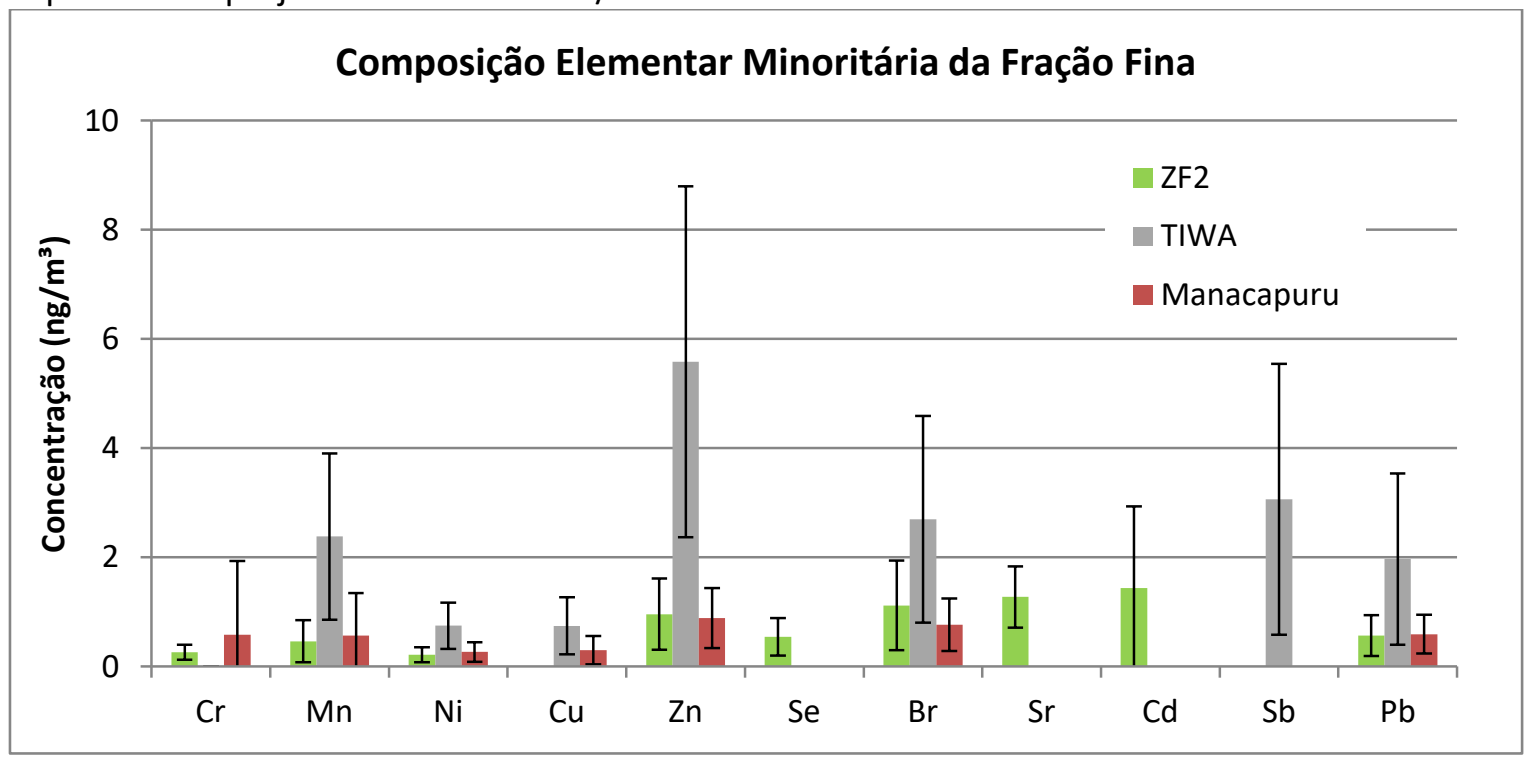

É possível notar que o sítio TIWA apresentou concentrações maiores que dos outros sítios, especialmente para elementos relacionados a processos industriais/veiculares como $\mathrm{Ti}, \mathrm{Mn}, \mathrm{Fe}, \mathrm{Ni}, \mathrm{Cu}, \mathrm{Zn}$ e $\mathrm{Pb}$. Ao analisar a correlação da série temporal de concentrações (Apêndice A), este grupo de elementos apresentou coeficiente de correlação de Pearson maior que $0,5(p>0,05)$ no TIWA, enquanto que nos outros sítios esse coeficiente apresentou 
valores menores. Para este mesmo grupo de elementos, a razão entre a concentração média do TIWA em relação ao sítio ZF2 varia entre 3,4 ( $\mathrm{Al}$, $\mathrm{Ti}$ e $\mathrm{Pb})$ e 5,8 (Zn). Enquanto isso elementos emitidos principalmente por fontes regionais como a marinha (emissora de $\mathrm{Cl}$ ) e, queima de biomassa junto com biogênica (emissora de $\mathrm{P}, \mathrm{S}$ e K) mostraram uma razão entre concentrações mais próximas da unidade, variando de 1,3 (Cl) até 1,9 (K). Outro fato que chama a atenção é a presença de Sb no TIWA, enquanto que nos outros sítios não foi possível medi-lo. Este elemento é utilizado sob a forma de $\mathrm{Sb}_{2} \mathrm{~S}_{3}$ nos freios de automóveis (GARG et al., 2000).

A Figura 47 mostra a concentração média dos elementos majoritários na fração grossa nos três sítios que são $\mathrm{Al}, \mathrm{Si}, \mathrm{Ca}, \mathrm{Fe}$ e $\mathrm{Na}, \mathrm{S}, \mathrm{K}$ e $\mathrm{P}$, elementos associados à poeira mineral do solo e processos de queima de biomassa/processos biogênicos, respectivamente (PAULIQUEVIS et al., 2012).

Figura 47: concentração média dos elementos majoritários da fração grossa nos três sítios durante o período do projeto GoAmazon2014/15.

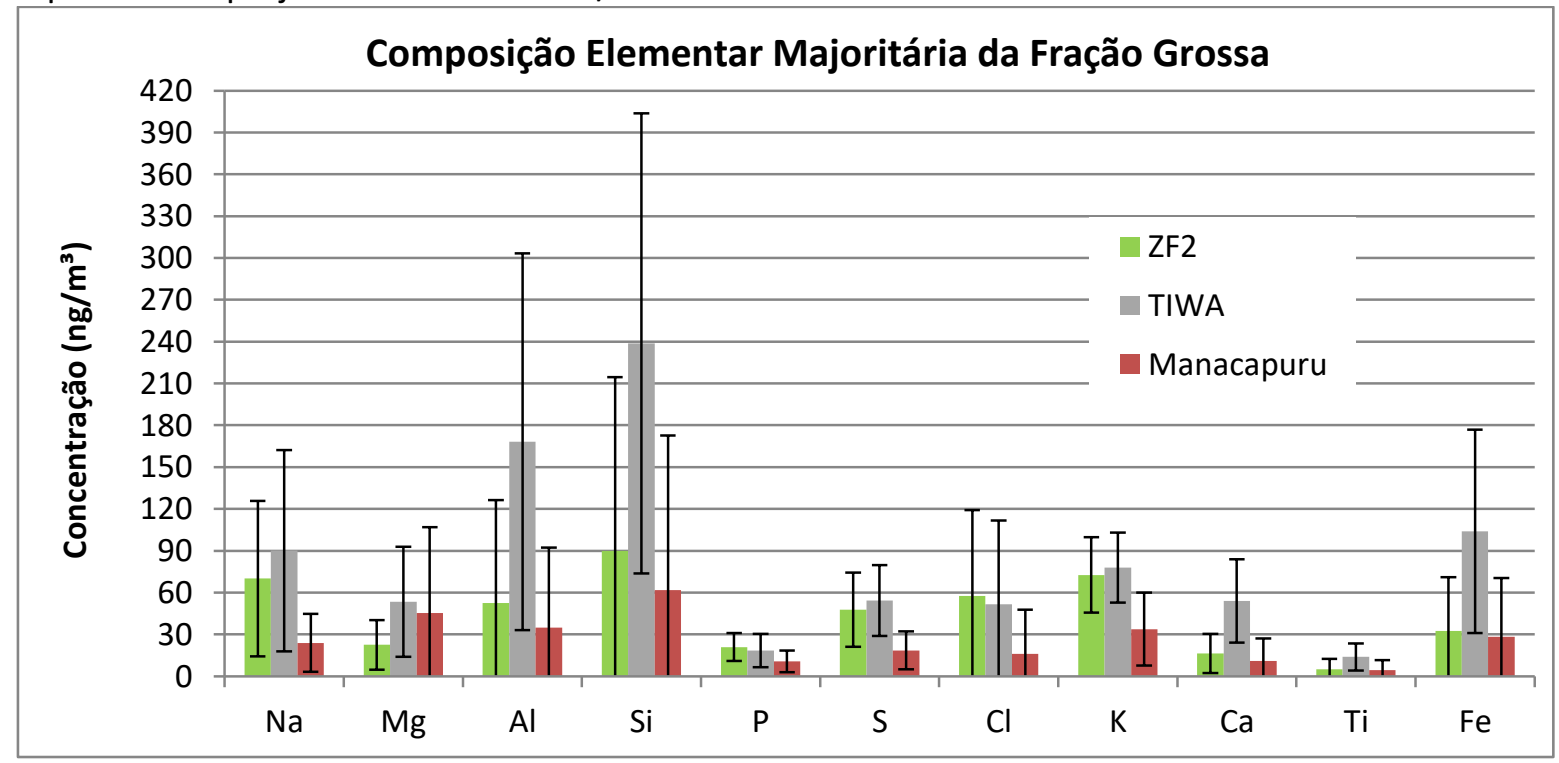

A Figura 48 mostra os elementos com menor concentração na fração grossa. O Zn e $\mathrm{Mn}$, elementos que se relacionam à poeira do solo se destacam com sua concentração elevada em relação aos demais elementos em todos os sítios. 
Figura 48: concentração média dos elementos minoritários da fração grossa nos três sítios durante o período do projeto GoAmazon2014/15.

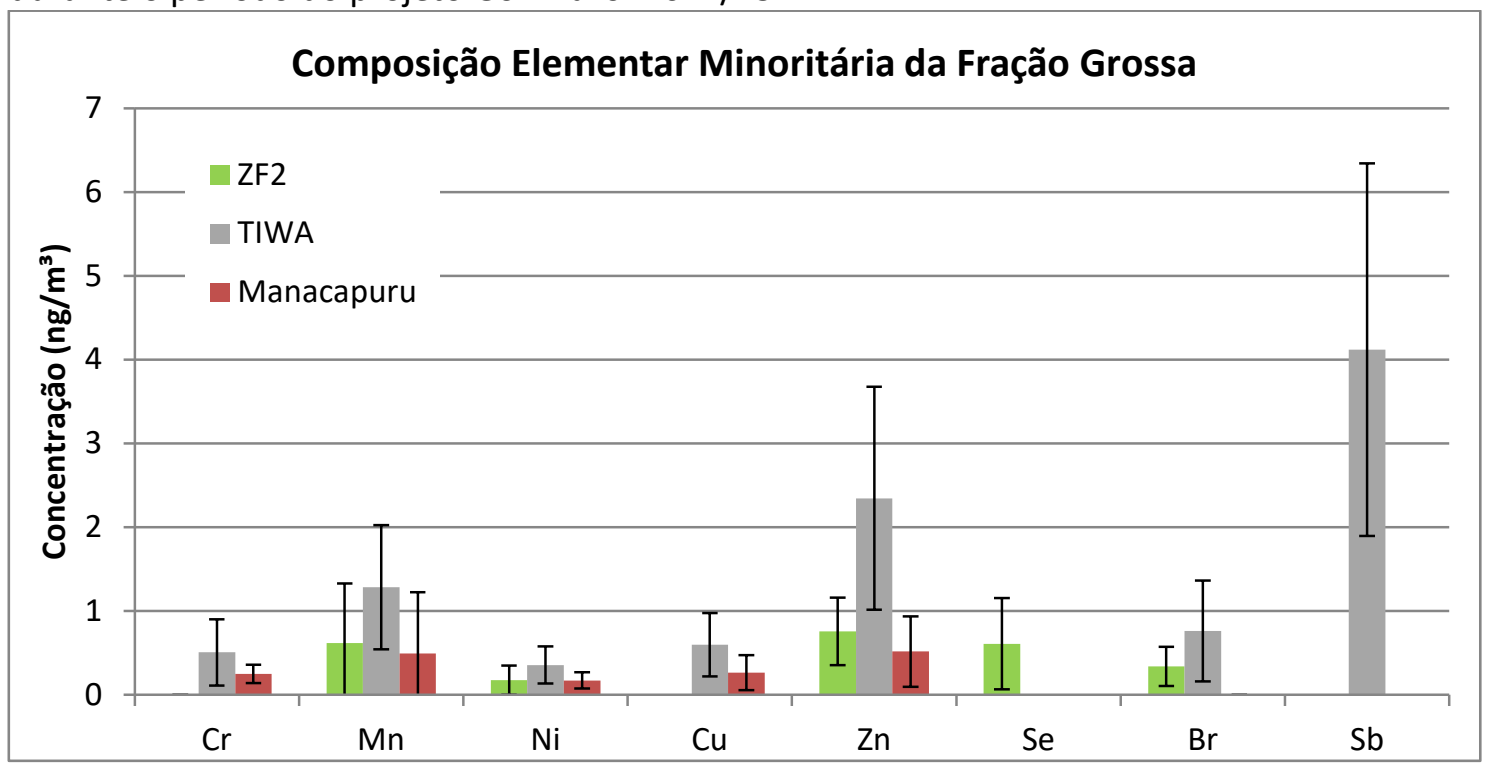

Assim como para o MPF, é possível notar que as concentrações médias encontradas no TIWA para a fração grossa são maiores que as encontradas na ZF2. Elementos associados ao solo como $\mathrm{Mg}$, $\mathrm{Al}, \mathrm{Si}, \mathrm{Ca}, \mathrm{Ti}, \mathrm{Fe}, \mathrm{Ni}$ e $\mathrm{Zn}$ apresentam razão entre a concentração média do TIWA e ZF2 entre 2,0 (Ni) e 3,3 (Ca). O P, ligado ao aerossol biogênico na moda grossa, é o único elemento que ocorre com menor concentração no sítio TIWA.

\subsection{Análise do aerossol carbonáceo na Amazônia Central}

Nesta seção os resultados de carbono orgânico (OC) e carbono elementar (EC) obtidos através da análise termo óptico estão expostos. Os resultados foram obtidos através da aplicação do protocolo EUSAAR_2 (CAVALLI et al., 2010) nos filtros de quartzo.

\subsubsection{Série temporal dos aerossóis carbonáceos}

A coleta de material carbonáceo pode sofrer artefatos positivos e negativos. Os positivos aumentam a concentração, pois compostos voláteis gasosos podem adsorver no filtro ou no material particulado, aumentando a concentração medida. Artefatos negativos podem ocorrer pela evaporação de compostos no aerossol coletado. A coleta de parte dos filtros nos sítios ZF2 e Manacapuru foi realizada através do método QBQ a fim de estimar a concentração de OC gasoso que adere ao filtro de quartzo. Verificou-se que nestes sítios a concentração de OC dos filtros de backup é muitas vezes menor que o limite de detecção de $0,2 \mu \mathrm{gC} / \mathrm{m}^{2}$. Observou-se que dos 36 filtros coletados por este método na ZF2, apenas 12 apresentaram resultados acima do limite de detecção, e em Manacapuru, dos 44 filtros, 24 
apresentaram quantidades de carbono mensuráveis através da técnica termo-óptica, de forma que a média de artefato de OC medido para cada sítio, foi de $0,07 \mu \mathrm{g} / \mathrm{m}^{3}$ na ZF2 - em média $4 \%$ do OC do filtro superior -, ante $0,34 \mu \mathrm{g} / \mathrm{m}^{3}$ em Manacapuru, que representa, em média, $6 \%$ da concentração de OC do filtro superior. Ambos os percentuais de artefato

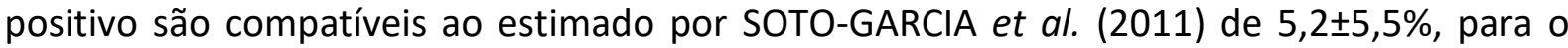
período de seca.

Por se tratarem de valores baixos e não haver medidas do backup filter em todas as amostragens, os valores apresentados neste capítulo são referentes aos medidos no filtro superior, sem o decréscimo de qualquer artefato positivo ou negativo. A série temporal das componentes carbonáceas de carbono medidas na Amazônia Central são apresentadas nas figuras abaixo, assim como a razão OC/EC. A maior quantidade de filtros foi coletada durante a estação seca de 2014, período do IOP2 do GoAmazon2014/15 (MARTIN et al., 2016). É possível observar que a fração carbonácea majoritária encontrada na Amazônia Central é de carbono orgânico, tanto na estação seca quanto na chuvosa.

As séries temporais de OC e EC presentes nas Figuras 50 a 52, apresentaram concentrações maiores durante a estação seca, resultado das emissões de queimadas, tanto de VOCs, que formam SOA, quando EC. A influência da pluma da cidade de Manaus na concentração de $\mathrm{OC}$ pode ser verificada ao notarmos que mesmo na estação chuvosa os sítios vento abaixo da cidade apresentam maiores concentrações de OC do que a ZF2.

Figura 49: série temporal de OC e EC no MPF da ZF2 e a relação OC/EC em vermelho.

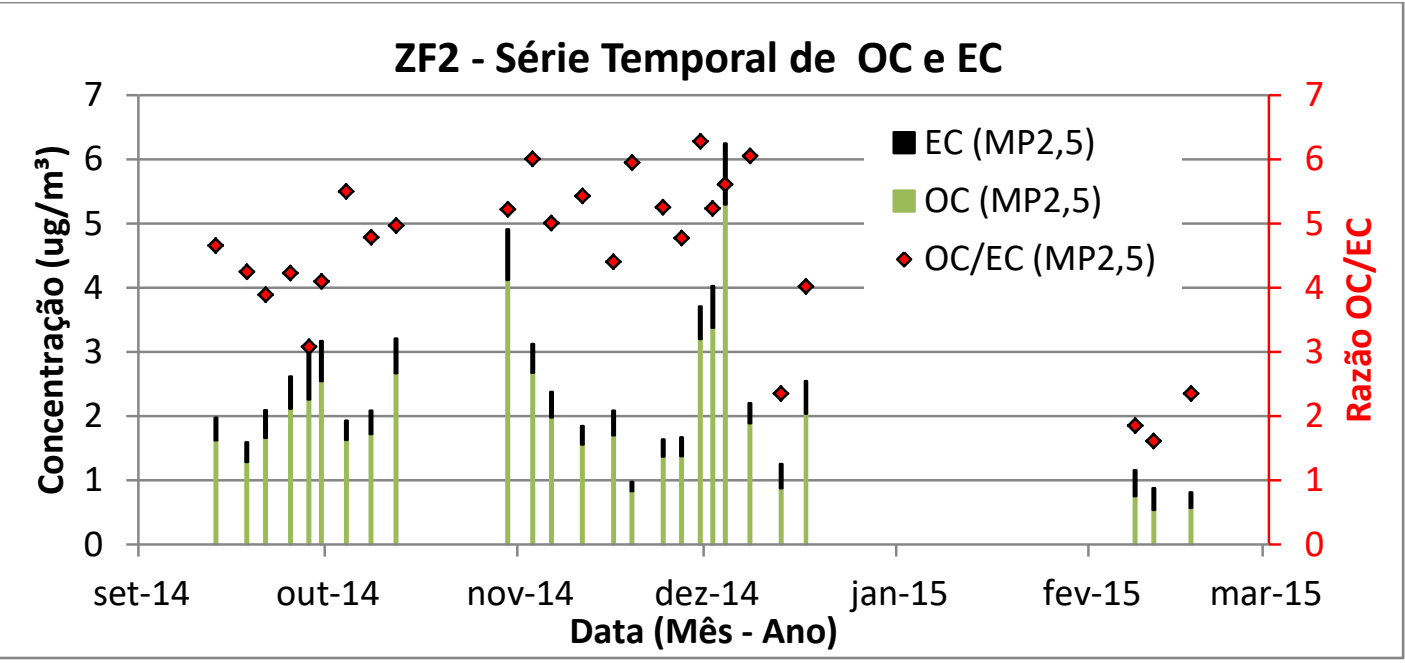


Figura 50: série temporal de OC e EC no MPF do sítio TIWA e a relação OC/EC em vermelho.

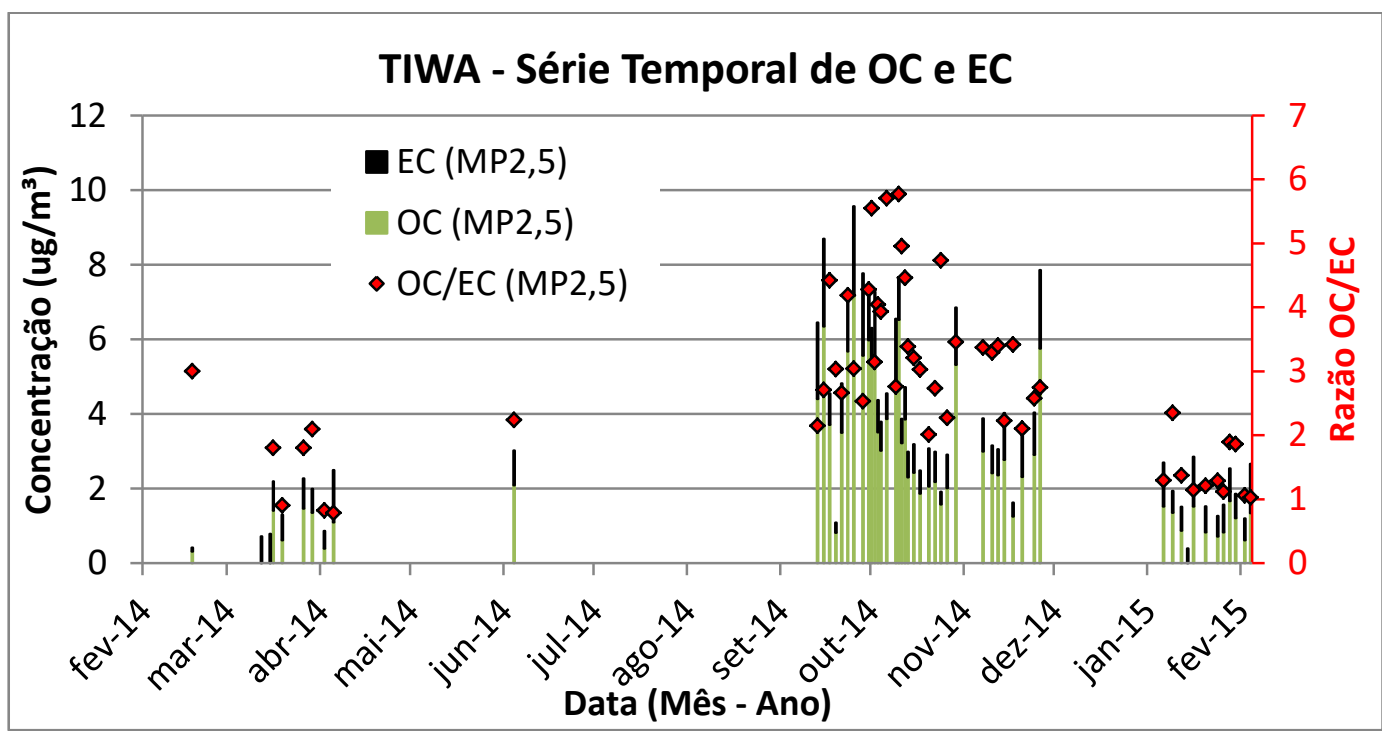

Figura 51: série temporal de OC e EC no MPF de Manacapuru e a relação OC/EC em vermelho.

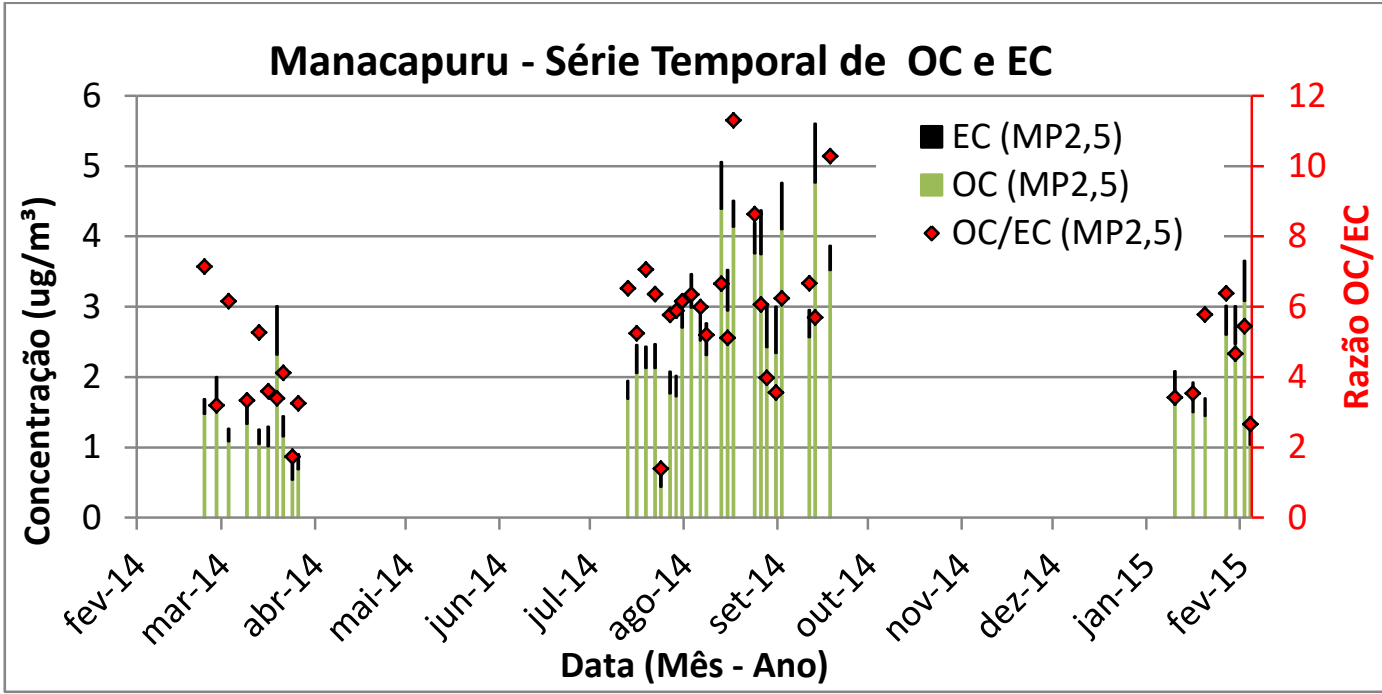

Tabela 7: concentrações médias de OC, EC, razão OC/EC e o número de amostras (N) para os sítios ZF2, Manacapuru e TIWA para a estação seca de 2014.

\begin{tabular}{ccccccccccc}
\hline \multicolumn{10}{c}{ Média de OC e EC para a estação seca de 2014} \\
Sítio & \multicolumn{1}{c}{ OC $\left(\mathrm{ug} / \mathrm{m}^{3}\right)$} & EC $\left(\mathrm{ug} / \mathrm{m}^{3}\right)$ & \multicolumn{3}{c}{ OC/EC } & $\mathrm{N}$ \\
\hline ZF2 & 2,04 & \pm & 0,78 & 0,40 & \pm & 0,18 & 5,6 & \pm & 2,7 & 20 \\
TIWA & 3,64 & \pm & 1,70 & 1,12 & \pm & 0,57 & 3,4 & \pm & 1,0 & 35 \\
Manacapuru & 3,55 & \pm & 3,26 & 0,48 & \pm & 0,23 & 6,9 & \pm & 3,5 & 25 \\
\hline
\end{tabular}

Dentre os três sítios, a maior concentração média de OC e EC é encontrada no TIWA, com média de $3,6 \pm 1,7 \mu \mathrm{g} / \mathrm{m}^{3}$ e $1,1 \pm 0,6 \mu \mathrm{g} / \mathrm{m}^{3}$, respectivamente conforme Tabela 7 . Este valor é semelhante ao encontrado por MONTEIRO DOS SANTOS et al. (2016) na cidade de São Paulo durante o verão: $3,1 \pm 1,5 \mu \mathrm{g} / \mathrm{m}^{3}$ e $1,8 \pm 0,9 \mu \mathrm{g} / \mathrm{m}^{3}$, para OC e EC. As medidas de OC e EC 
da ZF2 também apresentam grande semelhança com as medidas por GILARDONI et al. (2011) obtidas no mesmo local em 2008 na moda fina: 2,3 $22,0 \mu \mathrm{g} / \mathrm{m}^{3}$ e $0,24 \pm 0,16 \mu \mathrm{g} / \mathrm{m}^{3}$ para OC e EC, respectivamente, durante a estação seca.

BRITO et al. (2013) através de estudos em túneis verificou que uma significativa parte do MPF emitido por automóveis corresponde a matéria orgânica (42\% para veículos leves e $39 \%$ para veículos pesados) e carbono elementar (17\% para veículos leves e $52 \%$ para veículos pesados) o que pode explicar uma parte da maior concentração média de OC e EC no sítio TIWA. Por sua vez, Manacapuru apresenta concentração de EC semelhante ao da ZF2, mas com maior valor de OC. A menor razão OC/EC encontrada foi no TIWA, com 3,4. Este valor é ainda maior que o encontrado em cidades como São Paulo, onde esta razão chega a ser menor que a unidade (MONTEIRO DOS SANTOS et al., 2016). Tal fato pode ser explicado devido à disponibilidade de VOCs emitidos pela vegetação ao redor da cidade de Manaus que são oxidados pela pluma gerada na cidade transformando-se em SOA. Este efeito também é notado na razão OC/EC de Manacapuru.

\subsubsection{Análise da fração orgânica dos termogramas}

É possível verificar a volatilidade dos aerossóis orgânicos através da quantidade de carbono medida em cada um dos estágios de temperatura contidos no protocolo EUSAAR_2 aplicado à técnica termo-óptica. O EUSAAR_2 contempla quatro estágios de temperatura durante a primeira etapa (associada à fração orgânica de carbono), com atmosfera de He. A Tabela 8 mostra as concentrações médias de carbono em cada estágio de temperatura por sítio durante a estação seca de 2014. O carbono pirolítico (PC, do inglês Pyrolytic Carbon) também está incluso por se tratar, a princípio, de carbono orgânico.

Tabela 8: concentrações de carbono obtidos durante as etapas com atmosfera inerte do método termo-óptico e carbono pirolítico.

\begin{tabular}{|c|c|c|c|c|c|c|c|c|c|}
\hline \multicolumn{10}{|c|}{ Fração de Carbono Orgânico por Espécie } \\
\hline \multirow{3}{*}{$\begin{array}{c}\text { Espécie } \\
\text { OC1 }\end{array}$} & \multirow{2}{*}{\multicolumn{3}{|c|}{$\frac{\mathrm{ZF} 2}{\text { Conc. }\left(\mu \mathrm{g} / \mathrm{m}^{3}\right)}$}} & \multirow{2}{*}{\multicolumn{3}{|c|}{$\frac{\text { TIWA }}{\text { Conc. }\left(\mu \mathrm{g} / \mathrm{m}^{3}\right)}$}} & \multirow{2}{*}{\multicolumn{3}{|c|}{$\frac{\text { Manacapuru }}{\text { Conc. }\left(\mu \mathrm{g} / \mathrm{m}^{3}\right)}$}} \\
\hline & & & & & & & & & \\
\hline & 0,09 & \pm & 0,07 & 0,07 & \pm & 0,17 & 0,15 & \pm & 0,18 \\
\hline OC2 & 0,54 & \pm & 0,20 & 1,00 & \pm & 0,44 & 0,91 & \pm & 0,77 \\
\hline OC3 & 0,46 & \pm & 0,19 & 0,82 & \pm & 0,33 & 0,93 & \pm & 0,65 \\
\hline OC4 & 0,19 & \pm & 0,07 & 0,42 & \pm & 0,18 & 0,37 & \pm & 0,16 \\
\hline PC & 0,77 & \pm & 0,32 & 1,32 & \pm & 0,73 & 1,20 & \pm & 1,55 \\
\hline
\end{tabular}


Verifica-se que o PC, apresenta a maior concentração em todos os sítios, sendo responsável por 33,7\% (Manacapuru) a 37,5\% (ZF2) das concentrações de carbono orgânico. Segundo KHAN et al. (2012) a alta concentração de PC pode ser explicada devido à presença de Brown Carbon originário de processos de queimada que é facilmente pirolisado durante a análise termo-óptica. Através da análise fatorial de termogramas de aerossol coletado na Amazônia, GILARDONI et al. (2011) encontrou um fator com alta quantidade de PC, semelhantes a termogramas obtidos em locais fortemente impactados por queimadas. $\mathrm{O}$ OC1 aparece em todos os sítios como a espécie com menor concentração, variando entre 4,5\% (ZF2) e 2,0\% (TIWA) da concentração de OC. Em trabalhos anteriores, verificou-se que esta espécie de carbono está associada a processos de queimada vegetal (CHOW et al., 2004; GILARDONI et al., 2011; LIU et al., 2006) apesar de também poder estar associado a processos de combustão de motores. O OC2 aparece como a segunda espécie mais presente nos sítios ZF2 e TIWA, participando de 25,6\% (Manacapuru) a 27,6\% (TIWA) da concentração média de OC. Segundo GILARDONI et al. (2011), a assinatura dessa espécie em conjunto com porções de OC1 e OC3 apresentou correlação com perfis de SOA medidos em laboratório. O OC4 apresenta concentrações que variam entre 9,1\% (ZF2) a 11,5\% (TIWA) da concentração média de OC.

\subsection{Reconstituição da massa gravimétrica}

Com os resultados expostos nas seções anteriores (elementos traços, BC e fração orgânica) foi possível realizar a reconstituição da massa gravimétrica a partir de seis tipos de aerossol: BCe, Elementos traços, Solo, Sal Marinho, Sulfato, e Matéria Orgânica. A reconstrução dos elementos foi realizada de acordo com procedimentos descritos por MAENHAUT et al. (2005), onde através de cálculos de fração elementar, busca-se obter a concentração de compostos de acordo com a forma mais comum encontrada na atmosfera. O cálculo da matéria orgânica através do carbono orgânico foi realizado de acordo com constantes de conversão que visam quantificar o tanto de átomos de, por exemplo, oxigênio, hidrogênio e nitrogênio que estão associados ao carbono medido para aquele tipo de matéria orgânica. Para a ZF2 foi utilizado um fator de conversão de 1,7 (CHEN et al., 2009; GILARDONI et al., 2011), enquanto que para o TIWA foi utilizado o fator 1,6 encontrado na seção 4.1.4. Por conta dos problemas encontrados em Manacapuru não foi realizado o balanço de massa para este sítio. 
A Tabela 9 mostra o percentual de cada tipo de aerossol em relação à concentração obtida por gravimetria para o MPF da ZF2. Nota-se que em ambas as estações o principal componente é a matéria orgânica, seguida do sulfato e outros elementos em menores concentrações. As concentrações de matéria orgânica, sulfato e solo durante a estação chuvosa de $1,05 \pm 0,16 \mu \mathrm{g} / \mathrm{m}^{3}, 0,28 \pm 0,18 \mu \mathrm{g} / \mathrm{m}^{3}$ e $0,37 \pm 0,38 \mu \mathrm{g} / \mathrm{m}^{3}$ respectivamente, são compatíveis com as obtidas por CHEN et al. (2009) e FUZZI et al. (2007) e simulação realizada por WANG et al. (2016) em regiões pristinas da Amazônia Central. Comparando a estação seca com a chuvosa, verifica-se que o aerossol de solo cresce em participação na composição do aerossol de 3,5\% $\left(187 \mathrm{ng} / \mathrm{m}^{3}\right)$ para $23,1 \%\left(367 \mathrm{ng} / \mathrm{m}^{3}\right)$, respectivamente. Este aumento na concentração de aerossol de solo pode ser explicado devido ao transporte de longa distância de poeira do Saara que ocorre na estação chuvosa (BAARS et al., 2011; BENAMI et al., 2010; SWAP et al., 1992). A matéria orgânica foi o principal constituinte do MPF, com mais de $50 \%$ da massa, resultado este que concorda com o trabalho de GILARDONI et al. (2011). Verifica-se que em ambas as estações a massa obtida a partir da reconstituição é compatível com cerca de $100 \%$ da massa gravimétrica.

Tabela 9: reconstrução de massa do MPF da ZF2 expostas em percentual da concentração gravimétrica média. $O$ valor médio de MPF foi de $5,5 \mu \mathrm{g} / \mathrm{m}^{3}$ e $2,2 \mu \mathrm{g} / \mathrm{m}^{3}$ durante a estação seca e chuvosa, respectivamente. Soma não inclui o percentual de matéria orgânica, já que este não foi necessariamente medido em paralelo com os outros tipos de aerossóis.

\begin{tabular}{ccccccccc}
\hline \multicolumn{3}{c}{ ZF2 - Reconstrução de Massa do Material Particulado Fino } \\
\hline \multirow{2}{*}{ Componente } & \multicolumn{7}{c}{ Estação Seca } & \multicolumn{5}{c}{ Estação chuvosa } \\
\cline { 2 - 8 } & \multicolumn{2}{c}{$\%$ da gravimetria } & $\mathrm{N}$ & $\%$ da gravimetria & $\mathrm{N}$ \\
\hline BCe & $8,0 \%$ & \pm & $1,7 \%$ & 40 & $7,8 \%$ & \pm & $3,8 \%$ & 32 \\
Elementos traço & $3,0 \%$ & \pm & $0,6 \%$ & 40 & $3,2 \%$ & \pm & $1,3 \%$ & 32 \\
Solo & $3,5 \%$ & \pm & $2,1 \%$ & 40 & $23,1 \%$ & \pm & $20,1 \%$ & 32 \\
Sal Marinho & $1,6 \%$ & \pm & $0,7 \%$ & 40 & $1,4 \%$ & \pm & $1,1 \%$ & 32 \\
Sulfato & $18,4 \%$ & \pm & $3,3 \%$ & 40 & $21,5 \%$ & \pm & $8,0 \%$ & 32 \\
Soma* & $34,4 \%$ & \pm & $5,0 \%$ & 40 & $56,9 \%$ & \pm & $25,4 \%$ & 32 \\
Matéria orgânica & $54,6 \%$ & \pm & $13,0 \%$ & 18 & $57,9 \%$ & \pm & $8,9 \%$ & 8 \\
\hline
\end{tabular}

*Sem incluir a matéria orgânica

A reconstrução de massa do MPF do sítio TIWA pode ser observada na Tabela 10. Verifica-se grande contribuição da matéria orgânica para a constituição do aerossol neste sítio, seguido de $\mathrm{BCe}$, aerossóis de solo e sulfato, de forma que sal marinho junto com outros elementos traço constituem uma fração minoritária do aerossol neste sítio. O percentual de contribuição do BCe para o MPF, de $12,7 \pm 3,5 \%$ durante estação seca e $19,3 \pm 5,9 \%$ durante 
estação chuvosa fica abaixo do encontrado em São Paulo por JUNIOR (2015) e, comparandoo com outras capitais brasileiras, este percentual do MPF fica próximo do de cidades como Recife e Rio de Janeiro. (DE FATIMA ANDRADE et al., 2012). A concentração média de matéria orgânica neste sítio durante a estação seca é de $5,97 \pm 2,36 \mu \mathrm{g} / \mathrm{m}^{3}$ superior ao encontrado na ZF2 $\left(3,45 \pm 1,18 \mu \mathrm{g} / \mathrm{m}^{3}\right)$ e, aerossóis do tipo poeira mineral do solo também apresentam valores médios superiores aos verificados na ZF2. De modo geral, a soma da concentração de todos esses elementos (incluindo aerossóis do tipo matéria orgânica) é compatível com aquela medida através da gravimetria.

Tabela 10: reconstrução de massa do MPF do TIWA exposta em percentual da concentração gravimétrica média. $O$ valor médio de MPF foi de $11,0 \mu \mathrm{g} / \mathrm{m}^{3}$ e $3,7 \mu \mathrm{g} / \mathrm{m}^{3}$ durante a estação seca e chuvosa, respectivamente. Soma não inclui o percentual de matéria orgânica, já que este não foi necessariamente medido em paralelo com os outros tipos de aerossóis.

\begin{tabular}{|c|c|c|c|c|c|c|c|c|}
\hline \multicolumn{9}{|c|}{ TIWA - Reconstrução de Massa do Material Particulado Fino } \\
\hline \multirow{3}{*}{$\begin{array}{c}\text { Componente } \\
\mathrm{BCe}\end{array}$} & \multicolumn{4}{|c|}{ Estação Seca } & \multicolumn{4}{|c|}{ Estação chuvosa } \\
\hline & \multicolumn{3}{|c|}{$\%$ da gravimetria } & \multirow{2}{*}{$\frac{N}{45}$} & \multicolumn{3}{|c|}{$\%$ da gravimetria } & \multirow{2}{*}{$\frac{N}{27}$} \\
\hline & $12,7 \%$ & \pm & $3,5 \%$ & & $19,3 \%$ & \pm & $5,9 \%$ & \\
\hline Elementos traço & $2,8 \%$ & \pm & $0,4 \%$ & 45 & $3,4 \%$ & \pm & $0,6 \%$ & 27 \\
\hline Solo & $7,5 \%$ & \pm & $4,5 \%$ & 45 & $17,3 \%$ & \pm & $7,7 \%$ & 27 \\
\hline Sal Marinho & $1,7 \%$ & \pm & $0,7 \%$ & 45 & $1,7 \%$ & \pm & $0,4 \%$ & 27 \\
\hline Sulfato & $15,5 \%$ & \pm & $2,6 \%$ & 45 & $14,5 \%$ & \pm & $2,4 \%$ & 27 \\
\hline Soma* & $40,3 \%$ & \pm & $5,8 \%$ & 45 & $56,2 \%$ & \pm & $10,1 \%$ & 27 \\
\hline Matéria Orgânica & $79,8 \%$ & \pm & $37,5 \%$ & 35 & $49,2 \%$ & \pm & $22,9 \%$ & 17 \\
\hline
\end{tabular}

\subsection{Identificação das fontes de material particulado utilizando a ACPA}

Nesta secção os resultados de quantificação das fontes obtidas através do método de Análise de Componentes Principais Absoluta (ACPA) estão expostos de forma a sintetizar a concentração média de elemento por fator e o nível de explicação do modelo. A obtenção da concentração média dos elementos foi realizada através de regressões entre os elementos e os Absolute Principal Factor Scores (APFS) com nível de significância de igual ou superior a 95\%. É importante destacar que também foram realizadas regressões entre os APFSs e elementos que não participaram da ACPA. Esses elementos foram chamados de elementos complementares. A exposição segue a ordem de material particulado fino e grosso por sítio: ZF2, TIWA e Manacapuru. Vale ressaltar que os resultados aqui expostos são os obtidos após rotação ortogonal Varimax no procedimento de ACPA. 


\subsubsection{ACPA aplicada ao material particulado fino da ZF2}

A ACPA aplicada à série temporal de filtros da ZF2 foi capaz de explicar $94,1 \%$ da variabilidade das concentrações deste sítio através de três fatores principais: aerossol relacionado ao processo de queimadas, poeira mineral do solo e aerossol marinho, como pode ser visto na Tabela 11. Desta forma, a aplicação da ACPA nos elementos do MPF da ZF2 apresentou comunalidades próximas da unidade e percentuais das concentrações explicadas próximas de $100 \%$ da massa para todos os elementos.

Tabela 11: resultados da ACPA aplicada ao MPF da ZF2 coletado durante o GoAmazon2014/15 após rotação Varimax. A tabela mostra a concentração média de cada elemento por fator e o percentual que representa em relação à concentração média do mesmo. As duas últimas linhas mostram o autovalor e a variância associada a cada fator.

\begin{tabular}{|c|c|c|c|c|c|c|c|c|}
\hline \multicolumn{9}{|c|}{ ACPA - ZF2 - Material Particulado Fino } \\
\hline & \multicolumn{2}{|c|}{ Queimada } & \multicolumn{2}{|c|}{ Solo } & \multicolumn{2}{|c|}{ Marinho } & \multirow[b]{2}{*}{$\begin{array}{c}\text { \% da Concentração } \\
\text { Média }\end{array}$} & \multirow[b]{2}{*}{ Comunalidade } \\
\hline & $\begin{array}{l}\text { Conc. } \\
\left(\mathrm{ng} / \mathrm{m}^{3}\right)\end{array}$ & $\%$ & $\begin{array}{l}\text { Conc. } \\
\left(\mathrm{ng} / \mathrm{m}^{3}\right)\end{array}$ & $\%$ & $\begin{array}{l}\text { Conc. } \\
\left(\mathrm{ng} / \mathrm{m}^{3}\right)\end{array}$ & $\%$ & & \\
\hline $\mathrm{Na}{ }_{-} \mathrm{F}$ & 33,1 & 78 & 4,5 & 11 & 7,6 & 18 & 107 & 0,76 \\
\hline Al_F & 3,7 & 13 & 27,0 & 93 & $-1,0$ & -3 & 103 & 0,98 \\
\hline Si_F & $-2,0$ & -4 & 51,1 & 104 & - & - & 100 & 0,99 \\
\hline P_F & 5,8 & 77 & 1,0 & 13 & 0,7 & 9 & 99 & 0,98 \\
\hline S_F & 202,5 & 80 & 33,5 & 13 & 22,5 & 9 & 102 & 0,98 \\
\hline Cl_F & 1,4 & 36 & $-0,1$ & -4 & 2,5 & 68 & 101 & 0,97 \\
\hline K_F & 86,9 & 82 & 14,2 & 13 & 8,7 & 8 & 104 & 0,97 \\
\hline $\mathrm{Ca}_{-} \mathrm{F}$ & 1,7 & 26 & 3,9 & 59 & 1,0 & 15 & 100 & 0,89 \\
\hline Ti_F & 0,3 & 15 & 1,8 & 91 & $-0,1$ & -4 & 103 & 0,97 \\
\hline $\mathrm{Fe}_{-} \mathrm{F}$ & 3,7 & 23 & 13,2 & 83 & $-0,9$ & -6 & 100 & 0,98 \\
\hline Zn_F & 0,68 & 74 & 0,17 & 18 & 0,06 & 7 & 99 & 0,94 \\
\hline $\mathrm{Br} \_\mathrm{F}$ & 0,8 & 82 & - & - & 0,1 & 10 & 92 & 0,84 \\
\hline $\mathrm{BCe} \_\mathrm{F}$ & 266,3 & 83 & 55,1 & 17 & - & - & 100 & 0,96 \\
\hline MPF & 3147 & 81 & 462 & 12 & 371 & 9 & 102 & 0,96 \\
\hline Autovalor & 7,4 & & 4,7 & & 1,1 & & Variância Tc & tal (\%) \\
\hline Variância (\%) & 52,8 & & 33,7 & & 7,7 & & 94,1 & \\
\hline
\end{tabular}

O primeiro fator engloba grande parte da fração de $\mathrm{Na}, \mathrm{P}, \mathrm{S}, \mathrm{K}, \mathrm{Zn}, \mathrm{Br}$ e $\mathrm{BCe}$ e a série temporal de seus APFSs apresentaram forte sazonalidade, com maiores valores durante a estação seca, assim, caracterizou-se este fator como aerossóis associados a queima de biomassa. Verifica-se que este fator é responsável por uma alta fração (81\%) do MPF e explica 52,8\% da variância das concentrações para este sítio. 
O segundo fator possui consideráveis quantidades de $\mathrm{Al}, \mathrm{Si}, \mathrm{Ca}$, $\mathrm{Ti}$ e $\mathrm{Fe}$, elementos traçadores de poeira do solo. Este fator explica 33,7\% da variância das concentrações dos elementos e é responsável por, em média, 12\% do MPF da ZF2. Dentre os elementos complementares verifica-se que aproximadamente $25 \%$ da concentração média de $\mathrm{Mg}, \mathrm{Mn}$ e Ni estão associado a este fator.

O último fator é responsável por $68 \%$ da concentração média de $\mathrm{Cl}$ e $18 \%$ de $\mathrm{Na}$, além de menores quantidades de $\mathrm{Ca}$ e $\mathrm{Br}$, elementos associados ao aerossol marinho. Este fator é, em média, responsável por $9 \%$ da concentração de MPF e explica 1,1\% da variância dos elementos. Dentre os elementos complementares, o $\mathrm{Mg}$ tem por volta de $30 \%$ de suas concentrações explicadas por este fator.

ARANA \& ARTAXO (2014) aplicaram a técnica de ACPA sobre aerossóis coletados de fevereiro a outubro de 2008 neste mesmo sítio e obtiveram três fatores: queimadas, ressuspensão de poeira do solo e processos biogênicos naturais com concentrações de $2820 \mathrm{ng} / \mathrm{m}^{3}, 240 \mathrm{ng} / \mathrm{m}^{3}$ e $147 \mathrm{ng} / \mathrm{m}^{3}$ de MPF, respectivamente, valores próximos ao encontrado no presente trabalho, com exceção do fator biogênico, não extraído neste trabalho.

\subsubsection{ACPA aplicada ao material particulado grosso da ZF2}

A aplicação de ACPA no MPG da ZF2 foi capaz de explicar $82,8 \%$ da variabilidade das concentrações dos elementos deste sítio através de três fatores principais, conforme Tabela 12. esta forma, optou-se pela extração de três fatores, observando que exceto para os elementos S, Mn e Zn, as comunalidades encontradas estão próximas de 0,9, o percentual da concentração explicada para cada elemento encontra-se próximo dos $100 \%$ e a variância total de $82,8 \%$, tornando este um resultado estatisticamente satisfatório. 
Tabela 12: resultados da ACPA aplicada ao MPG da ZF2 coletado durante o GoAmazon2014/15 após rotação Varimax. A tabela mostra a concentração média de cada elemento por fator e o percentual que representa em relação à concentração média do mesmo. As duas últimas linhas mostram o autovalor e a variância associada a cada fator.

\begin{tabular}{|c|c|c|c|c|c|c|c|c|}
\hline \multicolumn{9}{|c|}{ ACPA - ZF2 - Material Particulado Grosso } \\
\hline & $\begin{array}{l}\text { Solo } \\
\text { Conc. } \\
\left(\mathrm{ng} / \mathrm{m}^{3}\right)\end{array}$ & $\begin{array}{l}\% \\
\%\end{array}$ & $\begin{array}{c}\text { Biogênico } \\
\text { Conc. } \\
\left(\mathrm{ng} / \mathrm{m}^{3}\right)\end{array}$ & $\%$ & $\begin{array}{c}\text { Marinho } 2 \\
\text { Conc. } \\
\left(\mathrm{ng} / \mathrm{m}^{3}\right)\end{array}$ & $\begin{array}{l}\% \\
\%\end{array}$ & $\begin{array}{c}\text { \% da Massa } \\
\text { Média }\end{array}$ & Comunalidade \\
\hline $\mathrm{Na} \_\mathrm{G}$ & 6,5 & 9,7 & 11,9 & 17,6 & 50,5 & 75,0 & 102,3 & 0,93 \\
\hline Al_G & 40,4 & 90,6 & - & - & 4,0 & 8,9 & 99,5 & 0,94 \\
\hline Si_G & 52,7 & 72,4 & 12,6 & 17,3 & 8,5 & 11,7 & 101,4 & 0,96 \\
\hline P_G & $-2,7$ & $-13,3$ & 24,9 & 123,2 & $-1,8$ & $-9,0$ & 100,9 & 0,91 \\
\hline S_G & 6,0 & 13,3 & 30,1 & 66,7 & 10,7 & 23,8 & 103,8 & 0,69 \\
\hline Cl_G & - & - & 14,9 & 32,3 & 30,0 & 65,2 & 97,5 & 0,90 \\
\hline K_G & - & - & 64,6 & 94,8 & 3,9 & 5,7 & 100,5 & 0,94 \\
\hline $\mathrm{Ca}_{-} \mathrm{G}$ & 3,7 & 26,1 & 5,0 & 34,7 & 5,5 & 38,6 & 99,4 & 0,87 \\
\hline Ti_G & 4,1 & 98,9 & $-0,1$ & $-1,8$ & 0,3 & 6,9 & 104,0 & 0,86 \\
\hline$M n \_G$ & 0,1 & 27,8 & 0,3 & 58,3 & 0,1 & 14,6 & 100,7 & 0,47 \\
\hline Fe_G & 16,9 & 62,0 & 4,8 & 17,5 & 5,5 & 20,1 & 99,5 & 0,92 \\
\hline Zn_G & 0,03 & 4,0 & 0,65 & 98,5 & - & - & 102,6 & 0,64 \\
\hline $\mathrm{BCe} \_\mathrm{G}$ & 3,9 & 10,3 & 30,2 & 78,9 & 4,5 & 11,7 & 100,9 & 0,70 \\
\hline MPG & 163 & 3,3 & 4230 & 86,0 & 626 & 12,7 & 102,0 & 0,87 \\
\hline Autovalor & \multicolumn{2}{|l|}{4,9} & \multicolumn{2}{|l|}{3,7} & \multicolumn{2}{|l|}{3,0} & \multicolumn{2}{|c|}{ Variância Total (\%) } \\
\hline Variância (\%) & \multicolumn{2}{|l|}{34,9} & \multicolumn{2}{|l|}{26,4} & \multicolumn{2}{|l|}{21,4} & \multicolumn{2}{|c|}{82,8} \\
\hline
\end{tabular}

O primeiro fator é responsável pela quase totalidade da concentração dos elementos $\mathrm{Al}$ e Ti, além de altas concentrações de $\mathrm{Si}$ e Fe, elementos traçadores do solo. O valor médio da contribuição deste fator no MPG total é um valor baixo, de 3,3\%, entretanto este fator tem o maior autovalor dentre os três fatores. Dentre os elementos complementares, esta fonte é responsável, por volta de $30 \%$ da concentração de $\mathrm{Mg}$.

O segundo fator explica mais de $50 \%$ da concentração média de $P$, além de elementos como $\mathrm{K}, \mathrm{Ca}, \mathrm{Mn}, \mathrm{Zn}$ e BCe. Esses elementos são característicos de emissões de queimadas e também de processos de emissão de aerossóis biogênicos. Por se tratar da ACPA na moda grossa, caracterizou-se esta fonte como aerossol devido a processos biogênicos. Além disso, a série temporal dos APFSs, que indicam a intensidade da fonte, é razoavelmente constante durante o período amostrado, característica da emissão biogênica na Amazônia (GILARDONI et al., 2011; PAULIQUEVIS et al., 2012; WANG et al., 2016). Dos elementos complementares, $65 \%$ da concentração média de Se e $\mathrm{Br}$ estão associados a este fator. 
O terceiro fator, responsável por grande parte de $\mathrm{Na}$ e $\mathrm{Cl}$, também apresenta boa parte da concentração média de $\mathrm{S}$ e $\mathrm{Ca}$, sendo assim claramente associado ao aerossol marinho. A presença de alguns elementos relacionados com o solo como Fe e $\mathrm{Mn}$ indicam que junto com o transporte de aerossol marinho temos uma mistura de poeira do solo, como já observado em trabalhos anteriores (ARTAXO; MAENHAUT, 1990; BEN-AMI et al., 2010; WANG et al., 2016). Dos elementos complementares, Mg apresentam 50\% e 36\% da sua concentração média neste fator. Este fator será chamado de marinho 2, conforme será discutido na seção 4.7.4.

\subsubsection{ACPA aplicada ao material particulado fino do TIWA}

Com a realização da ACPA para o material particulado fino no TIWA foi possível extrair cinco fatores, possibilitando a quantificação da atividade antrópica na região. A tentativa com seis fatores extrai um último fator não identificável e com autovalor menor que a unidade, optando-se, portanto, pelo modelo com cinco fatores. Esta solução explicou 93\% da variância total, as comunalidades apresentaram valores maiores que 0,8 , com a maioria próxima da unidade e observa-se que a soma de concentrações de cada elemento nos fatores apresenta valores próximos de $100 \%$ da concentração média do elemento, conforme as Tabelas 13 e 14.

A fim de evitar repetição na análise da identificação do processo físico associado aos fatores extraídos pela ACPA no MPF do TIWA, utilizarei sempre que possível resultados já discutidos em seções anteriores. Assim o primeiro, segundo e quarto fatores extraídos nesta seção possuem perfis semelhantes aos fatores "queimada", "solo" e "marinho", respectivamente, discutidos na seção 4.7.1 e assim são caracterizados. 
Tabela 13: resultados da ACPA aplicada ao MPF do TIWA coletado durante o GoAmazon2014/15 após rotação Varimax. A tabela mostra a concentração média de cada elemento por fator e o percentual que representa em relação à concentração média do mesmo. As duas últimas linhas mostram o autovalor e a variância associada a cada fator.

\begin{tabular}{|c|c|c|c|c|c|c|c|c|c|c|c|c|}
\hline \multicolumn{13}{|c|}{ ACPA - TIWA - Material Particulado Fino } \\
\hline & \multicolumn{2}{|c|}{ Queimada } & \multicolumn{2}{|c|}{ Solo } & \multicolumn{2}{|c|}{ Veicular } & \multicolumn{2}{|c|}{ Marinho } & \multicolumn{2}{|c|}{ Poluição } & \multirow{2}{*}{$\%$} & \multirow{2}{*}{ Comunalidade } \\
\hline & $\begin{array}{l}\text { Conc. } \\
\left(\mathrm{ng} / \mathrm{m}^{3}\right)\end{array}$ & $\%$ & $\begin{array}{l}\text { Conc. } \\
\left(\mathrm{ng} / \mathrm{m}^{3}\right)\end{array}$ & $\%$ & $\begin{array}{l}\text { Conc. } \\
\left(\mathrm{ng} / \mathrm{m}^{3}\right)\end{array}$ & $\%$ & $\begin{array}{l}\text { Conc. } \\
\left(\mathrm{ng} / \mathrm{m}^{3}\right)\end{array}$ & $\%$ & $\begin{array}{l}\text { Conc. } \\
\left(\mathrm{ng} / \mathrm{m}^{3}\right)\end{array}$ & $\%$ & & \\
\hline $\mathrm{Na} F$ & 36,8 & 55,4 & 12,1 & 18,2 & 7,0 & 10,6 & - & - & 9,4 & 14,2 & 98 & 0,82 \\
\hline Al_F & 19,1 & 26,8 & 36,3 & 50,9 & 7,1 & 9,9 & 2,5 & 3,6 & 7,2 & 10,1 & 101 & 0,99 \\
\hline Si_F & 11,7 & 10,5 & 59,3 & 53,4 & 11,9 & 10,7 & 9,7 & 8,7 & 17,8 & 16,0 & 99 & 0,92 \\
\hline P_F & 5,3 & 51,1 & 0,8 & 7,5 & 1,3 & 12,3 & 1,3 & 12,7 & 1,7 & 16,1 & 100 & 0,95 \\
\hline S_F & 183,6 & 60,0 & 20,9 & 6,8 & 29,7 & 9,7 & 33,4 & 10,9 & 40,0 & 13,1 & 100 & 0,97 \\
\hline $\mathrm{Cl} \_\mathrm{F}$ & 1,2 & 25,2 & 0,1 & 2,6 & 0,6 & 13,3 & 2,5 & 53,8 & 0,3 & 6,8 & 102 & 0,97 \\
\hline K_F & 97,5 & 59,9 & 22,3 & 13,7 & 23,8 & 14,6 & 23,2 & 14,3 & & 0,0 & 102 & 0,95 \\
\hline $\mathrm{Ca}_{-} \mathrm{F}$ & 1,9 & 10,5 & 5,8 & 32,1 & 4,8 & 26,7 & 1,4 & 7,8 & 4,5 & 24,8 & 102 & 0,90 \\
\hline Ti_F & 1,4 & 25,7 & 2,7 & 49,8 & 0,8 & 15,6 & - & - & 0,5 & 8,8 & 100 & 0,97 \\
\hline Mn_F & 0,4 & 16,6 & 0,4 & 18,8 & 0,8 & 37,6 & 0,2 & 10,3 & 0,4 & 20,6 & 104 & 0,80 \\
\hline $\mathrm{Fe}_{-} \mathrm{F}$ & 13,5 & 26,7 & 20,8 & 41,0 & 10,8 & 21,2 & 1,0 & 1,9 & 5,6 & 11,1 & 102 & 0,98 \\
\hline Ni_F & 0,06 & 10,2 & 0,09 & 14,9 & 0,10 & 15,5 & 0,04 & 6,3 & 0,34 & 54,1 & 101 & 0,93 \\
\hline $\mathrm{Cu}_{-} \mathrm{F}$ & 0,09 & 14,9 & 0,04 & 7,7 & 0,35 & 59,8 & - & - & 0,12 & 21,0 & 103 & 0,86 \\
\hline$Z n_{-} F$ & 0,77 & 15,8 & 0,56 & 11,6 & 2,37 & 48,9 & 1,05 & 21,5 & & - & 98 & 0,83 \\
\hline $\mathrm{Br}_{-} \mathrm{F}$ & 1,0 & 45,6 & 0,2 & 9,9 & 0,7 & 34,2 & 0,3 & 13,0 & & - & 103 & 0,92 \\
\hline $\mathrm{BCe} \_\mathrm{F}$ & 401,2 & 45,1 & 111,5 & 12,5 & 254,7 & 28,6 & 61,2 & 6,9 & 66,2 & 7,4 & 101 & 0,91 \\
\hline MPF & 3908 & 60,9 & 1010 & 15,7 & 713 & 11,1 & 613 & 9,6 & 285 & 4,4 & 102 & 0,96 \\
\hline Autovalor & \multicolumn{2}{|c|}{6,1} & \multicolumn{2}{|c|}{4,8} & \multicolumn{2}{|c|}{2,1} & \multicolumn{2}{|c|}{1,0} & \multicolumn{2}{|c|}{1,0} & \multicolumn{2}{|c|}{ Variância Total (\%) } \\
\hline Variância (\%) & \multicolumn{2}{|c|}{37,9} & \multicolumn{2}{|c|}{29,8} & \multicolumn{2}{|c|}{13,3} & \multicolumn{2}{|c|}{6,0} & \multicolumn{2}{|c|}{6,0} & \multicolumn{2}{|r|}{93,0} \\
\hline
\end{tabular}

Tabela 14: concentração média por fator dos elementos que não foram incluídos na ACPA.

\begin{tabular}{|c|c|c|c|c|c|c|c|c|c|c|c|c|}
\hline \multicolumn{13}{|c|}{ Elementos Complementares - TIWA - Material Particulado Fino } \\
\hline & \multicolumn{2}{|c|}{ Queimada } & \multicolumn{2}{|l|}{ Solo } & \multicolumn{2}{|c|}{ Veicular } & \multicolumn{2}{|c|}{ Marinho } & \multicolumn{2}{|c|}{ Poluição } & \multirow{2}{*}{$\begin{array}{c}\text { \% da Massa } \\
\text { Média }\end{array}$} & \multirow{2}{*}{$\begin{array}{c}\mathrm{N} \text { de } \\
\text { amostras }\end{array}$} \\
\hline & $\begin{array}{l}\text { Conc. } \\
\left(\mathrm{ng} / \mathrm{m}^{3}\right)\end{array}$ & $\%$ & $\begin{array}{l}\text { Conc. } \\
\left(\mathrm{ng} / \mathrm{m}^{3}\right)\end{array}$ & $\%$ & $\begin{array}{l}\text { Conc. } \\
\left(\mathrm{ng} / \mathrm{m}^{3}\right)\end{array}$ & $\%$ & $\begin{array}{l}\text { Conc. } \\
\left(\mathrm{ng} / \mathrm{m}^{3}\right)\end{array}$ & $\%$ & $\begin{array}{l}\text { Conc. } \\
\left(\mathrm{ng} / \mathrm{m}^{3}\right)\end{array}$ & $\%$ & & \\
\hline Mg_F & 2,85 & $18 \%$ & 5,61 & $35 \%$ & - & - & - & - & 3,04 & $19 \%$ & $72 \%$ & 45 \\
\hline V_F & 0,19 & $28 \%$ & 0,12 & $17 \%$ & 0,22 & $31 \%$ & - & - & - & - & $75 \%$ & 40 \\
\hline Cr_F & 0,16 & $52 \%$ & 0,06 & $20 \%$ & 0,09 & $29 \%$ & 0,08 & $26 \%$ & - & - & $127 \%$ & 29 \\
\hline $\mathrm{Rb} \_\mathrm{F}$ & 0,19 & $40 \%$ & - & - & - & - & - & - & - & - & $40 \%$ & 15 \\
\hline $\mathrm{Pb} \mathrm{F}$ & 0,23 & $15 \%$ & 0,16 & $10 \%$ & 0,78 & $50 \%$ & 0,27 & $17 \%$ & - & - & $92 \%$ & 41 \\
\hline
\end{tabular}

O terceiro fator apresenta altas concentrações relativas de $\mathrm{Cu}$ e $\mathrm{Zn}$, além de $\mathrm{Br}, \mathrm{Mn}$, Fe e BCe sendo caracterizado como fator devido a emissões veiculares. Além disso, como 
elemento complementar, $50 \%$ da concentração média de Pb está associada a este fator. Este fator é responsável em média por $11,1 \%$ do MPF do TIWA. A quinta componente possui consideráveis quantidades de $\mathrm{Ni}, \mathrm{Cu}, \mathrm{Ca}$ e $\mathrm{Mn}$, sendo caracterizada como poluição urbana. Este fator é responsável, em média, por $4,4 \%$ do MPF e explica $6 \%$ da variância dos dados neste sítio. Estes dois fatores associados exclusivamente ao impacto causado por atividades antrópicas de Manaus, poluição urbana e veicular, são responsáveis, em média, por $998 \mathrm{ng} / \mathrm{m}^{3}$, isto é $15,5 \%$ do MPF no TIWA.

\subsubsection{ACPA aplicada ao material particulado grosso do TIWA}

A ACPA aplicada no MPG do TIWA extraiu quatro fatores principais que explicam $88,4 \%$ da variância total dos dados. As comunalidades dos elementos ficaram próximas da unidade, com algumas exceções como o $\mathrm{Cl}$ e BCe. Desta forma, optou-se pelo modelo com quatro fatores. As Tabelas 15 e 16 apresentam o perfil encontrado pela ACPA e a concentração dos elementos complementares. Do mesmo modo que realizado na seção anterior, irei recorrer aos resultados encontrados para a ACPA do MPG no sítio ZF2, seção 4.7.2. Assim, associou-se o fator 1 à poeira mineral do solo e o fator 2 ao aerossol biogênico. O terceiro e quarto fator estão relacionados com processamento de aerossol marinho e são discutidos após a apresentação dos resultados. 
Tabela 15: resultados da ACPA aplicada ao MPG do TIWA coletado durante o GoAmazon2014/15 após rotação Varimax. A tabela mostra a concentração média de cada elemento por fator e o percentual que representa em relação à concentração média do mesmo. As duas últimas linhas mostram o autovalor e a variância associada a cada fator.

\begin{tabular}{|c|c|c|c|c|c|c|c|c|c|c|}
\hline \multicolumn{11}{|c|}{ ACPA - TIWA - Material Particulado Grosso } \\
\hline & \multicolumn{2}{|l|}{ Solo } & \multicolumn{2}{|c|}{ Biogênico } & \multicolumn{2}{|c|}{$\begin{array}{l}\text { Marinho } 1 \\
(\mathrm{HCl})\end{array}$} & \multicolumn{2}{|c|}{$\begin{array}{c}\text { Marinho } 2 \\
(\mathrm{NaCl})\end{array}$} & \multirow[b]{2}{*}{$\%$} & \multirow[b]{2}{*}{ Comunalidade } \\
\hline & $\begin{array}{l}\text { Conc. } \\
\left(\mathrm{ng} / \mathrm{m}^{3}\right)\end{array}$ & $\%$ & $\begin{array}{l}\text { Conc. } \\
\left(\mathrm{ng} / \mathrm{m}^{3}\right)\end{array}$ & $\%$ & $\begin{array}{l}\text { Conc. } \\
\left(\mathrm{ng} / \mathrm{m}^{3}\right)\end{array}$ & $\%$ & $\begin{array}{l}\text { Conc. } \\
\left(\mathrm{ng} / \mathrm{m}^{3}\right)\end{array}$ & $\%$ & & \\
\hline $\mathrm{Na} \_\mathrm{G}$ & 52,6 & 62 & 21,0 & 25 & - & - & 6,8 & 8 & 94,3 & 0,91 \\
\hline Al_G & 136,6 & 90 & - & - & 18,1 & 12 & 2,1 & 1 & 102,9 & 0,96 \\
\hline Si_G & 158,8 & 73 & - & - & 46,8 & 21 & 2,9 & 1 & 95,3 & 0,93 \\
\hline P_G & $-6,9$ & -37 & 27,3 & 148 & $-1,6$ & -8 & $-0,2$ & -1 & 101,0 & 0,96 \\
\hline S_G & 15,9 & 30 & 28,3 & 54 & 6,4 & 12 & 2,3 & 4 & 101,4 & 0,91 \\
\hline Cl_G & 0,0 & 0 & 17,6 & 38 & 20,9 & 45 & 4,2 & 9 & 92,6 & 0,76 \\
\hline K_G & 3,9 & 5 & 63,7 & 85 & 7,6 & 10 & 1,0 & 1 & 101,2 & 0,97 \\
\hline Ca_G & 20,0 & 40 & - & - & 27,5 & 54 & 1,3 & 3 & 96,7 & 0,90 \\
\hline Ti_G & 10,6 & 82 & - & - & 2,1 & 16 & 0,3 & 2 & 100,3 & 0,96 \\
\hline Mn_G & 0,6 & 50 & 0,2 & 15 & 0,4 & 35 & 0,0 & 2 & 102,7 & 0,82 \\
\hline Fe_G & 78,8 & 82 & - & - & 13,2 & 14 & 2,1 & 2 & 97,7 & 0,97 \\
\hline Cu_G & - & - & 0,09 & 18 & 0,37 & 76 & 0,01 & 2 & 96,3 & 0,78 \\
\hline Zn_G & 0,42 & 20 & 0,61 & 28 & 1,16 & 54 & - & - & 102,3 & 0,84 \\
\hline $\mathrm{BCe} \_\mathrm{G}$ & 40,0 & 38 & 44,4 & 42 & 20,4 & 19 & 2,5 & 2 & 102,4 & 0,67 \\
\hline MPG & 1116,0 & 17 & 4681,1 & 71 & 791,5 & 12 & 95,3 & 1 & 101,5 & 0,92 \\
\hline Autovalor & \multicolumn{2}{|l|}{5,8} & \multicolumn{2}{|l|}{2,6} & \multicolumn{2}{|l|}{2,6} & \multicolumn{2}{|l|}{2,3} & \multicolumn{2}{|c|}{ Variância Total (\%) } \\
\hline Variância (\%) & \multicolumn{2}{|l|}{38,4} & \multicolumn{2}{|c|}{17,4} & \multicolumn{2}{|l|}{17,4} & \multicolumn{2}{|l|}{15,2} & \multicolumn{2}{|r|}{88,4} \\
\hline
\end{tabular}

Tabela 16: concentração média por fator dos elementos que não foram incluídos na ACPA.

\begin{tabular}{|c|c|c|c|c|c|c|c|c|c|c|}
\hline \multicolumn{11}{|c|}{ Elementos Complementares - TIWA - Material Particulado Grosso } \\
\hline & \multicolumn{2}{|c|}{ Solo } & \multicolumn{2}{|c|}{ Biogênico } & \multicolumn{2}{|c|}{$\begin{array}{c}\text { Marinho } 1 \\
(\mathrm{HCl})\end{array}$} & \multicolumn{2}{|c|}{$\begin{array}{c}\text { Marinho } 2 \\
(\mathrm{NaCl})\end{array}$} & \multirow{2}{*}{$\begin{array}{l}\text { \% da Massa } \\
\text { Média }\end{array}$} & \multirow{2}{*}{$\begin{array}{c}\mathrm{N} \text { de } \\
\text { amostras }\end{array}$} \\
\hline & $\begin{array}{l}\text { Conc. } \\
\left(\mathrm{ng} / \mathrm{m}^{3}\right)\end{array}$ & $\%$ & $\begin{array}{l}\text { Conc. } \\
\left(\mathrm{ng} / \mathrm{m}^{3}\right)\end{array}$ & $\%$ & $\begin{array}{l}\text { Conc. } \\
\left(\mathrm{ng} / \mathrm{m}^{3}\right)\end{array}$ & $\%$ & $\begin{array}{l}\text { Conc. } \\
\left(\mathrm{ng} / \mathrm{m}^{3}\right)\end{array}$ & $\%$ & & \\
\hline Mg_G & 20,48 & $40 \%$ & - & - & 26,92 & $53 \%$ & - & - & $94 \%$ & 66 \\
\hline Cr_G & 0,30 & $60 \%$ & - & - & - & - & 0,02 & $4 \%$ & $64 \%$ & 42 \\
\hline
\end{tabular}

O terceiro fator é responsável por parte da concentração de $\mathrm{Cl}, \mathrm{Ca}, \mathrm{Mn}, \mathrm{Cu}$ e Zn e não apresentou regressão significativa com o elemento Na. Este fator é responsável por 17,4\% da variância dos dados e contribui com $12 \%$ da concentração de MPG, em média. A presença de $45 \%$ da concentração média de $\mathrm{Cl}$ neste fator junto com a ausência de Na sugere que este fator se relaciona ao termo $\mathrm{HCl}$ após a seguinte reação que ocorre na atmosfera: 


$$
2 \overbrace{\mathrm{NaCl}}^{\text {marinho } 2}+\mathrm{H}_{2} \mathrm{SO}_{4} \rightarrow \overbrace{\mathrm{Na}_{2} \mathrm{SO}_{4}}^{\text {marinho } 3}+2 \overbrace{\mathrm{HCl}}^{\text {marinho } 1}
$$

Por outro lado, o quarto fator apresenta maior equilíbrio entre os elementos $\mathrm{Na}$ e $\mathrm{Cl}$ em relação a outros fatores relacionados ao aerossol marinho que foram extraído ao longo deste trabalho, podendo-se tratar do $\mathrm{NaCl}$ antes da reação. Este fator contribui com aproximadamente $1 \%$ do MPG e sua variância explica $15,2 \%$ da variabilidade dos dados.

Desta forma identificou-se o terceiro fator como Marinho 1 - associado ao fator $\mathrm{HCl}$ da reação - e o quarto fator como Marinho 2 - associado ao $\mathrm{NaCl}$. Nas análises de MPG através do PMF também foi possível extrair fator que foi associado ao $\mathrm{Na}_{2} \mathrm{SO}_{4}$, e este será chamado de marinho 3. Esta distinção foi possível apenas para o MPG conforme as próximas seções, portanto, para os resultados de MPF a nomenclatura continuará sendo simplesmente marinho.

\subsubsection{ACPA aplicada ao material particulado fino de Manacapuru}

A ACPA do MPF de Manacapuru apresenta, de modo semelhante à ZF2, três fatores principais. Assim, a ACPA com três fatores apresentou comunalidades próximas da unidade para grande parte dos elementos, boa explicação da concentração média dos elementos e por explicar $90,5 \%$ da variância total dos dados. Os resultados estão expostos nas Tabelas seguintes. Os perfis dos fatores encontrados nesta análise foram semelhantes aos encontrados para os demais sítios na moda fina, seções 4.7.1 e 4.7.3. Desta forma, associouse o fator 1 ao aerossol gerado na queima de biomassa, o fator 2 aos processos de ressuspensão de poeira do solo e o fator 3 ao aerossol marinho mais processado que nos outros sítios, resultando em concentração nula de Na para este fator. 
Tabela 17: resultados da ACPA aplicada ao MPF de Manacapuru coletado durante o GoAmazon2014/15 após rotação Varimax. A tabela mostra a concentração média de cada elemento por fator e o percentual que representa em relação à concentração média do mesmo. As duas últimas linhas mostram o autovalor e a variância associada a cada fator.

\begin{tabular}{|c|c|c|c|c|c|c|c|c|}
\hline \multicolumn{9}{|c|}{ ACPA - Manacapuru - Material Particulado Fino } \\
\hline & \multicolumn{2}{|l|}{ Queimada } & \multicolumn{2}{|l|}{ Solo } & \multicolumn{2}{|l|}{ Marinho } & \multirow{2}{*}{$\%$} & \multirow{2}{*}{ Comunalidade } \\
\hline & Conc. $\left(\mathrm{ng} / \mathrm{m}^{3}\right)$ & $\%$ & Conc. $\left(\mathrm{ng} / \mathrm{m}^{3}\right)$ & $\%$ & Conc. $\left(\mathrm{ng} / \mathrm{m}^{3}\right)$ & $\%$ & & \\
\hline $\mathrm{Na} \_\mathrm{F}$ & 18,3 & 92 & 2,3 & 12 & - & - & 103,4 & 0,80 \\
\hline Al_F & 1,5 & 7 & 22,2 & 96 & - & - & 103,0 & 0,98 \\
\hline Si_F & - & - & 42,6 & 104 & 2,4 & 6 & 110,2 & 0,93 \\
\hline P_F & 4,1 & 88 & 0,6 & 14 & - & - & 101,6 & 0,92 \\
\hline S_F & 122,6 & 96 & 5,8 & 5 & - & - & 101,0 & 0,95 \\
\hline Cl_F & 1,5 & 63 & 0,1 & 4 & 0,7 & 31 & 98,7 & 0,97 \\
\hline K_F & 46,4 & 91 & - & - & 6,9 & 14 & 105,0 & 0,93 \\
\hline $\mathrm{Ca}_{-} \mathrm{F}$ & 1,4 & 25 & 3,9 & 70 & 0,4 & 7 & 101,4 & 0,85 \\
\hline Ti_F & 0,3 & 14 & 1,6 & 88 & $-0,1$ & -5 & 97,5 & 0,90 \\
\hline $\mathrm{Fe}_{-} \mathrm{F}$ & 3,2 & 22 & 12,2 & 84 & $-0,7$ & -5 & 100,0 & 0,94 \\
\hline$Z n_{-} F$ & 0,49 & 65 & 0,20 & 26 & 0,04 & 5 & 96,3 & 0,75 \\
\hline Bce_F & 199,0 & 88 & - & - & 21,5 & 10 & 98,0 & 0,89 \\
\hline MPF & 2202 & 90 & 148 & 6 & 117 & 5 & 100,7 & 0,96 \\
\hline Autovalor & 6,4 & & 4,6 & & 0,8 & & Variấ & ncia Total (\%) \\
\hline Variância (\%) & 49,1 & & 35,4 & & 6,0 & & & 90,5 \\
\hline
\end{tabular}

Tabela 18: concentração média por fator dos elementos que não foram incluídos na ACPA.

\begin{tabular}{|c|c|c|c|c|c|c|c|c|}
\hline \multicolumn{9}{|c|}{ Elementos Complementares - Manacapuru - Material Particulado Fino } \\
\hline & \multicolumn{2}{|l|}{ Queimada } & \multicolumn{2}{|l|}{ Solo } & \multicolumn{2}{|l|}{ Marinho } & \multirow{2}{*}{$\begin{array}{c}\text { \% da Massa } \\
\text { Média }\end{array}$} & \multirow{2}{*}{$\mathrm{N}$ de amostras } \\
\hline & Conc. $\left(\mathrm{ng} / \mathrm{m}^{3}\right)$ & $\%$ & Conc. $\left(\mathrm{ng} / \mathrm{m}^{3}\right)$ & $\%$ & Conc. $\left(\mathrm{ng} / \mathrm{m}^{3}\right)$ & $\%$ & & \\
\hline Mg_F & - & - & 4,08 & $56 \%$ & 0,74 & $10 \%$ & $66 \%$ & 45 \\
\hline Cr_F & 0,06 & $31 \%$ & 0,12 & $66 \%$ & - & - & $97 \%$ & 17 \\
\hline Mn_F & 0,13 & $31 \%$ & 0,20 & $51 \%$ & - & - & $83 \%$ & 54 \\
\hline $\mathrm{Ni} \_\mathrm{F}$ & 0,11 & $46 \%$ & 0,10 & $42 \%$ & $-0,03$ & $-12 \%$ & $76 \%$ & 52 \\
\hline $\mathrm{Cu} \_\mathrm{F}$ & 0,12 & $50 \%$ & 0,05 & $22 \%$ & - & - & $72 \%$ & 38 \\
\hline $\mathrm{Br}_{-} \mathrm{F}$ & 0,58 & $75 \%$ & - & - & 0,06 & $8 \%$ & $83 \%$ & 58 \\
\hline Pb_F & 0,23 & $46 \%$ & 0,17 & $35 \%$ & - & - & $82 \%$ & 25 \\
\hline
\end{tabular}

Não foi observado nenhum fator direto associado com poluição urbana de Manaus. Isso nos surpreendeu, pois Manacapuru, em teoria fica vento abaixo de Manaus. Outros estudos utilizando AMS (Suzanna Sá, em redação) também tiveram dificuldade em separar uma componente de poluição urbana em Manacapuru. Aparentemente a resiliência do 
sistema biogênico natural é grande, e a remoção por deposição chuvosa entre Manaus e Manacapuru é significativa. Observamos concentrações significativas de elementos associados a poluição urbana como $\mathrm{Pb}, \mathrm{Ni}, \mathrm{Cr}$, e $\mathrm{Cu}$, que estão associados aos fatores, como mostra a Tabela 18, mas não foram detectados em um número significativo de amostras para serem incorporados na ACPA. Durante a noite, a altura de camada de mistura é baixa, o que dificulta o transporte de Manaus a Manacapuru, e durante o dia a alta taxa de precipitação no caminho pode depositar uma fração significativa do aerossol de Manaus.

\subsubsection{ACPA aplicada ao material particulado grosso de Manacapuru}

A aplicação da ACPA no MPG de Manacapuru retornou quatro fatores principais. Com quatro fatores foi possível explicar $90,7 \%$ da variância dos dados, as comunalidades próximas da unidade e aproximadamente $100 \%$ da concentração média explicada. Além dos fatores biogênico, solo e marinho, na fração grossa, um último fator com $\mathrm{Ni}$ e $\mathrm{Zn}$ foi discriminado. As Tabelas 19 e 20 apresentam o resultado da ACPA da fração grossa do aerossol de Manacapuru e a concentração de elementos complementares, respectivamente.

O primeiro e segundo fator foram classificados como "biogênico" e "solo", respectivamente, devido a similaridade do perfil destes com os encontrados na aplicação da ACPA na moda grossa da ZF2 e TIWA.

O terceiro fator, apesar de extrair pouca concentração elementar, tem $\mathrm{Na}$ e $\mathrm{Cl}$ como elementos principais, característica do aerossol marinho 2. A contribuição deste fator para o MPG é de $1 \%$ e a variabilidade explicada por este é de $17,6 \%$ dos dados.

A última componente extraída é devido ao fator antrópico pela presença de altas concentrações de elementos como $\mathrm{Ni}$ e $\mathrm{Zn}$, além de outros metais pesado. Este fator é responsável por $14 \%$ da concentração média do MPG do TIWA. Dentre os elementos complementares, temos o $\mathrm{Cu}$, indicador de aerossol antrópico, associado a emissões metalúrgicas. 
Tabela 19: resultados da ACPA aplicada ao MPF de Manacapuru coletado durante o GoAmazon2014/15 após rotação Varimax. A tabela mostra a concentração média de cada elemento por fator e o percentual que representa em relação à concentração média do mesmo. As duas últimas linhas mostram o autovalor e a variância associada a cada fator.

\begin{tabular}{|c|c|c|c|c|c|c|c|c|c|c|}
\hline \multicolumn{11}{|c|}{ ACPA - Manacapuru - Material Particulado Grosso } \\
\hline & \multicolumn{2}{|c|}{ Biogênico } & \multicolumn{2}{|c|}{ Solo } & \multicolumn{2}{|c|}{$\begin{array}{c}\text { Marinho } 2 \\
(\mathrm{NaCl})\end{array}$} & \multicolumn{2}{|c|}{ Poluição } & \multirow{2}{*}{$\%$} & \multirow{2}{*}{ Comunalidade } \\
\hline & $\begin{array}{l}\text { Conc. } \\
\left(\mathrm{ng} / \mathrm{m}^{3}\right)\end{array}$ & $\%$ & $\begin{array}{c}\text { Conc. } \\
\left(\mathrm{ng} / \mathrm{m}^{3}\right)\end{array}$ & $\%$ & $\begin{array}{l}\text { Conc. } \\
\left(\mathrm{ng} / \mathrm{m}^{3}\right)\end{array}$ & $\%$ & $\begin{array}{l}\text { Conc. } \\
\left(\mathrm{ng} / \mathrm{m}^{3}\right)\end{array}$ & $\%$ & & \\
\hline $\mathrm{Na}$ _G & 14,7 & 68 & - & - & 0,6 & 3 & 5,5 & 26 & 96,8 & 0,79 \\
\hline Al_G & 8,3 & 31 & 11,5 & 43 & 0,6 & 2 & 6,3 & 24 & 99,6 & 0,99 \\
\hline Si_G & 18,2 & 40 & 15,2 & 34 & 1,5 & 3 & 10,0 & 22 & 99,3 & 0,94 \\
\hline P_G & 10,2 & 109 & - & - & - & - & $-0,7$ & -8 & 101,4 & 0,92 \\
\hline S_G & 14,8 & 94 & - & - & 0,2 & 1 & - & - & 94,8 & 0,87 \\
\hline Cl_G & 9,1 & 88 & 0,6 & 6 & 0,6 & 6 & - & - & 99,5 & 0,89 \\
\hline K_G & 26,3 & 88 & 1,2 & 4 & 0,4 & 1 & 1,9 & 6 & 99,5 & 0,94 \\
\hline Ca_G & 4,1 & 49 & 1,9 & 22 & 0,2 & 3 & 2,0 & 24 & 98,1 & 0,88 \\
\hline Ti_G & 0,4 & 11 & 2,2 & 62 & - & - & 1,0 & 29 & 100,9 & 0,97 \\
\hline Fe_G & 4,5 & 20 & 12,4 & 54 & 0,1 & 0 & 6,0 & 26 & 100,4 & 0,98 \\
\hline Ni_G & 0,01 & 5 & 0,01 & 6 & - & - & 0,14 & 88 & 97,9 & 0,93 \\
\hline Zn_G & 0,17 & 44 & 0,04 & 9 & 0,01 & 2 & 0,20 & 51 & 105,9 & 0,76 \\
\hline BCe_G & 14,2 & 72 & 1,5 & 8 & 0,1 & 1 & 3,7 & 19 & 99,6 & 0,88 \\
\hline MPG & 1548 & 76 & 184 & 9 & 18 & 1 & 284 & 14 & 100,2 & 0,95 \\
\hline Autovalor & \multicolumn{2}{|c|}{4,8} & \multicolumn{2}{|c|}{4,0} & \multicolumn{2}{|l|}{2,5} & \multicolumn{2}{|c|}{1,4} & \multicolumn{2}{|c|}{ Variância Total (\%) } \\
\hline Variância (\%) & \multicolumn{2}{|c|}{34,4} & \multicolumn{2}{|c|}{28,6} & \multicolumn{2}{|c|}{17,6} & \multicolumn{2}{|c|}{10,0} & \multicolumn{2}{|r|}{90,7} \\
\hline
\end{tabular}

Tabela 20: concentração média por fator dos elementos que não foram incluídos na ACPA.

\begin{tabular}{|c|c|c|c|c|c|c|c|c|c|c|}
\hline \multicolumn{11}{|c|}{ Elementos Complementares - Manacapuru - Material Particulado Grosso } \\
\hline & \multicolumn{2}{|c|}{ Biogênico } & \multicolumn{2}{|c|}{ Solo } & \multicolumn{2}{|c|}{$\begin{array}{c}\text { Marinho } 2 \\
(\mathrm{NaCl})\end{array}$} & \multicolumn{2}{|c|}{ Poluição } & \\
\hline & $\begin{array}{l}\text { Conc. } \\
\left(\mathrm{ng} / \mathrm{m}^{3}\right)\end{array}$ & $\%$ & $\begin{array}{l}\text { Conc. } \\
\left(\mathrm{ng} / \mathrm{m}^{3}\right)\end{array}$ & $\%$ & $\begin{array}{l}\text { Conc. } \\
\left(\mathrm{ng} / \mathrm{m}^{3}\right)\end{array}$ & $\%$ & $\begin{array}{l}\text { Conc. } \\
\left(\mathrm{ng} / \mathrm{m}^{3}\right)\end{array}$ & $\%$ & $\begin{array}{l}\% \text { da } \\
\text { Massa } \\
\text { Média }\end{array}$ & $\begin{array}{c}\mathrm{N} \text { de } \\
\text { amostras }\end{array}$ \\
\hline Mg_G & $-18,86$ & $-47 \%$ & 7,48 & $19 \%$ & - & - & 45,08 & $113 \%$ & $84 \%$ & 73 \\
\hline Mn_G & 0,12 & $34 \%$ & 0,05 & $15 \%$ & 0,01 & $2 \%$ & - & - & $52 \%$ & 46 \\
\hline $\mathrm{Cu}_{\mathrm{G}} \mathrm{O}$ & 0,10 & $43 \%$ & - & - & 0,00 & $1 \%$ & 0,09 & $38 \%$ & $82 \%$ & 39 \\
\hline
\end{tabular}

$\mathrm{O}$ terceiro fator, apesar de extrair pouca concentração elementar, tem $\mathrm{Na}$ e $\mathrm{Cl}$ como elementos principais, característica do aerossol marinho 2. A contribuição deste fator para o MPG é de $1 \%$ e a variabilidade explicada por este é de $17,6 \%$ dos dados.

A última componente extraída é devido ao fator antrópico pela presença de altas concentrações de elementos como $\mathrm{Ni}$ e $\mathrm{Zn}$, além de outros metais pesado. Este fator é responsável por $14 \%$ da concentração média do MPG do TIWA. Dentre os elementos 
complementares, temos o $\mathrm{Cu}$, indicador de aerossol antrópico, associado a emissões metalúrgicas.

\subsection{Identificação das fontes de material particulado utilizando o PMF}

A APCA é um método bem estabelecido, mas não leva em conta a incerteza dos elementos medidos, o que o método PMF faz com uma base estatística sólida. A aplicação do algoritmo de PMF utiliza duas matrizes para seu funcionamento: de concentração elementar e de incerteza das concentrações, sendo assim, foi necessário estimar as incertezas associadas às medidas de concentração dos elementos traço, BCe e MP. Os resultados da aplicação do PMF começam pelo sítio ZF2, nas frações fina e grossa, correspondentes às seções 4.8.2 e 4.8.3 e são seguidas dos sítios TIWA e Manacapuru.

\subsubsection{Construção da matriz de incertezas para o PMF}

As incertezas utilizadas no PMF foram estimadas levando em conta a incerteza da calibração e o coeficiente de variação dos resultados. Para cada filtro, foram realizado de duas a três medidas da composição elementar por FRX, tornando possível o cálculo do coeficiente de variação individual separado por elemento, sítio e fração de material particulado.

Também utilizou-se das incertezas relativas à calibração do equipamento (ARANA, ANDRÉA, 2014). Sendo assim, obteve-se a incerteza relativa para cada elemento através da seguinte equação:

$$
U_{\text {elemento }, k=1}=\underset{k}{1} \sqrt{u_{\text {calib }}^{2}+u_{C V}^{2}}
$$

Onde $\mathrm{u}_{\text {calib }}$ representa a incerteza relativa da curva de calibração, $\mathrm{u}_{\mathrm{cv}}$ representa o coeficiente de variação. Dessa forma, obteve-se a Tabela 21 , com os cálculos da incerteza média para cada elemento, sítio e fração do material particulado. A última coluna desta tabela representa os resultados obtidos por YATKIN et al. (2016) em um estudo similar que utilizou filtros com inlet MP10 em região rural da Itália. 
Tabela 21: incertezas relativas obtidas através da equação 17 com k=2 para cada sítio durante o projeto GoAmazon2014/15 e os obtidos por Yatkin et al. (2016). Esses resultados foram aplicados às concentrações elementares a fim de contrstuir a matriz de incerteza necessária para rodar o PMF.

\begin{tabular}{cccccccc}
\hline \multicolumn{6}{c}{ Incerteza Relativa Expandida (k=2) das medições de concentração elementar } \\
\hline Elemento & ZF2_F & TIWA_F & MCRU_F & ZF2_G & TIWA_G & MCRU_G & Yatkin et al. (2016) \\
\hline $\mathrm{Na}$ & $18 \%$ & $14 \%$ & $24 \%$ & $11 \%$ & $9 \%$ & $20 \%$ & - \\
$\mathrm{Mg}$ & $38 \%$ & $38 \%$ & $46 \%$ & $16 \%$ & $12 \%$ & $20 \%$ & $30 \%$ \\
$\mathrm{Al}$ & $11 \%$ & $7 \%$ & $18 \%$ & $9 \%$ & $6 \%$ & $10 \%$ & $12 \%$ \\
$\mathrm{Si}$ & $7 \%$ & $6 \%$ & $8 \%$ & $6 \%$ & $6 \%$ & $7 \%$ & $11 \%$ \\
$\mathrm{P}$ & $12 \%$ & $12 \%$ & $21 \%$ & $8 \%$ & $10 \%$ & $10 \%$ & - \\
$\mathrm{S}$ & $5 \%$ & $5 \%$ & $5 \%$ & $5 \%$ & $5 \%$ & $6 \%$ & $11 \%$ \\
$\mathrm{Cl}$ & $21 \%$ & $12 \%$ & $23 \%$ & $6 \%$ & $6 \%$ & $10 \%$ & $11 \%$ \\
$\mathrm{~K}$ & $4 \%$ & $4 \%$ & $5 \%$ & $4 \%$ & $4 \%$ & $5 \%$ & $11 \%$ \\
$\mathrm{Ca}$ & $9 \%$ & $7 \%$ & $10 \%$ & $6 \%$ & $5 \%$ & $7 \%$ & $11 \%$ \\
$\mathrm{Ti}$ & $22 \%$ & $18 \%$ & $29 \%$ & $18 \%$ & $9 \%$ & $24 \%$ & $11 \%$ \\
$\mathrm{~V}$ & $48 \%$ & $48 \%$ & $56 \%$ & $45 \%$ & $35 \%$ & $54 \%$ & $32 \%$ \\
$\mathrm{Cr}$ & $43 \%$ & $48 \%$ & $41 \%$ & $54 \%$ & $44 \%$ & $46 \%$ & $39 \%$ \\
$\mathrm{Mn}$ & $41 \%$ & $23 \%$ & $48 \%$ & $35 \%$ & $32 \%$ & $49 \%$ & $20 \%$ \\
$\mathrm{Fe}$ & $6 \%$ & $5 \%$ & $7 \%$ & $6 \%$ & $5 \%$ & $6 \%$ & $11 \%$ \\
$\mathrm{Ni}$ & $49 \%$ & $32 \%$ & $36 \%$ & $51 \%$ & $40 \%$ & $53 \%$ & $52 \%$ \\
$\mathrm{Cu}$ & $43 \%$ & $32 \%$ & $47 \%$ & $34 \%$ & $28 \%$ & $46 \%$ & $26 \%$ \\
$\mathrm{Zn}$ & $22 \%$ & $8 \%$ & $22 \%$ & $19 \%$ & $11 \%$ & $31 \%$ & $13 \%$ \\
$\mathrm{Se}$ & $43 \%$ & $40 \%$ & $51 \%$ & $48 \%$ & $41 \%$ & $48 \%$ & - \\
$\mathrm{Br}$ & $38 \%$ & $25 \%$ & $35 \%$ & $47 \%$ & $45 \%$ & $50 \%$ & $33 \%$ \\
$\mathrm{Rb}$ & $54 \%$ & $52 \%$ & $47 \%$ & $49 \%$ & $44 \%$ & $63 \%$ & - \\
$\mathrm{Sr}$ & $45 \%$ & $57 \%$ & $57 \%$ & $41 \%$ & $52 \%$ & $40 \%$ & $36 \%$ \\
$\mathrm{Cd}$ & $55 \%$ & $70 \%$ & $22 \%$ & $44 \%$ & $56 \%$ & $44 \%$ & - \\
$\mathrm{Sb}$ & $62 \%$ & $55 \%$ & $49 \%$ & $58 \%$ & $46 \%$ & $47 \%$ & - \\
$\mathrm{Pb}$ & $57 \%$ & $42 \%$ & $54 \%$ & $57 \%$ & $42 \%$ & $57 \%$ & $61 \%$ \\
\hline
\end{tabular}

Observa-se que as incertezas são em geral significativas, quando leva-se em conta todos os possíveis erros associado. Entretanto, observa-se que para elementos críticos como $\mathrm{Al}, \mathrm{Si}, \mathrm{S}, \mathrm{K}, \mathrm{Fe}$ e outros, as incertezas totais são entre 5 a $10 \%$, que são valores aceitáveis para a incerteza total. Elementos próximos do limite de detecção podem ter incertezas maiores.

Nas secções seguintes são analisados os resultados obtidos através da análise PMF para cada localidade e fração de aerossol, para as diferentes estações seca e chuvosa.

\subsubsection{PMF aplicado ao material particulado fino da ZF2}

A aplicação do PMF na série temporal das concentrações do material particulado fino da ZF2 identificou quatro fontes: queimada, biogênico, solo e marinho. Para tanto, realizouse uma rotação Fpeak com intensidade de $-0,3$ já que com o resultado da rodada base não foi possível distinguir entre biogênico e queimada. Com esta rotação foi possível uma 
distinção maior entre as fontes biogênica e queimada: concentração de elementos como K, S e BCe, associados à queimada, diminuíram em um fator e aumentaram em outro. As propriedades das fontes solo e marinho foram pouco afetadas por esta rotação. As Tabelas 22 e 23 mostram a concentração média de elemento por fator e a intensidade de emissão da fonte nos diferentes períodos para o material particulado fino no sítio ZF2.

Tabela 22: resultados do PMF aplicado ao MPF da ZF2 coletado durante o GoAmazon2014/15. A tabela mostra a concentração média de cada elemento por fator e o percentual que representa em relação à concentração média do mesmo.

\begin{tabular}{|c|c|c|c|c|c|c|c|c|}
\hline \multicolumn{9}{|c|}{ PMF - ZF2 - Material Particulado Fino } \\
\hline & \multicolumn{2}{|l|}{ Queimada } & \multicolumn{2}{|c|}{ Biogênico } & \multicolumn{2}{|l|}{ Solo } & \multicolumn{2}{|l|}{ Marinho } \\
\hline & Conc. $\left(\mathrm{ng} / \mathrm{m}^{3}\right)$ & $\%$ & Conc. $\left(\mathrm{ng} / \mathrm{m}^{3}\right)$ & $\%$ & Conc. $\left(\mathrm{ng} / \mathrm{m}^{3}\right)$ & $\%$ & Conc. $\left(\mathrm{ng} / \mathrm{m}^{3}\right)$ & $\%$ \\
\hline $\mathrm{Na} \mathrm{F}_{\mathrm{H}}$ & 13,4 & 44,8 & 8,1 & 27,1 & 0,7 & 2,2 & 7,8 & 25,9 \\
\hline Al_F & 4,5 & 14,5 & 3,3 & 10,5 & 20,3 & 65,3 & 3,0 & 9,7 \\
\hline Si_F & 3,2 & 5,9 & 3,5 & 6,4 & 40,3 & 73,3 & 7,9 & 14,4 \\
\hline P_F & 3,3 & 42,5 & 2,3 & 29,9 & 0,2 & 2,9 & 1,9 & 24,7 \\
\hline S_F & 124,3 & 49,7 & 66,7 & 26,7 & 4,8 & 1,9 & 54,2 & 21,7 \\
\hline Cl_F & 0,1 & 2,5 & 0,3 & 9,8 & - & - & 2,6 & 87,7 \\
\hline K_F & 74,7 & 69,8 & 10,1 & 9,5 & 3,4 & 3,2 & 18,7 & 17,5 \\
\hline $\mathrm{Ca}$ _F & 0,8 & 11,2 & 1,0 & 14,3 & 2,8 & 41,3 & 2,2 & 33,2 \\
\hline Ti_F & 0,2 & 11,0 & 0,3 & 14,4 & 1,3 & 65,8 & 0,2 & 8,9 \\
\hline$M n \_F$ & 0,1 & 14,4 & 0,04 & 9,7 & 0,1 & 37,2 & 0,1 & 38,6 \\
\hline $\mathrm{Fe}_{-} \mathrm{F}$ & 3,0 & 17,4 & 3,5 & 20,5 & 9,7 & 56,0 & 1,0 & 6,1 \\
\hline$Z n_{-} F$ & 0,49 & 53,4 & 0,19 & 20,9 & 0,04 & 4,9 & 0,19 & 20,7 \\
\hline $\mathrm{Br}_{-} \mathrm{F}$ & 0,5 & 55,0 & 0,2 & 18,5 & - & - & 0,2 & 26,5 \\
\hline $\mathrm{BCe} \_\mathrm{F}$ & 214,0 & 67,7 & 63,6 & 20,1 & 8,7 & 2,8 & 29,7 & 9,4 \\
\hline MPF & 2060 & 55,3 & 992 & 26,6 & 127 & 3,4 & 547 & 14,7 \\
\hline
\end{tabular}

Tabela 23: concentração média de MPF associado a cada fator por estação. O percentual mostrado é relativo à concentração de MPF da estação.

\begin{tabular}{cccccccccc}
\hline \multicolumn{1}{c}{ PMF - ZF2 - Concentração de Material Particulado Fino nos diferentes fatores e nas } \\
diferentes estações \\
\hline \multirow{2}{*}{ Estação } & \multicolumn{2}{c}{ Queimada } & \multicolumn{2}{c}{ Biogênico } & Solo & \multicolumn{2}{c}{ Marinho } \\
\cline { 2 - 9 } & $\begin{array}{c}\text { Conc. } \\
\left(\mathrm{ng} / \mathrm{m}^{3}\right)\end{array}$ & $\%$ & $\begin{array}{c}\text { Conc. } \\
\left(\mathrm{ng} / \mathrm{m}^{3}\right)\end{array}$ & $\%$ & $\begin{array}{c}\text { Conc. } \\
\left(\mathrm{ng} / \mathrm{m}^{3}\right)\end{array}$ & $\%$ & $\begin{array}{c}\text { Conc. } \\
\left(\mathrm{ng} / \mathrm{m}^{3}\right)\end{array}$ & $\%$ \\
\hline Estação Seca & 3178 & 61 & 1589 & 31 & 92 & 2 & 734 & 14 \\
Estação Chuvosa & 1033 & 47 & 520 & 24 & 223 & 10 & 476 & 22 \\
\hline $\begin{array}{c}\text { Razão } \\
\text { Seca/Chuvosa }\end{array}$ & 3,08 & & 3,06 & & 0,41 & & 1,54 & \\
\hline
\end{tabular}

O primeiro fator encontrado é responsável por mais de $50 \%$, da concentração de elementos como $\mathrm{K}, \mathrm{Zn}, \mathrm{Br}$ e BCe além de ser responsável em média, durante a estação seca, por $61 \%$ do material particulado fino deste sítio, emitindo $3178 \mathrm{ng} / \mathrm{m}^{3}$, concentração que cai 
para aproximadamente 30\% durante a estação chuvosa. Esses elementos indicam se tratar do fator associado as emissões de queimadas.

O segundo fator abrange boa parte das concentrações de elementos como o $\mathrm{P}, \mathrm{Na}, \mathrm{S}$, $\mathrm{Zn}, \mathrm{Br}$ e BCe e é responsável em média por $1589 \mathrm{ng} / \mathrm{m}^{3}$ do MPF durante a estação seca e $520 \mathrm{ng} / \mathrm{m}^{3}$ durante a estação chuvosa. De forma semelhante ao primeiro fator, (emissões de queimadas), a diferença de intensidade de emissão dentre os dois períodos é de aproximadamente três vezes, entretanto a contribuição para o material particulado fino total é mais estável, oscilando entre $31 \%$ e $24 \%$ dentre as estações secas e chuvosas, respectivamente. Por esses fatores, vinculou-se este fator aos processos de emissão de aerossóis biogênicos da floresta.

Vale ressaltar neste ponto que os elementos característicos de queimadas e processos biogênicos naturais são semelhantes: $\mathrm{P}, \mathrm{K}, \mathrm{S}$ e $\mathrm{BCe}$, este último por conta da absorção de luz por matéria orgânica, influenciando na separação destes dois processos. Isso ocorre pelo fato da vegetação ser a fonte de ambos fatores, mas com processo de emissão diferentes. $26 \%$ dos bootstraps realizados para esses resultados mostraram coeficientes de determinação maior que 0,6 do fator biogênico com o de queimada, indicando certa ambiguidade entre os perfis encontrados nestes fatores. Em geral, o indicado é que até $80 \%$ das amostras correlacionem-se com outras bases (GARY NORRIS, RACHELLE DUVALL, STEVE BROWN, 2014).

O terceiro fator é responsável por grande parte das concentrações dos elementos Al, $\mathrm{Si}, \mathrm{Ca}$, Ti e Fe, próximo ou superior a $50 \%$ da concentração média desses elementos, sendo, portanto, caracterizado como emissões de aerossóis associados ao solo. Verifica-se, também, que durante a estação seca esse fator é responsável por $2 \%$ do material particulado fino, com concentração em torno de $98 \mathrm{ng} / \mathrm{m}^{3}$, e que, durante a estação chuvosa, observa-se que este valor aumenta mais de $100 \%$ atingindo $223 \mathrm{ng} / \mathrm{m}^{3}$ e, devido à menor concentração de material particulado fino na estação chuvosa, ele é responsável por aproximadamente $10 \%$ da concentração média de MPF. Isso ocorre porque na estação chuvosa a posição da ITCZ fica abaixo de Manaus, favorecendo a entrada de massas de ar trazendo poeira do deserto do Saara (ARTAXO et al., 2002, 2013). 
O quarto fator contém a quase totalidade de emissão do elemento $\mathrm{Cl}(87 \%)$ e grande parte da concentração de elementos como $\mathrm{Na}, \mathrm{S}, \mathrm{Ca}, \mathrm{Mn}$. Durante a estação seca, sua emissão média é de $734 \mathrm{ng} / \mathrm{m}^{3}$, cerca de $14 \%$ do MPF, enquanto que durante a chuvosa é de $476 \mathrm{ng} / \mathrm{m}^{3}$, cerca de $22 \%$ do MPF. Devido a estas características, atribui-se este fator ao aerossol marinho.

\subsubsection{PMF aplicado ao material particulado grosso da ZF2}

A análise PMF aplicada à série temporal de amostras da ZF2 identificou quatro fatores que compõem o material particulado grosso na ZF2. São eles: aerossol biogênico, ressuspensão do solo e dois fatores relacionados ao aerossol marinho. Esta extração de fontes foi satisfatoriamente quantificada no modelo básico e a aplicação de Fpeak não demonstrou vantagem na separação dos fatores. As tabelas abaixo mostram a concentração de elementos por fator e a contribuição de cada fator para a composição total de MPG na ZF2 por estação.

Tabela 24: resultados do PMF aplicado ao MPG da ZF2 coletado durante o GoAmazon2014/15. A tabela mostra a concentração média de cada elemento por fator e o percentual que representa em relação à concentração média do mesmo.

\begin{tabular}{ccccccccc}
\hline \multicolumn{7}{c}{ PMF - ZF2 - Material Particulado Grosso - Concentração por fatores } \\
\hline \multicolumn{2}{c}{ Biogênico } & \multicolumn{2}{c}{ Solo } & \multicolumn{2}{c}{$\begin{array}{c}\text { Marinho } 2 \\
(\mathrm{NaCl})\end{array}$} & $\begin{array}{c}\text { Marinho } 3 \\
\left(\mathrm{Na}_{2} \mathrm{SO}_{4}\right)\end{array}$ \\
\cline { 2 - 9 } & $\begin{array}{c}\text { Conc. } \\
\left(\mathrm{ng} / \mathrm{m}^{3}\right)\end{array}$ & $\%$ & $\begin{array}{c}\text { Conc. } \\
\left(\mathrm{ng} / \mathrm{m}^{3}\right)\end{array}$ & $\%$ & $\begin{array}{c}\text { Conc. } \\
\left(\mathrm{ng} / \mathrm{m}^{3}\right)\end{array}$ & $\%$ & $\begin{array}{c}\text { Conc. } \\
\left(\mathrm{ng} / \mathrm{m}^{3}\right)\end{array}$ & $\%$ \\
\hline Na_G & 2,3 & 3,8 & - & - & 36,1 & 59,2 & 22,6 & 37,0 \\
Al_G & 0,6 & 1,2 & 31,8 & 67,2 & 2,7 & 5,6 & 12,3 & 25,9 \\
Si_G & 2,8 & 3,2 & 59,4 & 68,9 & 7,0 & 8,1 & 17,1 & 19,9 \\
P_G & 16,8 & 81,5 & 0,4 & 1,9 & 1,1 & 5,5 & 2,3 & 11,0 \\
S_G & 11,9 & 25,2 & 2,0 & 4,3 & 6,9 & 14,6 & 26,3 & 55,9 \\
Cl_G & 6,0 & 12,1 & 6,1 & 12,2 & 37,7 & 75,8 & - & - \\
K_G & 42,7 & 58,9 & 8,4 & 11,6 & 9,4 & 12,9 & 12,0 & 16,6 \\
Ca_G & 2,4 & 14,8 & 6,0 & 37,3 & 5,8 & 36,2 & 1,9 & 11,6 \\
Ti_G & 0,0 & 0,2 & 2,4 & 62,2 & 0,0 & 0,5 & 1,5 & 37,1 \\
Fe_G & 0,7 & 2,1 & 19,4 & 61,1 & 2,4 & 7,6 & 9,3 & 29,2 \\
Zn_G & 0,41 & 59,5 & 0,07 & 10,2 & 0,09 & 13,7 & 0,11 & 16,6 \\
BCe_G & 17,1 & 43,1 & 4,7 & 11,8 & 3,0 & 7,5 & 14,9 & 37,6 \\
MPG & 2548 & 50,6 & 555 & 11,0 & 992 & 19,7 & 937 & 18,6 \\
\hline
\end{tabular}


Tabela 25: concentração média de MPG associado a cada fator por estação. O percentual mostrado é relativo à concentração de MPG da estação.

\begin{tabular}{ccccccccc}
\hline \multicolumn{2}{c}{ PMF - ZF2 - Concentração de Material Particulado Grosso nas diferentes estações } \\
& Biogênico & Solo & & $\begin{array}{c}\text { Marinho } 2 \\
(\mathrm{NaCl})\end{array}$ & \multicolumn{2}{c}{$\begin{array}{c}\text { Marinho } 3 \\
\left(\mathrm{Na}_{2} \mathrm{SO}_{4}\right)\end{array}$} \\
\hline \multirow{2}{*}{ Estação } & Conc. $\left(\mathrm{ng} / \mathrm{m}^{3}\right)$ & $\%$ & Conc. $\left(\mathrm{ng} / \mathrm{m}^{3}\right)$ & $\%$ & Conc. $\left(\mathrm{ng} / \mathrm{m}^{3}\right)$ & $\%$ & Conc. $\left(\mathrm{ng} / \mathrm{m}^{3}\right)$ & $\%$ \\
\hline Estação Seca & 2564 & 45 & 584 & 10 & 1236 & 22 & 1264 & 22 \\
Estação Chuvosa & 2903 & 59 & 906 & 18 & 931 & 19 & 511 & 10 \\
\hline Razão Seca/Chuvosa & 0,88 & & 0,64 & & 1,33 & 2,47 & \\
\hline
\end{tabular}

O primeiro fator é o principal responsável pela concentração de $\mathrm{P}$ - responsável por

81,5\% da concentração média deste elemento na moda grossa da ZF2 - além de ser importante na concentração de elementos como K, S, Zn e BCe. Este fator apresenta concentração maior durante a estação chuvosa, emitindo em média $2903 \mathrm{ng} / \mathrm{m}^{3}$ que representa $59 \%$ da concentração de material particulado neste período. Na estação seca a concentração cai para $2564 \mathrm{ng} / \mathrm{m}^{3}, 45 \%$ do material particulado grosso nesta estação. Verifica-se, então, que a razão de sua concentração entre a estação seca pela chuvosa é de 0,88, evidenciando a constância desta fonte durante o ano.

O segundo fator explica por volta de $60 \%$ da concentração média dos elementos Al, Si, Ti e Fe, além de 37,3\% de Ca. Nota-se em ambas as estações concentrações baixas devido a este fator devido à presença de detritos biológicos sobre o solo que dificultam à suspensão da poeira do solo. O aumento da concentração de MPG durante a estação chuvosa está relacionado com o material particulado vindo da África, composto principalmente por poeira do deserto do Saara (ARANA, A.; ARTAXO, 2014; BEN-AMI et al., 2010; SWAP et al., 1992). Desta forma, este fator corresponde à aerossóis associados à poeira do solo.

O terceiro fator é o principal responsável pela concentração média de $\mathrm{Na}$ e $\mathrm{Cl}$ e, apresenta também, expressivas contribuições na concentração de elementos como o Ca. Durante a estação seca, este fator é responsável por aproximadamente $1236 \mathrm{ng} / \mathrm{m}^{3}$ do material particulado grosso, correspondendo a $22 \%$ do MPG da ZF2. Já na estação chuvosa, esses números apresentam uma ligeira diminuição para $931 \mathrm{ng} / \mathrm{m}^{3}$ e $19 \%$. Conforme nomenclatura utilizada na seção 4.7.4 atribuiu-se este fator ao aerossol marinho do tipo 2 .

O quarto fator é responsável por consideráveis frações das concentrações de $\mathrm{Na}$, S e $\mathrm{BCe}$, além de outros elementos como Al, Ti e Fe. Verificando sua sazonalidade, nota-se concentração média de $1264 \mathrm{ng} / \mathrm{m}^{3}$, correspondendo a $22 \%$ da concentração média de 
material particulado grosso para este sítio. Com a estação seca, a concentração média cai para $511 \mathrm{ng} / \mathrm{m}^{3}$, representando $10 \%$ da concentração média de material particulado grosso. Assim este fator está associado ao aerossol marinho 3.

Observou-se na análise PMF do aerossol da ZF2 que temos componentes associadas a emissões naturais (solo e marinho) e também a aerossóis emitidos em queimadas. Não observou-se qualquer componente associado a poluição urbana.

\subsubsection{PMF aplicado ao material particulado fino do TIWA}

No TIWA foram obtidos seis diferentes componentes no material particulado fino. Eles podem ser identificados como: poluição veicular, aerossol marinho, aerossóis biogênicos, queimada, poeira do solo e a poluição de Manaus. A rodada básica neste sítio foi suficiente para chegar a estes fatores e não se observou melhoras através do uso das rotinas do Fpeak. O segundo, terceiro e quarto fator apresentaram perfis semelhantes aos fatores "marinho", "biogênico" e "queimada" extraídos na aplicação do PMF na ZF2, seção 4.8.2, e, desta maneira, foram classificados deste modo.

Nas Tabelas 26 e 27 verifica-se que o primeiro fator encontrado no TIWA é responsável por grande parte da concentração média de elementos como $\mathrm{Mn}, \mathrm{Ni}, \mathrm{Cu}, \mathrm{Zn}, \mathrm{Br}$, $\mathrm{Pb}$ e BCe. Devido aos elementos presentes neste fator, e a pouca variabilidade sazonal, este foi associado a emissões veiculares de Manaus. O perfil quantitativo do quinto fator mostra que grande parte das concentrações de $\mathrm{Al}, \mathrm{Si}$, Ti e Fe, elementos que caracterizam poeira do solo estão associados a este fator. É interessante notar que no sítio TIWA, este fator apresentou comportamento distinto ao da ZF2 na diferença entre estação seca e chuvosa: ocorre um aumento de MPF associado a este fator de $1381 \mathrm{ng} / \mathrm{m}^{3}$ na estação chuvosa para $1816 \mathrm{ng} / \mathrm{m}^{3}$ na estação seca, indicando a influência da ação antrópica na ressuspensão de poeira do solo através das atividades realizadas na cidade, especialmente durante a estação seca, quando a menor ocorrência de chuvas diminui a influência da remoção por deposição úmida, considerado um dos mais eficientes processos de remoção (WALLACE; HOBBS, 2006). Desta forma, torna-se notável a influência no processo de ressuspensão de solo provocado pela atividade antrópica em uma cidade.

O sexto fator possui alta concentração de $\mathrm{Na}, \mathrm{Al}, \mathrm{Cl}, \mathrm{Ca}, \mathrm{Mn}, \mathrm{Ti}, \mathrm{Fe}$ e $\mathrm{Cu}$, além de, em menores proporções, $\mathrm{Zn}, \mathrm{Br}$ e $\mathrm{Pb}$ e, portanto, foi considerado como sendo o fator associado 
à poluição. Sua concentração aproximadamente duplica durante a estação seca, passando de $479 \mathrm{ng} / \mathrm{m}^{3}$ (14\% do MPF) na estação chuvosa para $1004 \mathrm{ng} / \mathrm{m}^{3}$ ( $9 \%$ do MPF).

Os fatores associados à ação antrópica (fator veicular e de poluição) no sítio TIWA são responsáveis em média por concentrações de $1083 \mathrm{ng} / \mathrm{m}^{3}$ de MPF durante a estação seca e $641 \mathrm{ng} / \mathrm{m}^{3}$ durante a estação chuvosa. São valores significativos, que variam de $11 \%$ a 21\% do MPF no sítio do TIWA dependendo da estação.

Tabela 26: resultados do PMF aplicado ao MPF do TIWA coletado durante o GoAmazon2014/15. A tabela mostra a concentração média de cada elemento por fator e o percentual que representa em relação à concentração média do mesmo.

\begin{tabular}{cccccccccccccc}
\hline \multicolumn{10}{c}{ PMF - TIWA - Material Particulado Fino } \\
\hline & \multicolumn{1}{c}{ Veicular } & \multicolumn{1}{c}{ Marinho } & \multicolumn{1}{c}{ Biogênico } & Queimada & \multicolumn{3}{c}{ Solo } & \multicolumn{3}{c}{ Poluição } \\
\cline { 2 - 14 } & $\begin{array}{c}\text { Conc. } \\
\left(\mathrm{ng} / \mathrm{m}^{3}\right)\end{array}$ & $\%$ & $\begin{array}{c}\text { Conc. } \\
\left(\mathrm{ng} / \mathrm{m}^{3}\right)\end{array}$ & $\%$ & $\begin{array}{c}\text { Conc. } \\
\left(\mathrm{ng} / \mathrm{m}^{3}\right)\end{array}$ & $\%$ & $\begin{array}{c}\text { Conc. } \\
\left(\mathrm{ng} / \mathrm{m}^{3}\right)\end{array}$ & $\%$ & $\begin{array}{c}\text { Conc. } \\
\left(\mathrm{ng} / \mathrm{m}^{3}\right)\end{array}$ & $\%$ & $\begin{array}{c}\text { Conc. } \\
\left(\mathrm{ng} / \mathrm{m}^{3}\right)\end{array}$ & $\%$ \\
\hline Na_F & 3,4 & 4,3 & 0,1 & 0,1 & 30,7 & 39,8 & 7,9 & 10,2 & 16,0 & 20,7 & 19,2 & 24,8 \\
Al_F & 3,0 & 2,9 & 1,5 & 1,5 & 4,8 & 4,7 & 12,9 & 12,5 & 58,9 & 57,1 & 21,9 & 21,2 \\
Si_F & 22,1 & 14,2 & 2,2 & 1,4 & 7,8 & 5,0 & 5,4 & 3,5 & 103,8 & 66,9 & 13,8 & 8,9 \\
P_F & 1,6 & 12,6 & 0,5 & 4,2 & 5,4 & 43,0 & 2,5 & 19,5 & 1,7 & 13,1 & 1,0 & 7,6 \\
S_F & 33,1 & 8,6 & 3,6 & 0,9 & 195,2 & 50,7 & 86,9 & 22,6 & 55,7 & 14,5 & 10,7 & 2,8 \\
Cl_F & - & - & 2,8 & 53,1 & 0,3 & 6,2 & 0,8 & 15,6 & 0,2 & 3,7 & 1,1 & 21,4 \\
K_F & 11,7 & 5,8 & 18,4 & 9,0 & 37,4 & 18,4 & 100,6 & 49,6 & 34,8 & 17,2 & - & - \\
Ca_F & 2,5 & 9,7 & 1,4 & 5,4 & 2,4 & 9,4 & - & - & 8,3 & 32,1 & 11,3 & 43,4 \\
Ti_F & - & - & 0,2 & 3,1 & - & - & 1,1 & 13,5 & 4,0 & 51,4 & 2,5 & 32,0 \\
Mn_F & 0,8 & 38,1 & 0,1 & 2,8 & - & - & 0,5 & 25,6 & 0,3 & 15,6 & 0,4 & 18,0 \\
Fe_F & 4,0 & 5,5 & - & - & 2,8 & 3,8 & 11,9 & 16,4 & 30,0 & 41,3 & 23,9 & 33,0 \\
Ni_F & 0,23 & 37,5 & 0,05 & 8,3 & 0,09 & 14,8 & 0,10 & 17,2 & 0,13 & 22,2 & - & - \\
Cu_F & 0,19 & 30,9 & 0,03 & 5,2 & 0,07 & 10,8 & 0,11 & 17,7 & - & - & 0,22 & 35,4 \\
Zn_F & 2,68 & 49,1 & 0,42 & 7,6 & 0,72 & 13,2 & 0,95 & 17,4 & - & - & 0,70 & 12,7 \\
Br_F & 0,4 & 17,0 & 0,2 & 8,0 & 0,4 & 17,0 & 1,1 & 44,8 & - & - & 0,3 & 13,2 \\
Pb_F & 0,7 & 46,4 & - & - & 0,4 & 24,4 & 0,2 & 15,0 & 0,04 & 2,4 & 0,2 & 11,8 \\
BCe_F & 270,4 & 25,7 & 8,4 & 0,8 & 211,9 & 20,1 & 397,6 & 37,8 & 85,7 & 8,1 & 78,9 & 7,5 \\
MPF & 189 & 2,3 & 362 & 4,4 & 2295 & 28,0 & 3223 & 39,3 & 1397 & 17,1 & 729 & 8,9 \\
\hline
\end{tabular}

Tabela 27: concentração média de MPF associado a cada fator por estação. 0 percentual mostrado é relativo à participação do fator no MPF da estação seca ou chuvosa.

PMF - TIWA - Concentração de Material Particulado Fino nas diferentes estações

\begin{tabular}{|c|c|c|c|c|c|c|c|c|c|c|c|c|}
\hline Estação & Veicular & & Marinho & & Biogênico & & Queimada & & Solo & & Poluição & \\
\hline & $\begin{array}{l}\text { Conc. } \\
\left(\mathrm{ng} / \mathrm{m}^{3}\right)\end{array}$ & $\%$ & $\begin{array}{l}\text { Conc. } \\
\left(\mathrm{ng} / \mathrm{m}^{3}\right)\end{array}$ & $\%$ & $\begin{array}{l}\text { Conc. } \\
\left(\mathrm{ng} / \mathrm{m}^{3}\right)\end{array}$ & $\%$ & $\begin{array}{l}\text { Conc. } \\
\left(\mathrm{ng} / \mathrm{m}^{3}\right)\end{array}$ & $\%$ & $\begin{array}{l}\text { Conc. } \\
\left(\mathrm{ng} / \mathrm{m}^{3}\right)\end{array}$ & $\%$ & $\begin{array}{l}\text { Conc. } \\
\left(\mathrm{ng} / \mathrm{m}^{3}\right)\end{array}$ & $\%$ \\
\hline Seca & 190 & 2 & 427 & 4 & 3383 & 31 & 4644 & 43 & 1816 & 17 & 1004 & 9 \\
\hline Chuvosa & 254 & 7 & 345 & 10 & 668 & 19 & 928 & 26 & 1381 & 39 & 479 & 14 \\
\hline $\begin{array}{c}\text { Razão } \\
\text { Seca/Chuvosa }\end{array}$ & 0,75 & & 1,24 & & 5,06 & & 5,00 & & 1,32 & & 2,10 & \\
\hline
\end{tabular}




\subsubsection{PMF aplicado ao material particulado grosso do TIWA}

Para o MPG do TIWA, foram extraídos seis fatores. Os resultados apresentados são os obtidos na rodada básica. Dos seis fatores encontrados, o último fator apresentou perfil semelhante ao já encontrado na aplicação do PMF no material particulado grosso da ZF2 e, portanto, foi classificado com fator associado à emissão por processos biogênicos. Os demais fatores são discutidos após a exposição dos resultados, Tabelas 28 e 29.

Tabela 28: resultados do PMF aplicado ao MPG do TIWA coletado durante o GoAmazon2014/15. A tabela mostra a concentração média de cada elemento por fator e o percentual que representa em relação à concentração média do mesmo.

\begin{tabular}{lccccccccccccc}
\hline \multicolumn{10}{c}{ PMF - TIWA - Material Particulado Grosso } \\
\hline & $\begin{array}{c}\text { Marinho 3 } \\
\left(\mathrm{Na}_{2} \mathrm{SO}_{4}\right)\end{array}$ & \multicolumn{1}{c}{ Veicular } & \multicolumn{2}{c}{ Poluição } & $\begin{array}{c}\text { Marinho } 1 \\
(\mathrm{HCl})\end{array}$ & Solo & \multicolumn{2}{c}{ Biogênico } \\
\cline { 2 - 15 } & $\begin{array}{c}\text { Conc. } \\
\left(\mathrm{ng} / \mathrm{m}^{3}\right)\end{array}$ & $\%$ & $\begin{array}{c}\text { Conc. } \\
\left(\mathrm{ng} / \mathrm{m}^{3}\right)\end{array}$ & $\%$ & $\begin{array}{c}\text { Conc. } \\
\left(\mathrm{ng} / \mathrm{m}^{3}\right)\end{array}$ & $\%$ & $\begin{array}{c}\text { Conc. } \\
\left(\mathrm{ng} / \mathrm{m}^{3}\right)\end{array}$ & $\%$ & $\begin{array}{c}\text { Conc. } \\
\left(\mathrm{ng} / \mathrm{m}^{3}\right)\end{array}$ & $\%$ & $\begin{array}{c}\text { Conc. } \\
\left(\mathrm{ng} / \mathrm{m}^{3}\right)\end{array}$ & $\%$ \\
\hline Na_G & 46,8 & 56,2 & - & - & - & - & 2,2 & 2,6 & 34,3 & 41,2 & - & - \\
Al_G & 0,2 & 0,1 & 49,9 & 30,1 & 9,1 & 5,5 & 7,0 & 4,2 & 98,1 & 59,1 & 1,8 & 1,1 \\
Si_G & - & - & 51,4 & 21,7 & 35,6 & 15,0 & 30,7 & 13,0 & 113,0 & 47,8 & 5,7 & 2,4 \\
P_G & - & - & - & - & 1,9 & 10,3 & 0,0 & 0,1 & 0,3 & 1,8 & 15,9 & 87,9 \\
S_G & 23,0 & 42,6 & 7,9 & 14,7 & 2,6 & 4,8 & - & - & 11,6 & 21,6 & 8,8 & 16,4 \\
Cl_G & 12,8 & 24,6 & - & - & - & - & 38,2 & 73,6 & - & - & 0,9 & 1,8 \\
K_G & 13,1 & 16,8 & 11,7 & 15,0 & 7,6 & 9,7 & 2,6 & 3,3 & 8,9 & 11,4 & 34,0 & 43,7 \\
Ca_G & 15,0 & 27,9 & - & - & 26,3 & 48,9 & 1,2 & 2,3 & 11,3 & 20,9 & - & - \\
Ti_G & 1,3 & 9,5 & 3,6 & 26,4 & 1,4 & 10,2 & - & - & 7,4 & 53,9 & - & - \\
Mn_G & 0,2 & 14,6 & 0,2 & 15,5 & 0,3 & 25,3 & 0,2 & 14,5 & 0,3 & 26,1 & 0,05 & 4,0 \\
Fe_G & 9,4 & 9,1 & 30,2 & 29,2 & 6,7 & 6,5 & 2,2 & 2,1 & 53,7 & 52,1 & 0,9 & 0,9 \\
CU_G & 0,15 & 31,3 & 0,03 & 6,8 & 0,24 & 50,8 & 0,00 & 1,1 & 0,01 & 1,7 & 0,04 & 8,3 \\
Zn_G & 0,52 & 23,3 & 0,65 & 29,1 & 0,85 & 37,9 & - & - & - & - & 0,22 & 9,7 \\
BCe_G & 42,8 & 37,6 & 61,4 & 53,9 & - & - & - & - & 4,2 & 3,7 & 5,4 & 4,7 \\
MPG & 990 & 14,7 & 1281 & 19,0 & 497 & 7,4 & 264 & 3,9 & 1290 & 19,1 & 2420 & 35,9 \\
\hline
\end{tabular}

Tabela 29: concentração média de MPG associado a cada fator por estação. O percentual exposto é relativo à concentração de MPG da estação.

\begin{tabular}{|c|c|c|c|c|c|c|c|c|c|c|c|c|}
\hline \multicolumn{13}{|c|}{ PMF - TIWA - Concentração de Material Particulado Grosso nas diferentes estações } \\
\hline \multirow{3}{*}{ Estação } & Marinho & & & & & & Marinho & & & & & \\
\hline & $\begin{array}{c}3 \\
\left(\mathrm{Na}_{2} \mathrm{SO}_{4}\right)\end{array}$ & & Veicular & & Poluição & & $\begin{array}{c}1 \\
(\mathrm{HCl}) \\
\end{array}$ & & Solo & & Biogênico & \\
\hline & $\begin{array}{l}\text { Conc. } \\
\left(\mathrm{ng} / \mathrm{m}^{3}\right)\end{array}$ & $\%$ & $\begin{array}{l}\text { Conc. } \\
\left(\mathrm{ng} / \mathrm{m}^{3}\right)\end{array}$ & $\%$ & $\begin{array}{l}\text { Conc. } \\
\left(\mathrm{ng} / \mathrm{m}^{3}\right)\end{array}$ & $\%$ & $\begin{array}{l}\text { Conc. } \\
\left(\mathrm{ng} / \mathrm{m}^{3}\right)\end{array}$ & $\%$ & $\begin{array}{l}\text { Conc. } \\
\left(\mathrm{ng} / \mathrm{m}^{3}\right)\end{array}$ & $\%$ & $\begin{array}{l}\text { Conc. } \\
\left(\mathrm{ng} / \mathrm{m}^{3}\right)\end{array}$ & $\%$ \\
\hline Seca & 1264 & 18 & 1430 & 20 & 460 & 7 & 242 & 3 & 1924 & 28 & 2286 & 33 \\
\hline Chuvosa & 715 & 11 & 1272 & 20 & 723 & 11 & 323 & 5 & 660 & 10 & 2952 & 45 \\
\hline Razão Seca/Chuvosa & 1,77 & & 1,12 & & 0,64 & & 0,75 & & 2,92 & & 0,77 & \\
\hline
\end{tabular}

$\mathrm{O}$ primeiro fator é responsável por boa parte da emissão de elementos como $\mathrm{Na}, \mathrm{Cl}$,

S, Ca, Cu e BCe. Durante a estação seca, sua emissão média é de $1264 \mathrm{ng} / \mathrm{m}^{3}$, representando $18 \%$ da composição do $M P G$, esses valores decrescem para $715 \mathrm{ng} / \mathrm{m}^{3}$ e $11 \%$ na estação 
chuvosa, que mostra maior intensidade dessa fonte durante a estação seca. A alta concentração de $\mathrm{S}$ associado a este fator faz este fator estar relacionado com o fator marinho 3.

O segundo fator, possui consideráveis quantidades das concentrações médias de Al, $\mathrm{Si}, \mathrm{S}, \mathrm{Ti}, \mathrm{Mn}, \mathrm{Fe}, \mathrm{Zn}$ e BCe. Este fator permanece aproximadamente constante durante o ano, tendo sua contribuição decaído levemente de $1430 \mathrm{ng} / \mathrm{m}^{3}$ para $1272 \mathrm{ng} / \mathrm{m}^{3}$, da estação seca para chuvosa. Entretanto sua contribuição para o MPG é de $20 \%$ em ambas as épocas. Devido a este perfil de elementos, esta fonte foi caracterizada como devido a emissões veiculares.

O terceiro fator é responsável por grande parte das emissões de Ca, Mn, Cu e Zn. Sua variabilidade dentre as estações seca e chuvosa é de $460 \mathrm{ng} / \mathrm{m}^{3}$ para $723 \mathrm{ng} / \mathrm{m}^{3}$, isto é, de $7 \%$ para $11 \%$ do MPG total, respectivamente. Devido a este perfil de elementos, este perfil foi associado a poluição.

O quarto fator é responsável por $73,6 \%$ do $\mathrm{Cl}$ grosso e uma considerável parte de $\mathrm{Mn}$. As concentrações médias deste fator no TIWA são próximas dentre as duas estações: $242 \mathrm{ng} / \mathrm{m}^{3}$ e $323 \mathrm{ng} / \mathrm{m}^{3}$ na estação seca e chuvosa, respectivamente. Este fator foi associado ao aerossol marinho 1 por extrair uma parte significativa da concentração média de $\mathrm{Cl}$.

O quinto fator é responsável por grande parte das concentrações médias de Al, Si, Ti e Fe. Durante o ano sua concentração é a que mais varia: de $1924 \mathrm{ng} / \mathrm{m}^{3}$ ( $28 \%$ do MPG) para $660 \mathrm{ng} / \mathrm{m}^{3}$ (10\% do MPG), da estação seca para a chuvosa. Por conta deste perfil de elementos, esse fator foi associado à ressuspensão de poeira do solo. Este resultado mostra que os processos antrópicos que ocorrem dentro da cidade de Manaus suspendem grandes quantidades de poeira do solo, visto que na ZF2 o fator de transporte de poeira do Saara determina a sazonalidade deste fator.

\subsubsection{PMF aplicado ao material particulado fino de Manacapuru}

Em Manacapuru cinco fatores foram obtidos da aplicação do PMF na série temporal de concentrações, são eles: poluição, marinho, queimada, solo e biogênico. Contrário à análise ACPA, foi possível discriminar uma componente de poluição e Manaus em Manacapuru. Realizou-se Fpeak de intensidade 0,1, o que fez com que alguns elementos 
traço como o $\mathrm{Cl}$ no fator marinho, $\mathrm{P}$ no fator biogênico e $\mathrm{BCe}$ no fator poluição fossem maximizados nos respectivos fatores e minimizados em fatores menos relacionados com eles. O resultado da análise PMF podem ser observados nas Tabelas 30 e 31.

Tabela 30: resultados do PMF aplicado ao MPF de Manacapuru coletado durante o GoAmazon2014/15. A tabela mostra a concentração média de cada elemento por fator e o percentual que representa em relação à concentração média do mesmo.

\begin{tabular}{|c|c|c|c|c|c|c|c|c|c|c|}
\hline \multicolumn{11}{|c|}{ PMF - Manacapuru - Material Particulado Fino } \\
\hline & \multicolumn{2}{|c|}{ Biogênico } & \multicolumn{2}{|c|}{ Poluição } & \multicolumn{2}{|c|}{ Queimada } & \multicolumn{2}{|c|}{ Solo } & \multicolumn{2}{|c|}{ Marinho } \\
\hline & $\begin{array}{l}\text { Conc. } \\
\left(\mathrm{ng} / \mathrm{m}^{3}\right)\end{array}$ & $\%$ & $\begin{array}{l}\text { Conc. } \\
\left(\mathrm{ng} / \mathrm{m}^{3}\right)\end{array}$ & $\%$ & $\begin{array}{l}\text { Conc. } \\
\left(\mathrm{ng} / \mathrm{m}^{3}\right)\end{array}$ & $\%$ & $\begin{array}{l}\text { Conc. } \\
\left(\mathrm{ng} / \mathrm{m}^{3}\right)\end{array}$ & $\%$ & $\begin{array}{l}\text { Conc. } \\
\left(\mathrm{ng} / \mathrm{m}^{3}\right)\end{array}$ & $\%$ \\
\hline $\mathrm{Na}$ & 5,6 & 29,1 & 1,5 & 8,0 & 8,4 & 43,7 & 3,7 & 19,1 & 0,03 & 0,1 \\
\hline Al F & 0,5 & 1,4 & 7,6 & 21,2 & 1,9 & 5,2 & 26,0 & 72,3 & - & - \\
\hline Si_F & 1,6 & 2,4 & 5,3 & 8,0 & 3,3 & 4,9 & 53,9 & 81,1 & 2,4 & 3,6 \\
\hline P_F & 3,1 & 70,1 & - & - & 0,4 & 9,5 & 0,5 & 11,4 & 0,4 & 9,0 \\
\hline S_F & 67,0 & 51,1 & 7,5 & 5,7 & 48,0 & 36,6 & 8,7 & 6,7 & - & - \\
\hline $\mathrm{Cl} \_\mathrm{F}$ & - & - & - & - & 0,8 & 34,5 & 0,3 & 15,2 & 1,1 & 50,3 \\
\hline K_F & 1,3 & 2,3 & 9,2 & 16,5 & 38,9 & 69,9 & 6,3 & 11,4 & - & - \\
\hline Ca_F & 1,2 & 15,3 & - & - & - & - & 5,0 & 65,2 & 1,5 & 19,5 \\
\hline Ti_F & - & - & 1,0 & 37,9 & - & - & 1,7 & 61,7 & 0,01 & 0,5 \\
\hline Mn_F & 0,03 & 6,1 & 0,1 & 21,5 & 0,03 & 7,5 & 0,2 & 53,2 & 0,04 & 11,6 \\
\hline $\mathrm{Fe} \_\mathrm{F}$ & - & - & 8,6 & 39,7 & 0,3 & 1,4 & 12,8 & 58,9 & - & - \\
\hline Zn_F & 0,24 & 32,4 & 0,08 & 10,9 & - & - & 0,08 & 11,3 & 0,33 & 45,4 \\
\hline $\mathrm{Br}_{-} \mathrm{F}$ & 0,2 & 32,2 & 0,1 & 10,9 & 0,2 & 29,1 & - & - & 0,1 & 27,9 \\
\hline Bce_F & 23,7 & 10,4 & 57,5 & 25,2 & 79,4 & 34,8 & - & - & 67,4 & 29,6 \\
\hline $\mathrm{MPF}$ & 715 & 27,5 & 452 & 17,4 & 1123 & 43,2 & 234 & 9,0 & 75 & 2,9 \\
\hline
\end{tabular}

Tabela 31: concentração média de MPF associado a cada fator por estação. O percentual exposto é relativo à concentração de MPF da estação.

PMF - Manacapuru - Concentração de Material Particulado Fino nas diferentes estações

\begin{tabular}{|c|c|c|c|c|c|c|c|c|c|c|}
\hline \multirow[b]{2}{*}{ Estação } & \multicolumn{2}{|c|}{ Biogênico } & \multicolumn{2}{|c|}{ Poluição } & \multicolumn{2}{|c|}{ Queimada } & \multicolumn{2}{|c|}{ Solo } & \multicolumn{2}{|c|}{ Marinho } \\
\hline & $\begin{array}{l}\text { Conc. } \\
\left(\mathrm{ng} / \mathrm{m}^{3}\right)\end{array}$ & $\%$ & $\begin{array}{l}\text { Conc. } \\
\left(\mathrm{ng} / \mathrm{m}^{3}\right)\end{array}$ & $\%$ & $\begin{array}{l}\text { Conc. } \\
\left(\mathrm{ng} / \mathrm{m}^{3}\right)\end{array}$ & $\%$ & $\begin{array}{l}\text { Conc. } \\
\left(\mathrm{ng} / \mathrm{m}^{3}\right)\end{array}$ & $\%$ & $\begin{array}{l}\text { Conc. } \\
\left(\mathrm{ng} / \mathrm{m}^{3}\right)\end{array}$ & $\%$ \\
\hline Seca & 992 & 28 & 535 & 15 & 1889 & 54 & 127 & 4 & 95 & 3 \\
\hline Chuvosa & 476 & 26 & 396 & 22 & 525 & 29 & 406 & 22 & 61 & 3 \\
\hline $\begin{array}{c}\text { Razão } \\
\text { eca/Chuvose }\end{array}$ & 2,08 & & 1,35 & & 3,60 & & 0,31 & & 1,57 & \\
\hline
\end{tabular}

A análise do perfil elementar e variação sazonal, indica que o primeiro, terceiro, quarto e quinto fatores são semelhantes aos já encontrados para os sítios ZF2 e TIWA no MPF e correspondem aos fatores: "biogênico", "queimada", "solo" e "marinho". Salienta-se a importância do aerossol biogênico em Manacapuru, sendo em média responsável por 27,5\% do MPF deste sítio. 
O segundo fator extrai boa parte das concentrações médias de $\mathrm{Al}, \mathrm{Ti}, \mathrm{Mn}$, Fe e BCe e apresenta pouca variabilidade de emissão de MPF dentre as estações: $535 \mathrm{ng} / \mathrm{m}^{3}$ (15\% do MPF) na estação seca para $396 \mathrm{ng} / \mathrm{m}^{3}$ (22\% do MPF) na estação chuvosa. Por ter esta emissão quase constante e elementos associados a processos industriais, caracterizou-se este fator como Poluição. O fator poluição apresenta maior concentração em relação à massa total durante o período chuvoso. HOLANDA (2015) identifica maior impacto da pluma de Manaus em parâmetros ópticos durante o período chuvoso, quando a atmosfera apresenta menores concentrações de aerossóis e torna mais evidente a influência antrópica na região.

\subsubsection{PMF aplicado ao material particulado grosso de Manacapuru}

A aplicação do PMF na série temporal das concentrações do material grosso de Manacapuru resultou em quatro fatores extraídos. Foi necessária a rotação em Fpeak com intensidade de 0,6 para melhor compreensão dos diferentes fatores. Os resultados estão nas Tabelas 32 e 33 abaixo. O fator 1 apresenta perfil semelhante ao já encontrado para o MPG dos sítios ZF2 e TIWA e é, portanto, classificado como fator associado a aerossóis biogênicos emitidos pela vegetação.

O perfil da composição elementar do segundo fator compreende boa parte da concentração média de Ti, Fe e Al. Durante a estação seca é responsável, em média, por $356 \mathrm{ng} / \mathrm{m}^{3}$ (16\% do MPG) e 319ng/m³ (14\% do MPG) na estação chuvosa. Tais elementos são característicos da poeira do solo. Este aumento da intensidade deste fator durante a estação seca mostra um dos impactos causados pela atividade antrópica no TIWA - local onde a concentração de poeira do solo também aumenta durante a estação seca -, além do fato deste sítio estar envolto por pasto, de modo que a ressuspensão de poeira do solo seco é facilitada em relação ao solo úmido.

O terceiro fator possui altas concentrações de elementos como $\mathrm{Na}, \mathrm{S}, \mathrm{Cl}$ e $\mathrm{Zn}$, além de apresentar maior intensidade durante a estação seca: $187 \mathrm{ng} / \mathrm{m}^{3}$ ( $8 \%$ do MPG) que decresce para $136 \mathrm{ng} / \mathrm{m}^{3}$ (6\% do MPG) durante a estação chuvosa. Este fator foi associado ao aerossol marinho tipo 2 por ser responsável por boa parte da concentração média de $\mathrm{Na}$ e $\mathrm{Cl}$. O último fator apresenta alta quantidade de $\mathrm{Cl}, \mathrm{Ca}, \mathrm{Al}$ e Si e sua contribuição com o MPG 
é maior durante a estação chuvosa, participando em média com $23 \%$ do MPG. Este fator foi associado com aerossol marinho 1 devido à baixa concentração de Na e ausência de S.

Tabela 32: resultados do PMF aplicado ao MPG de Manacapuru coletado durante o GoAmazon2014/15. A tabela mostra a concentração média de cada elemento por fator e o percentual que representa em relação à concentração média do mesmo.

\begin{tabular}{|c|c|c|c|c|c|c|c|c|}
\hline \multicolumn{9}{|c|}{ PMF - Manacapuru - Material Particulado Grosso } \\
\hline & \multicolumn{2}{|c|}{ Biogênico } & \multicolumn{2}{|c|}{ Solo } & \multicolumn{2}{|c|}{$\begin{array}{c}\text { Marinho } 2 \\
(\mathrm{NaCl})\end{array}$} & \multicolumn{2}{|c|}{$\begin{array}{l}\text { Marinho } 1 \\
\quad(\mathrm{HCl})\end{array}$} \\
\hline & $\begin{array}{c}\text { Conc. } \\
\left(\mathrm{ng} / \mathrm{m}^{3}\right)\end{array}$ & $\%$ & $\begin{array}{l}\text { Conc. } \\
\left(\mathrm{ng} / \mathrm{m}^{3}\right)\end{array}$ & $\%$ & $\begin{array}{l}\text { Conc. } \\
\left(\mathrm{ng} / \mathrm{m}^{3}\right)\end{array}$ & $\%$ & $\begin{array}{l}\text { Conc. } \\
\left(\mathrm{ng} / \mathrm{m}^{3}\right)\end{array}$ & $\%$ \\
\hline $\mathrm{Na}$ & 6,35 & 31,1 & 1,68 & 8,2 & 9,37 & 45,8 & 3,03 & 14,8 \\
\hline Al_G & - & - & 16,5 & 48,3 & 2,85 & 8,4 & 14,8 & 43,4 \\
\hline Si_G & 2,46 & 4,1 & 15,8 & 26,2 & - & - & 42,0 & 69,7 \\
\hline P_G & 8,78 & 93,7 & - & - & - & - & 0,59 & 6,3 \\
\hline S_G & 8,67 & 53,1 & 1,42 & 8,7 & 6,25 & 38,2 & - & - \\
\hline Cl_G & - & - & - & - & 6,15 & 57,8 & 4,48 & 42,2 \\
\hline K_G & 23,6 & 69,7 & 1,09 & 3,2 & 0,09 & 2,6 & 8,29 & 24,5 \\
\hline Ca_G & 1,2 & 11,5 & 1,97 & 18,8 & 0,93 & 8,9 & 6,36 & 60,8 \\
\hline Ti_G & 0,01 & 0,2 & 3,39 & 86,2 & 0,54 & 13,6 & - & - \\
\hline $\mathrm{Fe} \_\mathrm{G}$ & - & - & 21,8 & 77,6 & 4,22 & 15,1 & 2,05 & 7,3 \\
\hline $\mathrm{Zn} \_\mathrm{G}$ & 0,16 & 45,8 & 0,08 & 23,6 & 0,07 & 19,7 & 0,04 & 10,9 \\
\hline BCe_G & 13,2 & 64,3 & 3,47 & 16,9 & 1,49 & 7,3 & 2,37 & 11,5 \\
\hline MPG & 1400 & 62,7 & 314 & 14,0 & 137 & 6,2 & 383 & 17,1 \\
\hline
\end{tabular}

Tabela 33: concentração média de MPG associado a cada fator por estação. O percentual exposto é relativo à concentração de MPG da estação.

PMF - Manacapuru - Concentração de Material Particulado Grosso nas diferentes estações

\begin{tabular}{ccccccccc}
\hline & \multicolumn{2}{c}{ Biogênico } & Solo & \multicolumn{2}{c}{$\begin{array}{c}\text { Marinho 2 } \\
(\mathrm{NaCl})\end{array}$} & \multicolumn{2}{c}{$\begin{array}{c}\text { Marinho } 1 \\
(\mathrm{HCl})\end{array}$} \\
\cline { 2 - 9 } Estação & $\begin{array}{c}\text { Conc. } \\
\left(\mathrm{ng} / \mathrm{m}^{3}\right)\end{array}$ & $\%$ & $\begin{array}{c}\text { Conc. } \\
\left(\mathrm{ng} / \mathrm{m}^{3}\right)\end{array}$ & $\%$ & $\begin{array}{c}\text { Conc. } \\
\left(\mathrm{ng} / \mathrm{m}^{3}\right)\end{array}$ & $\%$ & $\begin{array}{c}\text { Conc. } \\
\left(\mathrm{ng} / \mathrm{m}^{3}\right)\end{array}$ & $\%$ \\
\cline { 2 - 9 } Seca & 1505 & 67 & 356 & 16 & 187 & 8 & 248 & 11 \\
Chuvosa & 1379 & 61 & 319 & 14 & 136 & 6 & 514 & 23 \\
\hline $\begin{array}{c}\text { Razão } \\
\text { Seca/Chuvosa }\end{array}$ & 1,09 & & 1,12 & & 1,38 & & 0,48 & \\
\hline
\end{tabular}

4.8.8. Comparação entre os fatores encontrados pelos dois métodos multivariados (ACPA e PMF) para a fração fina do MP

Este capítulo apresenta a compilação dos resultados obtidos pelos métodos ACPA e PMF para o material particulado fino separados por fatores semelhantes entre os métodos. Uma análise mais detalhada foi realizada para os fatores associados ao aerossol marinho, biogênico e queimadas e estão expostos neste capítulo. Um quadro geral da atribuição de 
fontes de aerossóis para todos os sítios e todos os fatores discriminados pode ser vista na Figura 52.

Figura 52: concentração média e percentual em relação a concentração média de MPF separados por fatores semelhantes e sítios obtidos por meio da ACPA e PMF.

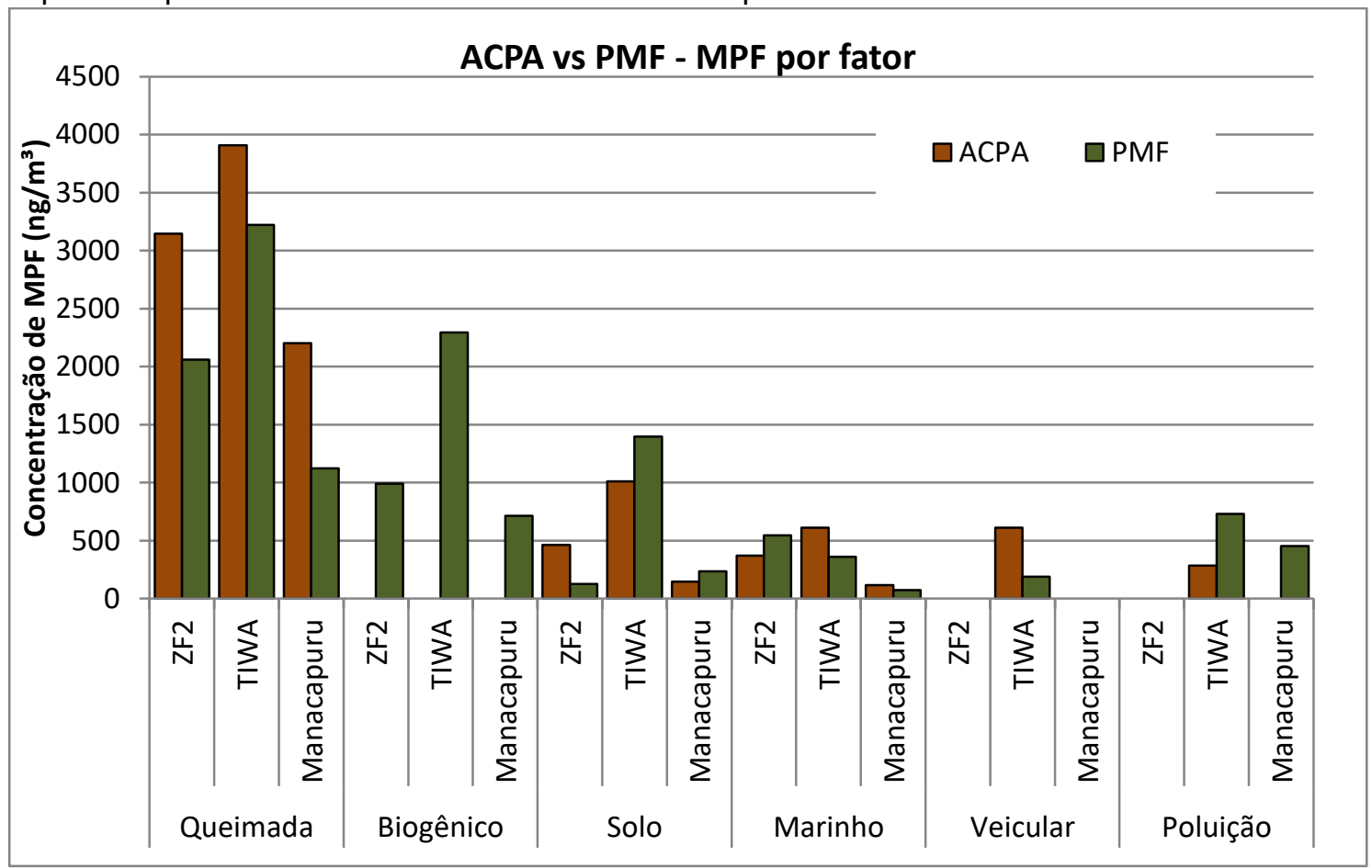

Dentre as diferenças dos resultados obtidos através das diferentes técnicas, verificase que o método PMF tem maior capacidade de discriminação de fatores. O PMF apresentou o fator biogênico em todos os sítios e também discriminou o fator de poluição em Manacapuru.

Análises de componentes principais absolutas realizadas em regiões remotas da Amazônia Central já foram objetos de diversos artigos (ARANA, A.; ARTAXO, 2014; ARTAXO et al., 1998; ECHALAR et al., 1998; PAULIQUEVIS et al., 2012). Estes trabalhos identificaram valores similares ao obtido neste trabalho pela ACPA em termos de impacto de aerossóis do solo.

Espera-se que fatores como queimada e processos biogênicos apresentem concentrações de MPF próximas nos diferentes sítios devido a proximidade espacial deles. O que se verifica, no entanto, é que o sítio TIWA apresenta aproximadamente de $1 \mu \mathrm{g} / \mathrm{m}^{3}$ a $2 \mu \mathrm{g} / \mathrm{m}^{3}$ de MPF associado aos fatores queimada e biogênico a mais, respectivamente, em comparação ao sítio ZF2. A explicação para esse aumento de MPF relacionado a estes fatores no sítio TIWA deve levar em conta que parte da emissão biogênica e de queimadas é 
de VOCs e que atividades antrópicas das cidades aumentam o potencial de oxidação de sua pluma. Desta forma verifica-se que a pluma de Manaus ao interagir com VOCs gera aproximadamente $3 \mu \mathrm{g} / \mathrm{m}^{3}$ a mais de MP do que em regiões sem a interferência desta pluma. Uma análise mais detalhada desses dois fatores está presente nas Figuras 53 e 54.

Figura 53: concentração média e percentual em relação a concentração média de MPF para as concentrações encontradas para o fator queimada através da ACPA e PMF. Escala Logarítmica.

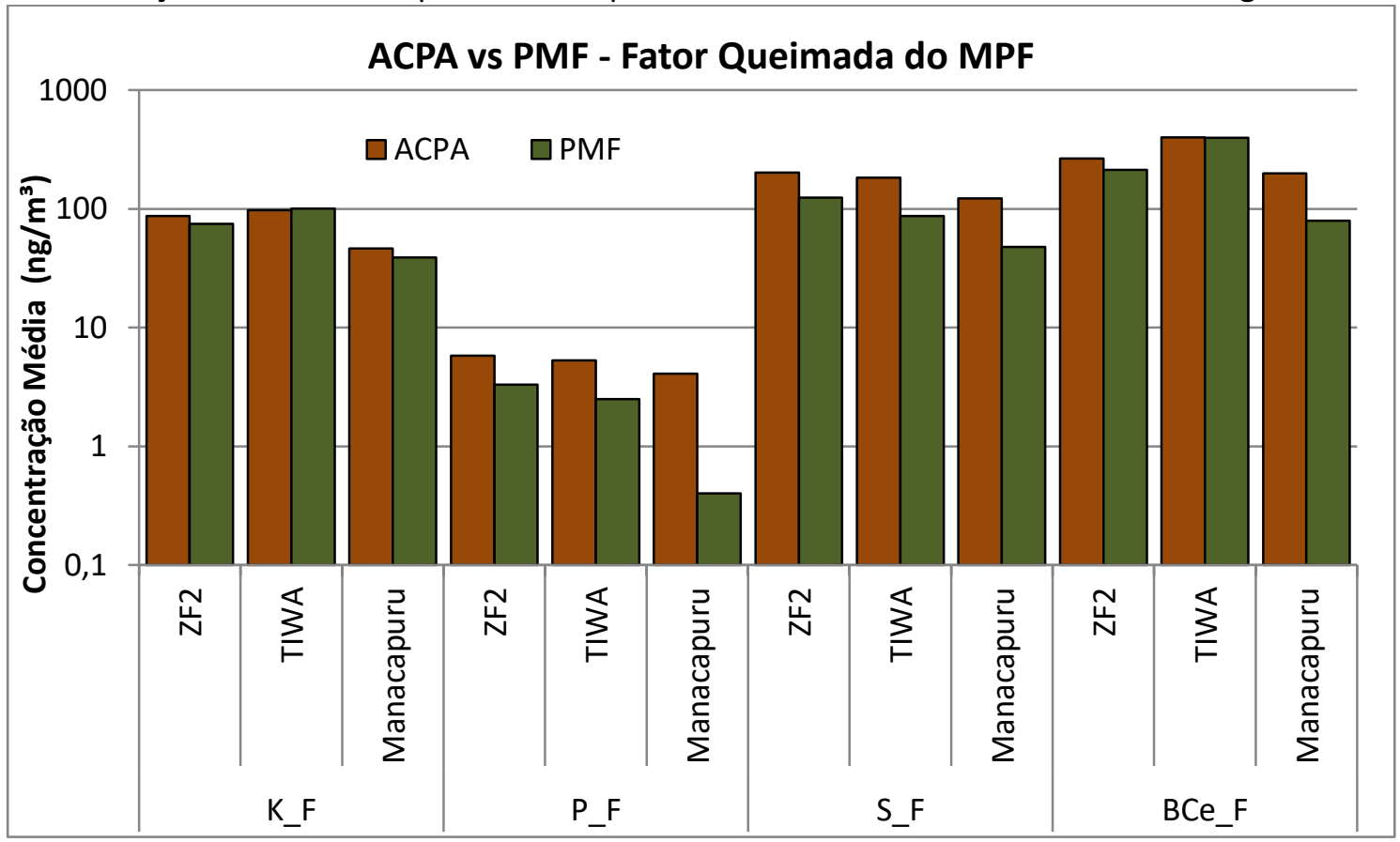

A Figura 53 expõe as concentrações e percentuais dos elementos assinatura extraídos para o fator queimada. A diferença relativa entre a concentração de BCe do TIWA e ZF2 (tomando a ZF2 como referência) no fator queimada varia entre +50 e $+85 \%$ dependendo da técnica e é a maior dentre os elementos chaves deste fator.

A Figura 54 mostra a concentração e percentual dos elementos característicos extraídos no fator de processos biogênicos. Verifica-se que a concentração de BCe extraído neste fator para o sítio TIWA é $148,3 \mathrm{ng} / \mathrm{m}^{3}$ maior em relação ao sítio ZF2. 
Figura 54: concentração média e percentual em relação a concentração média de MPF para as concentrações encontradas para o fator biogênico através do método PMF. A ACPA não extraiu este fator para o MPF.

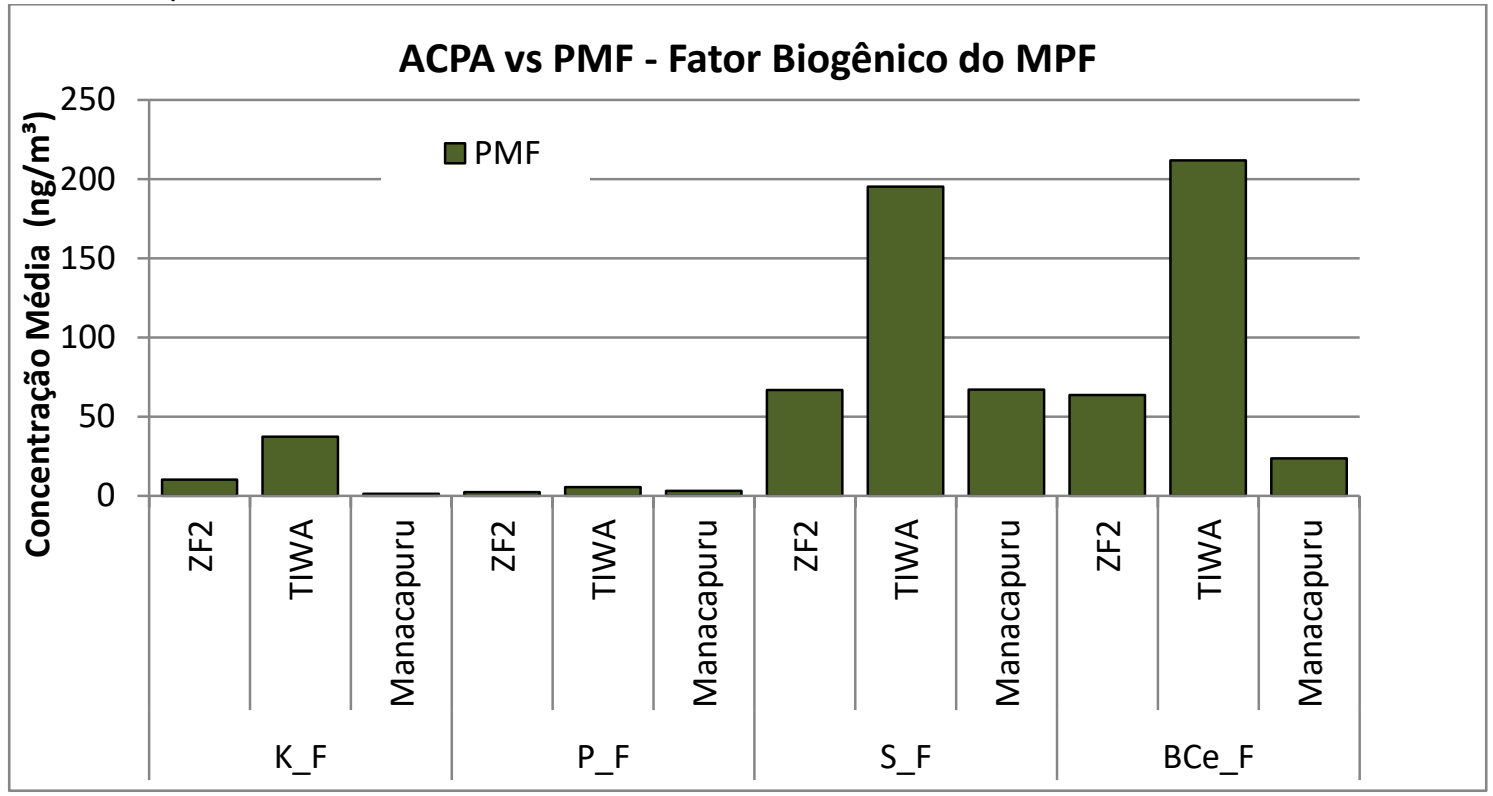

A diferença na concentração de BCe no sítios TIWA e ZF2 nos fatores queimada e biogênico ocorre devido à formação de SOA na interação de VOCs com a pluma da cidade de Manaus, pois sabe-se que parte do SOA é absorvedor de luz e influencia nas medidas de BCe. Nos fatores biogênico e queimada, o TIWA tem $332 \mathrm{ng} / \mathrm{m}^{3}$ a mais de concentração de BCe que a ZF2, concentração relevante, já que a concentração deste elemento no TIWA em média é de $889 \mathrm{ng} / \mathrm{m}^{3}$ durante o ano. A Figura abaixo, de um recente trabalho de Sá et al. (2017) ilustra o crescimento da massa de aerossóis orgânicos quando existe o impacto direto da pluma de Manaus em Manacapuru, resultado similar ao obtido nesta dissertação. Verifica-se um acréscimo de $3 \mu \mathrm{g} / \mathrm{m}^{3}$ em Manacapuru quando a pluma de Manaus atinge diretamente este sítio.

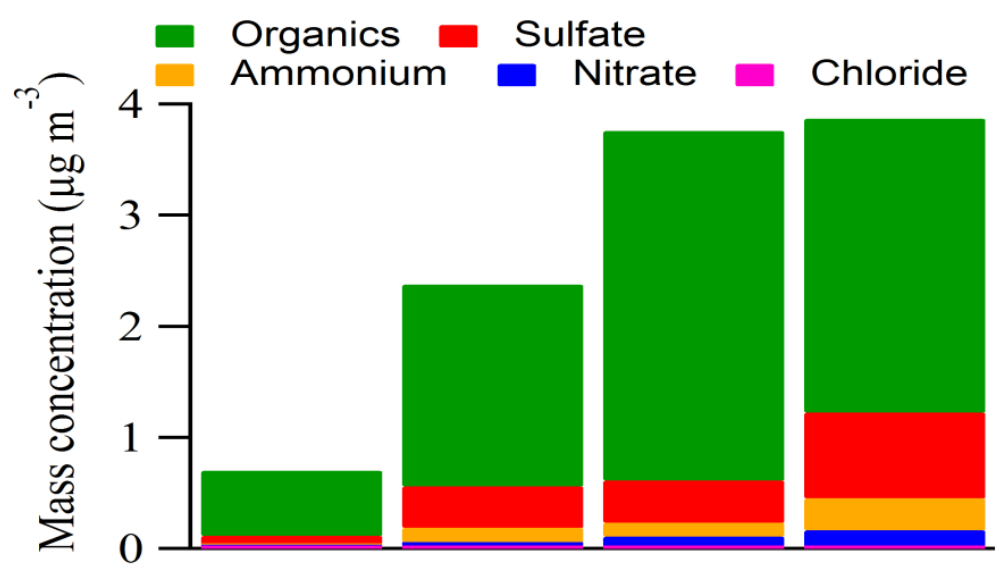

Figura 55: concentração de massa de aerossóis para diferentes impactos da pluma de Manaus (menor impacto à esquerda e maior impacto à direita). Observamos um acréscimo de $3 \mu \mathrm{g} / \mathrm{m}^{3}$ de orgânicos e também acréscimos significativos no sulfato. Medidas realizadas através de um espectrômetro de massa da Aerodyne. 
A Figura 56 expõe as concentrações e percentuais das concentrações dos elementos $\mathrm{Na}, \mathrm{S}$ e $\mathrm{Cl}$ extraídos no fator marinho. Verifica-se similaridades entre os métodos para os elementos $\mathrm{Na}$ e $\mathrm{Cl}$. Da diferença de composição deste fator dentre os diferentes sítios é possível verificar a depleção do $\mathrm{Cl}$, na qual o $\mathrm{NaCl}$ reage com $\mathrm{H}_{2} \mathrm{SO}_{4}$ formando $\mathrm{HCl}$ e $\mathrm{Na}_{2} \mathrm{SO}_{4}$ Equação 16 (LEE; CHAN; PAATERO, 1999; VENKATARAMAN et al., 2002; ZHUANG et al., 1999). Verifica-se que o aerossol marinho encontrado no TIWA e Manacapuru possui menos $\mathrm{Na}$ e $\mathrm{S}$ do que aquele encontrado na ZF2 enquanto a concentração de $\mathrm{Cl}$ apresenta menor variação dentre os sítios.

Figura 56: concentração média e percentual em relação a concentração média de MPF para as concentrações encontradas para o fator marinho através da ACPA e PMF.

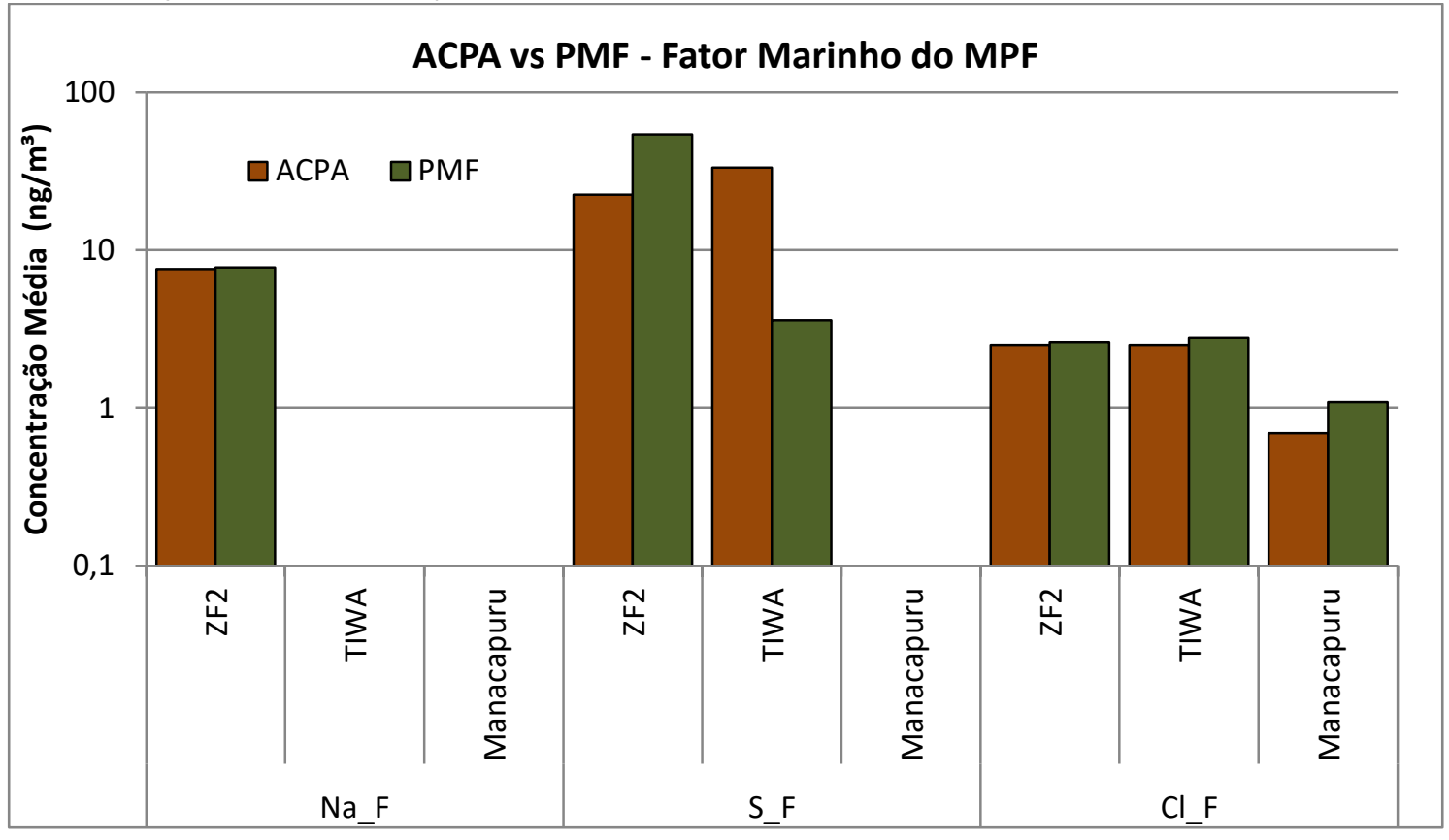

4.8.9. Comparação entre os fatores encontrados pelos dois métodos multivariados (ACPA e PMF) para a fração grossa do MP

Este capítulo apresenta a compilação dos resultados obtidos pelos métodos ACPA e PMF para o material particulado grosso separados por fatores semelhantes entre os métodos. Uma análise mais detalhada foi realizada para os fatores associados ao aerossol marinho e estão expostos neste capítulo. Um quadro geral da atribuição de fontes de aerossóis para todos os sítios e todos os fatores discriminados pode ser vista na Figura 57. 
Figura 57: concentração média e percentual em relação a concentração média de MPG para as concentrações encontradas por fator através da ACPA e PMF.

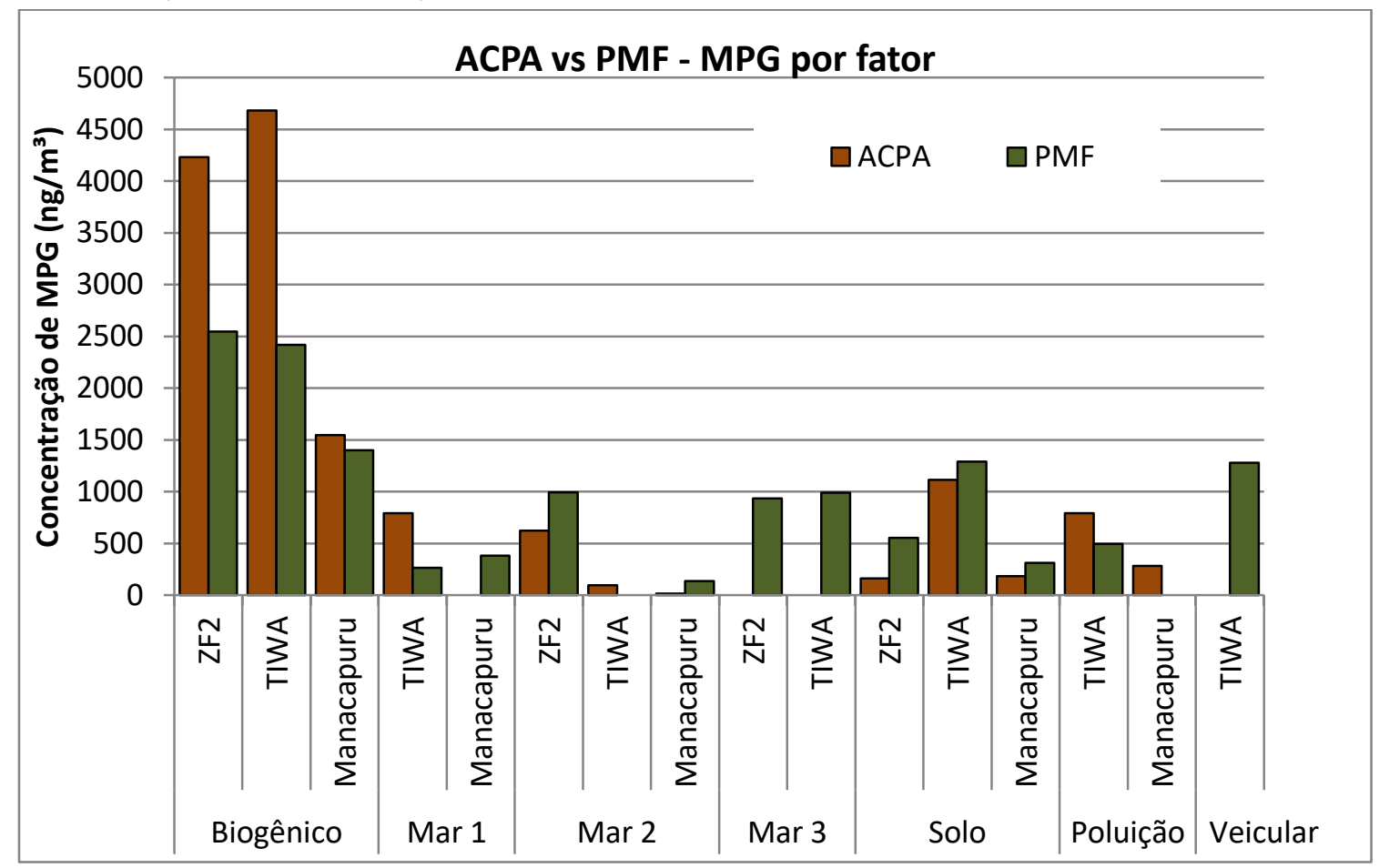

Pode-se verificar que o PMF conseguiu, de modo geral, extrair mais fatores do que a ACPA. Verifica-se a extração de dois fatores marinhos em cada sítio, além do fator veicular no TIWA. A ACPA identificou dois fatores relacionados ao aerossol marinho somente no sítio TIWA e, obteve uma fonte que o PMF não identificou em Manacapuru, relacionado com poluição.

Dentre as concentrações obtidas entre as diversas técnicas verifica-se que o fator biogênico apresenta concentrações próximas de MPG na ZF2 e TIWA em cada método, demonstrando uma concentração regional próxima. O MPG atribuído aos fatores marinhos pelo PMF é maior na ZF2 do que no TIWA: $1929 \mathrm{ng} / \mathrm{m}^{3}$ e $1254 \mathrm{ng} / \mathrm{m}^{3}$, respectivamente, resultado que reflete a deposição do aerossol marinho em seu trajeto.

Observando o MPG extraído no fator solo para o TIWA, fica clara a interferência da atividade antrópica na ressuspensão de poeira mineral do solo, de modo a apresentar um aumento de MPG de aproximadamente $700 \mathrm{ng} / \mathrm{m}^{3}$ em relação ao encontrado na ZF2 pela técnica do PMF.

Através da análise dos elementos $\mathrm{Na}, \mathrm{S}$ e $\mathrm{Cl}$ para os fatores relacionados ao aerossol marinho é possível verificar o processamento deste aerossol na atmosfera. O fator marinho 
1, Figura 58, foi extraído nos sítios TIWA e Manacapuru, ou seja, aqueles vento abaixo da cidade de Manaus, indicando a ocorrência do processo mostrado na Equação 16 logo após a cidade. Este fator é caracterizado por ter alta concentração de $\mathrm{Cl}$ e pouca concentração de $\mathrm{Na}$ e S. Ressalta-se que a ACPA identificou este fator somente no sítio TIWA, local mais próximo do ponto emissor da pluma de Manaus. Na Figura 59 está o fator marinho 2, relacionado ao $\mathrm{NaCl}$ anterior ao processamento do aerossol. O fator marinho 3, relacionado ao $\mathrm{Na}_{2} \mathrm{SO}_{4}$, com os elementos principais expostos na Figura 60 mostra maior concentração de $\mathrm{Na}$ no TIWA, de $46,8 \mathrm{ng} / \mathrm{m}^{3}$ quando comparado ao da $Z \mathrm{~F} 2$, de $22,6 \mathrm{ng} / \mathrm{m}^{3}$. A melhor separação de fatores que envolvem processamento do aerossol pelo PMF em relação à ACPA já foi observada anteriormente e cogitou-se que esta diferença possa estar relacionada aos diferentes métodos matemáticos utilizados (CESARI et al., 2016).

Figura 58: concentração média e percentual em relação a concentração média de MPG para as concentrações encontradas para o fator marinho 1 através da ACPA e PMF.

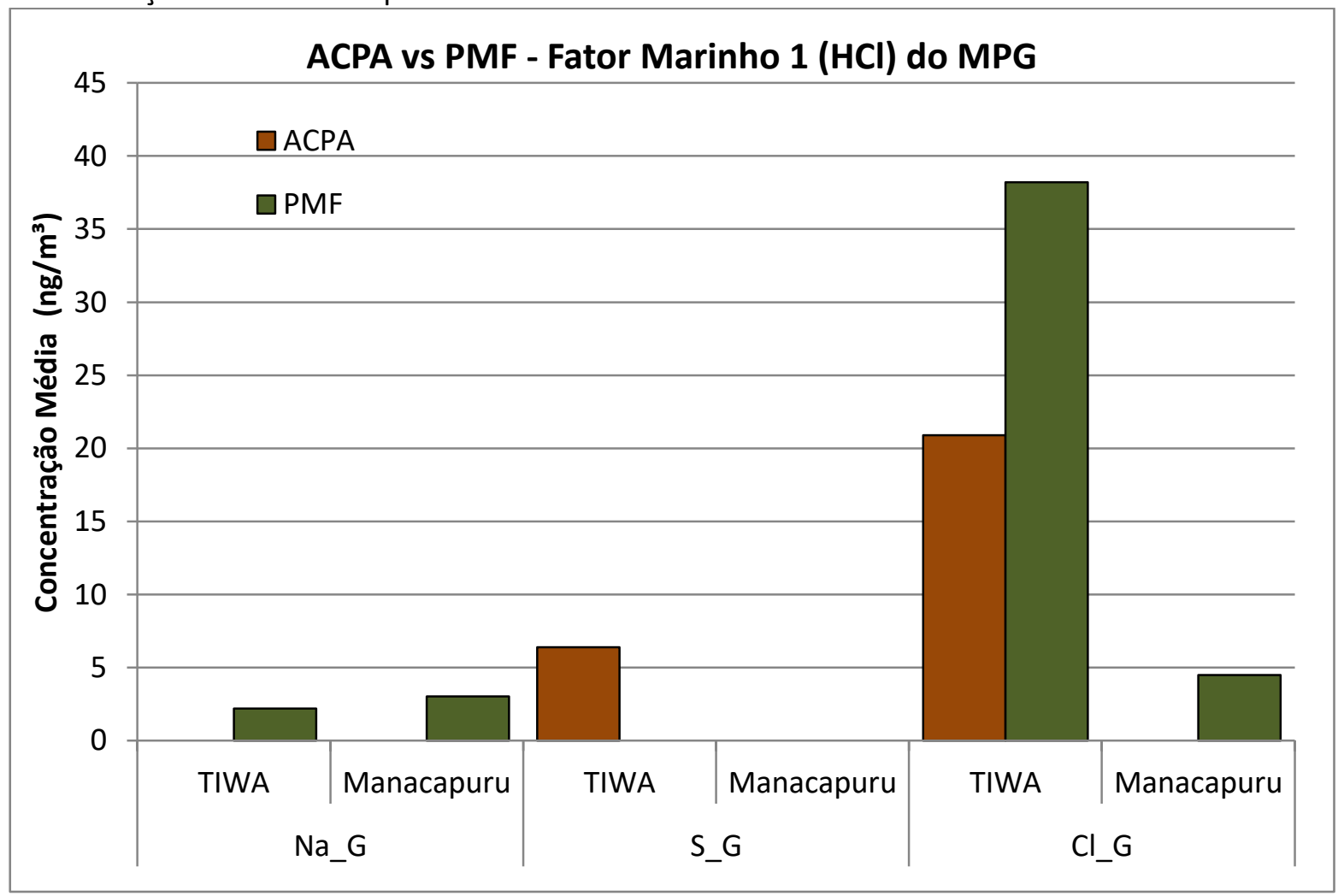


Figura 59: concentração média e percentual em relação a concentração média de MPG para as concentrações encontradas para o fator marinho 2 através da ACPA e PMF.

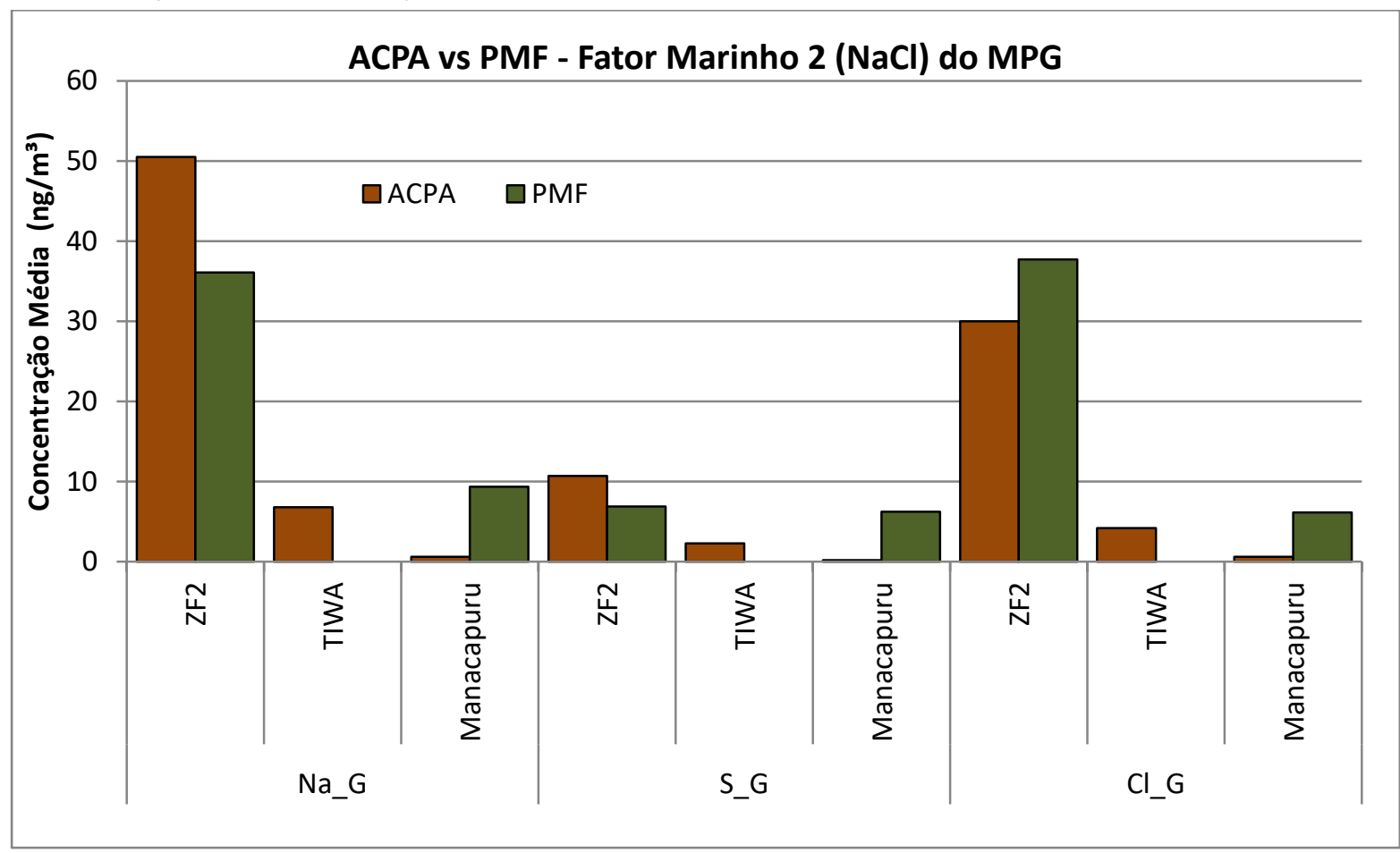

Figura 60: concentração média e percentual em relação a concentração média de MPG para as concentrações encontradas para o fator marinho 3 através da ACPA e PMF.

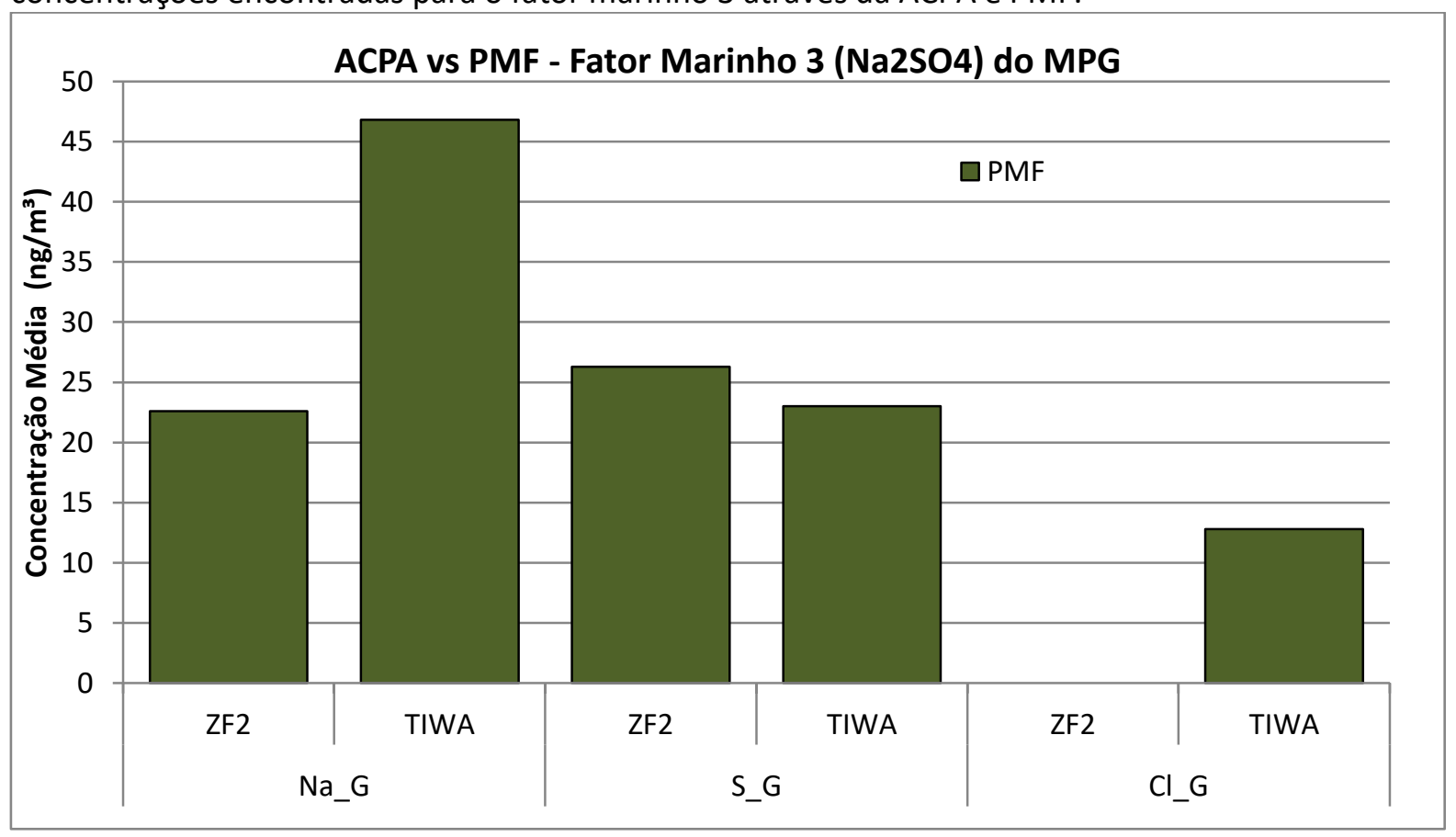




\section{Conclusões}

O presente trabalho avaliou de maneira inédita o impacto que as emissões atmosféricas da cidade de Manaus exerce na composição de partículas finas e grossas de aerossóis na Amazônia Central. As atividades foram parte integrante do experimento GoAmazon2014/15. Através de análises da composição orgânica e inorgânica do material particulado, coletado por filtros em sítios com e sem a influência da pluma urbana da cidade de Manaus foi possível a identificação e quantificação de fontes e processos que regulam a composição do aerossol com e sem influência antrópica. Um esforço particular foi feito na validação dos dados obtidos, através da comparação de técnicas e medidas em tempo real e integradas. O processo de validação de dados mostrou boa concordância entre as grandezas obtidas através dos filtros e aetalômetros, espectrômetros de massa e SMPS na maioria das análises.

A comparação entre diferentes técnicas de medidas possibilitou a obtenção de grandezas que refletem propriedades intrínsecas do aerossol, como a participação do carbono na matéria orgânica e a determinação do coeficiente de absorção mássico (MAC, do inglês, Mass Absorption Coefficient) e outras propriedades. Os valores de MAC encontrados no TIWA e Manacapuru estão entre aproximadamente $3,8 \mathrm{~m}^{2} / \mathrm{g}$ e $5,5 \mathrm{~m}^{2} / \mathrm{g}$, valores menores do que o sugerido pelo fabricante e que podem ser explicados devido a superestimação de EC como observado por CHENG et al. (2016) em medidas com OC/EC>3. O processo de "envelhecimento" do aerossol foi observado, com a comparação da participação orgânica nas estações amostradoras do TIWA e Manacapuru, sendo consistente com o fato de este estar mais distante de Manaus do que o TIWA.

A comparação realizada entre $\mathrm{BCe}$ e EC, ambas obtidas através de medidas em filtros no sítio ZF2 indicou grande similaridade nas concentrações medidas, com razões entre essas propriedades próximas de 1:1. Este foi um resultado surpreendente, levando em conta as diferentes metodologias empregadas e as premissas assumidas no cálculo de BCe a partir da atenuação ótica. No sítio TIWA esta razão ficou um pouco abaixo da unidade, provavelmente pela emissão fresca de BC, o que pode afetar a atribuição de EC nas técnicas termo-óptica.

A medida detalhada e por longo prazo da concentração de MP em local com influência da pluma de Manaus foi feita pela primeira vez. A fração fina apresentou 
sazonalidade característica da Amazônia, com concentrações bem maiores durante a estação seca devido a menor precipitação e a ocorrência de transporte de aerossóis originados pelas queimadas da região. Desta análise também se verificou maiores concentrações de MP no sítio TIWA em comparação com a ZF2, evidenciando o impacto que as atividades antrópicas de Manaus causam na região. Pelo fato do MPG ser majoritariamente associado a aerossóis biogênicos naturais e as emissões de solo, este demonstrou menor variabilidade na concentração ao longo do ano em relação ao MPF, com concentrações médias próximas para as diversas estações do ano em todos os sítios.

Também foram determinadas as concentrações elementares em aerossóis da Amazônia central, onde observou-se grandes variabilidades na concentração de elementos traços. Os elementos majoritários no aerossol correspondem aos elementos associados com a poeira mineral como o $\mathrm{Al}, \mathrm{Si}, \mathrm{Fe}$, e também com os elementos associados com aerossóis biogênicos e de queimada como o $\mathrm{P}, \mathrm{S}$ e K. Também observamos impacto significativo de aerossol marinho contendo $\mathrm{Na}$ e $\mathrm{Cl}$ em ambas as modas e impacto de poluição urbana nos sítios TIWA e Manacapuru. Na moda fina todos os elementos medidos apresentam maiores concentrações no sítio TIWA em relação à ZF2, mostrando a variedade de elementos químicos emitidos pela cidade de Manaus. Elementos relacionados a processos industriais e veiculares como $\mathrm{Mn}, \mathrm{Ni}, \mathrm{Cu}, \mathrm{Zn}$ e $\mathrm{Pb}$ formaram um grupo com coeficiente de correlação de Pearson de 0,5 entre si e estes apresentaram concentrações médias mais altas no TIWA que na ZF2 pelo menos por um fator três.

As concentrações de OC e EC durante a estação seca mostraram-se razoavelmente similares entre os vários sítios experimentais, devido ao transporte de aerossóis de queimadas, e com valores similares a estudos anteriores. No sítio TIWA observamos concentrações $1,6 \mu \mathrm{g} / \mathrm{m}^{3}$ e $0,6 \mu \mathrm{g} / \mathrm{m}^{3}$ maiores do que a ZF2 para OC e EC, respectivamente, evidenciando a influência da atividade antrópica também na concentração de aerossóis carbonáceos. Tais valores de OC e EC são comparáveis com os encontrados na cidade de São Paulo durante o verão (MONTEIRO DOS SANTOS et al., 2016). Da análise dos termogramas verificou-se que carbono pirolítico é o principal tipo de carbono orgânico das amostras em todos os sítios seguido do OC2. Essas frações de carbono quando analisadas levando em conta o trabalho de Gilardoni et al., (2011) estão associadas à aerossóis emitidos por queimadas e perfis de SOA, associação compatível com o período de coleta do aerossol. 
A reconstituição da massa gravimétrica da fração fina da ZF2 e do TIWA mostrou que a matéria orgânica é o principal constituinte do material particulado nesses sítios, variando entre $49,2 \%$ e $79,8 \%$ da concentração de MP medida por gravimetria. Verificou-se, em ambos os sítios, compatibilidade entre a massa gravimétrica e a reconstituição através de suas componentes. Estes valores concordam com as medidas de aerossol mass spectrometry de outros pesquisadores do GoAmazon (Sá et al., 2017)

As análise multivariadas conseguiram separar adequadamente os processos e fontes atuantes na variabilidade das concentrações elementares do aerossol. A aplicação da técnica de ACPA na série temporal do MPF dos sítios extraiu três fatores em todos os sítios: um associado com aerossol marinho, outro com aerossol de poeira mineral do solo e outro com aerossol produzido por queimadas, este responsável por pelo menos $60 \%$ do MPF. No sítio TIWA, a ACPA conseguiu discriminar duas fontes de aerossóis antropogênicas: veicular e de poluição que juntas são responsáveis por aproximadamente $15 \%$ da concentração média de MPF deste sítio, fato considerável, já que este sítio apresenta os maiores valores de concentração de MPF. Não se observou por esta técnica fatores diretamente relacionados com o aerossol antropogênico no sítio de Manacapuru. No MPG, três fontes de aerossol foram encontrados em todos os sítios: poeira mineral associada ao solo, aerossol biogênico e aerossol marinho em diferentes estágios de processamento. Surpreendentemente, um fator relacionado à poluição antropogênica foi encontrada no sítio Manacapuru que é responsável, em média, por 14\% da concentração de MPG deste sítio.

Uma técnica mais sofisticada e elaborada de análise multivariada, a PMF foi também aplicada neste estudo por ser um método mais recente e que está cada vez mais sendo utilizado. Foi feita uma comparação detalhada dos resultados das duas técnicas. Além da série temporal de concentrações utilizadas no método anterior, para o PMF foi necessário estimar a incerteza associada a cada elemento em cada amostra e sítio experimental. Para isso levou-se em conta o coeficiente de calibração e o desvio-padrão das medidas da fluorescência. Elementos chaves para a identificação de fontes como o P, S, Fe, Al, Si, K e Ca apresentaram incerteza relativa menores que 15\%, valores aceitáveis para a aplicação da técnica. 
Como resultado da aplicação do PMF na fração fina do aerossol, quatro fatores foram encontrados em todos os sítios: relacionado com o aerossol marinho, aerossol de poeira mineral do solo, aerossol biogênico e de queimada. No sítio TIWA emissões antropogênicas como a da poluição da cidade de Manaus e a frota de veículos foram responsáveis por, em média, $11 \%$ do MPF, resultado semelhante ao da ACPA. Em Manacapuru, um fator antropogênico foi encontrado associado à poluição de Manaus que é responsável por aproximadamente $17 \%$ do MPF deste sítio. Os resultados para a fração grossa apresentaram no mínimo quatro fatores nos sítios: um relacionado ao aerossol biogênico natural, outro relacionado com a poeira mineral do solo e, finalmente, dois fatores associados com o processamento do aerossol marinho.

Com a técnica PMF foi possível extrair mais fatores em cinco das seis base de dados utilizadas neste experimento. Os fatores que apenas o PMF extraiu foram biogênico (moda fina), fatores relacionados com o processamento do aerossol marinho (em todas as rodadas de moda grossa) e alguns fatores relacionados com a atividade antrópica. Este resultado chama a atenção para a melhor separação que o PMF possibilita em relação ao processamento do aerossol na atmosfera, já que o fator biogênico na moda fina é em parte composto por aerossol orgânico secundário, originários de VOCs emitidos pela vegetação.

Ao compararmos os fatores extraídos, um surpreendente resultado é a maior quantidade de MPF associado aos fatores biogênico e de queimada no sítio TIWA (sítio sob influência da cidade de Manaus), em relação à ZF2 (sítio de floresta intocada). Este resultado mostra que o maior potencial de oxidação da pluma da cidade, devido à emissão de NOx em processos de combustão, atua no sentido de transformar gases biogênicos VOCs em material particulado SOA. Desta forma verifica-se que além das emissões antrópicas diretas - aqui identificadas nos fatores poluição e veicular - a emissões da cidade interferem no ciclo de vida dos VOCs. Para efeito de comparação, o MPF associado aos fatores queimada e biogênico extraído pelo PMF, no TIWA é de aproximadamente $5,5 \mu \mathrm{g} / \mathrm{m}^{3}$, enquanto que na ZF2 é de $3,1 \mu \mathrm{g} / \mathrm{m}^{3}$.

A realização deste trabalho resultou em um amplo aprendizado da física de aerossóis atmosféricos por parte do aluno, que teve que lidar com diferentes propriedades dos aerossóis em diferentes condições atmosféricas. O trabalho mostrou-se interessante ao 
avaliar de forma quantitativa o impacto que áreas urbanas tem em regiões tropicais inclusive identificando processos químicos que ocorrem na atmosfera remota. 


\section{Bibliografia}

ANDRADE, M. F. Identificação de Fontes da Matéria Particulada do Aerossol Atmosférico de São Paulo. 1993. Universidade de São Paulo, 1993. Disponível em: <http://www.teses.usp.br/teses/disponiveis/43/431 31/tde-01072013-

164055/publico/45322Andrade.pdf>.

ANDREAE, M. O. Aerosols Before Pollution. Science, n. January, p. 50-51, 2007.

ANDREAE, M. O. et al. Effects of Anthropogenic Pollution on the Atmospheric Chemistry of the Tropical Rain Forest: Intensive Operating Periods ( IOPs ) of GoAmazon2014. GoAmazon White Paper, 2013.

ANDREAE, M. O. et al. The Amazon Tall Tower Observatory (ATTO): Overview of pilot measurements on ecosystem ecology, meteorology, trace gases, and aerosols. Atmospheric Chemistry and Physics, v. 15, n. 18, p. 10723-10776, 2015.

ANDREAE, M. O.; GELENCSÉR, A. Black carbon or brown carbon? The nature of lightabsorbing carbonaceous aerosols. Atmospheric Chemistry and Physics, v. 6, n. 3, p. 3419-3463, 2006.

ARANA, A. AEROSSÓIS ATMOSFÉRICOS NA AMAZÔNIA: COMPOSIÇÃO ORGÂNICA E INORGÂNICA EM REGIÕES COM DIFERENTES USOS DO SOLO. 2014. Instituto Nacional de Pesquisas da Amazônia, 2014.

ARANA, A.; ARTAXO, P. Elemental composition of the atmospheric aerosol in the central Amazon basin | Composição elementar do aerossol atmosférico na região central da bacia amazônica. Quimica Nova, v. 37, n. 2, 2014.

ARM. AMF Deployment, Manacapuru, Brazil. Disponível em: <https://dis.arm.gov/sites/amf/mao>. Acesso em: 11 jul. 2017.

ARTAXO, P. et al. Atmospheric aerosols in Amazonia and land use change: from natural biogenic to biomass burning conditions. Faraday Discussions, v. 165, p. 203-235, 2013.

ARTAXO, P. et al. Large-scale aerosol source apportionment in Amazonia. Journal of Geophysical Research. [S.I: s.n.]. , 1998

ARTAXO, P. et al. Physical and chemical properties of aerosols in the wet and dry seasons in Rondônia, Amazonia. Journal of Geophysical
Research D: Atmospheres, v. 107, n. 20, p. 1-14, 2002

ARTAXO, P. et al. Química atmosférica na Amazônia: a floresta e as emissões de queimadas controlando a composição da atmosfera amazônica. Acta Amazonica, v. 35, n. 2, p. 185-196, 2005.

ARTAXO, P.; MAENHAUT, W. Trace element concentrations and size distribution of biogenic aerosols from the amazon basin during the wet season. Nuclear Inst. and Methods in Physics Research, B, v. 49, n. 1-4, p. 366-371, 1990.

BAARS, $H$. et al. Further evidence for significant smoke transport from Africa to Amazonia. Geophysical Research Letters, v. 38, n. 20, 2011.

BEN-AMI, Y. et al. Transport of North African dust from the Bod??l?? depression to the Amazon Basin: A case study. Atmospheric Chemistry and Physics, v. 10, n. 16, p. 7533-7544, 2010.

BIRCH, M. E.; CARY, R. A. Elemental CarbonBased Method for Monitoring Occupational Exposures to Particulate Diesel Exhaust. Aerosol Science and Technology, v. 25, n. 3, p. 221-241, 1996. Disponível em: $<$ http://www.tandfonline.com/doi/abs/10.1080/027 86829608965393>.

BOUCHER, O. et al. Clouds and Aerosols. Climate Change 2013: The Physical Science Basis. Contribution of Working Group I to the Fifth Assessment Report of the Intergovernmental Panel on Climate Change, p. 571-657, 2013.

BRITO, J. et al. Physical-chemical characterisation of the particulate matter inside two road tunnels in the São Paulo Metropolitan Area. Atmospheric Chemistry and Physics, v. 13, n. 24, p. 12199-12213, 2013. Disponível em: <http://www.atmos-chemphys.net/13/12199/2013/>.

BROWN, S. G. et al. Methods for estimating uncertainty in PMF solutions: Examples with ambient air and water quality data and guidance on reporting PMF results. Science of the Total Environment, v. 518-519, p. 626-635, 2015. Disponível em: <http://dx.doi.org/10.1016/j.scitotenv.2015.01.022>

CASTANHO, A. D. D. A. A Determinação Quantitativa de Fontes de Material Particulado na Atmosfera da Cidade de São Paulo. p. 140, 1999. 
CAVALLI, F. et al. Toward a standardised thermal-optical protocol for measuring atmospheric organic and elemental carbon: the EUSAAR protocol. Atmospheric Measurement Techniques, v. 3, n. 1, p. 79-89, jan. 2010. Disponível em: <http://www.atmos-meas-tech.net/3/79/2010/>.

CESARI, D. et al. An inter-comparison of PM10 source apportionment using PCA and PMF receptor models in three European sites. Environmental Science and Pollution Research, v. 23, n. 15, p. 15133-15148, 2016.

CHEN, Q. et al. Mass spectral characterization of submicron biogenic organic particles in the Amazon Basin. Geophysical Research Letters, v. 36, n. 20, 2009.

CHENG, Y.; ENGLING, G.; MOOSM??LLER, $\mathrm{H}$.; et al. Light absorption by biomass burning source emissions. Atmospheric Environment, v. 127, p. 347354, 2016. Disponível em: <http://dx.doi.org/10.1016/j.atmosenv.2015.12.045 $>$.

CHENG, Y.; ENGLING, G.; MOOSMÜLLER, H.; et al. Light absorption by biomass burning source emissions. Atmospheric Environment, v. 127, p. 347354, 2016. Disponível em: <http://dx.doi.org/10.1016/j.atmosenv.2015.12.045 $>$.

CHOW, J. C. et al. Source profiles for industrial, mobile, and area sources in the Big Bend Regional Aerosol Visibility and Observational study. Chemosphere, v. 54, n. 2, p. 185-208, 2004.

CHOW, J. C. et al. The Dri Thermal Optical Reflectance Carbon Analysis System - Description, Evaluation and Applications in United-States AirQuality Studies. Atmospheric Environment Part AGeneral Topics, v. 27, n. 8, p. 1185-1201, jun. 1993. Disponível em: <isi:A1993LJ39000003>.

DE FATIMA ANDRADE, M. et al. Vehicle emissions and PM 2.5 mass concentrations in six Brazilian cities. Air Quality, Atmosphere and Health, v. 5, n. 1, p. 79-88, 2012.

ECHALAR, F. et al. Long-term monitoring of atmospheric aerosols in the Amazon Basin: Source identification and apportionment. Journal of Geophysical Research, v. 103, n. D24, p. 31849, 1998.

FINLAYSON-PITTS, B. J.; PITTS, J. N. Chemistry of the Upper and Lower Atmosphere: Theory, Experiments, and Applications. Chemistry of the Upper and Lower Atmosphere, p. 969, 1999.
FUZZI, S. et al. Critical assessment of the current state of scientific knowledge, terminology, and research needs concerning the role of organic aerosols in the atmosphere, climate, and global change. Atmospheric Chemistry and Physics Discussions, v. 5, n. 6, p. 11729-11780, 2005.

FUZZI, S. et al. Overview of the inorganic and organic composition of size-segregated aerosol in Rondo ^ nia , Brazil , from the biomass-burning period to the onset of the wet season. v. 112, 2007.

GARG, B. D. et al. Brake wear particulate matter emissions. Environmental Science and Technology, v. 34, n. 21, p. 4463-4469, 2000.

GARY NORRIS, RACHELLE DUVALL, STEVE BROWN, S. B. EPA Positive Matrix Factorization (PMF) 5.0 Fundamentals and User Guide. [S.I: s.n.], 2014.

GERAB, F. Técnicas Analíticas Nucleares Aplicadas à Medida em Larga Escala de Aerossóis Atmosféricos na Região Amazônica. 1996. 215 f. Universidade de São Paulo, 1996.

GILARDONI, S. et al. Sources of carbonaceous aerosol in the Amazon basin. Atmospheric Chemistry and Physics, v. 11, n. 6, p. 2747-2764, 2011.

HEIDAM, N. Z. Atmospheric aerosol factor models, mass and missing data. Atmospheric Environment (1967), v. 16, n. 8, p. 1923-1931, jan. 1982. Disponível em: $<$ http://linkinghub.elsevier.com/retrieve/pii/000469 8182904632>.

HOLANDA, B. A.; ARTAXO, P. Absorção da Radiação por Aerossóis na Amazônia. 2015. 93 f. Universidade de São Paulo, 2015.

HOPKE, P. K. A Guide to Positive Matrix Factorization. Journal of Neuroscience. Potsdam, NY: [s.n.], 1991. Disponível em: <www.epa.gov>.

HOPKE, P. K. et al. Characterization of the Gent Stacked Filter Unit PM ${ }_{10}$ Sampler. Aerosol Science and Technology, v. 27, n. 6, p. 726-735, $1997 . \quad$ Disponível em: $<$ http://www.tandfonline.com/doi/abs/10.1080/027 86829708965507>.

HUFFMAN, J. A. et al. Size distributions and temporal variations of biological aerosol particles in the Amazon rainforest characterized by microscopy and real-time UV-APS fluorescence techniques during AMAZE-08. Atmospheric Chemistry and 
Physics, v. 12, n. 24, p. 11997-12019, 2012.

IBGE. Mapa Integrado dos Zoneamentos Ecológico-Econômicos dos Estados da Amazônia Legal. Disponível em: <http://www.ibge.gov.br/home/geociencias/geograf ia/mapas_doc5.shtm>. Acesso em: 19 jul. 2017.

IMAZON. Mapas - Desmatamento na Amazônia Legal até 2011. Disponível em: <http://imazon.org.br/mapas/desmatamento-naamazonia-legal-ate-2011/>. Acesso em: 17 jul. 2017.

INPA. Torre TT34. Disponível em: <http://lba2.inpa.gov.br/index.php/torres/torresamazonas/am-tt34.html>. Acesso em: 11 jul. 2017.

INPE. Portal do Monitoramento de Queimadas $e$ Incêndios. Disponível em: $<$ https://prodwww-

queimadas.dgi.inpe.br/bdqueimadas/\#>. Acesso em: 5 fev. 2017.

JUNIOR, D. A. M. DOS S. Emissões Veiculares em São Paulo: Quantificação de Fontes com Modelos Receptores e Caracterização do Material Carbonáceo. 2015. Universidade de São Paulo, 2015.

KARANASIOU, A. et al. Thermal-optical analysis for the measurement of elemental carbon (EC) and organic carbon (OC) in ambient air a literature review. Atmos. Meas. Tech. Discuss, v. 8, p. 9649-9712, 2015. Disponível em: <www.atmosmeas-tech-discuss.net/8/9649/2015/>.

KHAN, B. et al. Differences in the OC/EC Ratios that Characterize Ambient and Source Aerosols due to Thermal-Optical Analysis. Aerosol Science and Technology, v. 46, n. 2, p. 127-137, 2012. Disponíve em: <http://www.tandfonline.com/doi/abs/10.1080/027 86826.2011.609194>.

KOLB, C. E.; WORSNOP, D. R. Chemistry and Composition of Atmospheric Aerosol Particles. Annual Review of Physical Chemistry, v. 63, n. 1, p. 471-491, 2012.

KUHN, U. et al. Impact of Manaus City on the Amazon Green Ocean atmosphere: Ozone production, precursor sensitivity and aerosol load. Atmospheric Chemistry and Physics, v. 10, n. 19, p. 9251-9282, 2010.

LEE, E.; CHAN, C. K.; PAATERO, P. Application of positive matrix factorization in source apportionment of particulate pollutants in Hong Kong. Atmospheric Environment, v. 33, n. 19, p.
3201-3212, 1999.

LIU, W. et al. Enhanced source identification of southeast aerosols using temperature-resolved carbon fractions and gas phase components. Atmospheric Environment, v. 40, n. SUPPL. 2, p. 445466, 2006.

LOUREIRO, A. et al. Calibration of reflectometer system to measure black carbon and field intercomparation in the Amazon Basin. 1994, Berkley, California: [s.n.], 1994.

MAENHAUT, W. et al. Chemical composition and mass closure for fine and coarse aerosols at a kerbside in Budapest, Hungary, in spring 2002 †. n. March, p. 290-296, 2005.

MARTIN, S. T.; ANDREAE, M. O.; ALTHAUSEN, D.; et al. An overview of the Amazonian Aerosol Characterization Experiment 2008 (AMAZE08). Atmospheric Chemistry and Physics, v. 10, n. 23, p. 11415-11438, 2010.

MARTIN, S. T. et al. Introduction: Observations and Modeling of the Green Ocean Amazon (GoAmazon2014/5). Atmospheric Chemistry and Physics, v. 16, n. 8, p. 4785-4797, 2016.

MARTIN, S. T.; ANDREAE, M. O.; ARTAXO, P.; et al. Sources and properties of Amazonian aerosol particles. Reviews of Geophysics, v. 48, n. 2, 2010.

MARTIN, S. T. et al. The green ocean amazon experiment (GOAMAZON2014/5) observes pollution affecting gases, aerosols, clouds, and rainfall over the rain forest. Bulletin of the American Meteorological Society, v. 98, n. 5, p. 981-997, 2017.

MMA. Desmatamento na Amazônia Legal. Disponível em: <http://www.mma.gov.br/mma-emnumeros/desmatamento>. Acesso em: 19 jul. 2017a.

MMA. Plano de Ação para Prevenção e Controle do Desmatamento na Amazônia Legal. Disponível em: <http://www.mma.gov.br/component/k2/item/616? Itemid=1155>

MONTEIRO DOS SANTOS, D. A. et al. Ambient concentrations and insights on organic and elemental carbon dynamics in S??o Paulo, Brazil. Atmospheric Environment, v. 144, n. November, p. 226-233, 2016.

NEPSTAD, D. et al. Slowing Amazon deforestation through public policy and interventions in beef and soy supply chains. Science, 
v. 344, n. 6188 , p. $1118-23,2014$. Disponível em: <http://www.ncbi.nlm.nih.gov/pubmed/24904156>.

NG, N. L. et al. An Aerosol Chemical Speciation Monitor (ACSM) for routine monitoring of the composition and mass concentrations of ambient aerosol. Aerosol Science and Technology, v. 45, n. 7, p. 770-784, 2011.

NIOSH. Elemental Carbon (Diesel Exhaust). In: ELLER, P. M. (Org.). . NIOSH Manual of Analytical Methods. $4^{\mathrm{a}}$ ed. Cincinnati, Ohio: National Institute of Occupational Safety and Health, 1996.

NORRIS, G. et al. Guidance Document for PMF Applications with the Multilinear Engine. Epa, 2009.

PAULIQUEVIS, T. et al. Aerosol and precipitation chemistry measurements in a remote site in Central Amazonia: The role of biogenic contribution. Atmospheric Chemistry and Physics, v. 12, n. 11, p. 4987-5015, 2012.

PETZOLD, A. et al. Recommendations for reporting black carbon measurements. Atmospheric Chemistry and Physics, v. 13, n. 16, p. 8365-8379, 2013.

POHLKER, C. et al. Biogenic Potassium Salt Particles as Seeds for Secondary Organic Aerosol in the Amazon. Science, v. 337, n. 6098, p. 1075-1078, 2012. Disponível em: <http://www.sciencemag.org/cgi/doi/10.1126/scien ce.1223264>

POLISSAR, A. V. et al. Atmospheric aerosol over Alaska: 2. Elemental composition and sources. Journal of Geophysical Research, v. 103, n. 98, p. 19045, 1998.

POSCHL, U. et al. Rainforest Aerosols as Biogenic Nuclei of Clouds and Precipitation in the Amazon. Science, v. 329, n. 5998, p. 1513-1516, 17 set. $2010 . \quad$ Disponível em: <http://www.sciencemag.org/cgi/doi/10.1126/scien ce.1191056>.

REFF, A.; EBERLY, S. I.; BHAVE, P. V. Receptor Modeling of Ambient Particulate Matter Data Using Positive Matrix Factorization : Review of Existing Methods Receptor Modeling of Ambient Particulate Matter Data Using Positive Matrix Factorization: Review o. Journal of the Air \& Waste Management, v. 57, n. November 2014, p. 37-41, 2007.

RIZZO, L. V. et al. Long term measurements of aerosol optical properties at a primary forest site in Amazonia. Atmospheric Chemistry and Physics, v. 13, n. 5, p. 2391-2413, 2013.

SÁ, S. DE. Comunicação Pessoal. . [S.I: s.n.]. , 2016

SATURNO, J. et al. Comparison of different Aethalometer correction schemes and a reference multi-wavelength absorption technique for ambient aerosol data. Atmospheric Measurement Techniques, v. 10, n. 8, p. 2837-2850, 2017.

SCHMID, O. et al. Spectral light absorption by ambient aerosols influenced by biomass burning in the Amazon Basin. I: Comparison and field calibration of absorption measurement techniques. Atmospheric Chemistry and Physics, v. 6, n. 11, p. 3443-3462, 2006. Disponível em: <http://www.atmos-chem-phys.net/6/3443/2006/>

SEIBERT, J. A.; BOONE, J. M. X-ray imaging physics for nuclear medicine technologists. Part 2: Xray interactions and image formation. Journal of nuclear medicine technology, v. 33, n. 1, p. 3-18, 2005.

SEINFELD, J. H.; PANDIS, S. N. Atmospheric Chemistry and Physics: From Air Pollution to Climate Change. [S.I: s.n.], 2006.

SOTO-GARC?A, L. L. et al. Evaluation of the carbon content of aerosols from the burning of biomass in the Brazilian Amazon using thermal, optical and thermal-optical analysis methods. Atmospheric Chemistry and Physics, v. 11, n. 9, p. 4425-4444, 12 maio 2011. Disponível em: $<$ http://www.atmos-chemphys.net/11/4425/2011/>

STEIN, A. F. et al. Noaa's hysplit atmospheric transport and dispersion modeling system. Bulletin of the American Meteorological Society. [S.I: s.n.]. , 2015

SUBRAMANIAN, R. et al. Evaluation of Measurement Methods Positive and Negative Artifacts in Particulate Organic Carbon Measurements with Denuded and Undenuded Sampler Configurations. v. 38, p. 27-48, 2004.

SUBRAMANIAN, R. et al. Positive and Negative Artifacts in Particulate Organic Carbon Measurements with Denuded and Undenuded Sampler Configurations Special Issue of Aerosol Science and Technology on Findings from the Fine Particulate Matter Supersites Program Evaluation of Meas. v. 6826, n. June 2017, 2010. 
SWAP, R. et al. Saharan dust in the Amazon Basin. Tellus, v. 44B, n. 2, p. 133-149, 1992.

THURSTON, G. D.; SPENGLER, J. D. A Multivariate Assessment of Meteorological Influences on Inhalable Particle Source Impacts. Journal of Climate and Applied Meteorology, v. 24, n. 11, p. 1245-1256, 1985. Disponível em: <http://journals.ametsoc.org/doi/abs/10.1175/1520 -0450(1985)024\%3C1245:AMAOMI\%3E2.0.CO;2>.

TURPIN, B. J.; LIM, H.-J. Species Contributions to PM2.5 Mass Concentrations: Revisiting Common Assumptions for Estimating Organic Mass. Aerosol Science and Technology, v. 35, n. 1, p. 602-610, 2001. Disponível em: <http://www.tandfonline.com/doi/abs/10.1080/027 86820119445>.

US EPA. Report to Congress on Black Carbon. . [S.I: s.n.], 2012. Disponível em: <https://www3.epa.gov/airquality/blackcarbon/201 2report/Cover.pdf>.

VAN GRIEKEN, R. E.; MARKOWICZ, A A. Handbook of X-ray spectrometry. [S.I: s.n.], 2002. v. $64 . \quad$ Disponível em: <http://pubs.acs.org/doi/abs/10.1021/ac800678s>.
VECCHI, R. et al. Organic and inorganic sampling artefacts assessment. Atmospheric Environment, v. 43, n. 10, p. 1713-1720, 2009.

VENKATARAMAN, C. et al. Aerosol size and chemical characteristics at Mumbai, India, during the INDOEX-IFP (1999). Atmospheric Environment, v. 36, n. 12, p. 1979-1991, 2002

WALLACE, J. M.; HOBBS, P. V. Atmospheric Science: An Introductory Survey: Second Edition. [S.I: s.n.], 2006.

WANG, Q. et al. Modeling investigation of light-absorbing aerosols in the Amazon Basin during the wet season. Atmospheric Chemistry and Physics, v. 16, n. 22, p. 14775-14794, 28 nov. 2016. Disponível em: <http://www.atmos-chemphys.net/16/14775/2016/>.

YATKIN, S. et al. An interlaboratory comparison study on the measurement of elements in PM10. Atmospheric Environment, v. 125, p. 61-68, 2016.

ZHUANG, H. et al. Formation of nitrate and non-sea-salt sulfate on coarse particles. Atmospheric Environment, v. 33, n. 26, p. 4223-4233, 1999. 


\section{APÊNDICE A - Concentrações Elementares na Moda Fina e Grossa}

\section{separadas por Estações e Correlação}

Tabela A.1: concentração em $\mathrm{ng} / \mathrm{m}^{3}$ dos elementos analisados por fluorescência, refletância e gravimetria na ZF2 para moda fina e grossa e estação seca e chuvosa.

\begin{tabular}{|c|c|c|c|c|c|c|c|c|c|c|c|c|c|c|c|c|}
\hline \multicolumn{17}{|c|}{ ZF2 - Concentração Média dos Elementos Traços, BCe e MP } \\
\hline & \multicolumn{8}{|c|}{ Moda Fina } & \multicolumn{8}{|c|}{ Moda Grossa } \\
\hline & Esta & ão & Seca & $\mathrm{N}$ & Estaç & $\mathrm{OCl}$ & uvosa & $\mathrm{N}$ & Esta & ão & Seca & $\mathrm{N}$ & Estaçã & $\mathrm{OCl}$ & uvosa & $\mathrm{N}$ \\
\hline $\mathrm{Na}$ & 61 & \pm & 43 & 45 & 18 & \pm & 20 & 26 & 90 & \pm & 56 & 45 & 40 & \pm & 40 & 30 \\
\hline Mg & 11 & \pm & 9 & 21 & 11 & \pm & 11 & 17 & 24 & \pm & 15 & 45 & 20 & \pm & 21 & 30 \\
\hline $\mathrm{Al}$ & 24 & \pm & 23 & 45 & 42 & \pm & 43 & 31 & 51 & \pm & 66 & 45 & 56 & \pm & 84 & 31 \\
\hline $\mathrm{Si}$ & 35 & \pm & 37 & 45 & 84 & \pm & 85 & 31 & 71 & \pm & 74 & 45 & 117 & \pm & 170 & 31 \\
\hline$P$ & 11 & \pm & 8 & 45 & 3 & \pm & 3 & 30 & 21 & \pm & 10 & 45 & 21 & \pm & 10 & 31 \\
\hline$S$ & 361 & \pm & 184 & 45 & 102 & \pm & 96 & 31 & 56 & \pm & 22 & 45 & 36 & \pm & 29 & 31 \\
\hline $\mathrm{Cl}$ & 4,7 & \pm & 4,4 & 39 & 3,4 & \pm & 3,3 & 22 & 54,6 & \pm & 37,6 & 43 & 61,7 & \pm & 84,2 & 31 \\
\hline $\mathrm{K}$ & 152 & \pm & 82 & 45 & 41 & \pm & 45 & 31 & 73 & \pm & 19 & 45 & 72 & \pm & 36 & 31 \\
\hline $\mathrm{Ca}$ & 6,7 & \pm & 3,7 & 45 & 7,7 & \pm & 7,1 & 31 & 15,4 & \pm & 7,0 & 45 & 17,8 & \pm & 20,2 & 31 \\
\hline $\mathrm{Ti}$ & 1,9 & \pm & 1,8 & 35 & 3,1 & \pm & 3,0 & 28 & 5,1 & \pm & 8,0 & 44 & 4,5 & \pm & 6,7 & 30 \\
\hline $\mathrm{Cr}$ & 0,3 & \pm & 0,1 & 7 & 0,2 & \pm & 0,1 & 5 & - & \pm & - & - & - & \pm & - & - \\
\hline $\mathrm{Mn}$ & 0,5 & \pm & 0,4 & 26 & 0,5 & \pm & 0,4 & 23 & 0,5 & \pm & 0,3 & 30 & 0,8 & \pm & 1,0 & 28 \\
\hline $\mathrm{Fe}$ & 15 & \pm & 12 & 45 & 21 & \pm & 21 & 31 & 31 & \pm & 25 & 45 & 35 & \pm & 52 & 31 \\
\hline $\mathrm{Ni}$ & 0,3 & \pm & 0,1 & 34 & 0,2 & \pm & 0,1 & 24 & 0,2 & \pm & 0,2 & 26 & 0,1 & \pm & 0,1 & 16 \\
\hline $\mathrm{Zn}$ & 1,3 & \pm & 0,6 & 45 & 0,5 & \pm & 0,4 & 28 & 0,7 & \pm & 0,3 & 43 & 0,8 & \pm & 0,5 & 31 \\
\hline Se & 0,6 & \pm & 0,4 & 25 & 0,4 & \pm & 0,2 & 13 & 0,7 & \pm & 0,6 & 26 & 0,4 & \pm & 0,3 & 14 \\
\hline $\mathrm{Br}$ & 1,4 & \pm & 0,8 & 45 & 0,4 & \pm & 0,4 & 18 & 0,4 & \pm & 0,2 & 17 & 0,3 & \pm & 0,2 & 15 \\
\hline $\mathrm{Sr}$ & 1,3 & \pm & 0,6 & 5 & 1,2 & \pm & 0,3 & 2 & - & \pm & - & - & - & \pm & - & - \\
\hline $\mathrm{Cd}$ & 2,4 & \pm & 1,9 & 3 & 0,7 & \pm & 0,3 & 4 & - & \pm & - & - & - & \pm & - & - \\
\hline $\mathrm{Pb}$ & 0,7 & \pm & 0,4 & 12 & 0,4 & \pm & 0,3 & 9 & - & \pm & - & - & - & \pm & - & - \\
\hline $\mathrm{BCe}$ & 460 & \pm & 244 & 45 & 124 & \pm & 157 & 31 & 43 & \pm & 10 & 45 & 37 & \pm & 26 & 31 \\
\hline MP* & 5,6 & \pm & 2,8 & 45 & 1,5 & \pm & 1,5 & 31 & 5,4 & \pm & 1,5 & 45 & 4,8 & \pm & 2,2 & 31 \\
\hline
\end{tabular}


Tabela A.2: concentração em $\mathrm{ng} / \mathrm{m}^{3}$ dos elementos analisados por fluorêscencia, refletância e gravimetria no TIWA para moda fina e grossa e estação seca e chuvosa.

\begin{tabular}{|c|c|c|c|c|c|c|c|c|c|c|c|c|c|c|c|c|}
\hline \multicolumn{17}{|c|}{ TIWA - Concentração Média dos Elementos Traços, BCe e MP } \\
\hline & \multicolumn{8}{|c|}{ Moda Fina } & \multicolumn{8}{|c|}{ Moda Grossa } \\
\hline & \multicolumn{3}{|c|}{ Estação Seca } & \multirow{2}{*}{$\frac{\mathrm{N}}{50}$} & Estação & \multicolumn{2}{|c|}{ Chuvosa } & \multirow{2}{*}{$\frac{N}{26}$} & \multicolumn{3}{|c|}{ Estação Seca } & \multirow{2}{*}{$\begin{array}{c}\mathrm{N} \\
43\end{array}$} & \multicolumn{3}{|c|}{ Estação Chuvosa } & \multirow{2}{*}{$\frac{N}{26}$} \\
\hline $\mathrm{Na}$ & 121 & \pm & 123 & & 38 & \pm & 20 & & 114 & \pm & 80 & & 51 & \pm & 29 & \\
\hline $\mathrm{Mg}$ & 33 & \pm & 39 & 28 & 15 & \pm & 9 & 22 & 50 & \pm & 42 & 43 & 60 & \pm & 34 & 26 \\
\hline Al & 126 & \pm & 163 & 50 & 71 & \pm & 42 & 26 & 200 & \pm & 155 & 43 & 116 & \pm & 65 & 26 \\
\hline Si & 162 & \pm & 210 & 50 & 139 & \pm & 88 & 26 & 257 & \pm & 187 & 43 & 209 & \pm & 114 & 26 \\
\hline$P$ & 17 & \pm & 11 & 50 & 6 & \pm & 2 & 25 & 16 & \pm & 13 & 42 & 22 & \pm & 8 & 26 \\
\hline $\mathrm{S}$ & 499 & \pm & 349 & 50 & 164 & \pm & 71 & 26 & 61 & \pm & 27 & 43 & 43 & \pm & 18 & 26 \\
\hline $\mathrm{Cl}$ & 6,3 & \pm & 3,4 & 50 & 3,6 & \pm & 1,9 & 26 & 49 & \pm & 66 & 39 & 56 & \pm & 50 & 26 \\
\hline $\mathrm{K}$ & 261 & \pm & 161 & 50 & 93 & \pm & 41 & 26 & 76 & \pm & 26 & 43 & 81 & \pm & 23 & 26 \\
\hline $\mathrm{Ca}$ & 32 & \pm & 45 & 50 & 19,2 & \pm & 8,5 & 26 & 54 & \pm & 31 & 43 & 54 & \pm & 28 & 26 \\
\hline $\mathrm{Ti}$ & 9,9 & \pm & 13,0 & 50 & 5,1 & \pm & 2,8 & 26 & 16,5 & \pm & 10,9 & 43 & 9,6 & \pm & 4,9 & 26 \\
\hline $\mathrm{Cr}$ & - & \pm & - & - & - & \pm & - & - & 0,6 & \pm & 0,4 & 29 & 0,3 & \pm & 0,2 & 15 \\
\hline $\mathrm{Mn}$ & 2,6 & \pm & 1,7 & 43 & 2,0 & \pm & 1,0 & 26 & 1,3 & \pm & 0,8 & 36 & 1,3 & \pm & 0,6 & 23 \\
\hline $\mathrm{Fe}$ & 84 & \pm & 93 & 50 & 48 & \pm & 23 & 26 & 123 & \pm & 82 & 43 & 72 & \pm & 36 & 26 \\
\hline $\mathrm{Ni}$ & 0,8 & \pm & 0,5 & 47 & 0,7 & \pm & 0,2 & 25 & 0,4 & \pm & 0,3 & 29 & 0,3 & \pm & 0,1 & 23 \\
\hline $\mathrm{Cu}$ & 0,9 & \pm & 0,6 & 37 & 0,6 & \pm & 0,4 & 24 & 0,6 & \pm & 0,4 & 28 & 0,6 & \pm & 0,4 & 23 \\
\hline $\mathrm{Zn}$ & 6,0 & \pm & 3,6 & 50 & 4,7 & \pm & 2,0 & 26 & 2,2 & \pm & 1,4 & 43 & 2,6 & \pm & 1,1 & 26 \\
\hline $\mathrm{Br}$ & 3,3 & \pm & 2,0 & 49 & 1,3 & \pm & 0,6 & 22 & 0,8 & \pm & 0,7 & 18 & 0,7 & \pm & 0,4 & 16 \\
\hline $\mathrm{Sb}$ & 3,8 & \pm & 2,5 & 10 & 1,2 & \pm & 0,5 & 4 & 5,0 & \pm & 2,0 & 7 & 2,5 & \pm & 1,6 & 4 \\
\hline $\mathrm{Pb}$ & 2,1 & \pm & 1,2 & 29 & 1,8 & \pm & 2,0 & 20 & - & \pm & - & - & - & \pm & - & - \\
\hline $\mathrm{BCe}$ & 1306 & \pm & 759 & 50 & 621 & \pm & 195 & 26 & 125 & \pm & 79 & 43 & 99 & \pm & 44 & 26 \\
\hline MP* & 11,2 & \pm & 7,5 & 50 & 3,4 & \pm & 1,2 & 26 & 7,2 & \pm & 2,7 & 43 & 6,4 & \pm & 1,7 & 26 \\
\hline
\end{tabular}


Tabela A.3 concentração em $\mathrm{ng} / \mathrm{m}^{3}$ dos elementos analisados por fluorêscencia, refletância e gravimetria em Manacapuru para moda fina e grossa e estação seca e chuvosa.

\begin{tabular}{|c|c|c|c|c|c|c|c|c|c|c|c|c|c|c|c|c|}
\hline \multicolumn{17}{|c|}{ Manacapuru - Concentração Média dos Elementos Traços, BCe e MP } \\
\hline & \multicolumn{8}{|c|}{ Moda Fina } & \multicolumn{8}{|c|}{ Moda Grossa } \\
\hline & Esta & :ão & seca & $N$ & Estaçã & $\mathrm{OCC}$ & uvosa & $\mathrm{N}$ & Estas & ão & eca & $\mathrm{N}$ & Estaçã & $\mathrm{OCC}$ & uvosa & $\mathrm{N}$ \\
\hline $\mathrm{Na}$ & 28 & \pm & 16 & 42 & 19 & \pm & 21 & 40 & 27 & \pm & 17 & 42 & 21 & \pm & 24 & 45 \\
\hline $\mathrm{Mg}$ & 6 & \pm & 4 & 22 & 17 & \pm & 25 & 27 & 25 & \pm & 31 & 38 & 65 & \pm & 76 & 38 \\
\hline $\mathrm{Al}$ & 20 & \pm & 18 & 42 & 53 & \pm & 97 & 46 & 30 & \pm & 29 & 42 & 40 & \pm & 74 & 46 \\
\hline $\mathrm{Si}$ & 33 & \pm & 35 & 42 & 102 & \pm & 190 & 46 & 45 & \pm & 43 & 42 & 77 & \pm & 146 & 46 \\
\hline$P$ & 6 & \pm & 3 & 42 & 4 & \pm & 3 & 44 & 10 & \pm & 7 & 42 & 11 & \pm & 8 & 42 \\
\hline$S$ & 181 & \pm & 79 & 42 & 86 & \pm & 77 & 46 & 22 & \pm & 13 & 42 & 15 & \pm & 13 & 45 \\
\hline $\mathrm{Cl}$ & 3,1 & \pm & 1,6 & 42 & 3,0 & \pm & 4,7 & 25 & 11,1 & \pm & 9,1 & 40 & 21,4 & \pm & 44,8 & 35 \\
\hline $\mathrm{K}$ & 77 & \pm & 37 & 42 & 37 & \pm & 40 & 46 & 33 & \pm & 18 & 42 & 35 & \pm & 31 & 46 \\
\hline $\mathrm{Ca}$ & 5,2 & \pm & 3,5 & 42 & 11,5 & \pm & 16,8 & 46 & 9,0 & \pm & 8,1 & 42 & 12,8 & \pm & 20,8 & 46 \\
\hline $\mathrm{Ti}$ & 1,7 & \pm & 1,5 & 39 & 4,0 & \pm & 6,6 & 42 & 4,3 & \pm & 5,4 & 39 & 4,6 & \pm & 8,3 & 44 \\
\hline $\mathrm{Cr}$ & 0,4 & \pm & 0,5 & 8 & 0,8 & \pm & 1,8 & 9 & 0,3 & \pm & 0,1 & 18 & 0,2 & \pm & 0,1 & 9 \\
\hline $\mathrm{Mn}$ & 0,4 & \pm & 0,2 & 28 & 0,7 & \pm & 1,0 & 31 & 0,4 & \pm & 0,2 & 24 & 0,6 & \pm & 1,0 & 25 \\
\hline $\mathrm{Fe}$ & 14 & \pm & 11 & 42 & 28 & \pm & 48 & 46 & 28 & \pm & 31 & 42 & 28 & \pm & 51 & 46 \\
\hline $\mathrm{Ni}$ & 0,2 & \pm & 0,1 & 20 & 0,3 & \pm & 0,2 & 36 & 0,2 & \pm & 0,1 & 28 & 0,2 & \pm & 0,1 & 33 \\
\hline $\mathrm{Cu}$ & 0,3 & \pm & 0,3 & 21 & 0,3 & \pm & 0,2 & 20 & 0,2 & \pm & 0,1 & 21 & 0,3 & \pm & 0,3 & 21 \\
\hline $\mathrm{Zn}$ & 1,0 & \pm & 0,6 & 42 & 0,7 & \pm & 0,4 & 40 & 0,5 & \pm & 0,4 & 42 & 0,5 & \pm & 0,5 & 37 \\
\hline $\mathrm{Br}$ & 0,9 & \pm & 0,5 & 38 & 0,5 & \pm & 0,3 & 24 & - & \pm & - & - & - & \pm & - & - \\
\hline $\mathrm{Pb}$ & 0,6 & \pm & 0,3 & 14 & 0,6 & \pm & 0,4 & 13 & - & \pm & - & - & - & \pm & - & - \\
\hline $\mathrm{BCe}$ & 319 & \pm & 139 & 42 & 152 & \pm & 105 & 46 & 23 & \pm & 12 & 42 & 20 & \pm & 16 & 46 \\
\hline MP* & 3,8 & \pm & 2,4 & 42 & 1,9 & \pm & 1,7 & 46 & 2,3 & \pm & 1,4 & 42 & 2,3 & \pm & 1,9 & 46 \\
\hline
\end{tabular}


Tabela A.4: correlação de Pearson da série temporal da concentração dos elementos na moda fina da ZF2.

Material Particulado Fino da ZF2 - Correlação de Pearson das Concentrações dos Elementos durante o GoAmazon2014/15

\begin{tabular}{|c|c|c|c|c|c|c|c|c|c|c|c|c|c|c|c|c|c|c|c|}
\hline & $\mathrm{Na}{ }_{-} \mathrm{F}$ & Mg_F & Al_F & Si_F & P_F & S_F & Cl_F & K_F & Ca_F & Ti_F & $\mathrm{Cr}_{2} \mathrm{~F}$ & Mn_F & $\mathrm{Fe} \_\mathrm{F}$ & $\mathrm{Ni} \_\mathrm{F}$ & Zn_F & Se_F & Br_F & Bce_F & MPF \\
\hline $\mathrm{Na} \_\mathrm{F}$ & 1 & $615^{* *}$ & ,221 & ,086 & $824^{* *}$ & $827^{* *}$ &, $457^{* *}$ & $811^{* *}$ &, $574^{* *}$ &, $273^{*}$ & $927^{* *}$ &, $561^{* *}$ &, $305^{* *}$ &, $669^{* *}$ &, $764^{* *}$ &, $557^{* *}$ &, $786^{* *}$ &, $762^{* *}$ & $835^{* *}$ \\
\hline Mg_F & $615^{* *}$ & 1 & $365^{*}$ &, $386^{*}$ & $380^{*}$ &, $398^{*}$ & $446^{* *}$ & $400^{*}$ &, $734^{* *}$ &, $392^{*}$ &,$- 999^{*}$ & $689^{* *}$ & $375^{*}$ &, $512^{* *}$ & $434^{* *}$ &, $737^{* *}$ & 319, & $361^{*}$ & $474^{* *}$ \\
\hline Al_F & ,221 &, $365^{*}$ & 1 & ,968 &, $249^{*}$ &, $293^{*}$ &,- 020 & $308^{* *}$ & $822^{* *}$ & $986^{* *}$ & ,580 &, $550^{* *}$ & $974^{* *}$ & $329^{*}$ & $334^{* *}$ & ,095 & 152 & $345^{* *}$ & $267^{*}$ \\
\hline Si_F & ,086 & $386^{*}$ & $968^{* *}$ & 1 & ,077 & 113 &,- 069 & 135 & $808^{* *}$ & $945^{* *}$ & ,206 & $470^{* *}$ & $928^{* *}$ & ,244 & ,166 &,- 060 &,- 016 & 170 & ,089 \\
\hline$P_{-} F$ & $824^{* *}$ &, $380^{*}$ & $249^{*}$ & ,077 & 1 & ,990 &, $467^{* *}$ & $974^{* *}$ & $470^{* *}$ & $278^{*}$ & ,939 &, $568^{* *}$ &, $351^{* *}$ &, $706^{* *}$ & $963^{* *}$ & $492^{* *}$ & $865^{* *}$ & $972^{* *}$ &, $963^{* *}$ \\
\hline S_F & $827^{* *}$ &, $398^{*}$ &, $293^{*}$ & 113 & $990^{* *}$ & 1 & $488^{* *}$ & $979^{* *}$ & $494^{* *}$ & $320^{* *}$ &, $964^{* *}$ &, $604^{* *}$ & $379^{* *}$ &, $696^{* *}$ &, $957^{* *}$ & $541^{* *}$ & $866^{* *}$ &, $976^{* *}$ & $978^{* *}$ \\
\hline Cl_F & $457^{* *}$ & $446^{* *}$ &,- 020 &,- 069 & $467^{* *}$ & $488^{* *}$ & 1 & $489^{* *}$ &, $261^{*}$ &,- 019 & ,274 & $653^{* *}$ &,- 040 &, $273^{*}$ & $440^{* *}$ & 294 & $429^{* *}$ & $416^{* *}$ & $478^{* *}$ \\
\hline K_F & $811^{* *}$ & $400^{*}$ & $308^{* *}$ & 135, & $974^{* *}$ & $979^{* *}$ & $489^{* *}$ & 1 & $507^{* *}$ & $324^{* *}$ & $916^{* *}$ & $617^{* *}$ & $395^{* *}$ & $687^{* *}$ & $958^{* *}$ & $624^{* *}$ & $878^{* *}$ & $979^{* *}$ &, $968^{* *}$ \\
\hline $\mathrm{Ca} F$ & $574^{* *}$ & $734^{* *}$ & $822^{* *}$ & $808^{* *}$ & $470^{* *}$ & $494^{* *}$ & $261^{*}$ &, $507^{* *}$ & 1 & $827^{* *}$ &, $753^{* *}$ &, $737^{* *}$ & $831^{* *}$ & $605^{* *}$ &, $512^{* *}$ & 283, &, $384^{* *}$ & $496^{* *}$ & $494^{* *}$ \\
\hline Ti_F &, $273^{*}$ & $392^{*}$ & $986^{* *}$ &, $945^{* *}$ & $278^{*}$ &, $320^{* *}$ &,- 019 &, $324^{* *}$ & $827^{* *}$ & 1 & ,597 &, $574^{* *}$ & $970^{* *}$ &, $386^{* *}$ &, $352^{* *}$ & ,078 & ,173 &, $359^{* *}$ &, $294^{*}$ \\
\hline Cr_F &, $927^{* *}$ &,$- 999^{*}$ & ,580 & 206 & ,939 & $964^{* *}$ & ,274 & $916^{* *}$ &, $753^{* *}$ & ,597 & 1 & ,571 & ,576 & ,057 & $915^{* *}$ & ,066 & $875^{* *}$ &, $932^{* *}$ &, $960^{* *}$ \\
\hline Mn_F & $561^{* *}$ & $689^{* *}$ & $550^{* *}$ & $470^{* *}$ &, $568^{* *}$ & $604^{* *}$ &, $653^{* *}$ &, $617^{* *}$ &, $737^{* *}$ &, $574^{* *}$ & ,571 & 1 & $555^{* *}$ &, $623^{* *}$ &, $612^{* *}$ & $478^{*}$ &, $548^{* *}$ &, $583^{* *}$ & $604^{* *}$ \\
\hline $\mathrm{Fe} \_\mathrm{F}$ &, $305^{* *}$ & $375^{*}$ &, $974^{* *}$ & $928^{* *}$ &, $351^{* *}$ &, $379^{* *}$ &,- 040 & $395^{* *}$ &, $831^{* *}$ & $970^{* *}$ & ,576 &, $555^{* *}$ & 1 & $396^{* *}$ & $423^{* *}$ & ,077 & ,225 & $437^{* *}$ & $344^{* *}$ \\
\hline $\mathrm{Ni} \_\mathrm{F}$ & $669^{* *}$ &, $512^{* *}$ & $329^{*}$ & 244 &, $706^{* *}$ & $696^{* *}$ &, $273^{*}$ & $687^{* *}$ & $605^{* *}$ & $386^{* *}$ & ,057 &, $623^{* *}$ & $396^{* *}$ & 1 &, $660^{* *}$ & 285 &, $552^{* *}$ &, $599^{* *}$ & $690^{* *}$ \\
\hline Zn_F &, $764^{* *}$ &, $434^{* *}$ &, $334^{* *}$ & 166 &, $963^{* *}$ &, $957^{* *}$ &, $440^{* *}$ &, $958^{* *}$ &, $512^{* *}$ & $352^{* *}$ & $915^{* *}$ &, $612^{* *}$ & $423^{* *}$ &, $660^{* *}$ & 1 &, $531^{* *}$ &, $852^{* *}$ & $967^{* *}$ &, $935^{* *}$ \\
\hline $\mathrm{Se} \_\mathrm{F}$ &, $557^{* *}$ &, $737^{* *}$ & ,095 &,- 060 & $492^{* *}$ &, $541^{* *}$ & ,294 &, $624^{* *}$ & ,283 & ,078 & ,066 & $478^{*}$ & ,077 & ,285 &, $531^{* *}$ & 1 &, $742^{* *}$ &, $556^{* *}$ &, $592^{* *}$ \\
\hline $\mathrm{Br}_{-} \mathrm{F}$ &, $786^{* *}$ & ,319 & , 152 &,- 016 & $865^{* *}$ &, $866^{* *}$ &, $429^{* *}$ & $878^{* *}$ &, $384^{* *}$ & 173, & $875^{* *}$ &, $548^{* *}$ & 225, &, $552^{* *}$ & $852^{* *}$ &, $742^{* *}$ & 1 & $857^{* *}$ & $859^{* *}$ \\
\hline Bce_F &, $762^{* *}$ & $361^{*}$ & $345^{* *}$ & 170, & $972^{* *}$ & $976^{* *}$ & $416^{* *}$ & $979^{* *}$ & $496^{* *}$ & $359^{* *}$ &, $932^{* *}$ &, $583^{* *}$ & $437^{* *}$ &, $599^{* *}$ & $967^{* *}$ & $556^{* *}$ & $857^{* *}$ & 1 & $946^{* *}$ \\
\hline MPF & $835^{* *}$ & $474^{* *}$ & $267^{*}$ & 089 & $963^{* *}$ & $978^{* *}$ & $478^{* *}$ & $968^{* *}$ & $494^{* *}$ &, $294^{*}$ &, $960^{* *}$ & $604^{* *}$ & $344^{* *}$ & $690^{* *}$ & $935^{* *}$ &, $592^{* *}$ & $859^{* *}$ & $946^{* *}$ & 1 \\
\hline
\end{tabular}

** Correlação significativa no nível 0,05 
Tabela A.5: correlação de Pearson da série temporal da concentração dos elementos na moda fina do TIWA.

Material Particulado Fino do TIWA - Correlação de Pearson das Concentrações dos Elementos durante o GoAmazon2014/15

\begin{tabular}{|c|c|c|c|c|c|c|c|c|c|c|c|c|c|c|c|c|c|c|c|c|}
\hline \multicolumn{21}{|c|}{ Material Particulado Fino do TIWA - Correlação de Pearson das Concentrações dos Elementos durante o GoAmazon2014/15 } \\
\hline & $\mathrm{Na}{ }_{-} \mathrm{F}$ & Mg_F & Al_F & Si_F & P_F & S_F & Cl_F & K_F & $\mathrm{Ca} \_\mathrm{F}$ & Ti_F & Mn_F & $\mathrm{Fe} \_\mathrm{F}$ & $\mathrm{Ni} \_\mathrm{F}$ & Cu_F & Zn_F & Br_F & Sb_F & $\mathrm{Pb} \_\mathrm{F}$ & Bce_F & MPF \\
\hline $\mathrm{Na}$ & 1 & ,559** & ,625** &, $437^{* *}$ &, $842 * *$ & ,838** &, $533 * *$ & ,784** & ,602** & ,635** &, $593 * *$ & ,693** &, $502 * *$ &, $417^{* *}$ & ,551** & ,793** & ,537* &, $510 * *$ &, $803 * *$ &, $818 * *$ \\
\hline Mg_F &, $559 * *$ & 1 &, $814 * *$ & ,769** &, $400 * *$ & ,378* & 216 &, $462 * *$ & ,789** &, $806 * *$ &, $452 * *$ &, $797 * *$ & ,352* & ,235 & ,370* & ,409** &,- 019 & ,099 & ,386** & ,460** \\
\hline Al_F &, $625^{* *}$ &, $814^{* *}$ & 1 &, $923 * *$ & ,488** &, $464^{* *}$ & ,273* &, $583 * *$ &, $833 * *$ &, $982 * *$ &, $590 * *$ &, $965^{* *}$ &, $567^{* *}$ &, $369 * *$ & ,433** &, $541 * *$ &,- 006 & 0,302 &, $592^{* *}$ & ,632** \\
\hline Si_F &, $437 * *$ & ,769** &, $923 * *$ & 1 & ,284* & ,261* & 149 & ,392** & ,781** & ,879** &, $549 * *$ & ,852** &, $551 * *$ & ,268* &, $407 * *$ & ,332** &,- 256 & 203 &, $412 * *$ &, $395 * *$ \\
\hline P_F &, $842 * *$ &, $400 * *$ & ,488** &, $284^{*}$ & 1 &, $974 * *$ &, $597 * *$ & ,909** &, $420 * *$ &, $496 * *$ &, $472^{* *}$ &, $562 * *$ & ,396** &, $418 * *$ &, $464^{* *}$ &, $818^{* *}$ &, $666 * *$ &, $579 * *$ & ,836** &, $926 * *$ \\
\hline S_F &, $838^{* *}$ & ,378* &, $464 * *$ & ,261* &, $974 * *$ & 1 &, $577 * *$ & ,921** &, $376 * *$ & ,458** & ,455** &, $528 * *$ &, $351 * *$ &, $377 * *$ & ,419** &, $824 * *$ & ,736** &, $548 * *$ &, $844^{* *}$ & ,926** \\
\hline Cl_F &, $533 * *$ & ,216 & ,273* & 149 &, $597 * *$ &, $577^{* *}$ & 1 &, $607 * *$ & ,319** & ,302* &, $453 * *$ & ,333** & ,278* &, $361 * *$ &, $487 * *$ &, $630 * *$ & 217 &, $406 * *$ &, $524 * *$ &, $589 * *$ \\
\hline K_F &, $784^{* *}$ &, $462 * *$ &, $583 * *$ &, $392 * *$ & ,909** &, $921^{* *}$ &, $607 * *$ & 1 & ,428** & ,585** &, $514 * *$ &, $631^{* *}$ &, $352 * *$ & ,402** & ,511** & ,879** & ,637* & ,646** &, $904 * *$ & ,956** \\
\hline Ca_F &, $602 * *$ & ,789** &, $833 * *$ & ,781** &, $420 * *$ &, $376 * *$ & ,319** & ,428** & 1 &, $864 * *$ &, $717 * *$ &, $895^{* *}$ &, $683 * *$ &, $572 * *$ &, $587 * *$ &, $515^{* *}$ &,- 184 &, $488 * *$ &, $531 * *$ &, $487^{* *}$ \\
\hline Ti_F &, $635^{* *}$ &, $806 * *$ &, $982 * *$ & ,879** & , $496 * *$ & ,458** & ,302* &, $585^{* *}$ &, $864 * *$ & 1 &, $604^{* *}$ &, $977^{* *}$ &, $582^{* *}$ &, $436 * *$ & ,479** &, $576^{* *}$ &,- 168 & ,385* &, $611^{* *}$ &, $648 * *$ \\
\hline$M n \_F$ &, $593 * *$ &, $452^{* *}$ &, $590 * *$ & ,549** &, $472^{* *}$ &, $455^{* *}$ & ,453** &, $514 * *$ &, $717^{* *}$ &, $604 * *$ & 1 & ,689** & ,616** &, $694 * *$ &, $653 * *$ & ,620** &,- 203 &, $585^{* *}$ & ,626** &, $503 * *$ \\
\hline $\mathrm{Fe} \_\mathrm{F}$ &, $693 * *$ &, $797^{* *}$ &, $965^{* *}$ &, $852 * *$ &, $562 * *$ &, $528 * *$ &, $333 * *$ & ,631** &, $895 * *$ &, $977^{* *}$ & ,689** & 1 & ,599** &, $522 * *$ &, $537 * *$ &, $635^{* *}$ & ,033 &, $480 * *$ &, $677^{* *}$ &, $688 * *$ \\
\hline $\mathrm{Ni} \_\mathrm{F}$ &, $502^{* *}$ &, $352 *$ &, $567^{* *}$ &, $551^{* *}$ &, $396 * *$ &, $351^{* *}$ &, $278^{*}$ &, $352^{* *}$ &, $683 * *$ &, $582 * *$ &, $616 * *$ & ,599** & 1 & ,482** &, $430 * *$ & ,420** & ,022 & 0,240 &, $478 * *$ &, $394 * *$ \\
\hline $\mathrm{Cu} \_\mathrm{F}$ &, $417^{* *}$ & ,235 &, $369 * *$ & ,268* & ,418** &, $377^{* *}$ &, $361^{* *}$ &, $402 * *$ &, $572 * *$ &, $436 * *$ &, $694 * *$ &, $522 * *$ &, $482 * *$ & 1 &, $617^{* *}$ & ,616** &,- 094 &, $595 * *$ &, $542 * *$ & ,438** \\
\hline$Z n \_F$ &, $551^{* *}$ & ,370* & ,433** &, $407^{* *}$ &, $464 * *$ & ,419** &, $487^{* *}$ &, $511^{* *}$ &, $587^{* *}$ & ,479** &, $653 * *$ &, $537 * *$ &, $430 * *$ &, $617^{* *}$ & 1 &, $694^{* *}$ &,- 386 &, $773 * *$ &, $675^{* *}$ & ,449** \\
\hline $\mathrm{Br} \_\mathrm{F}$ &, $793^{* *}$ &, $409 * *$ &, $541^{* *}$ &, $332 * *$ & ,818** &, $824 * *$ &, $630 * *$ & ,879** &, $515^{* *}$ &, $576 * *$ &, $620 * *$ &, $635^{* *}$ &, $420 * *$ &, $616 * *$ &, $694^{* *}$ & 1 & ,431 &, $635^{* *}$ &, $897^{* *}$ &, $852^{* *}$ \\
\hline$S b \_F$ & ,537* &,- 019 &,- 006 &,- 256 &, $666 * *$ &, $736 * *$ & ,217 & ,637* &,- 184 &,- 168 &,- 203 & ,033 & ,022 &,- 094 &,- 386 & ,431 & 1 & 160 & ,405 &, $747^{* *}$ \\
\hline $\mathrm{Pb} \_\mathrm{F}$ &, $510 * *$ & ,099 & 0,302 & 203 &, $579 * *$ &, $548 * *$ &, $406^{* *}$ &, $646 * *$ &, $488 * *$ & ,385* &, $585^{* *}$ &, $480 * *$ & 0,240 &, $595 * *$ &, $773 * *$ &, $635^{* *}$ & 160 & 1 &, $703 * *$ &, $524^{* *}$ \\
\hline Bce_F &, $803^{* *}$ &, $386^{* *}$ &, $592 * *$ &, $412 * *$ &, $836 * *$ &, $844 * *$ &, $524^{* *}$ &, $904 * *$ &, $531^{* *}$ &, $611^{* *}$ &, $626 * *$ &, $677^{* *}$ &, $478 * *$ &, $542 * *$ &, $675^{* *}$ &, $897^{* *}$ & ,405 & ,703** & 1 &, $884^{* *}$ \\
\hline MPF &, $818^{* *}$ &, $460 * *$ & ,632** & ,395** & ,926** & ,926** &, $589 * *$ & ,956** &, $487 * *$ & ,648** &, $503 * *$ & ,688** &, $394 * *$ & ,438** & ,449** &, $852 * *$ &, $747^{* *}$ &, $524 * *$ &, $884 * *$ & 1 \\
\hline
\end{tabular}

*Correlação significativa no nível 0,01

** Correlação significativa no nível 0,05 
Tabela A.6: correlação de Pearson da série temporal da concentração dos elementos na moda fina de Manacapuru.

Material Particulado Fino de Manacapuru - Correlação de Pearson das Concentrações dos Elementos durante o GoAmazon2014/15

\begin{tabular}{|c|c|c|c|c|c|c|c|c|c|c|c|c|c|c|c|c|c|c|c|c|}
\hline & $\mathrm{Na} \_\mathrm{F}$ & Mg_F & Al_F & Si_F & $P_{-} F$ & S_F & Cl_F & K_F & Ca_F & Ti_F & $\mathrm{Cr}_{-} \mathrm{F}$ & $M n \_F$ & $\mathrm{Fe} \_\mathrm{F}$ & $\mathrm{Ni} \_\mathrm{F}$ & $\mathrm{Cu}$ _F & Zn_F & $\mathrm{Br}_{-} \mathrm{F}$ & $\mathrm{Pb} \_\mathrm{F}$ & Bce_F & MPF \\
\hline $\mathrm{Na}$ _F & 1 & 058 & $244^{*}$ & 210 & $846^{* *}$ & $871^{* *}$ & $603^{* *}$ & $806^{* *}$ & $436^{* *}$ & 148, & 126, & $367^{* *}$ & ,268* & ,283* & $461^{* *}$ & $673^{* *}$ &, $755^{* *}$ & 331 &, $727^{* *}$ & $845^{* *}$ \\
\hline Mg_F & ,058 & 1 &, $666^{* *}$ &, $701^{* *}$ &,- 033 &,- 068 & ,059 & ,061 &, $663^{* *}$ &, $507^{* *}$ & ,029 & $454^{* *}$ &, $512^{* *}$ & ,019 & 111 & 189 &,- 014 & 195 &,- 073 &,- 066 \\
\hline Al_F & ,244 & $666^{* *}$ & 1 & $981^{* *}$ & ,264 & 185 & ,084 & 187 & $866^{* *}$ &, $898^{* *}$ &, $738^{* *}$ & $620^{* *}$ & $927^{* *}$ &, $367^{* *}$ & ,076 &, $363^{* *}$ & ,024 & 133 & 123, & 161 \\
\hline Si_F & 210, & ,701 & $981^{* *}$ & 1 & ,221 & 138, & ,088 & 150 & $860^{* *}$ & $821^{* *}$ & $630^{* *}$ &, $565^{* *}$ & $848^{* *}$ & 261 & ,046 & $307^{* *}$ & -,019 & ,046 & 051 & 095, \\
\hline P_F & $846^{* *}$ &,- 033 &, $264^{*}$ &, $221^{*}$ & 1 &, $962^{* *}$ &, $588^{* *}$ & $855^{* *}$ & $386^{* *}$ & ,161 & ,283 & $298^{*}$ &, $282^{*}$ & $351^{*}$ & $422^{* *}$ &, $773^{* *}$ &, $765^{* *}$ & ,262 & $811^{* *}$ & $901^{* *}$ \\
\hline S_F & $871^{* *}$ &,- 068 & 185 & 138 & $962^{* *}$ & 1 & $680^{* *}$ & $899^{* *}$ &, $327^{* *}$ & ,097 & 221 & ,257 & 213 & ,298* &, $371^{*}$ &, $738^{* *}$ & $801^{* *}$ & 202 & $870^{* *}$ & ,952 \\
\hline Cl_F & $603^{* *}$ & ,059 & ,084 & ,088 &, $588^{* *}$ & $680^{* *}$ & 1 &, $798^{* *}$ &, $241^{*}$ & -,041 &,- 014 & $301^{*}$ & ,042 &,- 047 & $379^{*}$ &, $569^{* *}$ &, $710^{* *}$ & ,064 &, $743^{* *}$ & ,708 \\
\hline K_F & $806^{* *}$ & 061 & 187, & 150, & $855^{* *}$ & $899^{* *}$ & ,798** & 1 & $316^{* *}$ & 093 & 247 & $307^{*}$ & 200 & 177, & $365^{*}$ & $727^{* *}$ & $835^{* *}$ & 292 & $928^{* *}$ & ,932 \\
\hline Ca_F & $436^{* *}$ &, $663^{* *}$ & $866^{* *}$ & $860^{* *}$ & ,386** & ,327** & $241^{*}$ & ,316 & 1 &, $736^{* *}$ &, $513^{*}$ & ,714 & ,786 & ,306 & 233, &, $525^{* *}$ &, $271^{*}$ & 392, &, $225^{*}$ & $278^{*}$ \\
\hline Ti_F & 148 & $507^{* *}$ & $898^{* *}$ & $821^{* *}$ & 161 & 097 &,- 041 & 093 &, $736^{* *}$ & 1 &, $781^{* *}$ & $608^{* *}$ & $968^{* *}$ & $572^{* *}$ & 124 & $329^{* *}$ &,- 010 & 193 & 112 & 115, \\
\hline $\mathrm{Cr}_{2} \mathrm{~F}$ & 126, & ,029 &, $738^{* *}$ & $630^{* *}$ & 283 & 221 &,- 014 & 247 &, $513^{*}$ &, $781^{* *}$ & 1 & ,483 & $823^{* *}$ & 491 & 489 & 160 &,- 161 &,- 048 & 213, & 204 \\
\hline$M n \_F$ &, $367^{* *}$ & $454^{* *}$ &, $620^{* *}$ &, $565^{* *}$ & ,298* & 257 & ,301 & $307^{*}$ &, $714^{* *}$ & $608^{* *}$ & ,483 & 1 & $676^{* *}$ & ,391 & 305 &, $561^{* *}$ & ,254 & 392 & ,286 & 241 \\
\hline $\mathrm{Fe} \_\mathrm{F}$ &, $268^{*}$ &, $512^{* *}$ &, $927^{* *}$ &, $848^{* *}$ & ,282 & 213 & ,042 & 200 &, $786^{* *}$ &, $968^{* *}$ & $823^{* *}$ &, $676^{* *}$ & 1 &, $592^{* *}$ & 177 &, $427^{* *}$ & ,077 & 223 & 208 & ,229* \\
\hline Ni_F &, $283^{*}$ & ,019 &, $367^{* *}$ & 261 & $351^{*}$ & ,298 &,- 047 & 177 & $306^{*}$ & $572^{* *}$ & ,491 & ,391 &, $592^{* *}$ & 1 & $455^{*}$ & $430^{* *}$ & 182 & ,275 & ,280* & 309* \\
\hline $\mathrm{Cu} \_\mathrm{F}$ & $461^{* *}$ & 111 & ,076, & ,046 &, $422^{* *}$ & $371^{*}$ & $379^{*}$ &, $365^{*}$ & 233 & 124, & 489 & 305 & 177, & $455^{*}$ & 1 &, $529^{* *}$ &, $548^{* *}$ & 461 & $412^{*}$ & ,393* \\
\hline Zn_F & $673^{* *}$ & 189, & $363^{* *}$ & $307^{* *}$ &, $773^{* *}$ &, $738^{* *}$ & $569^{* *}$ &, $727^{* *}$ &, $525^{* *}$ & $329^{* *}$ & 160 &, $561^{* *}$ & $427^{* *}$ & $430^{* *}$ & $529^{* *}$ & 1 &, $797^{* *}$ &, $503^{*}$ &, $782^{* *}$ & ,756 \\
\hline $\mathrm{Br} \_\mathrm{F}$ & $755^{* *}$ &,- 014 & ,024 &,- 019 & $765^{* *}$ & $801^{* *}$ &, $710^{* *}$ & $835^{* *}$ & $271^{*}$ &,- 010 &,- 161 & ,254 & 077 & 182 &, $548^{* *}$ & $797^{* *}$ & 1 &, $516^{*}$ & $853^{* *}$ & , 862 \\
\hline $\mathrm{Pb} \_\mathrm{F}$ & ,331 & 195 & ,133 & ,046 & ,262 & 202 & ,064 & ,292 & ,392 & 193 &,- 048 & ,392 & ,223 & ,275 & ,461 &, $503^{*}$ &, $516^{*}$ & 1 &, $400^{*}$ & ,294 \\
\hline Bce_F & $727^{* *}$ &,- 073 & ,123 & ,051 & $811^{* *}$ & $870^{* *}$ & $743^{* *}$ & $928^{* *}$ &, $225^{*}$ & 112 & 213 & ,286 & 208 & ,280* &, $412^{*}$ & $782^{* *}$ & $853^{* *}$ & $400^{*}$ & 1 & ,926 \\
\hline MPF & $845^{* *}$ &,- 066 & 161, & 095 & $901^{* *}$ &, $952^{* *}$ & ,708 & $932^{* *}$ & $278^{*}$ & 115, & 204 & 241 & ,229* & ,309* & ,393* &, $756^{* *}$ & $862^{* *}$ & 294 & $926^{* *}$ & 1 \\
\hline
\end{tabular}

*Correlação significativa no nível 0,01

** Correlação significativa no nível 0,05 
Tabela A 7: correlação de Pearson da série temporal da concentração dos elementos na moda grossa da ZF2.

Material Particulado Grosso da ZF2 - Correlação de Pearson das Concentrações dos Elementos durante o GoAmazon2014/15

\begin{tabular}{|c|c|c|c|c|c|c|c|c|c|c|c|c|c|c|c|c|c|c|}
\hline & $\mathrm{Na} \_\mathrm{G}$ & Mg_G & Al_G & Si_G & $P \_G$ & S_G & Cl_G & K_G & Ca_G & Ti_G & Mn_G & Fe_G & Ni_G & Zn_G & $\mathrm{Se} \_\mathrm{G}$ & Br_G & Bce_G & MPG \\
\hline Na_G & 1 &, $862^{* *}$ & ,274 & ,242 &,$- 255^{*}$ &, $641^{* *}$ &, $866^{\star *}$ & 224 &, $694^{\star *}$ &, $275^{\star}$ &, $238^{*}$ &, $328^{\star *}$ &, $623^{* *}$ &,- 003 & 350 &, $469^{*}$ &, $421^{\star *}$ &, $496^{* *}$ \\
\hline Mg_G & $862^{* *}$ & 1 &, $681^{* *}$ & $675^{\star *}$ &,$- 390^{* *}$ &, $660^{* *}$ &, $749^{* *}$ & 188, & $861^{* *}$ & $653^{* *}$ & $492^{* *}$ &, $705^{* *}$ & $698^{* *}$ & 089, & 319, & , 452 & $497^{* *}$ &, $493^{* *}$ \\
\hline Al_G & ,274 &, $681^{* *}$ & 1 &, $938^{* *}$ &,$- 417^{* *}$ &, $504^{* *}$ & ,121 & ,025 &, $588^{* *}$ &, $987^{* *}$ &, $465^{* *}$ &, $885^{* *}$ &, $636^{* *}$ & ,127 & ,244 & ,333 &, $401^{* *}$ & $249^{*}$ \\
\hline Si_G &, $242^{*}$ &, $675^{\star *}$ &, $938^{* *}$ & 1 &,$- 421^{* *}$ &, $377^{* *}$ & 194, &, 053 &, $721^{* *}$ &, $876^{\star *}$ &, $636^{\star *}$ &, $932^{* *}$ &, $534^{* *}$ & ,169 & ,079 & ,247 &, $403^{* *}$ & ,214 \\
\hline P_G &,$- 255^{\star}$ &,$- 390^{* *}$ &,$- 417^{* *}$ &,$- 421^{* *}$ & 1 & ,065 &,- 178 &, $730^{* *}$ &,$- 430^{* *}$ &,$- 387^{\star *}$ &,- 110 &,$- 491^{* *}$ &,- 202 &, $456^{\star *}$ & ,014 &,- 004 & ,128 &, $552^{* *}$ \\
\hline S_G &, $641^{* *}$ &, $660^{* *}$ &, $504^{* *}$ &, $377^{\star *}$ & ,065 & 1 &, $450^{* *}$ &, $539^{* *}$ &, $476^{* *}$ &, $544^{* *}$ & ,197 &, $364^{* *}$ & $816^{\star *}$ &, $314^{* *}$ &, $590^{* *}$ &, $514^{\star *}$ &, $743^{* *}$ & $674^{* *}$ \\
\hline Cl_G &, $866^{* *}$ &, $749^{* *}$ & ,121 & ,194 &,- 178 &, $450^{* *}$ & 1 &, $236^{*}$ &, $701^{* *}$ & ,088 & ,279* & $241^{*}$ &, $369^{*}$ & ,065 & 138, & 327, &, $286^{\star}$ &, $449^{* *}$ \\
\hline K_G & ,224 & ,188 & ,025 & ,053 &, $730^{* *}$ &, $539^{\star *}$ &, $236^{\star}$ & 1 & ,182 & ,017 &, $316^{* *}$ & ,021 &, $415^{* *}$ &, $641^{* *}$ & 324, & 302, &, $617^{\star \star}$ & $838^{* *}$ \\
\hline Ca_G &, $694^{* *}$ &, $861^{* *}$ &, $588^{* *}$ &, $721^{* *}$ &,$- 430^{* *}$ &, $476^{\star *}$ &, $701^{* *}$ & 182 & 1 &, $507^{\star *}$ &, $687^{* *}$ &, $750^{* *}$ &, $531^{* *}$ & ,089 & 202, & ,287 &, $475^{\star \star}$ &, $341^{* *}$ \\
\hline Ti_G &, $275^{*}$ &, $653^{* *}$ &, $987^{* *}$ &, $876^{* *}$ &,$- 387^{* *}$ &, $544^{* *}$ & ,088 & ,017 &, $507^{\star \star}$ & 1 &, $355^{* *}$ &, $826^{\star *}$ &, $662^{* *}$ & ,103 & 275 & ,381* &, $388^{* *}$ & ,261* \\
\hline Mn_G & ,238* &, $492^{* *}$ & $465^{* \star}$ &, $636^{\star *}$ &,- 110 & ,197 & ,279 &, $316^{* *}$ &, $687^{* *}$ &, $355^{* *}$ & 1 & $645^{* \star}$ & 177 & ,214 & ,188 & ,081 & $349^{* *}$ & ,298* \\
\hline $\mathrm{Fe} \_\mathrm{G}$ &, $328^{* *}$ &, $705^{\star *}$ &, $885^{\star *}$ &, $932^{* *}$ &,$- 491^{* *}$ &, $364^{* *}$ & $241^{\star}$ &, 021 &, $750^{* *}$ &, $826^{\star *}$ &, $645^{* *}$ & 1 &, $542^{* *}$ & ,050 & ,097 & ,214 &, $440^{* *}$ & ,177 \\
\hline Ni_G &, $623^{* *}$ &, $698^{* *}$ &, $636^{* *}$ &, $534^{* *}$ &,- 202 &, $816^{\star *}$ & ,369* &, $415^{\star *}$ &, $531^{* *}$ &, $662^{* *}$ & 177 &, $542^{\star *}$ & 1 & 153 &, $640^{* *}$ &, $660^{* *}$ &, $580^{\star *}$ &, $545^{\star *}$ \\
\hline Zn_G &,- 003 & ,089 & ,127 & ,169 &, $456^{* *}$ &, $314^{* *}$ & ,065 &, $641^{* \star}$ & ,089 & ,103 & ,214 & ,050 & ,153 & 1 & 075, &, $368^{*}$ &, $423^{* *}$ & $477^{* *}$ \\
\hline Se_G & ,350 & ,319 & ,244 & 079 & ,014 &, $590^{* *}$ & ,138 & ,324 & 202 & 275 & 188 & ,097 &, $640^{* *}$ & ,075 & 1 & 101 & ,151 &, $356^{\star}$ \\
\hline Br_G & ,469* &, $452^{*}$ & ,333 & ,247 &,- 004 &, $514^{* *}$ & ,327 & ,302 & ,287 & $381^{*}$ & ,081 & ,214 &, $660^{* *}$ &, $368^{*}$ & 101 & 1 & $469^{*}$ & ,382* \\
\hline Bce_G &, $421^{* *}$ &, $497^{* *}$ & $401^{* *}$ &, $403^{* *}$ & 128 &, $743^{* *}$ & ,286 &, $617^{* *}$ &, $475^{* *}$ &, $388^{* *}$ &, $349^{* *}$ &, $440^{* *}$ &, $580^{* *}$ &, $423^{* *}$ & 151 &, $469^{*}$ & 1 & $600^{* *}$ \\
\hline MPG & $496^{* *}$ & $493^{* *}$ & ,249* & 214, &, $552^{* *}$ &, $674^{* *}$ & $449^{* *}$ &, $838^{\star *}$ & $341^{* *}$ & ,261 & ,298* & 177, &, $545^{\star *}$ & $477^{* *}$ & ,356 & ,382* & $600^{* *}$ & 1 \\
\hline
\end{tabular}

*Correlação significativa no nível 0,01

** Correlação significativa no nível 0,05 
Tabela A.8: correlação de Pearson da série temporal da concentração dos elementos na moda grossa do TIWA.

Material Particulado Grosso do TIWA - Correlação de Pearson das Concentrações dos Elementos durante o GoAmazon2014/15

\begin{tabular}{|c|c|c|c|c|c|c|c|c|c|c|c|c|c|c|c|c|c|c|c|c|}
\hline \multicolumn{21}{|c|}{ Material Particulado Grosso do TIWA - Correlação de Pearson das Concentrações dos Elementos durante o GoAmazon2014/15 } \\
\hline & Na_G & Mg_G & Al_G & Si_G & P_G & S_G & Cl_G & K_G & Ca_G & Ti_G & Cr_G & Mn_G & Fe_G & Ni_G & Cu_G & Zn_G & $\mathrm{Br} \_\mathrm{G}$ & Sb_G & Bce_G & MPG \\
\hline Na_G & 1 & 223 & ,649** &, $615^{* *}$ &,$- 343^{* *}$ &, $864^{* *}$ &, $526^{* *}$ & ,305* &, $599^{* *}$ &, $722^{* *}$ & ,642 &, $581^{* *}$ &, $717^{* *}$ & , $315^{* *}$ & 216, & 213, & 343 & ,691* &, $626^{* *}$ &, $500^{* *}$ \\
\hline Mg_G & 223 & 1 & $467^{* *}$ &, $524^{* *}$ &,$- 334^{* *}$ & 198, & ,348** & 137, &, $532^{* *}$ & $476^{* *}$ & 263 & $651^{* *}$ & $482^{* *}$ & $461^{* *}$ & , $462^{* *}$ &, $514^{* *}$ & 202 & ,303 & , $441^{* *}$ & ,330** \\
\hline Al_G & $649^{* *}$ & $467^{* *}$ & 1 &, $956^{* *}$ &,$- 514^{* *}$ &, $543^{* *}$ & ,289* & ,093 & ,624 & ,966 & ,639** & ,729** &, $971^{* *}$ & ,397** & 182 &, $336^{* *}$ & -,035 & $856^{* *}$ &, $561^{* *}$ & , 433** \\
\hline Si_G &, $615^{* *}$ &, $524^{* *}$ & $956^{* *}$ & 1 &,$- 445^{* *}$ &, $568^{* *}$ & , 440 & 210 &, $713^{* *}$ & $923^{* *}$ &, $538^{* *}$ &, $834^{* *}$ &, $932^{* *}$ &, $439^{* *}$ & 238 &, $473^{* *}$ & ,005 & $841^{* *}$ &, $594^{* *}$ & $484^{* *}$ \\
\hline P_G &,$- 343^{* *}$ &,$- 334^{* *}$ &,$- 514^{* *}$ &,$- 445^{* *}$ & 1 &,- 025 & ,006 & $659^{* *}$ &,$- 415^{* *}$ &,$- 524^{* *}$ &,- 232 &,$- 334^{* *}$ &,$- 503^{* *}$ &,- 200 &,- 095 & -,112 & -,009 &,- 522 & -,191 & ,392** \\
\hline S_G &, $864^{* *}$ & 198 &, $543^{* *}$ &, $568^{* *}$ &,- 025 & 1 & ,620** & $630^{* *}$ &, $617^{* *}$ & $627^{* *}$ & ,524** &, $617^{* *}$ &, $629^{* *}$ & ,364** & , $325^{* *}$ &, $395^{* *}$ & ,439* & ,575 &, $746^{* *}$ & ,738** \\
\hline Cl_G &, $526^{* *}$ &, $348^{* *}$ & ,289* &, $440^{* *}$ & ,006 & $620^{* *}$ & 1 &, $525^{* *}$ &, $543^{* *}$ & $341^{* *}$ & 271 & $602^{* *}$ & $356^{* *}$ & 200 &, $445^{* *}$ & $350^{* *}$ & ,327 &,- 022 & ,436 &, $538^{* *}$ \\
\hline K_G & $305^{*}$ & ,137 & ,093 & ,210 & $659^{* *}$ & $630^{* *}$ &, $525^{* *}$ & 1 & ,225 & ,128 & 235 &, $375^{* *}$ & 156 & ,237 & 240 &, $340^{* *}$ & ,389* & ,096 & ,482** & $850^{* *}$ \\
\hline $\mathrm{Ca}_{-} \mathrm{G}$ &, $599^{* *}$ &, $532^{* *}$ & $624^{* *}$ &, $713^{* *}$ &,$- 415^{* *}$ & $617^{* *}$ &, $543^{* *}$ & 225 & 1 & ,689** & $328^{*}$ &, $772^{* *}$ & ,669** &, $458^{* *}$ & ,628** &, $718^{* *}$ & 183 & ,677 &, $582^{* *}$ & $410^{* *}$ \\
\hline Ti_G &, $722^{* *}$ &, $476^{* *}$ & $966^{* *}$ &, $923^{* *}$ &,$- 524^{* *}$ &, $627^{* *}$ & $341^{* *}$ & 128, & ,689** & 1 &, $611^{* *}$ &, $770^{* *}$ &, $996^{* *}$ &, $429^{* *}$ &, $254^{*}$ &, $361^{* *}$ & 100, & $845^{* *}$ & $607^{* *}$ & $455^{* *}$ \\
\hline $\mathrm{Cr}_{-} \mathrm{G}$ &, $642^{* *}$ & ,263 & ,639** &, $538^{* *}$ &,- 232 &, $524^{* *}$ & ,271 & ,235 & , 328* &, $611^{* *}$ & 1 & ,392* & $609^{* *}$ & ,276 & ,096 & ,130 &,- 102 & ,742* & $465^{* *}$ & ,430** \\
\hline$M n \_G$ &, $581^{* *}$ & ,651 &, $729^{* *}$ & $834^{* *}$ &,$- 334^{* *}$ & $617^{* *}$ & $602^{* *}$ &, $375^{* *}$ &, $772^{* *}$ &, $770^{* *}$ & ,392* & 1 &, $783^{* *}$ &, $516^{* *}$ &, $410^{* *}$ &, $575^{* *}$ & $344^{*}$ &, 546 &, $676^{* *}$ &, $522^{* *}$ \\
\hline $\mathrm{Fe}_{-} \mathrm{G}$ &, $717^{* *}$ &, $482^{* *}$ & $971^{* *}$ & $932^{* *}$ &,$- 503^{* *}$ & $629^{* *}$ & $356^{* *}$ & ,156 &, $669^{* *}$ & $996^{* *}$ & $609^{* *}$ &, $783^{* *}$ & 1 &, $410^{* *}$ & ,228 & $354^{* *}$ & ,127 & $853^{* *}$ &, $616^{* *}$ & $470^{* *}$ \\
\hline Ni_G &, $315^{* *}$ & $461^{* *}$ & $397^{* *}$ &, $439^{* *}$ &,- 200 &, $364^{* *}$ & ,200 & 237 &, $458^{* *}$ &, $429^{* *}$ & 276 &, $516^{* *}$ &, $410^{* *}$ & 1 & , 465 & ,399** & 213 & ,482 & $317^{* *}$ & ,298* \\
\hline $\mathrm{Cu}_{-} \mathrm{G}$ & 216 &, $462^{* *}$ & ,182 & ,238 &,- 095 & $325^{* *}$ &, $445^{* *}$ & ,240 & $628^{* *}$ &, $254^{*}$ & ,096 &, $410^{* *}$ & ,228 &, $465^{* *}$ & 1 &, $556^{* *}$ & 163 & 319 & ,258* & $403^{* *}$ \\
\hline Zn_G & 213 &, $514^{* *}$ & $336^{* *}$ & $473^{* *}$ &,- 112 & $395^{* *}$ & $350^{* *}$ & $340^{* *}$ &, $718^{* *}$ & $361^{* *}$ & 130 &, $575^{* *}$ & $354^{* *}$ & $399^{* *}$ &, $556^{* *}$ & 1 & ,037 & ,299 &, $552^{* *}$ & $406^{* *}$ \\
\hline $\mathrm{Br}_{-} \mathrm{G}$ & ,343 & 202 &,- 035 & ,005 & -,009 & ,439* & ,327 & 389* & 183 & 100 &,- 102 & $344^{*}$ & 127 & 213 & 163 & ,037 & 1 &,- 005 &, $507^{* *}$ & ,331 \\
\hline Sb_G & ,691* & ,303 & $856^{* *}$ & $841^{* *}$ &,- 522 & ,575 &,- 022 & ,096 & $677^{*}$ & $845^{* *}$ & ,742* & ,546 &, $853^{* *}$ & ,482 & ,319 & ,299 &,- 005 & 1 & 179 & ,344 \\
\hline Bce_G &, $626^{* *}$ &, $441^{* *}$ & ,561 &, $594^{* *}$ &,- 191 &, $746^{* *}$ & $436^{* *}$ & ,482** & $582^{* *}$ &, $607^{* *}$ & $465^{* *}$ &, $676^{* *}$ &, $616^{* *}$ &, $317^{* *}$ & ,258* &, $552^{* *}$ &, $507^{* *}$ & 179 & 1 & ,612 \\
\hline MPG &, $500^{* *}$ & $330^{* *}$ &, $433^{* *}$ & $484^{* *}$ & $392^{* *}$ &, $738^{* *}$ & $538^{* *}$ & $850^{* *}$ & $410^{* *}$ &, $455^{* *}$ & $430^{* *}$ &, $522^{* *}$ & $470^{* *}$ & ,298* & ,403 & $406^{* *}$ & 331 & ,344 & ,612 & 1 \\
\hline
\end{tabular}

*Correlação significativa no nível 0,01

** Correlação significativa no nível 0,05 
Tabela A.9: correlação de Pearson da série temporal da concentração dos elementos na moda grossa de Manacapuru.

Material Particulado Grosso de Manacapuru - Correlação de Pearson das Concentrações dos Elementos durante o GoAmazon2014/15

\begin{tabular}{|c|c|c|c|c|c|c|c|c|c|c|c|c|c|c|c|c|c|c|}
\hline & $\mathrm{Na}$ _G & Mg_G & Al_G & Si_G & P_G & S_G & Cl_G & K_G & Ca_G & Ti_G & Cr_G & Mn_G & $\mathrm{Fe} \_\mathrm{G}$ & $\mathrm{Ni} \_\mathrm{G}$ & $\mathrm{Cu}$ _G & Zn_G & Bce_G & MPG \\
\hline $\mathrm{Na}$ _G & 1 &,- 121 &, $410^{* *}$ &, $516^{* *}$ &, $492^{* *}$ &, $791^{* *}$ &, $738^{* *}$ & $675^{* *}$ & $626^{* *}$ & 129 & 374 & $417^{* *}$ &, $220^{*}$ & 161 & $375^{*}$ &, $670^{* *}$ &, $689^{* *}$ & $691^{* *}$ \\
\hline Mg_G &,- 121 & 1 & $305^{* *}$ &, $249^{*}$ &,$- 393^{* *}$ &,$- 440^{* *}$ &,- 135 &,$- 251^{*}$ & ,210 & $335^{* *}$ &,- 097 & ,089 & $311^{* *}$ &, $561^{* *}$ & ,228 & 207 &,- 199 &,- 076 \\
\hline Al_G &, $410^{* *}$ &, $305^{* *}$ & 1 & ,939** & , 168 & $289^{* *}$ &, $493^{* *}$ &, $426^{* *}$ &, $834^{* *}$ & $875^{* *}$ & 178, & $680^{* *}$ &, $931^{* *}$ &, $327^{* *}$ & ,224 &, $546^{* *}$ &, $530^{* *}$ &, $590^{* *}$ \\
\hline Si_G &, $516^{* *}$ & $249^{*}$ &, $939^{* *}$ & 1 & $279^{*}$ & $367^{* *}$ &, $692^{* *}$ &, $570^{* *}$ & $900^{* *}$ & $672^{* *}$ & 153, &, $785^{* *}$ &, $761^{* *}$ & $322^{* *}$ & $321^{*}$ &, $565^{* *}$ &, $569^{* *}$ &, $643^{* *}$ \\
\hline P_G &, $492^{* *}$ &,$- 393^{* *}$ &, 168 & $279^{*}$ & 1 &, $790^{* *}$ &, $576^{* *}$ & $917^{* *}$ &, $353^{* *}$ &,- 014 & 275 & 268 & ,044 &,- 054 & 157, & $396^{* *}$ &, $738^{* *}$ & $842^{* *}$ \\
\hline S_G &, $791^{* *}$ &,$- 440^{* *}$ &, $289^{* *}$ &, $367^{* *}$ &, $790^{* *}$ & 1 & $604^{* *}$ &, $832^{* *}$ & $479^{* *}$ & ,086 & $483^{*}$ & ,287 & 154 &,- 091 & ,281 &, $587^{* *}$ &, $793^{* *}$ &, $795^{* *}$ \\
\hline Cl_G &, $738^{* *}$ & -135 & $493^{* *}$ &, $692^{* *}$ &, $576^{* *}$ & $604^{* *}$ & 1 &, $778^{* *}$ &, $672^{* *}$ & 103, & 213 & $669^{* *}$ & $219^{*}$ & 123, &, $464^{* *}$ &, $540^{* *}$ &, $571^{* *}$ &, $684^{* *}$ \\
\hline K_G &, $675^{* *}$ &,$- 251^{*}$ & $426^{* *}$ &, $570^{* *}$ & $917^{* *}$ & $832^{* *}$ &, $778^{* *}$ & 1 &, $612^{* *}$ & ,143 & 320 &, $534^{* *}$ &, $233^{*}$ & 100 & $371^{*}$ &, $573^{* *}$ & $837^{* *}$ &, $923^{* *}$ \\
\hline Ca_G &, $626^{* *}$ & ,210 &, $834^{* *}$ &, $900^{* *}$ & $353^{* *}$ & $479^{* *}$ &, $672^{* *}$ &, $612^{* *}$ & 1 &, $547^{* *}$ & 261 &, $746^{* *}$ &, $641^{* *}$ &, $284^{* *}$ & 304 &, $623^{* *}$ &, $609^{* *}$ &, $714^{* *}$ \\
\hline Ti_G & 129, & $335^{* *}$ & $875^{* *}$ &, $672^{* *}$ &,- 014 & 086 & 103 & 143, &, $547^{* *}$ & 1 & 173 &, $435^{* *}$ & $987^{* *}$ & $293^{* *}$ & ,005 &, $402^{* *}$ &, $365^{* *}$ &, $392^{* *}$ \\
\hline $\mathrm{Cr}_{-} \mathrm{G}$ & 374 &,- 097 & ,178 & 153 & 275 &, $483^{*}$ & ,213 & ,320 & ,261 & 173 & 1 & 242 & 173 &,- 108 & $627^{*}$ & ,267 & ,356 & ,250 \\
\hline Mn_G & $417^{* *}$ & ,089 & $680^{* *}$ &, $785^{* *}$ & 268 & 287 &, $669^{* *}$ &, $534^{* *}$ &, $746^{* *}$ & $435^{* *}$ & 242 & 1 &, $515^{* *}$ & ,172 & $413^{*}$ & $429^{* *}$ & $489^{* *}$ &, $519^{* *}$ \\
\hline $\mathrm{Fe}_{-} \mathrm{G}$ &, $220^{*}$ &, $311^{* *}$ &, $931^{* *}$ &, $761^{* *}$ & ,044 & 154 &, $219^{*}$ &, $233^{*}$ &, $641^{* *}$ & $987^{* *}$ & 173, &, $515^{* *}$ & 1 & $307^{* *}$ & ,062 & $452^{* *}$ & $436^{* *}$ & $463^{* *}$ \\
\hline Ni_G & 161 &, $561^{* *}$ &, $327^{* *}$ &, $322^{* *}$ &,- 054 &,- 091 & 123 & 100 &, $284^{* *}$ &, $293^{* *}$ &,- 108 & 172 & $307^{* *}$ & 1 & 172 & $458^{* *}$ &, $252^{*}$ & 212 \\
\hline Cu_G & $375^{*}$ & ,228 & 224 &, $321^{*}$ & 157 & 281 &, $464^{* *}$ & $371^{*}$ & 304 & ,005 & $627^{*}$ &, $413^{*}$ & ,062 & 172 & 1 & $483^{* *}$ & 274 & 314 \\
\hline Zn_G & $670^{* *}$ & 207, &, $546^{* *}$ &, $565^{* *}$ &, $396^{* *}$ &, $587^{* *}$ &, $540^{* *}$ &, $573^{* *}$ & $623^{* *}$ & $402^{* *}$ & 267 &, $429^{* *}$ & $452^{* *}$ & $458^{* *}$ & $483^{* *}$ & 1 & $600^{* *}$ &, $693^{* *}$ \\
\hline Bce_G & $689^{* *}$ & -199 &, $530^{* *}$ &, $569^{* *}$ &, $738^{* *}$ &, $793^{* *}$ &, $571^{* *}$ & $837^{* *}$ & $609^{* *}$ & $365^{* *}$ & 356, & $489^{* *}$ & $436^{* *}$ &, $252^{*}$ & 274 & $600^{* *}$ & 1 & $873^{* *}$ \\
\hline MPG &, $691^{* *}$ &,- 076 &, $590^{* *}$ &, $643^{* *}$ & $842^{* *}$ &, $795^{* *}$ & $684^{* *}$ & $923^{* *}$ &, $714^{* *}$ & $392^{* *}$ & 250 & $519^{* *}$ & $463^{* *}$ & 212, & 314 & $693^{* *}$ & $873^{* *}$ & 1 \\
\hline
\end{tabular}

*Correlação significativa no nível 0,01

** Correlação significativa no nível 0,05 


\section{APÊNDICE B - Material complementar da análise de componentes principais (ACP)}

\section{B1. Factor Scores da ACP aplicada ao MPF da ZF2}

Tabela B 1: matriz de factor scores da ACP aplicada ao MPF da ZF2.

\begin{tabular}{cccc}
\hline \multicolumn{4}{c}{ Factor Loadings da ACP aplicada ao MPF da ZF2 } \\
\hline & Queimada & Solo & Marinho \\
\hline P_F &, 972 &, 134 &, 119 \\
S_F &, 965 &, 170 &, 142 \\
K_F &, 959 &, 184 &, 143 \\
MPF &, 956 &, 147 &, 147 \\
Bce_F &, 956 &, 216 &, 053 \\
Zn_F &, 943 &, 215 &, 090 \\
Br_F &, 911 &, 033 &, 115 \\
Na_F &, 817 &, 159 &, 264 \\
Si_F &,- 042 &, 992 &, 006 \\
Al_F &, 144 &, 980 &,- 033 \\
Ti_F &, 172 &, 970 &,- 035 \\
Fe_F &, 250 &, 952 &,- 097 \\
Ca_F &, 360 &, 833 &, 259 \\
Cl_F &, 378 &,- 047 &, 907 \\
Autovalor & 7,4 & 4,7 & 1,1 \\
Variância(\%) & 52,8 & 33,7 & 7,7 \\
\hline
\end{tabular}

\section{ACPA_ZF2 Fino}

- Queimada

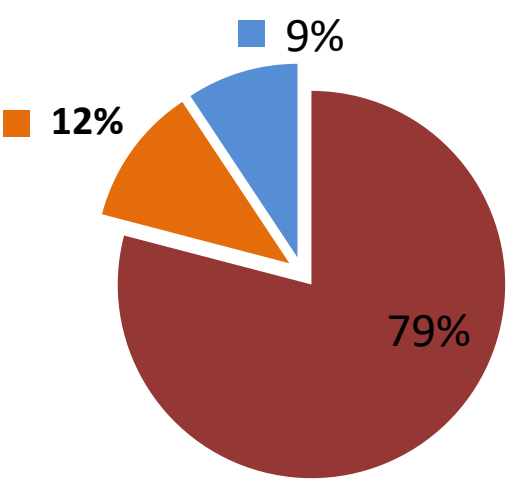

Figura B 1: percentual de MPF associado a cada fator obtido pela ACPA para o sítio ZF2. 


\section{B2. Factor Scores da ACP aplicada ao MPG da ZF2}

Tabela B 2: matriz de factor scores da ACP aplicada ao MPG da ZF2.

\begin{tabular}{cccc}
\hline \multicolumn{4}{c}{ Factor Loadings da ACP aplicada ao MPG da ZF2 } \\
\hline & Solo & Biogênico & Marinho 2 \\
\hline Al_G &, 962 &, 011 &, 229 \\
Si_G &, 941 &, 044 &, 171 \\
Fe_G &, 923 &, 003 &, 296 \\
Ti_G &, 901 &, 006 &, 231 \\
Ca_G &, 715 &, 110 &, 640 \\
Mn_G &, 643 &, 302 &, 232 \\
K_G &, 074 &, 950 &, 211 \\
P_G &,- 355 &, 864 &,- 185 \\
MPG &, 023 &, 830 &, 462 \\
Zn_G &, 164 &, 787 &,- 011 \\
Bce_G &, 383 &, 656 &, 306 \\
Na_G &, 273 &, 112 &, 937 \\
Cl_G &, 293 &, 146 &, 883 \\
Mg_G &, 509 &, 116 &, 833 \\
S_G &, 165 &, 586 &, 624 \\
Autovalor & 4,9 & 3,7 & 3,0 \\
Variância (\%) & 34,9 & 26,4 & 21,4 \\
\hline
\end{tabular}

\section{ACPA ZF2 Grosso}

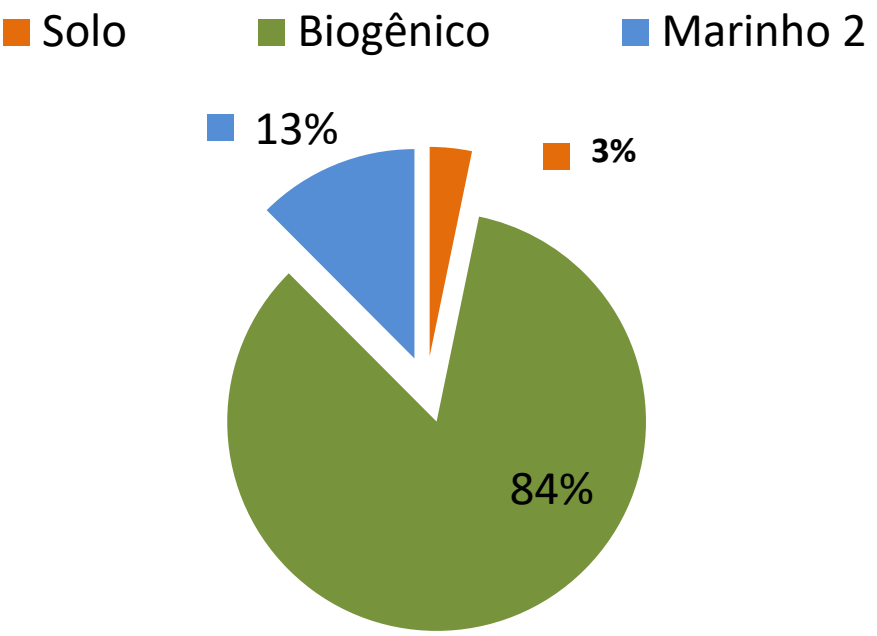

Figura B 2: percentual de MPF associado a cada fator obtido pela ACPA para o sítio ZF2. 


\section{B3. Factor Scores da ACP aplicada ao MPF do TIWA}

Tabela B 3: matriz de factor scores da ACP aplicada ao MPF do sítio TIWA.

\begin{tabular}{cccccc}
\hline \multicolumn{5}{c}{ Factor Loadings da ACP aplicada ao MPF do TIWA } \\
\hline \multicolumn{5}{c}{ Queimada } & \multicolumn{3}{c}{ Solo } & Veicular & Marinho & Poluição \\
\hline S_F &, 948 &, 140 &, 125 &, 132 &, 118 \\
P_F &, 920 &, 170 &, 160 &, 165 &, 144 \\
MPF &, 902 &, 327 &, 152 &, 055 &, 114 \\
K_F &, 898 &, 284 &, 189 &,- 017 &, 164 \\
Bce_F &, 801 &, 300 &, 416 &, 060 &, 070 \\
Br_F &, 772 &, 233 &, 488 &, 008 &, 183 \\
Na_F &, 760 &, 363 &, 212 &, 215 &, 145 \\
Si_F &, 103 &, 941 &, 111 &, 110 &, 057 \\
Al_F &, 342 &, 919 &, 128 &, 091 &, 033 \\
Ti_F &, 341 &, 896 &, 198 &, 093 &, 040 \\
Fe_F &, 396 &, 848 &, 291 &, 122 &, 026 \\
Ca_F &, 184 &, 772 &, 412 &, 294 &, 108 \\
Cu_F &, 257 &, 168 &, 844 &, 224 &,- 028 \\
Zn_F &, 294 &, 293 &, 756 &,- 041 &, 298 \\
Mn_F &, 273 &, 429 &, 638 &, 319 &, 188 \\
Ni_F &, 204 &, 433 &, 296 &, 781 &, 084 \\
Cl_F &, 478 &, 065 &, 234 &, 096 &, 819 \\
Autovalor & 6,1 & 4,9 & 2,7 & 1,0 & 1,0 \\
Variância (\%) & 35,9 & 28,5 & 16,0 & 5,9 & 5,6 \\
\hline & & & & &
\end{tabular}

\section{ACPA_TIWA Fino}

Q Queimada Solo Veicular Marinho Poluição

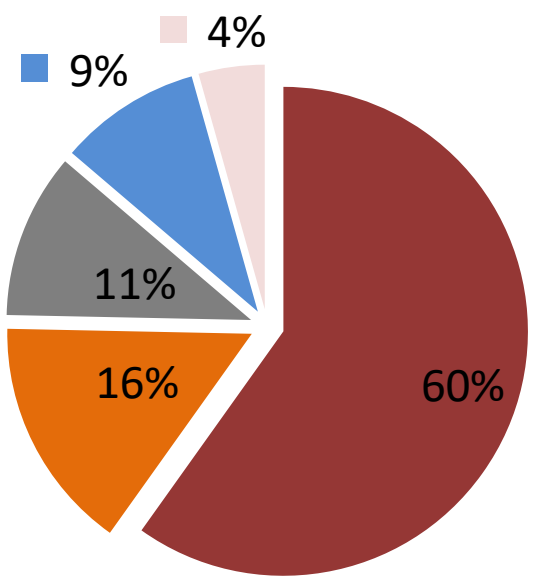

Figura B 3: percentual de MPF associado a cada fator obtido pela ACPA para o sítio ZF2. 


\section{B4. Factor Scores da ACP aplicada ao MPG do TIWA}

Tabela B 4: matriz de factor scores da ACP aplicada ao MPF do sítio TIWA.

\begin{tabular}{ccccc}
\hline \multicolumn{5}{c}{ Factor Loadings da ACP aplicada ao MPG do TIWA } \\
\hline & Solo & Biogênico & Marinho (HCl) & Marinho 2 (NaCl) \\
\hline Al_G &, 962 &,- 017 &, 115 &, 138 \\
Fe_G &, 945 &, 009 &, 142 &, 238 \\
Ti_G &, 938 &,- 019 &, 162 &, 240 \\
Si_G &, 914 &, 063 &, 258 &, 157 \\
Mn_G &, 702 &, 147 &, 467 &, 290 \\
Bce_G &, 591 &, 347 &, 292 &, 341 \\
K_G &, 106 &, 913 &, 201 &, 292 \\
P_G &,- 461 &, 848 &,- 105 &,- 112 \\
MPG &, 385 &, 783 &, 254 &, 309 \\
Cu_G &, 026 &, 060 &, 844 &, 255 \\
Zn_G &, 328 &, 240 &, 823 &,- 051 \\
Ca_G &, 542 &,- 025 &, 697 &, 343 \\
Na_G &, 587 &, 064 &, 022 &, 746 \\
Cl_G &, 138 &, 235 &, 396 &, 729 \\
S_G &, 492 &, 421 &, 182 &, 675 \\
Autovalor & 5,8 & 2,6 & 2,6 & 2,3 \\
Variância (\%) & 38,4 & 17,4 & 17,4 & 15,2 \\
\hline
\end{tabular}

\section{ACPA_TIWA Grosso}

Solo Biogênico Marinho $1 \square$ Marinho 2
Figura B 4: percentual de MPF associado a cada fator obtido pela ACPA para o sítio ZF2.

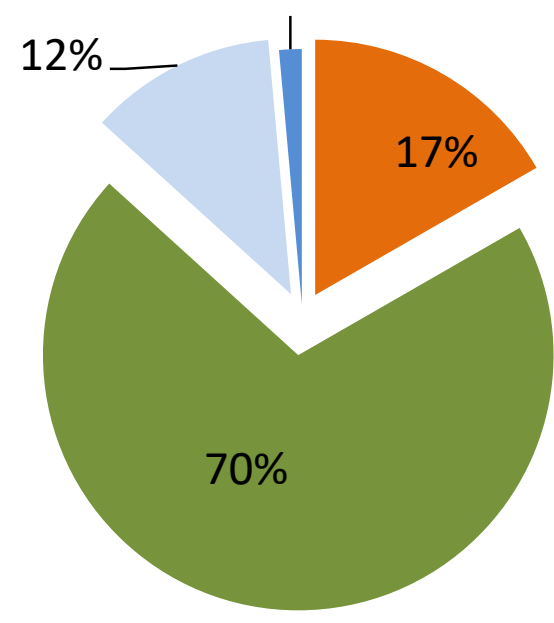




\section{B5. Factor Scores da ACP aplicada ao MPF de Manacapuru}

Tabela B 5: matriz de factor scores da ACP aplicada ao MPF do sítio Manacapuru.

\begin{tabular}{cccc}
\hline \multicolumn{4}{c}{ Factor Loadings da ACP aplicada ao MPF de Manacapuru } \\
\hline & Queimada & Solo & Marinho \\
\hline S_F &, 970 &, 086 &, 066 \\
MPF &, 969 &, 071 &, 109 \\
P_F &, 946 &, 170 &,- 029 \\
Bce_F &, 915 &, 044 &, 217 \\
K_F &, 912 &, 086 &, 310 \\
Na_F &, 879 &, 172 &, 042 \\
Zn_F &, 792 &, 336 &, 095 \\
Al_F &, 102 &, 982 &, 045 \\
Si_F &, 038 &, 956 &, 122 \\
Fe_F &, 180 &, 943 &,- 116 \\
Ti_F &, 065 &, 936 &,- 131 \\
Ca_F &, 257 &, 873 &, 150 \\
Cl_F &, 653 &, 011 &, 737 \\
Autovalor & 6,4 & 4,6 & 0,8 \\
Variância (\%) & 49,1 & 35,4 & 6,0 \\
\hline
\end{tabular}

\section{ACPA_Manacapuru Fino}

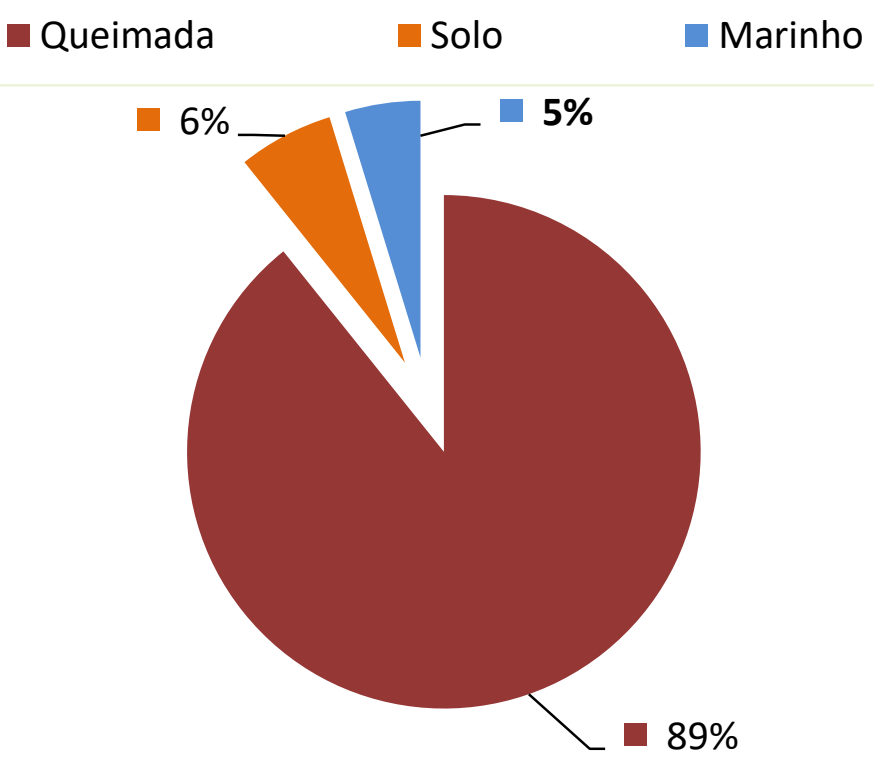

Figura B 5:

percentual de MPF associado a cada fator obtido pela ACPA para o sítio ZF2. 


\section{B6. Factor Scores da ACP aplicada ao MPG de Manacapuru}

Tabela B 6: matriz de factor scores da ACP aplicada ao MPF do sítio Manacapuru.

\begin{tabular}{ccccc}
\hline \multicolumn{5}{c}{ Factor Loadings da ACP aplicada ao MPG de Manacapuru } \\
\hline & Biogênico & Solo & Marinho 2 (NaCl) & Poluição \\
\hline P_G &, 949 &,- 033 &, 105 &,- 071 \\
K_G &, 880 &, 139 &, 378 &, 042 \\
S_G &, 878 &, 037 &, 311 &,- 039 \\
MPG &, 848 &, 360 &, 284 &, 156 \\
Bce_G &, 833 &, 327 &, 178 &, 209 \\
Fe_G &, 100 &, 975 &, 051 &, 138 \\
Ti_G &, 055 &, 972 &,- 065 &, 138 \\
Al_G &, 171 &, 902 &, 362 &, 134 \\
Si_G &, 228 &, 731 &, 586 &, 125 \\
Cl_G &, 470 &, 121 &, 810 &, 034 \\
Na_G &, 563 &, 066 &, 658 &, 202 \\
Ca_G &, 321 &, 602 &, 626 &, 143 \\
Ni_G &,- 036 &, 196 &, 054 &, 940 \\
Zn_G &, 473 &, 300 &, 375 &, 551 \\
Autovalor & 4,8 & 4,0 & 2,5 & 1,4 \\
Variância (\%) & 34,4 & 28,6 & 17,6 & 10,0 \\
\hline
\end{tabular}

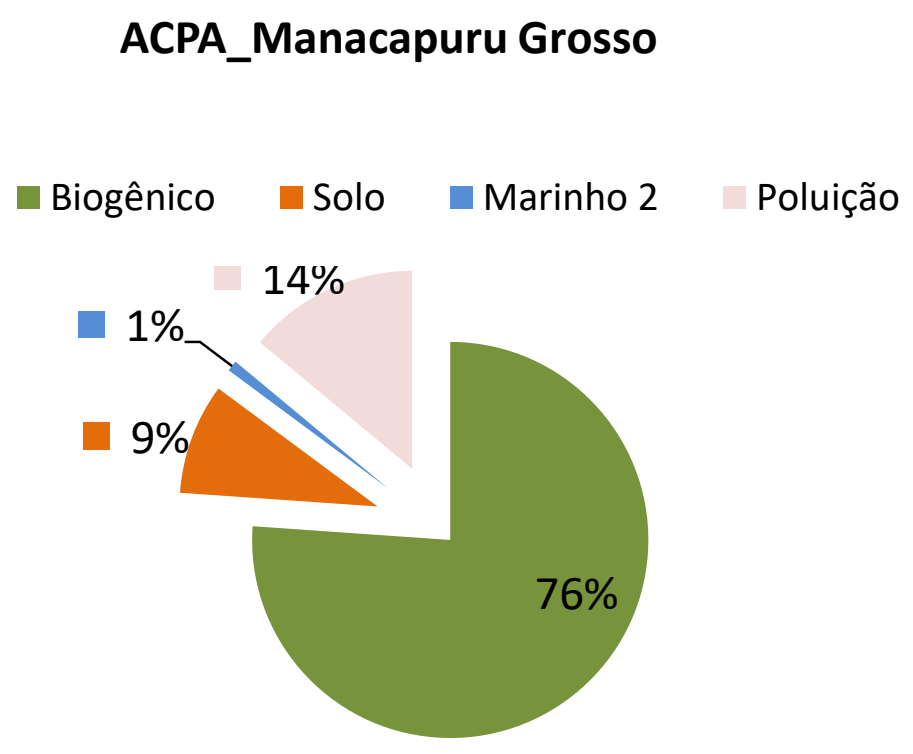

Figura B 6: percentual de MPF associado a cada fator obtido pela ACPA para o sítio ZF2. 


\section{Anexo A - Pôster apresentado no São Paulo School of Advanced}

\section{Science on Climate Change: Scientific Basis, Adaptation, Vulnerability}

and Mitigation 2017

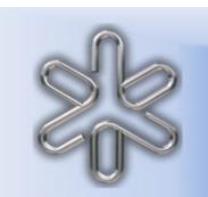

Work Summary

The objective of this work was to analyze aerosol sources and processe looking at the aerosol elemental composition.

Aerosols were collected in Nuclepore filters at three sites in Central Amazonia between mar/14 and sept/15 using stacked filter units (SFU), which separate fine and coarse particulate matter (FPM and CPM). They were analyzed in order to obtain mass concentration, equivalent Black Carbon (eBC) and elemental chemical composition;

Comparisons of eBC from these filters with absorption coefficient measured by aethalometers were made in order to validate the data;

PMF 5.0 (Positive Matrix Factorization) was applied on the filter time series and extracted several factors for each site: biomass burning, biogenic processes, soil dust, marine aerosol, vehicular, and urban pollution factors.

\section{Results and Discussion}
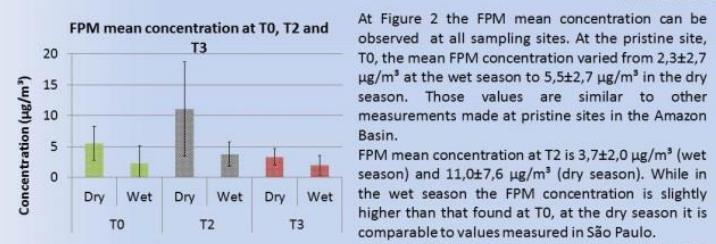
season) and $11,0 \pm 7,6 \mu \mathrm{\mu g} / \mathrm{m}^{3}$ (dry season). While in
the wet season the $\mathrm{FPM}$ concentration is slightly
higher than that found at $T 0$, at the dry season it is comparable to values measured in São Paulo.

Figure 2 - Mean fine particle (FPM) concentrations at At T3 the FPM mean concentration is $3,211,3 \mathrm{\mu g} / \mathrm{m}^{3}$
$T 0, T 2$ and $\mathrm{T} 3$ for the GoAmazon $14 / 15$ for wet and dry at the dry season and $1,9 \pm 1,5 \mathrm{\mu g} / \mathrm{m}^{3}$ at the wet

CPM mean concentration at TO,

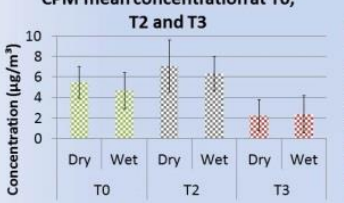

At figure 3 it can be observed the CPM mean concentration at the three sampling sites. At the pristine site of TO the CPM mean concentration varied between $4,7 \pm 1,7 \mu \mathrm{g} / \mathrm{m}^{3}$ (wet season) and aerosols are mainly related to primary biogenic particles, and also dust transport from Sahara at the wet season. CPM mean concentration at TIWA was of $7,1 \pm 2,5 \mathrm{\mu g} / \mathrm{m}^{3}$ during dry season and $6,3 \mathrm{\mu g} / \mathrm{m}^{3}$ Figure 3 - mean coarse particle mode (CPM) at the dry season and $2,3 \pm 1,8 \mu \mathrm{\mu g} / \mathrm{m}^{3}$ at the wet Figure 3 - mean coarse particle mode $(\mathrm{CPM})$ at the
concentrations at $\mathrm{T}, \mathrm{T} 2$ and $\mathrm{T} 3$ for the season.
GoAmazon $14 / 15$.

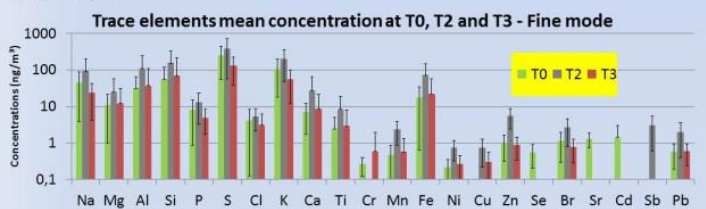

$\mathrm{Na} \mathrm{Mg} \mathrm{Al} \mathrm{Si} \mathrm{P} \mathrm{S} \mathrm{Cl} \mathrm{K} \mathrm{Ca} \mathrm{Ti} \mathrm{Cr} \mathrm{Mn} \mathrm{Fe} \mathrm{Ni} \mathrm{Cu} \mathrm{Zn} \mathrm{Se} \mathrm{Br} \mathrm{Sr} \mathrm{Cd} \mathrm{Sb} \mathrm{Pb}$ and $T 3$. Please note the logarithm scal.

作 related to industria//vehicular processes like $\mathrm{Al}, \mathrm{Ti}, \mathrm{Mn}, \mathrm{Fe}, \mathrm{Ni}, \mathrm{Cu}, \mathrm{Zn}$ and $\mathrm{Pb}$. This group of elements showed Pearson Correlation Coefficient higher than 0,5 at $T 2(p>0,05)$ between each other and the ratio elements that are mainly emitted to range from 3,4 (Al,

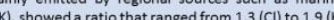

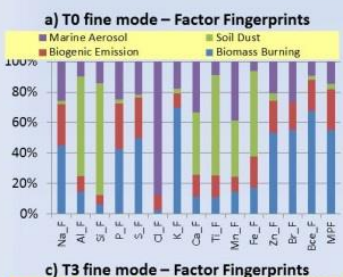

b) 72 fine mode - Factor Fingerprints

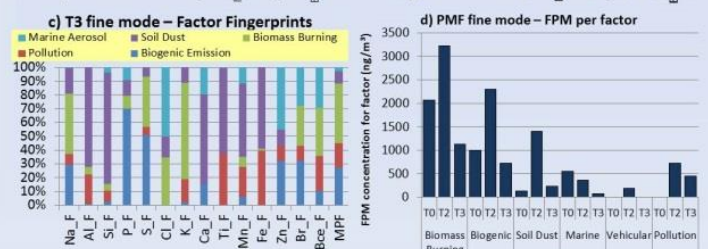

Figure 8 - Factor fingerprints extracted by the Receptor Model PMF 5.0 for a) TO, b)T2 and c)T3 fine mode

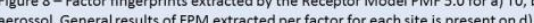

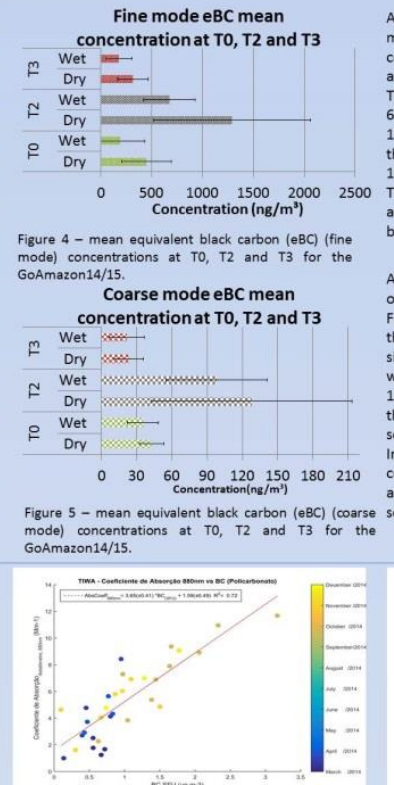

At figure 4 it can be observed the fine mode $\mathrm{eBC}$ mean concentration at $\mathrm{TO}, \mathrm{T} 2$ and $\mathrm{T} 3$. The mean t dry season and $190 \pm 240 \mathrm{ng} / \mathrm{m}^{3}$ at wet season. Fo The mean eBC concentration at fine mode is of $220 \pm 653 \mathrm{ng} / \mathrm{m}^{3}$ at the dry season and, finally, at $\mathrm{T}$ $178 \pm 124 \mathrm{ng} / \mathrm{m}^{3}$ at $\mathrm{dr} y$ and wet season, respectively. The values found at $T 0$ are similar to previous studies The is a combination or the absoption properties of

At figure 5 the $\mathrm{eBC}$ mean concentration can be For TO we found concentrations of $42 \pm 11 \mathrm{ng} / \mathrm{m}^{3}$ at the wet season and $35 \pm 13 \mathrm{ng} / \mathrm{m}^{3}$ at the dry season, similar to previous studies. At $\mathrm{T} 2$ these concentration were of $98 \pm 43 \mathrm{ng} / \mathrm{m}^{3}$ for the wet season and (20173ng/m' at the diy season and, finally, at 13 pristine regions, the coarse mode $\mathrm{eBC}$

composed of absorbing primary biogenic particles and is essentially constant throughout the year, as

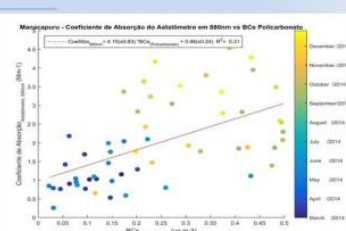

figure 7 - absorption coefficient measured by aethalometers versus eBC obtained by reflectance on Nuclepore filters

At figure 7.a, a significant correlation is observed between the absorption coefficient measured by filters at T2. At Figure 7.b, with the same comparison for T3, is possible to at $550 \mathrm{~nm}$ ) from Nuclepore specially for the dry season (green to yellow points) that leads to a low $R^{2}(0,31)$. That low $R^{2}$ for $T 3$ indicates a problem in the collection of aerosol by SFU.

At figure 8 the factor fingerprints extracted by PMF5. 0 can be observed at TO, T2 and T3 for the The figure 8 a shows that at the pristine region To four factors were extracted: Marine Aerosol (with high percentage of Cl concentration along $\mathrm{Mn}$ and $\mathrm{Na}$ ), Biogenic Emission ( $\mathrm{W}$. Considerably percentage of $\mathrm{P}$, $\mathrm{S}$ Biomass Burning (with high percentage of $P, S, K, Z n, B r$ and eBC concentration). These four factors were found at all sites.

At T2 factor fingerprints, figure 8b, two more factors can be recognized: Pollution and Vehicular Emission. The first is related with $\mathrm{Na}, \mathrm{Al}, \mathrm{Si}, \mathrm{Ca}, \mathrm{Ti}, \mathrm{Mn}, \mathrm{Fe}, \mathrm{Cu}, \mathrm{Zn}, \mathrm{Pb}$ and $\mathrm{eBC}$ and the second is related to high percentage of $\mathrm{Ni}, \mathrm{Cu}, \mathrm{Zn}, \mathrm{Br}, \mathrm{Pb}$ ande $\mathrm{eBC}$ concentration.
$\mathrm{At} \mathrm{T}$
$\mathrm{T}$, only one more factor was found in relation to TO: Pollution. This factor is characterized by considerablycontributionsto Al, $\mathrm{Si}, \mathrm{K}, \mathrm{Ti}, \mathrm{Mn}, \mathrm{Fe}, \mathrm{Zn}, \mathrm{Br}$ and eBC concentration. At figure $8 \mathrm{~d}$ the contribution of each factor for the FPM is shown. We can see that for all sites, biomass burning is the main contributor for the FPM mass. Comparing the FPM associated with this factor at T0 and $\mathrm{T} 2$, we can see that $\mathrm{PMF}$ extracted $1 \mathrm{ug} / \mathrm{m}^{3}$ more from the latter. This may have happened due the ambiguity of the elements $K, Z n$ and

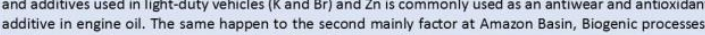
that has as key elements, also associated with vehicularemission. The Soil dust factor is also much more higher in TIWA, probably associated with the high activity of the city.
Marine factor decreases from $T 0$ to $T 2$ and analyzing the composition of this factor, from $T 0$ to $T 2$ is possible to notice the reaction of $\mathrm{Cl}$ depletion, as less $\mathrm{Na}$ and $\mathrm{S}$ is found at $\mathrm{T} 2$ than at $\mathrm{TO}$, but the $\mathrm{C}$

concentration still similar on both sites.
The last two factors of figure 8d shows that vehicular and pollution accounts for $918 \mathrm{ng} / \mathrm{m}^{3}$ on the FPM o
T2. At T3 the pollution factor accounted to $17 \%$ of FPM mean concentration. 


\section{Anexo B - Pôster apresentado no 5th iLEAPS Science Conference:}

\section{Understanding the impact of land-atmosphere exchanges (2017)}

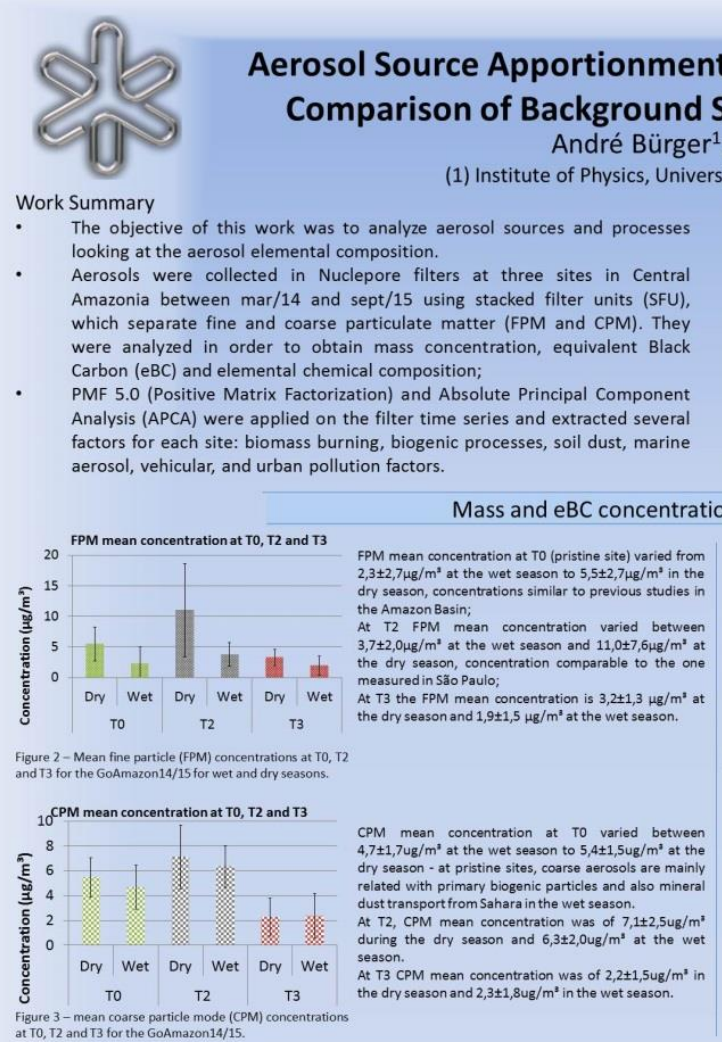

\section{Aerosol Source Apportionment in the GoAmazon Experiment: Aackground Stations versus Polluted Sites \\ Andre Bürger ${ }^{1}$; Paulo Artaxo*1
(1) Institute of Physics, University of São Paulo, São Paulo, Brazil}
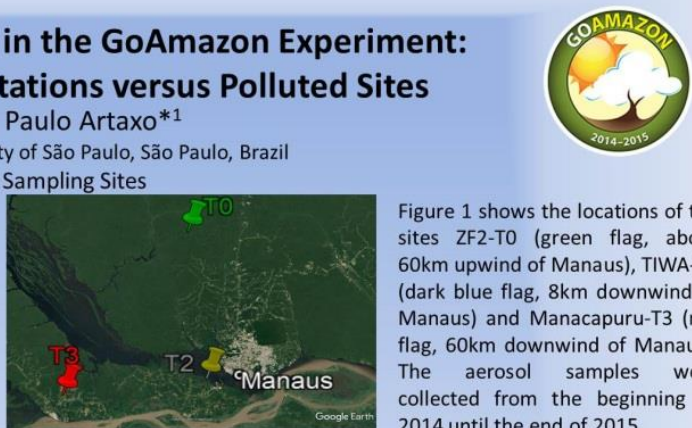

Figure 1: Sampling sites at Central Amazoni

Figure 1 shows the locations of the sites ZF2-TO (green flag, about $60 \mathrm{~km}$ upwind of Manaus), TIWA-T2 (dark blue flag, $8 \mathrm{~km}$ downwind of Manaus) and Manacapuru-T3 (red flag, $60 \mathrm{~km}$ downwind of Manaus). The collected from the beginning of 2014 until the end of 2015

on for wet and dry season

\section{APCA and PMF Results}

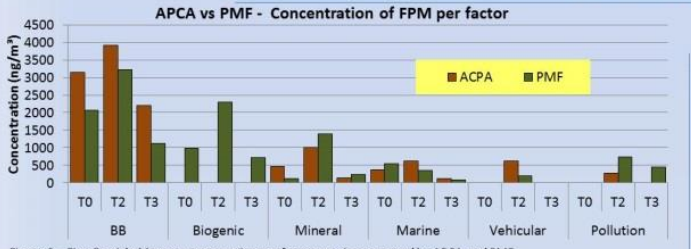

Figure 6 - Fine Particle Matterconcentration per factor pers

3 factors extracted at all sites with APCA and PMFE

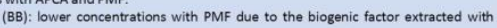

Mineral Dust Aerosol: accounts for about $1000 \mathrm{ng} / \mathrm{m}^{\prime}$ at $\mathrm{T} 2$ and for less than $500 \mathrm{ng} / \mathrm{m}^{\prime}$ at $\mathrm{TO}$, showing the Bround dust that is resuspendedbythe cities activities;

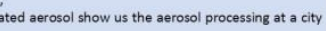

o, it was possible to extract a biogenic, vehicular and pollution factor.

The biogenic factor, as the biomass burning factor, is higher at $T 2$ indicating the oxidation of the vocs

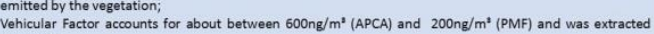
- Vehicular Factor accounts for about between $600 \mathrm{ng} / \mathrm{m}^{3}$ (APCA) and $200 \mathrm{ng} / \mathrm{m}^{2}$ (PMF) and was extracted
only in T2;
Pollution factor at $\mathrm{T} 2$ accounts for about $280 \mathrm{ng} / \mathrm{m}^{2}$ (APCA) and $729 \mathrm{ng} / \mathrm{m}^{2}$ (PMF) and at $T 3$ accounts for
about $450 \mathrm{ng} / \mathrm{m}^{3}$.

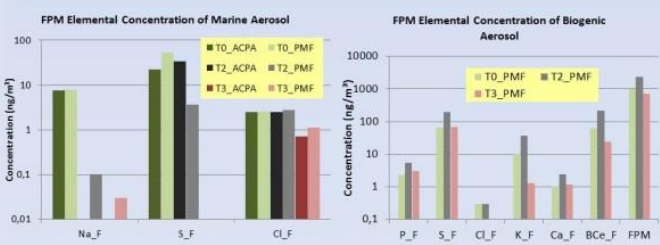

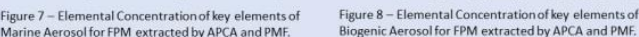
Figure 7 shows the aging of marine aerosol, from the pristine region, TO, until T3. It is possible to observe Figure 8 shows higher concentrations of biogenic aerosols at $\mathrm{T} 2$, related with the higher atmospheric

\section{DFAPESP QRCNPq}
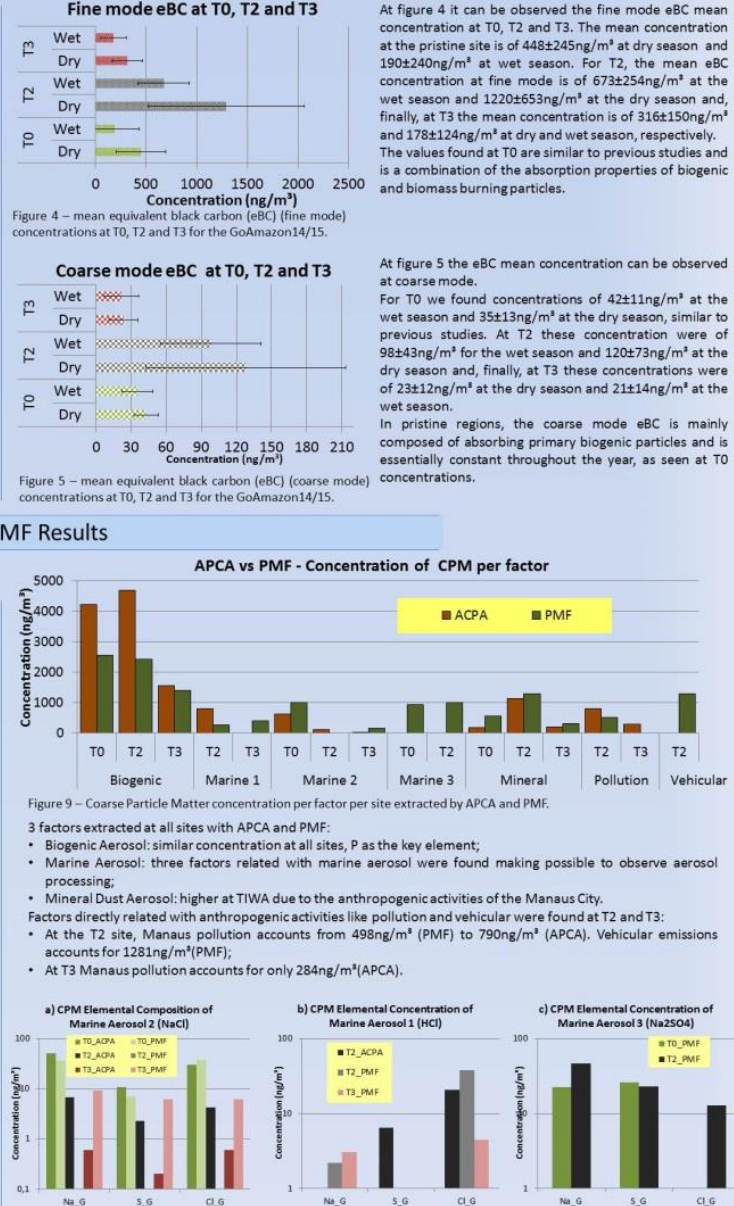

Coarse mode $B C$ at $T 0, T 2$ and 33

$f$ Wet

Dry

$\simeq$ Wet

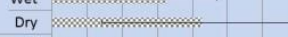

Wet

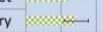

$\begin{array}{lllllll}30 & 60 & 90 & 120 & 150 & 180 & 2\end{array}$

Figure 5 - mean equivalent black carbon (eBC) (coarse mode) concentrations. At figure 4 it can be observed the fine mode $\mathrm{eBC}$ mean
concentration at $T 0, T 2$ and $T 3$. The mean concentration $190 \pm 240 \mathrm{ng} / \mathrm{m}^{2}$ at wet season. For $\mathrm{T} T 2$, the mean eBC entration at fine mode is of $673 \pm 254 \mathrm{ng} / \mathrm{m}^{2}$ at wet season and $1220 \pm 653 \mathrm{ng} / \mathrm{m}^{2}$ at the dry season and finaly, at 13 the mean concentration is of $316 \pm 150 \mathrm{ng} / \mathrm{m}^{2}$ The values found at $T 0$ are similar to previous studies and and biomass burning particles.

Af figure 5 the e
coarse mode. For For 72 these concentration ware of $98+43 \mathrm{ng} / \mathrm{m}^{2}$ for the wet season and $120 \pm 73 \mathrm{ng} / \mathrm{m}^{2}$ at the dry season and, finally, at $T 3$ these concentrations were
of $23+12 n g / \mathrm{m}^{\prime}$ at the dry season and $21 \pm 14 \mathrm{ng} / \mathrm{m}^{3}$ at the

pristine regions, the coarse mode $\mathrm{BCC}$ is mainly esentially constant throughout the year, as seen at TO

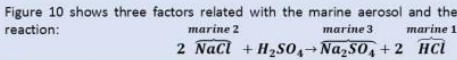
Key Findings:

It was observed higher particulate matter and black carbon concentration at $\mathrm{T} 2$ site; Biogenic factor associated with the conversion of VOC into SOA in the fine mode was observed only by PMF;

Direct anthropogenic emissions- vehicular and pollution factors - at $\mathrm{T} 2$ varies from $880 \mathrm{ng} / \mathrm{m}^{3}$ (ACPA) to $930 \mathrm{ng} / \mathrm{m}^{3}$ (PMF) in fine mode. In the coarse mode $790 \mathrm{ng} / \mathrm{m}^{3}$ (APCA) to $1780 \mathrm{ng} / \mathrm{m}^{3}$ (PMF);

Three types of marine aerosol were observed, with different chemistry processing 